
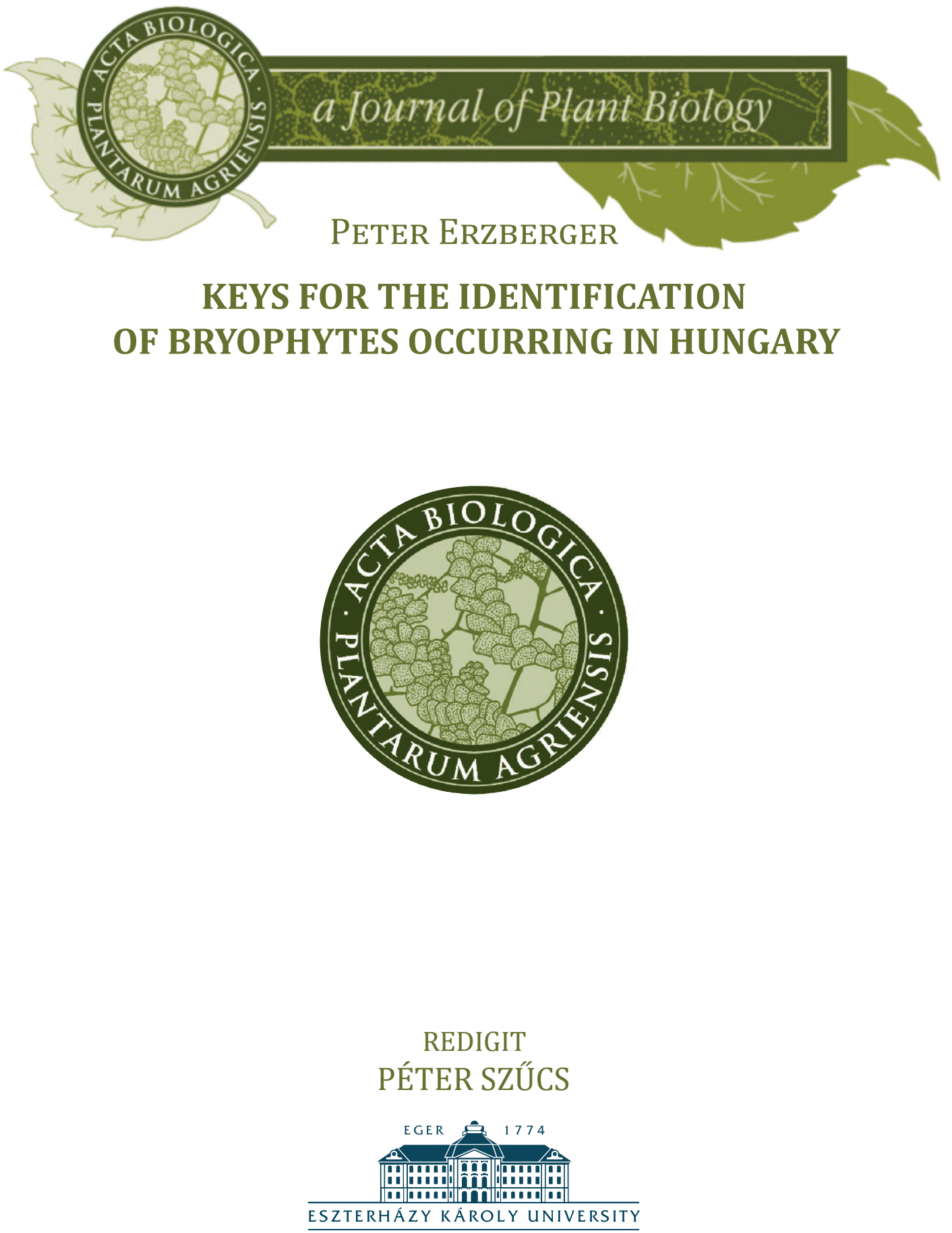

Eger, 2021 



\section{ACTA BIOLOGICA PLANTARUM AGRIENSIS (ABPA)}

from Acta Academiae Paedagogicae Agriensis Sectio Biologiae

a Journal of Plant Biology

TOMUS 9.

NUMERUS 2.

PETER ERZBERGER

\section{KEYS FOR THE IDENTIFICATION OF BRYOPHYTES OCCURRING IN HUNGARY}

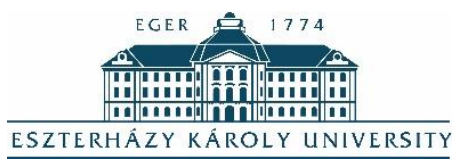

Eger

2021 
Editor-in-Chief:

Tamás Pócs (Taxonomy)

Editorial Board:

Éva Darkó (Biotechnology)

Sándor Dulai (Physiology, Stress and Ecophysiology)

Marianna Marschall (Biochemistry, Stress and Ecophysiology)

István Molnár (Molecular Biology)

Márta Molnár-Láng (Genetics)

László Mustárdy (Cell Biology)

Sándor Orbán (Ecology)

Mária Papp (Anatomy)

Erika Pénzes-Kónya (Ecology)

Andrea Sass-Gyarmati (Taxonomy)

Péter Szűcs (Ecology, Taxonomy)

Zsolt Zsófi (Grapevine Biology and Physiology)

András Vojtkó (Geobotany)

Editor:

Péter Szűcs

Managing Editor:

Erika Pénzes-Kónya

Technical Editor:

Péter Szücs

Reviewers of paper:

Christian Berg, Frank Müller, Tamás Pócs

\section{HU ISSN 2061-6716 (Print)}

HU ISSN 2063-6725 (Online)

Papers of this volume are available: http://abpa.ektf.hu/

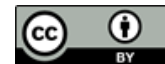

A kiadásért felelős az Eszterházy Károly Egyetem rektora

Megjelent az EKE Líceum Kiadó gondozásában/Published by Líceum Publisher EKE

Kiadóvezető/Head of publisher: Nagy Andor

Tördelőszerkesztő/Layout editor: Szűcs Péter Megjelent/Year of publication: 2021

Nyomdai munkák: Eszterházy Károly Egyetem nyomdája

/Printed by Károly Eszterházy University Press

Felelős vezető/Responsible of printing: Kérészy László

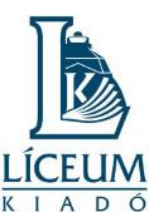




\title{
KEYS FOR THE IDENTIFICATION OF BRYOPHYTES OCCURRING IN HUNGARY
}

\section{Peter Erzberger}

Belziger Str. 37, D 10823 Berlin, Germany, E-mail: erzberger.peter@gmail.com

\begin{abstract}
Keys for the identification of all bryophytes presently known to occur in Hungary are presented. The three groups: Hornworts (2 taxa), Liverworts (149 taxa), and Mosses (541 taxa) are treated separately. Bryophyte identification using these keys proceeds in two steps: 1 . Artificial keys to the genera, 2. Keys from genera to species, arranged systematically according to recent taxonomy. Each species of the Hungarian bryophyte flora is assigned to one of six frequency classes (very common: cc, common: c, widespread: $w$, rare: $r$, very rare: rr, not seen: n.s.). A glossary explaining the technical terms used in the keys and an index of genera are included.
\end{abstract}

Keywords: Genera, species, glossary, mosses, liverworts, hornworts

\section{INTRODUCTION}

Identification of Hungarian bryophytes up to now had to rely on either keys in Hungarian published 68 and 38 years ago, respectively, long out of print (Boros 1953, Orbán and Vajda 1983), and out-of-date in many respects, or on keys written in various languages for other countries or regions (e.g. for liverworts and hornworts: Smith (1991), Paton (1999), Damsholt (2002), Schumacker and Váňa (2005), Frey et al. (2006), Casas et al. (2009), Atherton et al. (2010) in English, Gradstein and van Melick (1996), Siebel and During (2006) in Dutch, Müller (1905-1916, 1951-1958), Frahm and Frey (1992, 2004), Frey et al. (1995), Nebel and Philippi (2005) in German; for mosses: Smith (1978, 2004), Casas et al. (2006), Frey et al. (2006), Atherton et al. (2010) in English, Touw and Rubers (1989), Siebel and During (2006) in Dutch, Frahm and Frey (1992, 2004), Frey et al. (1995), Nebel and 
Philippi (2000, 2001) in German, Brugués et al. (eds.) (2007), Brugués and Guerra (eds.) (2015), Guerra et al. (eds.) (2006, 2010, $2014,2016)$ in Spanish, to name just a few). None of these treatments by itself allows the identification of all bryophytes presently known in the Hungarian bryophyte flora, except Frey et al. (2006). Therefore, time is overdue to present an accurate and updated tool for naming all bryophyte taxa of Hungary, including the many that have been discovered as new members of the Hungarian bryoflora in recent years. This need became particularly urgent during the first stages of the Hungarian bryophyte recording project (Erzberger 2012, Erzberger and Németh 2016, Erzberger 2020) when new contributors to the project had to be guided in improving their identifications skills. To remedy this, the author then compiled a preliminary version of identification keys, which was circulated among the participants of the recording project and continuously improved according to the accumulating experience.

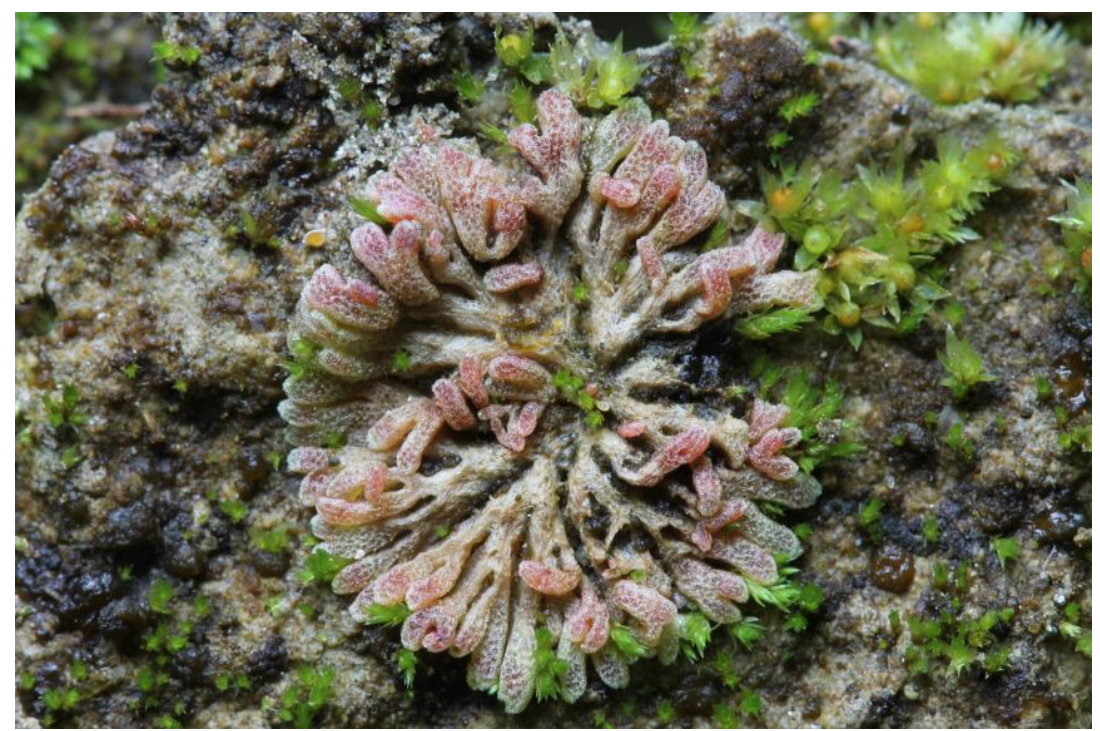

Figure 1. Riccia frostii Austin, Hungary, Győr-Moson-Sopron County, Vének, bank of the Danube, 02.10.2015 photo by Csaba Németh

Taxonomy and nomenclature closely follow the most recent European and Hungarian checklists (Hodgetts et al. 2020, Erzberger and Papp 2020). Here authorities to all names can be found; they have been deliberately omitted in this treatment. To 
facilitate the use of older works, the names used in older checklists (Erzberger and Papp 2004, Papp et al. 2010) are included as synonyms. To give an overwiew of the underlying taxonomy, a conspectus of classification has been included. A glossary explaining all technical terms used in the keys has also been compiled.

As a consequence of recent taxonomic developments, mainly based on molecular evidence, many species have changed their generic names and many genera have been transferred to different families. Thus the conventional approach of three steps in bryophyte identification - keys to families, keys to genera of each family, keys to species of each genus - is no longer practical, since many families lack easily observable morphological defining characters. I have therefore followed Guerra et al. (eds.) (2016) and Casas et al. $(2006,2009)$ in first giving a key to genera and then within each genus (containing more than one species in Hungary) a key to species.

However, for families with a \pm clear-cut morphological definition, keys are provided directly to all or nearly all species of the familiy (Table 1).

Table 1. Families for which a direct key to species is provided

\begin{tabular}{lclc}
\hline \multicolumn{1}{c}{ Liverworts } & page & \multicolumn{1}{c}{ Mosses } & page \\
\hline Aneuraceae & 109 & Bartramiaceae & 189 \\
Calypogeiaceae & 98 & Bryaceae & 190 \\
Cephaloziaceae & 86 & Dicranaceae & 139 \\
Lejeuneaceae & 108 & $\begin{array}{l}\text { Ditrichaceae s.l. incl. Saelania, } \\
\text { Flexitrichum }\end{array}$ & 143 \\
Lophocoleaceae & 104 & Funariaceae & 131 \\
Pelliaceae & 111 & Grimmiaceae & 175 \\
Plagiochilaceae & 106 & Polytrichaceae & 126 \\
Scapaniaceae excluding & 95 & Rhabdoweisiaceae & 142 \\
$\quad$ Schistochilopsis & & Seligeriaceae & 174 \\
\hline
\end{tabular}

In some cases these keys are additional to the keys from genus to species, but in others there are no separate keys from genus to species. This applies in particular where genera are keyed out collectively (often along the delimitations of taxa formerly in use), not separately, because their morphological delimitation is not useful for a simple key. Some of the newly established genera have been included in collective keys to species (Table 2). 
Table 2. Groups of genera treated collectively in keys to species

\begin{tabular}{|c|c|c|}
\hline \multicolumn{2}{|r|}{ Liverworts } & \multirow{2}{*}{$\frac{\text { page }}{85}$} \\
\hline Barbilophozia group & Barbilophozia, Neoorthocaulis & \\
\hline $\begin{array}{l}\text { Jungermanniaceae } \\
\text { group }\end{array}$ & $\begin{array}{l}\text { Endogemma, Jungermannia, Liochlaena, } \\
\text { Nardia, Solenostoma, Syzygiella }\end{array}$ & 101 \\
\hline Lophoziaceae group & $\begin{array}{l}\text { Barbilophozia, Isopaches, Lophozia, } \\
\text { Lophoziopsis, Mesoptychia, Neoorthocaulis, } \\
\text { Obtusifolium, Schistochilopsis, Trilophozia, } \\
\text { Tritomaria }\end{array}$ & 89 \\
\hline Marchantiales pp. & $\begin{array}{l}\text { Asterella, Clevea, Conocephalum, Lunularia, } \\
\text { Mannia, Marchantia, Reboulia }\end{array}$ & 112 \\
\hline Riccia group & Oxymitra, Riccia, Ricciocarpos & 115 \\
\hline \multicolumn{2}{|r|}{ Mosses } & page \\
\hline Amblystegium group & $\begin{array}{l}\text { Amblystegium, Hygroamblystegium, } \\
\text { Pseudoamblystegium, Pseudocampylium, } \\
\text { Serpoleskea }\end{array}$ & 216 \\
\hline Anomodon group & Anomodon, Claopodium, Pseudanomodon & 230 \\
\hline Bryum s.l. & Bryum, Imbribryum, Ptychostomum & 190 \\
\hline Brachythecium s.l. & $\begin{array}{l}\text { Brachytheciastrum, Brachythecium, } \\
\text { Sciuro-hypnum }\end{array}$ & 223 \\
\hline Calliergon group & Calliergon, Straminergon & 218 \\
\hline Gymnostomum group & Gymnostomum, Gyroweisia & 170 \\
\hline Hурпит s.l. & Buckia, Hypnum & 227 \\
\hline Mnium group & Mnium, Plagiomnium, Rhizomnium & 201 \\
\hline Neckera s.l. & Alleniella, Exsertotheca, Neckera & 228 \\
\hline Pottia s.l. & $\begin{array}{l}\text { Hennediella, Microbryum (excl. M. } \\
\text { curvicollum, M. floerkeanum), Tortula } \\
\text { caucasica, T. lindbergii, T. protobryoides, } \\
\text { T. truncata }\end{array}$ & 153 \\
\hline Tortula s.l. & $\begin{array}{l}\text { Hilpertia, Syntrichia, Tortula (excl. T.acaulon, } \\
\text { T. caucasica, T. lindbergii, T. protobryoides, } \\
\text { T. truncata) }\end{array}$ & 160 \\
\hline
\end{tabular}

This approach, although at first glance seeming to lack systematic rigour, should provide the possibility to enter the process of identification at various taxonomic levels (family, group of morphologically similar genera, genus) and thus enable a comparison among taxa that could easily be confounded, although in some cases not related taxonomically. A similar purpose is intended by various notes mentioning differences between related or unrelated taxa.

The keys have been adapted from the references mentioned above and others (e.g. Watson 1981), and from additional treatments of special groups which are indicated at the families or 
genera, including personal experience of the author. In general, only taxa from the most recent Hungarian checklist (Erzberger and Papp 2020) have been considered, plus three species added to the Hungarian bryoflora after the publication of the checklist (Hydrogonium croceum, Orthothecium rufescens, Rhytidiadelphus loreus), their names are printed in bold, but some taxa that might be expected (or have been doubtfully recorded) have in a few cases been included (printed in normal case).

As an additional information the frequency of recent occurrences of taxa (based on records since 1974, i.e. after the era of Á. Boros) is included in the following categories: very common: cc, common: c, widespread: $w$, rare: $r$, very rare: rr, not seen: n.s. (i.e. no record after 1973). These estimates are based on a preliminary evaluation of the recording project (Erzberger and Németh 2016, Erzberger 2020) which will be published elsewhere, and their accuracy should not be overestimated, since coverage of the country is far from complete; in particular the lowlands are sorrowfully under-represented. The frequency may help mainly beginners to check the result of their identification, excluding very rare and rare species, which are unlikely to be found without experience.

Acknowledgements - I am indebted to Péter Szűcs for editing the keys, to Csaba Németh for providing the photograph of Riccia frostii (Fig. 1.) and to the participants of the recording project for feedback on the preliminary keys and their contributions to the dataset. Special thanks are due to Christian Berg (Graz), Frank Müller (Dresden) and Tamás Pócs (Eger) for their constructive criticism of the manuscript resulting in many essential improvements.

\section{REFERENCES}

Atherton, I., Bosanquet, S.D.S. \& LAWLEy, M. (eds.) (2010). Mosses and Liverworts of Britain and Ireland. A Field Guide. British Bryological Society, Plymouth, 848 pp.

Bakalin, V.A. (2016). Notes on Lophozia VIII. The Lectotypification of Lophozia longiflora (Nees) Schiffn. (Lophoziaceae, Hepaticae). Herzogia 29: 635-643. https://doi.org/10.13158/heia.29.2.2016.635

BARÁth, K. \& ERZBERGER, P. (2019). Heterocladium heteropterum, a new member of the Hungarian bryophyte flora. Studia Botanica Hungarica 50(2): 323-329. https://doi.org/10.17110/StudBot.2019.50.2.323

Baráth, K., ERzBerger, P., KovÁCS, A. \& PAPP, B. (2016). Heterocladium dimorphum (Brid.) Schimp. (Heterocladiaceae) - an old element of the Hungarian bryophyte flora rediscovered. Studia Botanica Hungarica 47: 269-278. 
http://dx.doi.org/10.17110/StudBot.2016.47.2.269

Bergamini, A. (2001). Provisorischer Schlüssel zur Unterscheidung steriler Philonotis-Proben. http://www.bryolich.ch/pdfs/Philonotis_key.pdf

BLOCKEEL, T.L. (2017). The Ulota crispa group in Britain and Ireland, with notes on other species of the genus. Field Bryology 117: 8-19.

Blockeel, T.L., OchYRA, R. \& Gos, L. (2000). Seligeria campylopoda Kindb. in the British Isles. Journal of Bryology 22: 29-33. https://doi.org/10.1179/jbr.2000.22.1.29

Blom, H. (1996). A revision of the Schistidium apocarpum complex in Norway and Sweden. Bryophytorum Bibliotheca 49, J. Cramer, Borntraeger, Berlin, 333 pp.

Boros, Á. (1953). Magyarország mohái (Bryophyta Hungariae). Akadémiai Kiadó, Budapest, $360 \mathrm{pp}$.

Boros, Á. (1968). Bryogeographie und Bryoflora Ungarns. Akadémiai Kiadó, Budapest, $466 \mathrm{pp}$.

Brugués, M., Cros, R.M. \& Guerra, J. (eds.) (2007). Flora Briofítica Ibérica. Vol. I, Sphagnales, Andreaeales, Polytrichales, Tetraphidales, Buxbaumiales, Diphysciales. Universidad de Murcia, Sociedad Española de Briología, Murcia, 183 pp.

Brugués, M. \& Guerra, J. (eds.) (2015). Flora Briofítica Ibérica. Vol. II, Archidiales, Dicranales, Fissidentales, Seligeriales, Grimmiales. Universidad de Murcia, Sociedad Española de Briología, Murcia, 355 pp.

Caparrós, R., Lara, F., Draper, I., MazimpaKa, V. \& Garilleti, R. (2016). Integrative taxonomy sheds light on an old problem: the Ulota crispa complex (Orthotrichaceae, Musci). Botanical Journal of the Linnean Society 180: 427451. https://doi.org/10.1111/boj.12397

Casas, C., Brugués, M., Cros, R.M. \& SÉrgio, C. (2006). Handbook of Mosses of the Iberian Peninsula and the Balearic Islands. Institut d'Estudis Catalans, Barcelona, $349 \mathrm{pp}$.

Casas, C., Brugués, M., Cros, R.M., SÉrgio, C. \& Infante, M. (2009). Handbook of Liverworts and Hornworts of the Iberian Peninsula and the Balearic Islands. Institut d'Estudis Catalans, Barcelona, $177 \mathrm{pp}$.

Caspari, S., Dürhammer, O., SAuer, M. \& Schmidt, C. (2018). Rote Liste und Gesamtartenliste der Moose (Anthocerotophyta, Marchantiophyta und Bryophyta) Deutschlands. In: Metzing, D., Hofbauer, N., LudwiG, G. \& MatzKeHAJEK, G. (eds.): Rote Liste gefährdeter Tiere, Pflanzen und Pilze Deutschlands. Band 7: Pflanzen. Landwirtschaftsverlag, Münster. Naturschutz und Biologische Vielfalt 70(7): 361-489.

Csiky, J., ErzBerger, P., KovÁcs, D. \& Deme, J. (2014). Campylopus pyriformis (Schultz) Brid. in the Western Mecsek Mts. (South Transdanubia, Hungary) / Campylopus pyriformis (Schultz) Brid. a Ny-Mecsekben. Kitaibelia 19: 366-367.

Csiky, J., ErzBerger, P., KovÁcs, D. \& Deme, J. (2015). Campylopus flexuosus (Hedw.) Brid. in the Western Mecsek Mts. (South Transdanubia, Hungary). / Campylopus flexuosus (Hedw.) Brid. a Nyugat-Mecsekben. Kitaibelia 20(1): 2837. https://doi.org/10.17542/kit.20.28

Damsholt, K. (2002). Illustrated Flora of Nordic Liverworts and Hornworts. Nordic Bryological Society, Lund. 837 pp.

Demaret, F. (1993). Bryum Hedw. In: De Sloover, J.-L., Demaret, F., De Zuttere, Ph. \& ARTs, TH. (eds.) Flore Générale de Belgique Bryophytes Vol III. Fascicule 2. 
Ministère de l' Agriculture, Jardin Botanique National de Belgique, Meise, pp. 152-258.

Deme, J., Erzberger, P., Kovács, D., Tóth, I. Zs. \& Csiky, J. (2020). Buxbaumia viridis (Moug. ex Lam. \& DC.) Brid. ex Moug. \& Nestl. in Hungary predominantly terricolous and found in managed forests. Cryptogamie, Bryologie 41: 89-103. https://doi.org/10.5252/cryptogamie-bryologie2020v41a8

DiERSSEN, K. (1996). Bestimmungsschlüssel der Torfmoose in Norddeutschland. Mitt. Arbeitsgem. Geobot. Schleswig-Holstein \& Hamburg 50: 1-86.

DüLl-HERmanns, I. (1981). Spezielle Untersuchungen zur modernen Taxonomie von Thuidium abietinum und der Varietät hystricosum. Journal of Bryology 11: 467487.

ElLIS, L.T. \& PricE, M.J. (2015). Review of the type specimens of species described by J. Hedwig in Phascum Hedw. (Pottiaceae). Journal of Bryology 37: 23-41. https://doi.org/10.1179/1743282014Y.0000000116

ERZBERGER, P. (1996). Zur Verbreitung von Hedwigia stellata in Europa. Herzogia 12: 221-238.

Erzberger, P. (1998). Tortula brevissima Schiffn. - eine für die Flora Ungarns neue Moosart. Botanikai Közlemények 85: 63-72.

ERzBerger, P. (1999). Distribution of Dicranum viride and Dicranum tauricum in Hungary. Studia Botanica Hungarica 29: 35-47.

ErzBerger, P. (2001). Ditrichum crispatissimum (Muell. Hal.) Paris, a new species of the Hungarian bryoflora, and Ditrichum flexicaule (Schleich. ex Schwaegr.) Hampe in Hungary. Studia Botanica Hungarica 32: 87-105.

ERzBerger, P. (2002). Funaria muhlenbergii and Funaria pulchella (Funariaceae, Bryophyta) in Hungary. Studia Botanica Hungarica 33: 47-63.

ERzBerger, P. (2005). The bulbilliferous species of Pohlia (Bryaceae, Musci) in Hungary. Studia Botanica Hungarica 36: 67-75.

ERzBERger, P. (2009). The genera Grimmia and Coscinodon (Grimmiaceae, Musci) in Hungary. Studia Botanica Hungarica 40: 37-124.

ERZBERGER, P. (2012). Project plan: Bryophyte mapping of Hungary. Abstracts of 8th ECCB Conference in Budapest, April 2012, p. 6.

Erzberger, P. (2016). The genus Fissidens Hedw. (Bryophyta) in Hungary. Studia Botanica Hungarica 47: 41-139. http://dx.doi.org/10.17110/StudBot.2016.47.1.41

ERZBERGER, P. (2020). Bryophyte recording in Hungary in the 21st century. Field Bryology 123: 21-33.

Erzberger, P. \& BARÁth, K. (2017). Plagiothecium latebricola Schimp. - a new member of the Hungarian bryoflora. Studia Botanica Hungarica 48(2): 189197. https://doi.org/10.17110/StudBot.2017.48.2.189

Erzberger, P., Bednarek-Ochyra, H. \& Ochyra, R. (2016). Grimmiaceae subfam. Racomitrioideae (Bryophyta) in Hungary. Polish Botanical Journal 61(1): 2351. https://doi.org/10.1515/pbj-2016-0015

Erzberger, P. \& NÉmeth, Cs. (2014). Campylopus flexuosus (Hedw.) Brid.: a moss new to the Hungarian bryophyte flora. / Új faj Magyarország mohaflórájában: Campylopus flexuosus (Hedw.) Brid. Kitaibelia 19: 22-28.

ERZBERGER, P. \& NÉMETH, Cs. (2016). Bryophyte recording in Hungary - results 20122015. $-11^{\text {th }}$ International Conference "Advances in research on the flora and 
vegetation of the Carpato-Pannonian region", Budapest, 12-14 February 2016 (lecture). Book of Abstracts, p. 17.

Erzberger, P., Németh, Cs., Deme, J. \& Csiky, J. (2018). Stomatal anatomy allows clarification of historical collections of Buxbaumia Hedw. in Hungary. Studia Botanica Hungarica 49(1): 71-82. https://doi.org/10.17110/StudBot.2018.49.1.71

Erzberger, P., NÉmeth, Cs., Sauer, M., Nagy, J. \& Papp, B. (2020). Plagiothecium platyphyllum Moenk. - a rare species in Hungary. Studia Botanica Hungarica 51(1): 25-40. https://doi.org/10.17110/StudBot.2020.51.1.25

ERZBERGER, P. \& PAPP, B. (2000). Orthotrichum sprucei discovered in continental Central Europe. Herzogia 14: 213-215.

ERzBerger, P. \& PAPP, B. (2004). Annotated checklist of Hungarian bryophytes. Studia Botanica Hungarica 35: 91-149.

ERzBERger, P. \& PAPP, B. (2018). Tortella fasciculata and T. pseudofragilis (Pottiaceae, Bryophyta) in Hungary. Studia Botanica Hungarica 49(2): 39-48. https://doi.org/10.17110/StudBot.2018.49.2.39

ERzBerger, P. \& PAPP, B. (2020). The checklist of Hungarian bryophytes - second update. Studia Botanica Hungarica 51(2): 11-76. https://doi.org/10.17110/StudBot.2020.51.2.11

ERzBerger, P. \& SchröDER, W. (2008). The genus Schistidium (Grimmiaceae, Musci) in Hungary. Studia Botanica Hungarica 39: 27-88.

Erzberger, P. \& Schröder, W. (2013). The genus Bryum (Bryaceae, Musci) in Hungary. Studia Botanica Hungarica 44: 5-192.

Frahm, J.-P. \& AhmED, J. (2004). Barbula sardoa (Schimp.) J.-P. Frahm, a new name for Barbula convoluta Hedw. var. commutata (Jur.) Husn. Journal of Bryology 26(1): 29-35.

Frahm, J.-P. \& Frey, W. (1992). Moosflora. 3rd. ed. Ulmer, Stuttgart, 528 pp.

FRAHM, J.-P. \& FREY, W. (2004). Moosflora. 4th. ed. Ulmer, Stuttgart, 538 pp.

Frey, W., Frahm, J.-P., Fischer, E. \& Lobin, W. (1995). Die Moos- und Farnpflanzen Europas. Fischer, Stuttgart, Jena, New York, 426 pp.

FreY, W., Frahm, J.-P., Fischer, E. \& LoBin, W. (2006). The Liverworts, Mosses and Ferns of Europe. English edition revised and edited by T.L.Blockeel. Harley Books, Colchester, 512 pp.

Gallego, M.T. (2005). A taxonomic study of the genus Syntrichia Brid. (Pottiaceae, Musci) in the Mediterranean region and Macaronesia. Journal of Hattori Botanical Laboratory 98: 47-122.

Gallego, M.T., Hugonnot, V. \& Cano, M.J. (2018). Taxonomic resurrection of an awnless variety of Syntrichia ruralis and comparison with other European muticous taxa in this genus. Journal of Bryology 40(3): 244-250.

https://doi.org/10.1080/03736687.2018.1468971

Godfrey, M. \& Hill, M. (2012). Sphagnum Workshop, November 2011. Field Bryology 106: 69.

Gradstein, S.R. \& van Melick, H.M.H. (1996). De Nederlandse Levermossen en Hauwmossen. Flora en verspreidingsatlas van de Nederlandse Hepaticae en Anthocerotae. Stichting Uitgeverij van de Koninklijke Nederlandse Natuurhistorische Vereniging, Utrecht, 366 pp. 
Guerra, J., Brugués, M., Cano, M.J. \& Cros, R.M. (eds.) (2010). Flora Briofítica Ibérica. Vol. IV, Funariales, Splachnales, Bryales, Timmiales. Universidad de Murcia, Sociedad Española de Briología, Murcia, 317 pp.

Guerra, J., CAno, M.J. \& Brugués, M. (eds.) (2014). Flora Briofítica Ibérica. Vol. V, Orthotrichales, Hedwigiales, Leucodontales, Hookeriales. Universidad de Murcia, Sociedad Española de Briología, Murcia, $261 \mathrm{pp}$.

Guerra, J., Cano, M.J. \& Brugués, M. (eds.) (2016). Flora Briofítica Ibérica. Vol. VI, Hypnales. Universidad de Murcia, Sociedad Española de Briología, Murcia, 463 pp.

Guerra, J., Cano, M.J. \& Ros, R.M. (eds.) (2006). Flora Briofítica Ibérica. Vol. III, Pottiales, Encalyptales. Universidad de Murcia, Sociedad Española de Briología, Murcia, 305 pp.

Hassel, K., Kyrkjeeide, M.O., Yousefi, N., Prestø, T., Stenøien, H.K., Shaw, J.A. \& FLATBERG, K.I. (2018). Sphagnum divinum (sp. nov.) and S. medium Limpr. and their relationship to S. magellanicum Brid. Journal of Bryology 40: 197-222. https://doi.org/10.1080/03736687.2018.1474424

HEDENÄs, L. (1994). The Hedwigia ciliata complex in Sweden, with notes on the occurrence of taxa in Fennoscandia. Journal of Bryology 18: 139-157.

HEDEnÄs, L. \& BiSANG, I. (2002). Drepanocladus sordidus und D. stagnatus, zwei Sippen für die Schweiz angegeben. Meylania 23: 15-20.

Hedenäs, L. \& BisAng, I. (2004). Key to the European Dicranum species. Herzogia 17: 179-197.

Hedenäs, L., HeinRichS, J. \& Gallego, M.T. (2019). The Scandinavian Syntrichia ruralis complex (Musci. Pottiaceae): a chaos of diversification. Plant Systematics and Evolution 305: 639-661. https://doi.org/10.1007/s00606-019-01596-0

HodgetTS, N.G., SöDerströM, L., BlockeEl, T.L., CASPari, S., Ignatov, M.S., Konstantinova, N.A., Lockhart, N., PAPP, B., Schröck, C., Sim-Sim, M., Bell, D., Bell, N.E., Blom, H.H., Bruggeman-Nannenga, M.A., Brugués, M., Enroth, J., Flatberg, K.I., Garilleti, R., Hedenäs, L., Holyoak, D.T., Hugonnot, V., Kariyawasam, I., KöCKInGER, H., KuČERA, J., LARA, F. \& Porley, R.D. (2020). An annotated checklist of bryophytes of Europe, Macaronesia and Cyprus. Journal of Bryology 42(1): 1116. https://doi.org/10.1080/03736687.2019.1694329

Номм, Тн. (2017). Leaf-born gemmae in Syntrichia virescens (De Not.) Ochyra - a neglected feature in bryological literature. Frahmia 15: 1-4.

Hugonnot, V. (2010). Towards an improved understanding of the taxonomy of Riccia ciliata Hoffm. (Marchantiopsida: Ricciaceae). Journal of Bryology 32: 300-303. https://doi.org/10.1179/jbr.2010.32.4.300

JimÉnEZ, J.A. (2006). Didymodon Hedw. In: Guerra, J., CANo, M.J. \& Ros, R.M. (eds.) Flora Briofítica Ibérica. Vol. III, Pottiales, Encalyptales. Universidad de Murcia, Sociedad Española de Briología, Murcia. pp. 217-244.

Jovet-Ast, S. (1986). Les Riccia de la région méditerranée. Cryptogamie Bryologie Lichénologie 7 Suppl. 3: 287-431.

KöCKINGER, H. (2017). Die Horn- und Lebermoose Österreichs (Anthocerotophyta und Marchantiophyta) Catalogus Florae Austriae, Teil 2. Heft 2. Biosystematic and Ecology Series 32: 1-382. https://doi.org/10.2307/j.ctt1v2xvg0

KöCKInGER, H. \& HEDENÄS, L. (2017). A farewell to Tortella bambergeri (Pottiaceae) as understood over the last decades. Journal of Bryology 39: 213-225. https://doi.org/10.1080/03736687.2017.1307313 
KoŠNAR, J. \& KolÁŘ, F. (2009). A taxonomic study of selected European taxa of the Tortula muralis (Pottiaceae, Musci) complex: variation in morphology and ploidy level. Preslia 81: 399-421.

KUČERA, J. (2000). Illustrierter Bestimmungsschlüssel zu den mitteleuropäischen Arten der Gattung Didymodon. Meylania 19: 1-49.

Kučera, J., Blockeel, T.L., Erzberger, P., PAPP, B., SoldÁn, Z., Vellak, K., Werner, O. \& Ros, R.M. (2018). The Didymodon tophaceus Complex (Pottiaceae, Bryophyta) Revisited: New Data Support the Subspecific Rank of Currently Recognized Species. Cryptogamie, Bryologie 39(2): 241-257. https://doi.org/10.7872/cryb/v39.iss2.2018.241

KuČERA, J., KoŠnAR, J. \& WERner, O. (2013). Partial generic revision of Barbula (Musci: Pottiaceae): Re-establishment of Hydrogonium and Streblotrichum, and the new genus Gymnobarbula. Taxon 62: 21-39. https://doi.org/10.1002/tax.621004

Laine, J., Flatberg, K.-I., Harju, P., Timonen, T., Minkkinen, K., Laine, A., Tuittila, E.-S. \& VASANDER, H. (2018). Sphagnum mosses. The Stars of European Mires. University of Helsinki Department of Forest Sciences, Helsinki, 326 pp. $+>1000$ photographs.

Laine, J., Harju, P., Timonen, T., Laine, A., Tuittila, E.-S., Minkkinen, K. \& Vasander, H. (2011). The intricate beauty of Sphagnum mosses - a Finnish guide to identification. University of Helsinki Department of Forest Sciences Publications 2: 1-191.

LANDWEHR, J. (1984). Nieuwe Atlas Nederlandse bladmossen. Thieme, Zutphen, 568 pp.

LimPRICHT, K.G. (1890). Die Laubmoose Deutschlands, Oesterreichs und der Schweiz. I. Abtheilung: Sphagnaceae, Andreaeaceae, Archidiaceae, Bryinae (Cleistocarpae, Stegocarpae [Acrocarpae]). (= Dr. L. Rabenhorst's Kryptogamenflora von Deutschland, Österrreich und der Schweiz 2. Aufl.). Kummer, Leipzig, 836 pp.

Lüth, M. (2019). Mosses of Europe. A Photographic Flora. Vol. 1-3. Michael Lüth, Freiburg, $1360 \mathrm{pp}$.

MaIER, E. (2010). The Genus Grimmia Hedw. (Grimmiaceae, Bryophyta) A morphological-anatomical study. Boissiera 63: 1-377.

MaGiLl, R.E. (ed.) (1990). Glossarium Polyglottum Bryologiae. Missouri Botanical Garden, St Louis, 297 pp.

Malcolm, B. \& Malcolm, N. (2000). Mosses and Other Bryophytes. An Illustrated Glossary. Micro-Optics Press, Nelson, New Zealand, 220 pp.

MASTRACCI, M. (1993). Taxonomic significance of stem and leaf-sheath anatomy in Timmia Hedw. Journal of Bryology 17: 481-487.

MASTRACCI, M. (2003). Thamnobryum neckeroides (Bryopsida: Neckeraceae): lectotypification, synonymies, diagnostic characters, habitat and distribution. Journal of Bryology 25(2): 115-120.

MEINUnGER, L. \& SCHRÖDER, W. (2007). Verbreitungsatlas der Moose Deutschlands. 3 vols. Regensburgische Botanische Gesellschaft, Regensburg, 636, 700, 709 pp.

MülLER, F. (2017). Didymodon sicculus and Tortula pallida new for Germany from inland salt marshes in eastern Germany. Herzogia 30: 387-396.

https://doi.org/10.13158/heia.30.2.2017.387 
MülLER (FRIB.), K. (1905-1916). Die Lebermoose Deutschlands, Oesterreichs und der Schweiz. In: RABENHORST, G.L. (founder), Kryptogamenflora (ed. 2) Vol. 6 part 1, 871 pp., part 2, 947 pp., Kummer, Leipzig.

MÜlLER (FRIB.), K. (1951-1958). Die Lebermoose Europas. In: RABENHORST, G.L. (founder), Kryptogamenflora (ed. 3) Vol. 6 Geest \& Portig, Leipzig, 1365 pp.

MuRRAY, B.M. (1987). Andreaeaceae. In: MogensEN, G.S. (ed.): Illustrated moss flora of arctic North America and Greenland 3. Andreaeobryaceae - Tetraphidaceae. Meddel. Grønland, Biosci. 23: 1-36.

MurRaY, B.M. (1988). The genus Andreaea in Britain and Ireland. Journal of Bryology 15(1): 17-82.

Nebel, M. \& Philippi, G. (eds.) (2000). Die Moose Baden-Württembergs, I. (Andreaeales bis Funariales). Ulmer, Stuttgart, $512 \mathrm{pp}$.

Nebel, M. \& Philippi, G. (eds.) (2001). Die Moose Baden-Württembergs, II. (Schistostegales bis Hypnobryales). Ulmer, Stuttgart, 529 pp.

Nebel, M. \& PhilippI, G. (eds.) (2005). Die Moose Baden-Württembergs, III. (Sphagnopsida, Marchantiopsida, Anthocerotophyta). Ulmer, Stuttgart, 487 pp.

NÉmETH, Cs. \& ERZBERGER, P. (2015). Anacamptodon splachnoides (Amblystegiaceae): Hungarian populations of a moss species with a peculiar habitat. Studia Botanica Hungarica 46(1): 61-75. https://doi.org/10.17110/StudBot.2015.46.1.61

Nyнolm, E. (1960). Illustrated Moss Flora of Fennoscandia II. Musci. Fasc. 4. Swedish Natural Science Research Council, Lund, pp. 284-408.

Nyнolm, E. (1979). Illustrated Moss Flora of Fennoscandia II. Musci. Fasc. 5, ed. 2. Swedish Natural Science Research Council, Stockholm, pp. 407-647.

Nyнolm, E. (1981). Illustrated Moss Flora of Fennoscandia II. Musci. Fasc. 6, ed. 2. Swedish Natural Science Research Council, Stockholm, pp. 647-799.

Nyноцм, E. (1987). Illustrated Flora of Nordic Mosses. Fasc. 1. Fissidentaceae Seligeriaceae. Nordic Bryological Society, Copenhagen and Lund, pp. 1-72.

Nyноцм, E. (1990). Illustrated Flora of Nordic Mosses. Fasc. 2. Pottiaceae Splachnaceae - Schistostegaceae. Nordic Bryological Society, Copenhagen and Lund.pp. 75-141.

Nyнolm, E. (1993). Illustrated Flora of Nordic Mosses. Fasc. 3. Bryaceae Rhodobryaceae - Mniaceae - Cinclidiaceae - Plagiomniaceae. Nordic Bryological Society, Copenhagen and Lund, pp. 145-244.

Nyнolm, E. (1998). Illustrated Flora of Nordic Mosses, Fasc. 4 (Aulacomniaceae Meesiaceae - Catascopiaceae - Bartramiaceae - Timmiaceae - Encalyptaceae Grimmiaceae - Ptychomitraceae - Hedwigiaceae - Orthotrichaceae). Nordic Bryological Society, Copenhagen and Lund, pp. 249-404.

ORBÁN, S. \& VAJDA, L. (1983). Magyarország mohaflórájának kézikönyve (Handbook of the Hungarian bryophyte flora). Akadémiai Kiadó, Budapest, 518 pp.

PAPP, B., ERZBerger, P., Ódor, P., Hock, Zs., SZÖVÉnYI, P., SZuRdoKI, E. \& Tóth, Z. (2010). Updated checklist and red list of Hungarian bryophytes. Studia Botanica Hungarica 41: 31-59.

PAton, J.A. (1999). The Liverwort Flora of the British Isles. Harley Books, Great Horkesley, $626 \mathrm{pp}$.

PláŠEK, V., SAWICKI, J., TRÁvničKovÁ, V., PASEČNÁ, M. (2009). Orthotrichum moravicum (Orthotrichaceae), a new moss species from the Czech Republic. The Bryologist 112: 329-336. https://doi.org/10.1639/0007-2745-112.2.329 
SchlÜsslmaYR, G. (2005). Soziologische Moosflora des Südlichen Oberösterreich. Stapfia 84: 1-695.

SCHUMACKER, R. \& VÁŇA, J. (2005). Identification keys to the liverworts and hornworts of Europe and Macaronesia (distribution \& status). Second edition fully revised and updated. Sorus, Poznań, $209 \mathrm{pp}$.

Siebel, H.N. \& DuRING, H.J. (2006). Beknopte Mosflora van Nederland en België. KNNV Uitgeverij, Utrecht, $559 \mathrm{pp}$.

Sмiтh, A.J.E. (1978). The Moss Flora of Britain and Ireland. Cambridge University Press, Cambridge, New York, Port Chester, Melbourne, Sidney, 706 pp.

Smith, A.J.E. (1991). The Liverworts of Britain \& Ireland. Cambridge University Press, Cambridge, $362 \mathrm{pp}$.

Smith, A.J.E. (2004). The Moss Flora of Britain and Ireland, $2^{\text {nd }}$ ed. University Press, Cambridge, $1012 \mathrm{pp}$.

SzURDoкI, E. (2000). Tőzegmohás élőhelyek Magyarországon: kutatás, kezelés, védelem. CEEWEB Munkacsoport, Miskolc, $184 \mathrm{pp}$.

SzURDOKI, E. (2003). Peatmosses of North Hungary. Studia Botanica Hungarica 34: 55-79.

SZURdoki, E., MÁRTon, O. \& SzövÉNYI, P. (2014). Genetic and morphological diversity of Sphagnum angustifolium, S. flexuosum, S. fallax in Europe. Taxon 63(2): 237248. https://doi.org/10.12705/632.6

SZURDoKI, E. \& NAGY, J. (2002). Sphagnum dominated mires and Sphagnum occurrences of North-Hungary. Folia Historico-Naturalia Musei Matraensis 26: 67-84.

Szurdoki, E., Tóth, Z. \& Pelles, G. (1999-2000). The Sphagnum populations of the Zemplén Mts, NE Hungary. Studia Botanica Hungarica 30-31: 113-125.

SzWEYKowSKI, J. \& MENDELAK, M. (1964). Experimental investigations of the variability of Riccia gougetiana and Riccia ciliifera from Czechoslovakia. Acta Societatis Botanicorum Poloniae 33: 359-369.

Touw, A. \& Rubers, W.V. (1989). De Nederlandse Bladmossen. Stichting Uitgeverij Koninklijke Nederlandse Natuurhistorische Vereniging, Utrecht, 532 pp.

Vigalondo, B., Draper, I., Mazimpaka, V., Calleja, J.A., Lara, F. \& Garilleti, R. (2020). The Lewinskya affinis complex (Orthotrichaceae) revisited: species description and differentiation. The Bryologist 123(3): 454-481. https://doi.org/10.1639/0007-2745-123.3.454

Watson, E.V. (1981). British Mosses and Liverworts. Cambridge University Press, Cambridge, 537 pp.

WolsKi, G.J. \& KRAWCZYK, P. (2020). Resurrection of the Plagiothecium longisetum Lindb. and proposal of the new species - P. angusticellum. PLoS ONE 15(3): e0230237. https://doi.org/10.1371/journal.pone.0230237

ZüNDORF, H.-J. (1988). Moose Mecklenburgs II: Leucobryum glaucum und Leucobryum juniperoideum. Botanischer Rundbrief für den Bezirk Neubrandenburg 20: 55-60. 


\section{TABLE OF CONTENTS}

$\begin{array}{lr}\text { CONSPECTUS OF CLASSIFICATION } & 20\end{array}$

$\begin{array}{ll}\text { Anthocerotophyta (Hornworts) } & 20\end{array}$

Marchantiophyta (Liverworts) 20

$\begin{array}{ll}\text { Bryophyta (Mosses) } & 23\end{array}$

PRELIMINARY REMARKS - HOW TO USE THESE KEYS 30

ABBREVIATIONS $\quad 30$

FREQUENCY CLASSES $\quad 31$

RECOMMENDED LITERATURE

PART I: GENERAL KEYS

1. Key to the main groups of bryophytes 36

2. Keys to genera of thalloid bryophytes $\quad 37$

$\begin{array}{ll}\text { Hornworts } & 37\end{array}$

Thalloid liverworts $\quad 37$

Group 1 Thallus with internal differentiation; dorsal epidermis with pores; rhizoids smooth or warty

Group 2 Thallus without internal differentiation, dorsal epidermis without pores, rhizoids smooth $\quad 38$

3. Keys to genera of foliose liverworts $\quad 39$

Group 3 Leaves simple, succubous $\quad 40$

Group 4 Leaves 3-5-lobed $\quad 41$

Group 5 Leaves conduplicate, underleaves lacking $\quad 41$

Group 6 Leaves conduplicate, underleaves present $\quad 42$

Group 7 Leaves bilobed, transversely or subtransversely inserted $\quad 42$

Group 8 Leaves bilobed, longitudinally or obliquely inserted, succubous

4. Keys to genera of mosses $\quad 44$

Group 9 Leaves distichous or complanate $\quad 47$

Group 10 Costa or ventral leaf surface with filaments or lamellae $\quad 48$

Group 11 Leaves with hyaline point or costa excurrent in hair point $\quad 48$

Group 12 Leaves bordered with narrow cells or margin pluristratose $\quad 50$

Group 13 Acrocarps with indehiscent capsule $\quad 51$

Group 14 Acrocarps with immersed or emergent capsule $\quad 51$

Group 15 Acrocarps with exserted globose or subglobose capsule $\quad 52$

Group 16 Acrocarps with exserted strumose capsule 53

Group 17 Acrocarps with exserted capsule and peristome lacking or rudimentary 53

Group 18 Acrocarps with exserted capsule, striate or sulcate when dry and peristome well developed

Group 19 Acrocarps with exserted erect capsule, peristome teeth 16, entire or slightly and irregularly divided

Group 20 Acrocarps with exserted erect capsule, peristome teeth 16, divided halfway or to the base (32 teeth)

Group 21 Acrocarps with exserted capsule, inclined or pendulous, peristome simple 
Group 22 Acrocarps with exserted capsule, inclined to pendulous, peristome double

Group 23 Acrocarps with propagules on stems, leaves or in receptacles

Group 24 Acrocarps with costa 1/3 or more of leaf base

62

Group 25 Acrocarps with lamina cells $18 \mu \mathrm{m}$ wide or more

63

Group 26 Acrocarps with alar cells differentiated

66

Group 27 Acrocarps with lamina cells isodiametric and leaf margins denticulate or dentate, at least near apex or base

66

Group 28 Acrocarps with lamina cells isodiametric and excurrent costa

Group 29 Acrocarps with isodiametric lamina cells, leaf apex obtuse or rounded, apiculate or not and costa not excurrent

Group 30 Acrocarps with isodiametric cells, apex acute, subacute or acuminate, margins recurved at least on one side, costa not excurrent or lacking

Group 31 Acrocarps with isodiametric cells, apex acute, subacute or acuminate, margins plane or recurved at base only, costa not excurrent

Group 32 Acrocarps with lamina cells elongate, leaves acuminate or subulate and apex consisting largely or entirely of costa

Group 33 Acrocarps with lamina cells elongate, leaf apex obtuse to acuminate, costa percurrent or excurrent, short or lacking

Group 34 Pleurocarps with long costa and lamina cells short, at least at margins

Group 35 Pleurocarps with longitudinally plicate leaves, costa long and lamina cells elongate

Group 36 Pleurocarps with squarrose or falcate leaves, long costa and elongated lamina cells

Group 37 Pleurocarps with long costa, elongated lamina cells and rounded, obtuse, or obtuse and apiculate apex

Group 38 Pleurocarps with long costa, elongated lamina cells and acute or acuminate apex

Group 39 Pleurocarps with short or lacking costa, short lamina cells at least at margin

Group 40 Pleurocarps with short or lacking costa, elongated lamina cells and rounded, obtuse or apiculate apex

Group 41 Pleurocarps with distinctly falcate or squarrose leaves, short or lacking costa, elongated lamina cells and acute or acuminate apex

Group 42 Pleurocarps with straight, slightly falcate or squarrose leaves, costa single, short, long and double, or lacking, elongated lamina cells and acute or acuminate apex

PART II: SPECIAL KEYS

5. Keys to species of Liverworts

Key to species of Barbilophozia group, incl. Neoorthocaulis floerkii 85

Key to species of Cephaloziaceae 86

Key to species of Cephaloziella $\quad 87$ 
Key to Lophoziaceae group. (incl. Barbilophozia, Isopaches, Lophozia,

Lophoziopsis, Mesoptychia, Neoorthocaulis, Obtusifolium,

Schistochilopsis, Trilophozia and Tritomaria)

89

$\begin{array}{ll}\text { Key to species of Diplophyllum and the genus Scapania } & 94 \\ \text { Key to species of Scapania } & 95\end{array}$

Supplementary 'key' to species of Scapania according to habitats 98

Key to species of Calypogeia 98

Key to species of Marsupella $\quad 100$

$\begin{array}{ll}\text { Key to species of Nardia } & 100\end{array}$

Key to Jungermanniaceae group (incl. Endogemma, Jungermannia, Liochlaena, Nardia, Solenostoma, Syzygiella) $\quad 101$

Key to species of Mesoptychia 103

Key to species of Lophocoleaceae $\quad 104$

Key to species of Plagiochilaceae 106

Key to species of Frullania 106

$\begin{array}{ll}\text { Key to species of Lejeuneaceae } & 108\end{array}$

$\begin{array}{ll}\text { Key to species of Porella } & 108\end{array}$

$\begin{array}{ll}\text { Key to species of Radula } & 109\end{array}$

Key to species of Aneuraceae $\quad 109$

Key to species of Metzgeria $\quad 110$

Key to species of Fossombronia 111

Key to species of Pelliaceae 111

Key to Marchantiales pp. (incl. Asterella, Clevea, Conocephalum, Lunularia, Mannia, Marchantia, Reboulia) 112

Key to species of Riccia group (incl. Oxymitra, Riccia, and Ricciocarpos) 115

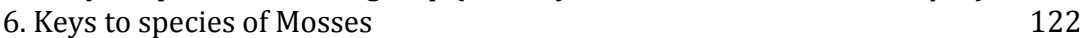

Key to sections and species of Sphagnum 122

Key to the varieties of Andreaea rupestris $\quad 126$

$\begin{array}{ll}\text { Key to species of Polytrichaceae } & 126\end{array}$

Auxiliary key for sterile plants of Polytrichum, Polytrichastrum and Pogonatum

130

130

130

131

133

133

135

135

137

139

142

143

145

145

146

147

147 
Key to infraspecific taxa of Didymodon tophaceus 151

Key to species of Microbryum 151

Key to Pottia s.l., incl. Hennediella heimii, Tortula caucasica, T.

lindbergii, T. protobryoides, T. truncata, but without species

formerly in Phascum: Microbryum curvicollum, M. floerkeanum 153

Key to species of Pseudocrossidium 155

Key to species of Pterygoneurum 155

Key to species of Syntrichia 156

Key to species of Tortula s.l. (excl. T. acaulon, T. caucasica, T. lindbergii,

T. protobryoides, T. truncata, incl. Syntrichia, Tortula cernua,

$\begin{array}{ll}\text { Hilpertia velenovskyi) } & 160\end{array}$

Key to species of Tortula 166

Key to varieties of Streblotrichum convolutum 169

Key to species of Ephemerum 169

Key to species of Gymnostomum group $\quad 170$

$\begin{array}{ll}\text { Key to species of Hydrogonium } & 171\end{array}$

$\begin{array}{ll}\text { Key to species of Tortella } & 171\end{array}$

Key to species of Trichostomum 172

Key to species of Weissia 173

Key to species of Seligeriaceae $\quad 174$

Key to species of Grimmiaceae $\quad 175$

Key to species of Hedwigia 188

Key to species of Bartramiaceae $\quad 189$

$\begin{array}{ll}\text { Key to species of Bryaceae } & 190\end{array}$

Key to species of Pohlia 198

Key to species of Mnium, Plagiomnium and Rhizomnium 201

Key to species of Orthotrichaceae 203

Key to species of Aulacomnium 211

Key to species of Fontinalis $\quad 211$

Key to species of Plagiothecium $\quad 212$

Key to species of Orthothecium 214

Key to species of Fabronia $\quad 214$

Key to species of Palustriella 214

Key to species of Campyliadelphus 215

Key to species of Campylium 215

Key to species of Drepanocladus 215

Key to species of Amblystegium group (incl. Amblystegium,

Hygroamblystegium, Pseudoamblystegium, Pseudocampylium and

Serpoleskea) 216

Key to species of Calliergon s.l. incl. Straminergon 218

Key to species of Scorpidium 218

Key to species of Pseudoleskeella 219

Key to varieties of Abietinella abietina $\quad 219$

Key to species of Thuidium 219

Key to species of Eurhynchium 220

Key to species of Rhynchostegium 220

Key to species of Cirriphyllum 221

Key to species of Oxyrrhynchium 221 
Key to species of Rhynchostegiella 222

Key to species of Homalothecium 222

Key to species of Brachythecium s.l. (incl. Brachytheciastrum,

Brachythecium and Sciuro-hypnum) 223

Key to species of Hypnum s.l. incl. Buckia 227

Key to species of Taxiphyllum 228

Key to species of Calliergonella 228

Key to species of Rhytidiadelphus 228

Key to species of Neckera s.l. incl. Alleniella, Exsertotheca 228

Key to species of Thamnobryum 229

Key to species of Isothecium $\quad 229$

Key to species of Anomodon s.l. incl. Pseudanomodon, Claopodium 230

$\begin{array}{ll}\text { GLOSSARY } & 231\end{array}$

INDEX OF GENERA 253 


\section{CONSPECTUS OF CLASSIFICATION}

The taxonomic hierarchy presented below is based on the most recent European checklist (Hodgetts et al. 2020), and the most recent Hungarian checklist for the set of taxa considered (Erzberger and Papp 2020). Although it represents the most up-todate classification, it will probably be outdated very soon since current concepts are in a state of flux due to ongoing molecular work. Only orders, families and genera are listed in this conspectus.

\section{Anthocerotophyta (Hornworts)}

Order

Family

Order

Family
1. Anthocerotales

1. Anthocerotaceae

1. Anthoceros

2. Notothyladales

2. Notothyladaceae

2. Phaeoceros

Marchantiophyta (Liverworts)

$\begin{array}{lll}\text { Order } & 3 . & \text { Jungermanniales } \\ \text { Family } & 3 . & \text { Adelanthaceae } \\ \text { Family } & 3 . & \text { Syzygiella } \\ & 4 . & \text { Anastrophyllaceae } \\ & 4 . & \text { Anastrophyllum } \\ & 5 . & \text { Barbilophozia } \\ & 6 . & \text { Crossocalyx } \\ & 7 . & \text { Gymnocolea } \\ \text { Family } & 8 . & \text { Isopaches } \\ & 9 . & \text { Neoorthocaulis } \\ & 10 . & \text { Sphenolobus } \\ \text { Family } & 5 . & \text { Cephaloziaceae } \\ & 11 . & \text { Cephalozia } \\ & 12 . & \text { Fuscocephaloziopsis } \\ & 13 . & \text { Nowellia } \\ & 6 . & \text { Cephaloziellaceae } \\ & 14 . & \text { Cephaloziella } \\ & 15 . & \text { Obtusifolium }\end{array}$


Family

7. Lophoziaceae

16. Lophozia

17. Lophoziopsis

18. Trilophozia

19. Tritomaria

Family

8. Scapaniaceae

20. Diplophyllum

21. Scapania

Family

22. Schistochilopsis

9. Calypogeiaceae

Family

23. Calypogeia

10. Endogemmataceae

Family

24. Endogemma

11. Gymnomitriaceae

25. Marsupella

26. Nardia

Family

12. Jungermanniaceae

27. Liochlaena

28. Jungermannia

29. Mesoptychia

Family

13. Solenostomataceae

30. Solenostoma

Family

14. Blepharostomataceae

31. Blepharostoma

Family

15. Lepidoziaceae

32. Bazzania

33. Lepidozia

Family

16. Lophocoleaceae

34. Chiloscyphus

35. Lophocolea

Family

17. Plagiochilaceae

36. Pedinophyllum

37. Plagiochila

Family

18. Trichocoleaceae

Order

38. Trichocolea

Family

4. Porellales

19. Frullaniaceae

39. Frullania

Family

20. Lejeuneaceae

40. Cololejeunea 
Family

Family

Order

Family

Order

Family

Family

Order

Family

Order

Family

Order

Family

Order

Family

Order

Family

Family

Family

Family

Family
41. Lejeunea

21 Porellaceae

42. Porella

22. Radulaceae

43. Radula

5. Ptilidiales

23. Ptilidiaceae

44. Ptilidium

6. Metzgeriales

24. Aneuraceae

45. Aneura

46. Riccardia

25. Metzgeriaceae

47. Metzgeria

7. Fossombroniales

26. Fossombroniaceae

48. Fossombronia

$8 . \quad$ Pelliales

27. Pelliaceae

49. Apopellia

50. Pellia

9. Blasiales

28. Blasiaceae

51. Blasia

10. Lunulariales

29. Lunulariaceae

52. Lunularia

11. Marchantiales

30. Aytoniaceae

53. Asterella

54. Mannia

55. Reboulia

31. Cleveaceae

56. Clevea

32. Conocephalaceae

57. Conocephalum

33. Marchantiaceae

58. Marchantia

34. Oxymitraceae

59. Oxymitra 
Family

Order

Family

$\begin{array}{ll}\text { 35. } & \text { Ricciaceae } \\ \text { 60. } & \text { Riccia } \\ \text { 61. } & \text { Ricciocarpos } \\ \text { 12. } & \text { Sphaerocarpales } \\ \text { 36. } & \text { Sphaerocarpaceae } \\ \text { 62. } & \text { Sphaerocarpos }\end{array}$

Bryophyta (Mosses)
13. Sphagnales

37. Sphagnaceae

63. Sphagnum

14. Andreaeales

38. Andreaeaceae

64. Andreaea

15. Tetraphidales

39. Tetraphidaceae

65. Tetraphis

16. Polytrichales

40. Polytrichaceae

66. Atrichum

67. Pogonatum

68. Polytrichastrum

69. Polytrichum

17. Buxbaumiales

41. Buxbaumiaceae

70. Buxbaumia

18. Diphysciales

42. Diphysciaceae

71. Diphyscium

19. Timmiales

43. Timmiaceae

72. Timmia

20. Encalyptales

44. Encalyptaceae

73. Encalypta

21. Funariales

45. Funariaceae

74. Pyramidula

75. Entosthodon 
Order

Family

Family

Family

Family

Family

Family

Family

Family

Family

Family

Family

Family

Family
76. Funaria

77. Physcomitrium

22. Dicranales

46. Distichiaceae

78. Distichium

47. Flexitrichaceae

79. Flexitrichum

48. Archidiaceae

80. Archidium

49. Leucobryaceae

81. Campylopus

82. Dicranodontium

83. Leucobryum

50. Amphidiaceae

84. Amphidium

51. Aongstroemiaceae

85. Dichodontium

52. Dicranellaceae

86. Dicranella

53. Fissidentaceae

87. Fissidens

54. Dicranaceae

88. Dicranum

89. Paraleucobryum

55. Rhabdoweisiaceae

90. Cnestrum

91. Cynodontium

92. Dicranoweisia

93. Rhabdoweisia

56. Bruchiaceae

94. Bruchia

57. Ditrichaceae

95. Ceratodon

96. Ditrichum

97. Pleuridium

98. Pseudephemerum

99. Trichodon

58. Pottiaceae

100. Acaulon

101. Aloina 


\begin{tabular}{|c|c|c|}
\hline & 102. & Barbula \\
\hline & 103. & Bryoerythrophyllum \\
\hline & 104. & Chenia \\
\hline & 105. & Cinclidotus \\
\hline & 106. & Crossidium \\
\hline & 107. & Didymodon \\
\hline & 108. & Hennediella \\
\hline & 109. & Hilpertia \\
\hline & 110. & Microbryum \\
\hline & 111. & Pseudocrossidium \\
\hline & 112. & Pterygoneurum \\
\hline & 113. & Syntrichia \\
\hline & 114. & Tortula \\
\hline & 115. & Streblotrichum \\
\hline & 116. & Chionoloma \\
\hline & 117. & Ephemerum \\
\hline & 118. & Eucladium \\
\hline & 119. & Gymnostomum \\
\hline & 120. & Gyroweisia \\
\hline & 121. & Hydrogonium \\
\hline & 122. & Hymenostylium \\
\hline & 123. & Splachnobryum \\
\hline & 124. & Tortella \\
\hline & 125. & Trichostomum \\
\hline & 126. & Weissia \\
\hline Order & 23. & Grimmiales \\
\hline Family & 59. & Saelaniaceae \\
\hline & 127. & Saelania \\
\hline Family & 60. & Seligeriaceae \\
\hline & 128. & Blindia \\
\hline & 129. & Blindiadelphus \\
\hline & 130. & Seligeria \\
\hline Family & 61. & Ptychomitriaceae \\
\hline & 131. & Brachydontium \\
\hline & 132. & Campylostelium \\
\hline Family & 62. & Grimmiaceae \\
\hline & 133. & Racomitrium \\
\hline & 134. & Coscinodon \\
\hline & 135. & Grimmia \\
\hline & 136. & Schistidium \\
\hline
\end{tabular}


Order

Family

Order

Family

Family

Order

Family

Family

Order

Family

Order

Family

Order

Family

Order

Family
24. Hedwigiales

63. Hedwigiaceae

137. Hedwigia

25. Bartramiales

64. Bartramiaceae

138. Bartramia

139. Plagiopus

140. Philonotis

65. Meesiaceae

141. Amblyodon

142. Leptobryum

143. Meesia

26. Bryales

66. Bryaceae

144. Bryum

145. Imbribryum

146. Ptychostomum

147. Rhodobryum

67. Mniaceae

148. Pohlia

149. Mnium

150. Plagiomnium

151. Rhizomnium

27. Orthotrichales

68. Orthotrichaceae

152. Codonoblepharon

153. Lewinskya

154. Nyholmiella

155. Orthotrichum

156. Pulvigera

157. Ulota

158. Zygodon

28. Orthodontiales

69. Orthodontiaceae

159. Orthodontium

29. Aulacomniales

70. Aulacomniaceae

160. Aulacomnium

30. Hookeriales

71. Hookeriaceae 


\section{Order}

Family

Family

Family

Family

Family

Family

Family

Family
161. Hookeria

31. Hypnales

72. Fontinalaceae

162. Fontinalis

73. Plagiotheciaceae

163. Herzogiella

164. Isopterygiopsis

165. Plagiothecium

166. Myurella

167. Orthothecium

168. Platydictya

169. Pseudotaxiphyllum

74. Fabroniaceae

170. Fabronia

75. Pterigynandraceae

171. Pterigynandrum

76. Climaciaceae

172. Climacium

77. Amblystegiaceae

173. Cratoneuron

174. Palustriella

175. Amblystegium

176. Anacamptodon

177. Campyliadelphus

178. Campylium

179. Campylophyllopsis

180. Conardia

181. Drepanocladus

182. Hygroamblystegium

183. Hygrohypnum

184. Leptodictyum

185. Pseudoamblystegium

186. Pseudocampylium

187. Serpoleskea

188. Tomentypnum

78. Calliergonaceae

189. Calliergon

190. Sarmentypnum

191. Straminergon

79. Scorpidiaceae 
Family

Family

Family

Family

Family

Family

Family

Family

Family

Family
192. Hamatocaulis

193. Sanionia

194. Scorpidium

80. Leskeaceae

195. Claopodium

196. Leskea

81. Pseudoleskeaceae

197. Lescuraea

82. Pseudoleskeellaceae

198. Pseudoleskeella

83. Thuidiaceae

199. Abietinella

200. Helodium

201. Thuidium

84. Brachytheciaceae

202. Eurhynchium

203. Plasteurhynchium

204. Pseudoscleropodium

205. Rhynchostegium

206. Cirriphyllum

207. Microeurhynchium

208. Oxyrrhynchium

209. Rhynchostegiella

210. Brachytheciastrum

211. Brachythecium

212. Eurhynchiastrum

213. Homalothecium

214. Kindbergia

215. Sciuro-hypnum

85. Hypnaceae

216. Hypnum

86. Callicladiaceae

217. Callicladium

87. Taxiphyllaceae

218. Taxiphyllum

88. Pylaisiadelphaceae

219. Platygyrium

89. Pylaisiaceae

220. Buckia

221. Calliergonella 
Family

Family

Family

Family

Family

Family

Family

Family

Family

Family

Family
222. Homomallium

223. Ptilium

224. Pylaisia

90. Sematophyllaceae

225. Sematophyllum

91. Hylocomiaceae

226. Hylocomiadelphus

227. Hylocomium

228. Loeskeobryum

229. Pleurozium

230. Rhytidiadelphus

92. Rhytidiaceae

231. Rhytidium

93. Entodontaceae

232. Entodon

94. Leucodontaceae

233. Leucodon

234. Nogopterium

95. Antitrichiaceae

235. Antitrichia

96. Neckeraceae

236. Alleniella

237. Exsertotheca

238. Homalia

239. Leptodon

240. Neckera

241. Pseudanomodon

242. Thamnobryum

97. Heterocladiellaceae

243. Heterocladiella

98. Lembophyllaceae

244. Heterocladium

245. Isothecium

99. Myuriaceae

246. Ctenidium

100. Anomodontaceae

247. Anomodon 


\section{PRELIMINARY REMARKS - HOW TO USE THESE KEYS}

The keys presented below require the use of a compound microscope and ideally also of a stereomicroscope, preferably equipped with micrometer eyepieces to enable measurement of small distances. Some preparation skills are also useful.

Following the directions in the keys, beginning with the key to the main groups of bryophytes (1.), the user will eventually arrive at the name of a genus or a group of genera, which can then be looked up in the second part, keys to species of liverworts and hornworts (5.), and keys to species of mosses (6.), to obtain the name of the species in question. If there is only one species to a genus, the species name is given already in part one.

After arriving at a species name, it is essential that the result should be carefully compared with illustrations and descriptions of the species including remarks about its ecological demands. Unfortunately, in this respect the user must consult some of the treatments listed below, since an up-to-date bryophyte flora of Hungary is still missing. Since numerous bryophyte taxa that were not hitherto known to occur in Hungary have been detected during the last years, it is always possible that the user might try to identify a plant that is not treated in the present keys. It is only by consulting detailed descriptions and illustrations that such a situation can be noticed. Also, the keys cannot take account of every possibility given that certain taxa show a wide range of variability. If the user cannot decide between the alternatives in a given couplet of the key, both paths should be followed. Often taxa that may display both character states of a given couplet have been keyed out under both alternatives.

\section{ABBREVIATIONS}

agg. aggregate, a group of related species (or microspecies) which are difficult to distinguish from one another

pp. pro parte, meaning part of a taxon, e.g. only some species of a genus, not all

s.l. sensu lato, meaning in the wider sense, when a name may denote different circumscriptions of a taxon, e.g. Ulota crispa s.l. (U. crispa s.str., U. crispula, U. intermedia)

s.str. sensu stricto, meaning in the narrow sense 


\section{FREQUENCY CLASSES}

$\begin{array}{ll}\text { cc } & \text { very common } \\ \text { c } & \text { common } \\ \text { w } & \text { widespread } \\ \text { r } & \text { rare } \\ \text { rr } & \text { very rare }\end{array}$

n.s. not seen, i.e. without records after 1973

\section{RECOMMENDED LITERATURE}

(References for particular groups can be found in the second part: Keys to species. Without aiming at completeness, these have often been selected because of some reference to Hungary. They usually will guide the user to other important references.)

\section{Hornworts and liverworts}

\section{Illustrations and descriptions}

Paton, J.A. (1999). The Liverwort Flora of the British Isles. Harley Books, Great Horkesley, 626 pp. - Line drawings of many details, often showing variability of characters.

Does not treat the following liverworts: Anastrophyllum michauxii, Asterella saccata, Cephalozia lacinulata, Cephaloziella divaricata var. scabra, C. varians, Clevea hyalina, Conocephalum salebrosum, Frullania cleistostoma, F. jackii, Liochlaena subulata, Lophocolea minor, Lophozia ascendens, Mannia fragrans, M. triandra, Oxymitra incrassata, Porella baueri, Riccia ciliata, $R$. ciliifera, $R$. frostii, $R$. gougetiana, $R$. papillosa, $R$. warnstorfii, Scapania apiculata, S. mucronata. The treatment of Conocephalum conicum is out-dated. The plants described and illustrated under Riccia bifurca belong to R. subbifurca agg. (Meinunger and Schröder 2007).

DAmsholT, K. (2002). Illustrated Flora of Nordic Liverworts and Hornworts. Nordic Bryological Society, Lund. 837 pp. - Very precise drawings, taxonomically up to date.

Does not treat the following liverworts: Calypogeia suecica, Cephaloziella divaricata var. scabra, Cololejeunea rossettiana, Conocephalum salebrosum, Frullania cleistostoma, Mannia triandra, Oxymitra incrassata, Pedinophyllum interruptum, Riccia crozalsii, $R$. 
frostii, R. gougetiana, R. papillosa, Scapania parvifolia, Sphaerocarpos europaeus.

Casas, C., Brugués, M., Cros, R.M., SÉrgio, C. \& Infante, M. (2009). Handbook of Liverworts and Hornworts of the Iberian Peninsula and the Balearic Islands. Institut d'Estudis Catalans, Barcelona, 177 pp. - Keys, short descriptions, illustrations of some essential features.

Does not treat the following liverworts: Anastrophyllum michauxii, Asterella saccata, Cephalozia lacinulata, Cephaloziella divaricata var. scabra, C. varians, Endogemma caespiticia, Frullania cleistostoma, F. jackii, Fuscocephaloziopsis macrostachya, Liochlaena subulata, Mannia triandra, Riccia rhenana, Scapania lingulata, S. parvifolia.

SMITH, A.J.E. (1991). The Liverworts of Britain \& Ireland. Cambridge University Press, Cambridge, 362 pp. - Second choice after the publication of Paton (1999) as concerns the illustrations as well as the descriptions. Missing taxa are the same as in Paton (1999).

FREY, W., FRAHM, J.-P., FISCHER, E. \& LOBIN, W. (2006). The Liverworts, Mosses and Ferns of Europe. English edition revised and edited by T.L. Blockeel. Harley Books, Colchester, 512 pp. - Treats all species occurring in Hungary, but mostly very briefly, and not all are illustrated. Illustrations for most taxa missing in other accounts can usually be found.

SCHUMACKER, R. \& VÁŇA, J. (2005). Identification keys to the liverworts and hornworts of Europe and Macaronesia (distribution \& status). Second edition fully revised and updated. Sorus, Poznań, 209 pp. - only keys, no descriptions, no illustrations, but covering all of Europe.

\section{Mosses}

\section{Illustrations}

LÜTH, M. (2019). Mosses of Europe. A Photographic Flora. Vol. 1-3. Michael Lüth, Freiburg, 1360 pp. - Nearly all mosses occurring in Hungary are shown in very attractive photographs, including many microscopic details! Available for purchase on www.mosses-of-europe.com. Many of Michael Lüth's brilliant moss photographs can also be found / downloaded on his website: www.milueth.de, www.bildatlas-moose.de 
LANDWEHR, J. (1984). Nieuwe Atlas Nederlandse bladmossen. Thieme, Zutphen, 568 pp. - Excellent drawings of the species occurring in Netherlands; most of the drawings (including also those of the corresponding atlas on liverworts) have been included in the following:

Siebel, H.N. \& DURING, H.J. (2006). Beknopte Mosflora van Nederland en België. KNNV Uitgeverij, Utrecht, 559 pp. - with keys and descriptions in Dutch.

\section{Illustrations and descriptions}

Atherton, I., BoSAnquet, S.D.S. \& LAWLey, M. (eds.) (2010). Mosses and Liverworts of Britain and Ireland. A Field Guide. British Bryological Society, Plymouth, 848 pp. - Many of the species occurring in Hungary can be found in this useful book, with many helpful photographs, but without reference to microscopic details, only field characters (visible with a hand-lens) are treated.

CASAS, C., BruguÉs, M., Cros, R.M. \& SÉRgio, C. (2006). Handbook of Mosses of the Iberian Peninsula and the Balearic Islands. Institut d'Estudis Catalans, Barcelona, 349 pp. - Mainly keys, short descriptions and line drawings of important characters. For the list of taxa missing in the Iberian Peninsula, see the next reference.

Guerra, J. \& CROS, R.M. (coord.) (2006-2016). Flora Briofítica Ibérica. 6 Volumes. Universidad de Murcia, Sociedad Española de Briología, Murcia. (In Spanish). - Very detailed line drawings and extensive descriptions.

Does not treat the following mosses: Anacamptodon splachnoides, Anomodon rugelii, Blindiadelphus campylopodus, Brachythecium capillaceum, Brachythecium geheebii, Bruchia flexuosa, Bryum barnesii, Bryum stirtonii, Bryum violaceum, Bryum warneum, Callicladium haldanianum, Cinclidotus danubicus, Cnestrum schisti, Crossidium laxefilamentosum, Cynodontium tenellum, Dicranella crispa, Dicranella humilis, Dicranum fulvum, Didymodon glaucus, Ditrichum pallidum, Drepanocladus lycopodioides, Drepanocladus sendtneri, Drepanocladus sordidus, Fissidens arnoldii, Grimmia plagiopodia, Grimmia teretinervis, Helodium blandowii, Hilpertia velenovskyi, Hydrogonium consanguineum, Hypnum pallescens var. reptile, Lescuraea saviana, Microbryum muticum, Neckera pennata, Nyholmiella gymnostoma, Orthodontium lineare, Orthotrichum urnigerum, Physcomitrium 
eurystomum, Physcomitrium sphaericum, Plagiothecium latebricola, Pohlia lutescens, Pohlia nutans subsp. schimperi, Polytrichum perigoniale, Pseudocampylium radicale, Racomitrium microcarpon, Rhynchostegium rotundifolium, Schistidium confusum, Schistidium lancifolium, Sematophyllum adnatum, Sphagnum inundatum, Sphagnum obtusum, Sphagnum riparium, Splachnobryum obtusum, Taxiphyllum densifolium, Thamnobryum neckeroides, Tortula cernua, Tortula muralis subsp. obtusifolia, Weissia rostellata.

Reference to the six volumes of Flora Briofítica Ibérica and their content

Brugués, M., Cros, R.M. \& Guerra, J. (eds.) (2007). Flora Briofítica Ibérica. Vol. I, Sphagnales, Andreaeales, Polytrichales, Tetraphidales, Buxbaumiales, Diphysciales. Universidad de Murcia, Sociedad Española de Briología, Murcia, 183 pp.

BRuguÉs, M.\& GuerRA, J. (eds.) (2015). Flora Briofítica Ibérica. Vol. II, Archidiales, Dicranales, Fissidentales, Seligeriales, Grimmiales. Universidad de Murcia, Sociedad Española de Briología, Murcia, $355 \mathrm{pp}$.

Guerra, J., Cano, M.J. \& Ros, R.M. (eds.) (2006). Flora Briofítica Ibérica. Vol. III, Pottiales, Encalyptales. Universidad de Murcia, Sociedad Española de Briología, Murcia, 305 pp.

Guerra, J., BruguÉs, M., CANO, M.J. \& Cros, R.M. (eds.) (2010). Flora Briofítica Ibérica. Vol. IV, Funariales, Splachnales, Bryales, Timmiales. Universidad de Murcia, Sociedad Española de Briología, Murcia, 317 pp.

Guerra, J., CANo, M.J. \& BruguÉs, M. (eds.) (2014). Flora Briofítica Ibérica. Vol. V, Orthotrichales, Hedwigiales, Leucodontales, Hookeriales. Universidad de Murcia, Sociedad Española de Briología, Murcia, 261 pp.

Guerra, J., CAno, M.J. \& Brugués, M. (eds.) (2016). Flora Briofítica Ibérica. Vol. VI, Hypnales. Universidad de Murcia, Sociedad Española de Briología, Murcia, 463 pp.

Keys and detailed descriptions (in German), some photographs

Nebel, M. \& PhilipPI, G. (eds.) (2000). Die Moose BadenWürttembergs, I. (Andreaeales bis Funariales). Ulmer, Stuttgart, $512 \mathrm{pp}$. 
Nebel, M. \& PhilippI, G. (eds.) (2001). Die Moose BadenWürttembergs, II. (Schistostegales bis Hypnobryales) Ulmer, Stuttgart, $529 \mathrm{pp}$.

Nebel, M. \& PhilipPI, G. (eds.) (2005). Die Moose BadenWürttembergs, III. (Sphagnopsida, Marchantiopsida, Anthocerotophyta) Ulmer, Stuttgart, 487 pp.

Short descriptions (in English) and original drawings mainly by the author, often showing very useful details

Nyнolm, E. (1960). Illustrated Moss Flora of Fennoscandia II. Musci.

Fasc. 4. Swedish Natural Science Research Council, Lund, pp. 284-408.

NyHoLM, E. (1979). Illustrated Moss Flora of Fennoscandia II. Musci. Fasc. 5, ed. 2. Swedish Natural Science Research Council, Stockholm, pp. 407-647.

Nyнolm, E. (1981). Illustrated Moss Flora of Fennoscandia II. Musci.

Fasc. 6, ed. 2. Swedish Natural Science Research Council, Stockholm, pp. 647-799.

Nyнolm, E. (1987). Illustrated Flora of Nordic Mosses. Fasc. 1. Fissidentaceae - Seligeriaceae. Nordic Bryological Society, Copenhagen and Lund, pp. 1-72.

Nyнolm, E. (1990). Illustrated Flora of Nordic Mosses. Fasc. 2. Pottiaceae - Splachnaceae - Schistostegaceae. Nordic Bryological Society, Copenhagen and Lund. pp. 75-141.

Nyнolm, E. (1993). Illustrated Flora of Nordic Mosses. Fasc. 3. Bryaceae - Rhodobryaceae - Mniaceae - Cinclidiaceae Plagomniaceae. Nordic Bryological Society, Copenhagen and Lund, pp. 145-244.

Nyнolm, E. (1998). Illustrated Flora of Nordic Mosses, Fasc. 4 (Aulacomniaceae - Meesiaceae - Catascopiaceae - Bartramiaceae - Timmiaceae - Encalyptaceae - Grimmiaceae - Ptychomitraceae - Hedwigiaceae - Orthotrichaceae). Nordic Bryological Society, Copenhagen and Lund, pp. 249-404. 


\section{PART I: GENERAL KEYS}

\section{KEY TO THE MAIN GROUPS OF BRYOPHYTES}

1 Plants thallose, i.e. a more or less flat gametophyte, not differentiated into stem and leaves............................................... 2

- $\quad$ Plants not thallose, differentiated into stems and leaves........3

2 Thallus cells usually with a single, large chloroplast; capsule cylindrical, dehiscing by 2 valves. Hornworts

- Thallus cells with numerous chloroplasts; capsule globose, ovoid, ellipsoid or cylindrical, dehiscing by 4 valves or irregular. Thalloid liverworts

\section{Leafy liverworts Mosses}

\section{Differences between liverworts and mosses}

\section{liverworts}

gametophyte a thallus

leaves deeply lobed or segmented

leaves never with costa ( but beware of vitta in Diplophyllum albicans)

leaves without costa, cells isodiametric, never prosenchymatic

leaves arranged in 3 ranks, 2 ranks of lateral leaves and 1 rank of (smaller) underleaves, which may be lacking rhizoids consisting of a single cell each

seta weak, hyaline, elongating rapidly and dying after a few days

spore capsule containing spores and elaters, but without peristomium

capsule globose or ovoid, without lid, splitting into 4 valves

capsule blackish, without chloloplasts and wall without stomata mosses

gametophyte never a thallus leaves never deeply lobed or segmented leaves with or without costa

leaves without costa, cells prosenchymatic, never isodiametric leaves not in 3 or 2 ranks (but beware of Fissidens, Distichium: leaves in 2 ranks, but leaves costate) rhizoids made up of more than one cell, with oblique cross-walls

seta stout, brown, red, yellow, elongating slowly and long persisting, usually visible for a year spore capsule containing spores only, with peristomium in the majority of cases

capsule pear-shaped to cylindrical, typically with lid and peristome capsule green with chloroplasts when young, usually brown when ripe, wall often with stomata 


\section{KEYS TO GENERA OF THALLOID BRYOPHYTES}

\section{Hornworts}

- $\quad$ Thallus variously lobed, lobes with crispate margins; spores dark brown or blackish; mature antheridia 50-90 $\mu \mathrm{m}$ long Anthoceros agrestis (r)

- Thallus lobed, but margins only rarely crispate; spores yellowish, rarely yellowish brown; proximal face of spores with weak, centrally placed papillae

Phaeoceros carolinianus $(\mathrm{r})$

\section{Thalloid liverworts}

1 Thallus circular, completely covered by clavate involucres on dorsal side

Sphaerocarpos europaeus (Sphaerocarpos texanus) (n.s.)

- Thallus not as above, not covered completely by clavate involucres.

2 Dorsal epidermis reticulate, with pores or irregular openings, and usually with air chambers visible in cross section; rhizoids dimorphic, smooth or warty, respectively; thallus with chlorenchyma and parenchyma differentiated.

Group 1

- Dorsal epidermis not reticulate, without pores or air chambers; rhizoids smooth; thallus not differentiated into chlorenchyma and parenchyma

Group 2

Group 1 Thallus with internal differentiation; dorsal epidermis with pores; rhizoids smooth or warty

1 Dorsal side of thallus with gemma receptacles ………............. 2

- $\quad$ Dorsal side of thallus without gemma receptacles..................... 3

2 Gemma receptacles semilunar.............Lunularia cruciata (r)

- Gemma receptacles cup-shaped.........Marchantia pp. (p.112)

3 Plants in incomplete or complete rosettes; chlorenchyma with air canals or with air chambers with irregular openings or small pores; capsule totally or partially immersed in thallus. Riccia group (p.115) 
- $\quad$ Plants not in rosettes; chlorenchyma with air chambers with simple or barrel-shaped pores; capsule not immersed in thallus.

4 Pores barrel-shaped (cross section), conspicuous

Marchantia (p.112)

- $\quad$ Pores simple, conspicuous or not

5 Epidermis conspicuously reticulate, with elongate areolae 1 mm or longer

Conocephalum (p.112)

- $\quad$ Epidermis conspicuously reticulate, with areolae less than 1 mm long, or reticule lacking.

6 Thallus surface indistinctly reticulate, when dry parchmentlike, smooth except for the slightly elevated, simple pores; ventral scales metallic purple, with 2 filiform appendages; pores prominent, surrounded by $4-5$ concentric rings of cells. Reboulia hemisphaerica $(\mathrm{w})$

- Thallus distinctly reticulate; ventral scales coloured or hyaline, with 1-2 lanceolate appendages; pores prominent or not, surrounded by 1-5 concentric rings of cells.

7 Ventral scales lacking marginal slime hairs, triangular, hyaline, with a lanceolate appendage; air chambers high, obliquely in 2-3 layers.

Clevea hyalina (Athalamia hyalina) $(\mathrm{r})$

- Ventral scales with marginal 1-celled slime hairs; air chambers low, vertically in 1-3 layers.

8 Archegonia and sporophytes not surrounded by laciniate pseudoperianth; crushed thallus with or without smell of cedar oil; dorsal thallus epidermis with or without trigones...

Mannia (p.112)

- Archegonia and sporophytes surrounded by laciniate pseudoperianth; crushed thallus with a faint smell of rotten freshwater fish; dorsal thallus epidermis without trigones...... Asterella saccata $(\mathrm{w})$

\section{Group 2 Thallus without internal differentiation, dorsal epidermis without pores, rhizoids smooth}

1 Thallus with obliquely inserted crisped or undulate leaf-like lobes.

- $\quad$ Thallus without leaf-like lobes. 
2 Gemmae dimorphic, (i) stellate, about $400 \mu \mathrm{m}$, (ii) globose or ellipsoidal, about $100 \mu \mathrm{m}$, produced in flask-like receptacles on the dorsal surface of the thallus.

Blasia pusilla (r)

- Gemmae lacking. Fossombronia (p.111)

3 Thallus furcate, to $2 \mathrm{~mm}$ wide, with unicellular hairs at margins, on ventral or on both sides, sometimes glabrous; midrib narrow, clearly distinct on the dorsal side; gametangia and sporophytes on small branches on ventral side of midrib. Metzgeria (p.110)

- Thallus simple, furcate, pinnate, palmate or irregularly branched, more than $3 \mathrm{~mm}$ wide, glabrous; midrib indistinct or poorly distinct on the dorsal side; gametangia and sporophytes on dorsal side of thallus or on lateral branches....

4 Thallus furcate; gametangia on dorsal side of thallus. 4

- Thallus simple, pinnate, palmate or irregularly branched; gametangia on small lateral branches.

5 Slime papillae restricted to ventral side of costa near apex, on stalk 1-5 (6) cells long; thalli with miniature apical branches proliferating in autumn; dioicous; involucres subhorizontal to erect, tubular, with dentate-ciliate lobes; male tubercles $c a 200 \mu \mathrm{m}$ wide, cells surrounding aperture not papilliform; calcicole.

Apopellia endiviifolia (Pellia endiviifolia) (w)

- $\quad$ Slime papillae on stalk 1 cell long, on both ventral and dorsal sides of costa near apex; caducous branches absent; dioicous or monoicous; calcifuge.

Pellia (p.111)

6 Thallus simple or irregularly branched, $3 \mathrm{~mm}$ wide or more; more than 6 oil bodies in each epidermal cell.

Aneura pinguis $(\mathrm{w})$

- $\quad$ Thallus 1-4-pinnately branched or palmate, lobes $<2 \mathrm{~mm}$ wide; 0-2 oil bodies in each epidermal cell Riccardia (p.109)

\section{KEYS TO GENERA OF FOLIOSE LIVERWORTS}

1 Leaves laciniate, divided almost to base into filiform segments, or leaves with longly ciliate or laciniate margins....

- Leaves simple or lobed, without laciniate or ciliate margins... 
2 Leaves laciniate, divided almost to base into 3-4 uniseriate segments. Blepharostoma trichophyllum (r)

- $\quad$ Leaves divided into 2-5 lobes that are not uniseriate, with longly ciliate or laciniate margins.

3 Leaf lamina very reduced .............Trichocolea tomentella (rr)

- Leaf lamina well developed......Ptilidium pulcherrimum (w)

4(1) Leaves simple (but sometimes apex 3-dentate) ........................5

- Leaves lobed

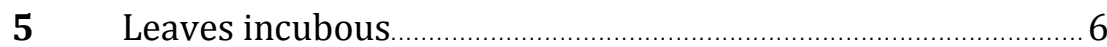

- Leaves succubous ............................................................... 3

6 Leaf apex rounded to bilobed; underleaves bilobed, retuse, emarginate or rounded ...................................Calypogeia (p.98)

- Leaf apex truncate, usually with 1-3 teeth; underleaves orbicular quadrate, irregularly 4-5-lobed.

Bazzania trilobata (r)

7(4) Leaves 3-5-lobed ...................................................... 4

- Leaves bilobed .

8 Leaves conduplicate, ventral lobe sometimes sac-shaped or

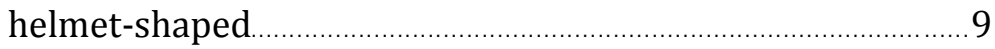

- $\quad$ Leaves not conduplicate ........................................................... 10

9 Underleaves lacking ......................................................... 5

- Underleaves present ................................................. Group 6

10 Leaves transversely or subtransversely inserted....... Group 7

- Leaves obliquely or longitudinally inserted, succubous.

Group 8

\section{Group 3 Leaves simple, succubous}

1 Underleaves present, conspicuous, bilobed ............................

- $\quad$ Underleaves lacking, minute or small, rarely bilobed ............... 3

2 All leaves simple, with rounded or retuse apex.

Chiloscyphus (p.104)

- At least some lower leaves bilobed ............. Lophocolea (p.104)

3 Leaf margin toothed, at least at apex........PIagiochila (p.106)

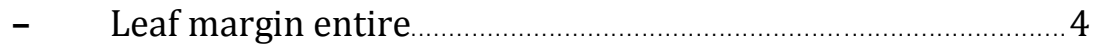

$4 \quad$ Underleaves present, at least on young plants ……………...... 5

- Underleaves lacking or caducous................................................. 6

5 Lower leaves spreading, apical leaves imbricate, pressed face to face; perianth mouth laciniate. 
- $\quad$ Leaves not as above; perianth mouth at most crenulate

6 Leaves strongly obliquely to longitudinally inserted... Nardia (p.100)

- $\quad$ Leaves transversely to obliquely inserted. 7

$7 \quad$ Plants prostrate; rhizoids only at stem apex; leaves plane Pedinophyllum interruptum $(\mathrm{w})$

- $\quad$ Plants procumbent or ascending; rhizoids lacking or scarce on underground stems; leaves convex.....Plagiochila (p.106)

8 Lower leaves spreading, apical leaves imbricate, pressed face to face; perianth mouth laciniate.

Syzygiella autumnalis (Jamesoniella autumnalis) (r)

- Leaves not as above; perianth mouth at most crenulate

Jungermanniaceae group (incl. Endogemma, Jungermannia, Liochlaena, Solenostoma) (p.101)

\section{Group 4 Leaves 3-5-lobed}

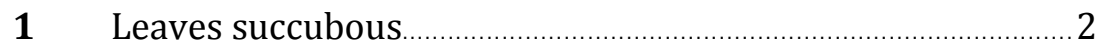

- Leaves incubous or nearly transverse ......................................... 3

2 Lower leaves bilobed, upper leaves sometimes irregularly 35-lobed. Lophoziaceae group (p.89)

- $\quad$ All leaves 3-4-lobed

3 Underleaves lacking.

Barbilophozia group (incl. Neoorthocaulis floerkei) (p.85)

Tritomaria s.l. (incl. Trilophozia quinquedentata) (p.89)

- Underleaves present, similar to leaves, although smaller; leaves incubous. Lepidozia reptans $(\mathrm{w})$

\section{Group 5 Leaves conduplicate, underleaves lacking}

1 Dorsal lobe larger than ventral lobe

- Dorsal lobe similar in size to ventral lobe or smaller...............3 3

2 Plants medium-sized, shoots ca $2 \mathrm{~mm}$ wide; rhizoids originate from the lobule..................................... Radula (p.109)

- Plants minute, shoots $<0.5 \mathrm{~mm}$ wide; rhizoids originate from the stem............................................... Cololejeunea (p.108)

3 Ventral lobe narrowly lingulate, twice as long as wide; gemmae when present angulate. Diplophyllum (p.94) 
- Ventral lobe orbicular to widely lingulate, less than twice as long as wide; gemmae when present ovoid to ellipsoidal.

Scapania (p.95)

\section{Group 6 Leaves conduplicate, underleaves present}

1 Ventral lobe with spinosely toothed margin

- Ventral lobe with entire margin

Porella arboris-vitae (r)

2 Lobule parallel or nearly parallel to stem, almost free from stem; keel very short; shoots mostly large, 2.5-5 mm; cells with few or numerous oil bodies.

- $\quad$ Lobule parallel to ventral leaf margin; keel long; shoots 0.9$1.3 \mathrm{~mm}$ wide; cells with numerous small oil bodies.

\section{Lejeunea cavifolia $(\mathrm{w})$}

3 Ventral lobe mostly sac-shaped or helmet-shaped (but evolute in Frullania cleistostoma); ocelli (cells with one large oil body) present in dorsal lobe or not, cells with few oil bodies..

- Ventral lobe plane or convex; ocelli absent, cells with numerous (15-40) oil bodies.

Porella (p.108)

\section{Group 7 Leaves bilobed, transversely or subtransversely inserted}

$1 \quad$ Underleaves present

- $\quad$ Underleaves absent or very small............................................. 3

2 Plants filiform or very small, leaves to $0.3 \mathrm{~mm}$ long. Cephaloziella (p.87)

- $\quad$ Plants not filiform, small to large, leaves to $1.5 \mathrm{~mm}$ long. Barbilophozia group (incl. Neoorthocaulis floerkei) (p.85)

3 Leaves appressed; branches julaceous or dorsiventrally compressed, often clavate. Marsupella (p.100)

- Leaves not appressed; branches not as above. 4

4 Leaves asymmetrical, with ventral margin widely incurved and saccate. Nowellia curvifolia $(\mathrm{w})$

- $\quad$ Leaves not or only slightly asymmetrical; ventral margin not saccate. 5 
$5 \quad$ Plants filiform, very small; usually ventrally branched

Cephaloziella (p.87)

- Plants not filiform, small to medium-sized; laterally branched.

6 Leaves channelled or strongly concave …………………..... 7

- $\quad$ Leaves not channelled, \pm concave ………….............................. 10

7 Usually with reddish gemmae at margins of upper leaves.....8

- Gemmae lacking......................................... Marsupella (p.100)

8 Minute species, plants only 2-10 (12) mm long and $0.2 \mathrm{~mm}$ wide; lateral leaves slighty concave, \pm transversely inserted, 2-lobed to 1/3-1/2, sometimes 3-lobed, lobes lanceolate, acute; cell walls uniformly thickened or trigones occasionally present; underleaves absent or sparse, minute, subulate; perianths rare; on rotting wood and bark; stolons absent.

Crossocalyx hellerianus (Anastrophyllum hellerianum) (rr)

- Larger species; if shoots only 2-6 mm long, then plants wider than $0.2 \mathrm{~mm}$ or lateral leaves lobed to $2 / 3-3 / 4$; (compare Lophozia ascendens on rotting wood)...

9 Lateral leaves conduplicate-concave (boat-shaped), nearly transversely inserted, $0.3-0.7 \mathrm{~mm}$ long; shoots $0.7-1.5 \mathrm{~mm}$ wide, leaves with regular pectinate arrangement; walls of leaf cells almost equally thickened, trigones very small or absent; mid-leaf cells (12) 14-18 (20) $\mu \mathrm{m}$ wide, arranged in \pm concentric circles near lobe apex; gemmae angulate, 2celled.

Sphenolobus minutus (Anastrophyllum minutum) (rr)

- Lateral leaves as long as wide, transversely inserted on antical side of stem, obliquely on postical side, (0.5) 0.7-1.8 $\mathrm{mm}$ long, 2-lobed to $1 / 3$, lobes acute, equal, slightly squarrose; plants $2.5 \mathrm{~cm}$ long and 1-2 mm wide; walls of leaf cells thick, trigones small to large, not bulging; shoots brownish green; gemmae ovoid to angulate.

Anastrophyllum michauxii (n.s.)

10(6) Usually with gemmae at apex and margins of upper leaves; cortex not translucent, not revealing the medulla; living plants with oil bodies.

Lophoziaceae group (p.89)

- Usually without gemmae; cortex translucent, revealing the medulla; living plants without oil bodies.

Cephaloziaceae pp. (p.86) 


\section{Group 8 Leaves bilobed, longitudinally or obliquely inserted, succubous}

1 Underleaves conspicuous...................................................... 2

- Underleaves lacking or underleaves small, subulate or lanceolate

2 Rhizoids restricted to base of underleaves; underleaves bilobed 1/2-3/4, with teeth on each side. Lophocolea (p.104)

- Rhizoids scattered along the ventral surface of stem; underleaves simple, lanceolate, usually with lateral teeth

Mesoptychia heterocolpos (Leiocolea heterocolpos) (n.s.)

3 Plants very small, filiform.

Cephaloziella (p.87)

- $\quad$ Plants small to medium-sized. 4

4 Cortex translucent, revealing the medulla; living plants without oil bodies.

Cephaloziaceae pp. (p.86)

- Cortex not translucent, not revealing the medulla; living plants with oil bodies.

5 Plants with gemmae.

Lophoziaceae group (p.89)

- Plants without gemmae.

6 Underleaves small.

- $\quad$ Underleaves lacking or rudimentary ………………………….... 8

7 Cuticle smooth Nardia (p.100)

- Cuticle papillose Mesoptychia (p.103)

8 Plants acidophilous, perianths usually caducous; underleaves absent

Gymnocolea inflata $(\mathrm{r})$

- Plants calcicolous, perianths not caducous; underleaves present (except in M. badensis)

Mesoptychia (p.103)

\section{KEYS TO GENERA OF MOSSES}

1 Leaf lamina consisting of a network of narrow green cells enclosing large, inflated, hyaline cells; plants with branches in fascicles.

Sphagnum (p.122)

- Plants lacking above combination of characters.

2 Plants dark brownish, reddish or blackish; saxicolous; fragile when dry; capsule opening with 4 longitudinal slits giving rise to 4 valves united at the top; lamina cells thickwalled, reddish to brownish..Andreaea rupestris (r) (p.126) 
- Plants lacking above combination of characters $\ldots \ldots \ldots \ldots \ldots \ldots \ldots \ldots . . . .3$

3 Basal lamina cells elongate, thick-walled, sinuose, nodulose... Racomitrium (p.175)

- Basal lamina cells different................................................... 4

$4 \quad$ Capsule with peristome of 4 triangular teeth, erect when dry and moist. Tetraphis pellucida (w)

- Capsule with peristome of more than 4 teeth, or plants without capsules.

5 Stem leaves arranged in 2 rows, distichous, \pm complanate.......

Group 9

- $\quad$ Stem leaves arranged in 3 or more rows, not complanate.....6

6 Ventral (adaxial) surface of costa or lamina with filaments or lamellae.

Group 10

- Ventral surface of costa or lamina without filaments or lamellae.

7 At least upper leaves with a hyaline tip or costa excurrent in hair point

Group 11

- $\quad$ Leaves without hyaline tip or hair point 8

8 Leaves bordered with several rows of elongate, narrow cells or leaf margin pluristratose.

Group 12

- $\quad$ Leaves unbordered, leaf margin 1-2-stratose ……………….....9

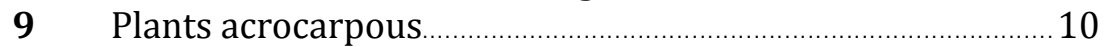

- Plants pleurocarpous ......................................................................... 32

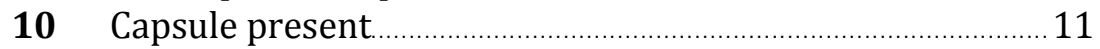

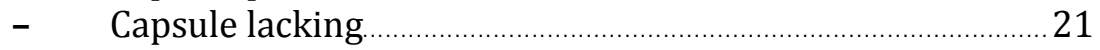

11 Capsule indehiscent ………………….................... Group 13

- Capsule dehiscent ................................................................. 12

12 Capsule immersed or emergent …………............. Group 14

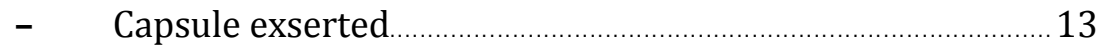

13 Plants minute, capsule larger than plant, ovoid to ellipsoid, asymmetric, on warty stalk ......................... Buxbaumia (p.130)

- $\quad$ Plants lacking this combination of characters.........................14

14 Capsule globose or sub-globose................................. Group 15

- Capsule ovoid, oblong, cylindrical, ellipsoid or pyriform......15

15 Capsule strumose......................................................... Group 16

- Capsule not strumose.............................................................16

16 Peristome absent or rudimentary …………............ Group 17

- $\quad$ Peristome well developed .................................................... 17

17 Capsule striate or sulcate when dry........................... Group 18

- $\quad$ Capsule smooth or only very slightly striate when dry.........18 
18 Capsule erect or nearly so; seta straight, rarely curved .......19

- Capsule inclined or pendulous; seta straight or curved .......20

19 Peristome teeth 16, entire or divided at the tip only, or slightly and irregularly divided.

Group 19

- $\quad$ Peristome teeth 16, divided longitudinally to halfway or more (32 teeth).

Group 20

20 Peristome single........................................................ Group 21

- Peristome double........................................................ Group 22

21(10) Propagules present on stem or leaves or in receptacles

Group 23

- $\quad$ Propagules absent on stem or leaves or in receptacles........22

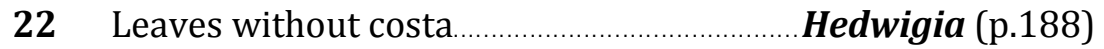

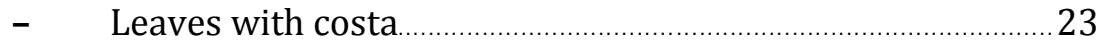

23 Costa wide, 1/3 or more of leaf base........................... Group 24

- $\quad$ Costa narrow, less than $1 / 3$ of leaf base.....................................24

24 Lamina cells $18 \mu \mathrm{m}$ wide or more .............................. Group 25

- Lamina cells less than $18 \mu$ m wide......................................... 25

25 Alar cells differentiated from basal cells..................... Group 26

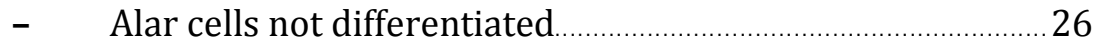

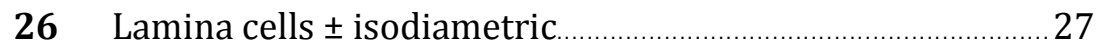

- Lamina cells longer than wide $\quad$ L................................................... 31

27 Leaf margin denticulate or dentate, at least near apex or base.

Group 27

- $\quad$ Leaf margin entire, crenulate or papillose-crenulate............28

28 Costa excurrent ..................................................... Group 28

- Costa not excurrent ................................................................. 29

29 Leaf apex rounded or obtuse, apiculate or not.........Group 29

- Leaf apex acute or acuminate................................................. 30

30 Leaf margin recurved at least on one side.................. Group 30

- $\quad$ Leaf margin plane or recurved only at base............... Group 31

31(26) Leaf apex acuminate or subulate, formed in part or entirely by costa.

Group 32

- Leaf apex obtuse to acuminate, costa percurrent to excurrent, short or lacking.

Group 33

32(9) Costa single, extending more than $1 / 2$ way up leaf ...............33

- Costa single, extending less than $1 / 2$ way up leaf, or if double, short or long, or lacking.

33 Lamina cells short, to twice as long as wide, or median cells elongate and marginal cells short.

Group 34

- $\quad$ Lamina cells elongate, more than twice as long as wide........34 
$34 \quad$ Leaves longitudinally plicate, at least at base........... Group 35

- Leaves plane or only slightly longitudinally plicate...............35

35 Leaves squarrose, falcate or circinate ........................ Group 36

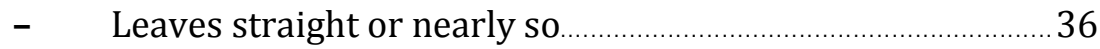

36 Leaf apex rounded, obtuse or apiculate..................... Group 37

- $\quad$ Leaf apex acute or acuminate .................................... Group 38

37(32) Lamina cells short, to twice as long as wide, or median cells elongate and marginal cells short.

Group 39

- $\quad$ Lamina cells elongate, more than twice as long as wide.......38

38 Leaf apex rounded, obtuse or apiculate...................... Group 40

- Leaf apex acute or acuminate............................................... 39

39 Leaves distinctly falcate or squarrose ...................... Group 41

- Leaves straight or very slightly falcate or squarrose.

Group 42

\section{Group 9 Leaves distichous or complanate}

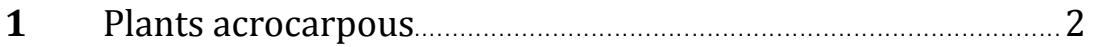

- Plants pleurocarpous ...................................................................

2 Lower part of leaf conduplicate........................Fissidens (p.137)

- Leaf not conduplicate, narrowed to subulate point.

Distichium capillaceum (w)

3 Median lamina cells 60-80 $\mu$ m wide.......Hookeria lucens (rr)

- $\quad$ Median lamina cells 4-45 $\mu$ m wide ............................................ 4

4 Alar cells differentiated, hyaline, decurrent.

Plagiothecium (p.212)

- $\quad$ Alar cells greenish or yellowish, differentiated or not ............5

5 Costa single

- $\quad$ Costa double or short and lacking ………………………….... 7

6 Leaves oblong to spathulate, costa extending 1/2 - 3/4 up leaf. Homalia trichomanoides $(\mathrm{w})$

- $\quad$ Leaves lanceolate or ovate-lanceolate, costa extending 2/3 up leaf to almost to apex.

Leptodictyum riparium (c)

7 Leaves mostly oblong-ovate to oblong or lingulate.

- Leaves mostly lanceolate, ovate or ovate-lanceolate ................ 9

8 Median lamina cells 8-80 $\mu \mathrm{m}$ long.

Neckera s.l. (incl. Alleniella, Exsertotheca) (p.228)

- Median lamina cells 45-160 $\mu$ m long. 
9 Flagelliform branchlets in leaf axils

Pseudotaxiphyllum elegans $(\mathrm{w})$

- Flagelliform branchlets absent, leaves only slightly complanate.

Isopterygiopsis pulchella $(\mathrm{r})$

\section{Group 10 Costa or ventral leaf surface with filaments or} lamellae

1 Costa with simple or branched filaments, at least in distal part.

- $\quad$ Costa with lamellae, at least in distal part, sometimes with a few filaments.

2 Leaf margin widely incurved, leaves rigid

- Leaf margin incurved or plane, leaves not rigid.

Aloina (p.145)

Crossidium (p.147)

3 Plants to 0.5 (1) cm tall; costa with 2-4 lamellae; peristome rudimentary or lacking.

Pterygoneurum (p.155)

- Plants 0.5-6 cm tall; costa with 4 or more lamellae; peristome well developed, with 32 or 64 teeth (Polytrichaceae).

4 Costa narrow, with 4-7 ventral lamellae; leaves with a border of long narrow cells.

Atrichum (p.126)

- Costa broad, with more than 7 lamellae on the ventral surface; leaves unbordered.

5 Capsule not angled, without apophysis and stomata, peristome teeth 32; leaves muticous.........Pogonatum (p.126)

- Capsule angled or not, with apophysis and stomata; peristome teeth 64 ; leaves muticous or with hair point...........6

6 Capsule not angled; end cell of lamellae papillose, higher than wide..Polytrichastrum alpinum (Polytrichum alpinum) (n.s.)

- Capsule angled; end cell of lamellae smooth.

Polytrichum (p.126)

Group 11 Leaves with hyaline point or costa excurrent in hair point

1 Pleurocarps with papillose cells, hyaline point only visible in microscope.

- $\quad$ Acrocarps, hyaline point visible to the naked eye or with a handlens. 
2 Plants regularly 2-3-pinnate; stem leaves with a long fine acumen, consisting of 3-4 uniseriate cells.

Thuidium assimile (Thuidium philibertii) (w)

- Plants irregularly branched, stem leaves with a long, uniseriate hyaline point.

Claopodium rostratum (Anomodon rostratus) (w)

3 Costa lacking Hedwigia (p.188)

- Costa present 4

4 Plants julaceous, silvery when dry...... Bryum argenteum (cc), Ptychostomum zieri (Plagiobryum zieri) (r)

- $\quad$ Plants not julaceous, not silvery when dry... 5

5 Capsule pale yellow, \pm smooth, emergent; exostome of 16 free teeth, reflexed when dry.. Orthotrichum diaphanum (cc)

- $\quad$ Capsule and peristome different ..................................................... 6

6 Costa wide, 1/2-1/3 of width of leaf base, hair point reflexed when dry. Campylopus introflexus (w)

- $\quad$ Costa narrow, less than $1 / 3$ of width of leaf base........................7

$7 \quad$ Lamina cells smooth or finely papillose

- Lamina cells strongly papillose...................................................12

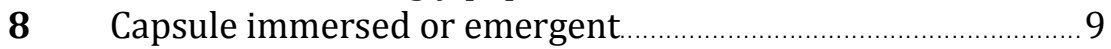

- Capsule exserted...................................................................... 10

9 Capsule indehiscent, calyptra cucullate ..................... Tortula pp.

(Tortula acaulon pp.) (p.166)

- $\quad$ Capsule dehiscent, calyptra cucullate, mitrate or campanulate Grimmiaceae pp. (p.175)

10 Lamina cells smooth in median part of leaf, papillose on strongly revolute margins. Hilpertia velenovskyi $(\mathrm{r})$

- $\quad$ Lamina cells smooth throughout ...............................................11

11 At least some lamina cells sinuose......Grimmiaceae pp. (p.175)

- Lamina cells not sinuose.

Tortula pp. (Pottia) (p.153)

12(7) Basal cells of leaf forming a distinct ovate group of hyaline cells on both sides of costa.

- Basal cells of leaf not forming a distinct ovate group on both sides of costa.. 14

13 Peristome teeth not spirally twisted or lacking; calyptra covering the whole capsule; basal hyaline cells with pale orange cross walls distinctly thickened .........Encalypta (p.130)

- $\quad$ Peristome teeth spirally twisted; calyptra partially covering the capsule; basal cells different. Syntrichia (p.155) 
14 Capsule immersed, indehiscent ..........Microbryum pp. (p.151), Tortula pp. (Tortula acaulon pp.) (p.166)

- $\quad$ Capsule exserted or emergent, dehiscent... Tortula pp. (p.166)

\section{Group 12 Leaves bordered with narrow cells or margin pluristratose}

1 Marginal cells short; margin 2-5-stratose

- Marginal cells longer and narrower than the rest of lamina cells; margin uni- to pluristratose.

2 Leaf margin recurved; lamina cells strongly papillose; central strand well developed............... Dialytrichia mucronata

- $\quad$ Leaf margin plane; lamina cells smooth or faintly papillose; central strand absent. Cinclidotus (p.146)

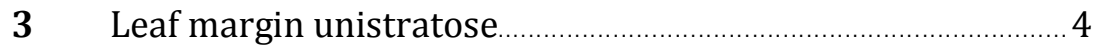

- $\quad$ Leaf margin bi- to pluristratose

$4 \quad$ Upper and median lamina cells papillose......... Tortula (p.166)

- Upper and median lamina cells smooth ...................................5

5 Plants rhizomatous; leaves crowded in terminal rosette.

Rhodobryum (p.190)

- Plants not rhizomatous; leaves crowded in terminal rosette or not

6 Sterile shoots often creeping; leaf margin dentate or (sometimes only faintly) denticulate....Plagiomnium (p.201)

- $\quad$ Sterile shoots erect; leaf margin \pm denticulate, rarely entire.... Bryum s.l. (incl. Imbribryum, Ptychostomum) (p.190)

7(3) Leaf margin entire; leaves less than twice as long as wide..

Rhizomnium punctatum (w)

- Leaf margin entire below, denticulate towards apex, or dentate \pm all round; leaves more than twice as long as wide...

8 Lamina cells papillose, sometimes only faintly so; leaf margin entire below, denticulate towards apex.

Tortula (cernua, schimperi) (p.166)

- Lamina cells smooth; leaf margin dentate

9 Leaf margin with simple teeth.

Bryum s.l. (incl. Imbribryum, Ptychostomum) (p.190)

- $\quad$ Leaf margin with geminate teeth Mnium (p.201) 


\section{Group 13 Acrocarps with indehiscent capsule}

1 Capsule exserted Tortula protobryoides (Pottia bryoides, Protobryum bryoides) (w)

- Capsule immersed or emergent.

2 Capsule with conspicuous neck, 1/3-1/2 of capsule length; capsule emergent. Bruchia flexuosa (rr)

- $\quad$ Capsule without perceptible neck

3 Plants with persistent protonema 3

- Plants without persistent protonema.. Ephemerum (p.169)

4 Lamina cells smooth, more than $25 \mu$ m wide.

Physcomitrium patens

(Aphanorrhegma patens, Physcomitrella patens) (w)

- $\quad$ Lamina cells smooth or papillose, less than $25 \mu$ m wide......... 5

5 Capsule with \pm differentiated lid; leaves incurved, crisped when dry.

Weissia (longifolia, rostellata) (p.173)

- Capsule without lid; leaves not crisped when dry... 6

6 Capsule globose, with translucent walls, spores mostly 1620 in number, $100-200 \mu \mathrm{m} . .$. Archidium alternifolium (n.s.)

- $\quad$ Capsule globose or \pm apiculate, with opaque wall, spores

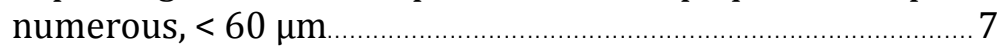

7 Lamina cells rectangular or linear …….................................. 8

- Lamina cells quadrate, rounded, hexagonal or elliptical......... 9

8 Leaves subulate, at least the upper ones; lamina cells $8 \mu \mathrm{m}$ wide. Pleuridium (p.143)

- $\quad$ Leaves acuminate; lamina cells 9-13 $\mu \mathrm{m}$ wide.

Pseudephemerum nitidum $(\mathrm{w})$

9 Plants bulbiform; costa with stereids only; capsule not or only minutely apiculate. Acaulon (p.145)

- $\quad$ Plants not bulbiform; costa with stereids and guide cells; capsule apiculate. Microbryum pp. (p.151), Tortula pp. (p.166)

\section{Group 14 Acrocarps with immersed or emergent capsule}

1 Capsule large, ovoid, asymmetrical; perichaetial leaves ciliate. Diphyscium foliosum (w)

- Capsule and perichaetial leaves not as above.

2 Leaves without costa. Hedwigia (p.188)

- Leaves costate. 
3 Lid coming off attached to columella; capsule smooth

Schistidium (p.175)

- $\quad$ Lid not coming off attached to columella; capsule smooth or striate.

4 Plants minute; growing on calcareous rocks; capsule emergent to exserted. Seligeria (acutifolia) (p.174)

- $\quad$ Plants medium-sized; growing on calcareous or acidic rocks or on tree trunks.

5 Leaf cells mamillose; capsule globose

Bartramia halleriana (rr)

- $\quad$ Leaf cells papillose or smooth; capsule shortly cylindrical....6 6

6 Stomata phaneropore.

- Stomata cryptopore.

Orthotrichum (p.203)

7 Leaves concave, with erect-incurved or involute margins and obtuse or rounded apices, gemmae abundant, in particular on the ventral surface of leaves; capsules rare.

Nyholmiella (p.203)

- Leaves not as above, with recurved margins and acute to acuminate apices; gemmae occasional; capsules frequent

Lewinskya (p.203)

\section{Group 15 Acrocarps with exserted globose or subglobose capsule}

$1 \quad$ Peristome lacking (Funariaceae pp.) ………………………...... 2

- $\quad$ Peristome single or double (Bartramiaceae)............................... 3

2 Calyptra inflated, contracted at base, cucullate, covering all of the capsule.

Pyramidula tetragona $(\mathrm{r})$

- Calyptra small, mitriform, not covering all of the capsule....Physcomitrium (eurystomum, sphaericum) (p.131)

3 Leaves lanceolate, not sheathing at base....Philonotis (p.189)

- Leaves narrowly lanceolate to linear lanceolate, sheathing at base.

4 Lamina cells with finely striate cuticle

- Lamina cells mamillose.

Plagiopus oederianus (r) Bartramia (p.189) 


\section{Group 16 Acrocarps with exserted strumose capsule}

1 Costa with a central layer of green cells surrounded by hyaline cells (cross section); plants whitish or glaucous.

Leucobryum glaucum (w)

- Costa not as above; plants not whitish or glaucous

2 Peristome teeth divided near to base, reddish, with a paler border or not.

Ceratodon (p.143)

- $\quad$ Peristome teeth divided to halfway, reddish, striate in the lower part

3 Lamina cells longly rectangular, smooth; margin plane

Dicranella cerviculata $(\mathrm{rr})$

- At least upper lamina cells quadrate or oblate, mamillose; margin recurved.

Cynodontium (p.142)

\section{Group 17 Acrocarps with exserted capsule and peristome lacking or rudimentary}

1 Calyptra inflated, 4-angled; spores 50-65 $\mu \mathrm{m}$...

- Calyptra not inflated or angled; spores smaller..................... 2

$2 \quad$ Capsule striate or sulcate when dry ......................................... 3

- Capsule smooth when dry ........................................................... 4

3 Leaves linear-lanceolate; gemmae lacking.

Amphidium mougeotii (r)

- Leaves lanceolate to oblong-lanceolate; plants with ovoid gemmae; lamina cells papillose.............Zygodon rupestris $(\mathrm{r})$

4(2) Median lamina cells 20-50 $\mu \mathrm{m}$ wide, thin-walled (Funariaceae pp.) ............................................................... 5

- Median lamina cells less than $20 \mu \mathrm{m}$ wide, thin-walled or

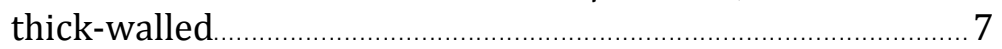

5 Exothecial cells longer than wide..

Entosthodon hungaricus (w)

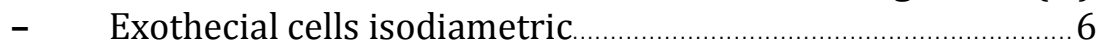

6 Calyptra mitriform ................................Physcomitrium (p.131)

- $\quad$ Calyptra cucullate...........................Entosthodon fascicularis (r)

7(4) Plants minute; lamina cells smooth....Seligeria donniana (r)

- $\quad$ Plants small to robust; lamina cells papillose

8 Calyptra cylindrical, covering capsule; basal leaf cells forming a well-delimited group......................Encalypta (p.130) 
- $\quad$ Calyptra cucullate, not covering capsule; basal leaf cells not forming a well-delimited group.

9 Costa excurrent.

- Costa not excurrent.

10 Leaves linear-lanceolate or lanceolate; margin incurved to strongly involute, rarely plane

Weissia (p.173)

- Leaves ovate-lanceolate, ovate or obovate; margin plane or recurved.

11 Lid conical........Microbryum (davallianum, muticum) (p.151)

- Lid rostrate. Tortula pp. (Pottia) (p.153)

12(9) Lid attached to columella after dehiscence.............................13

- $\quad$ Lid not attached to columella after dehiscence........................14

13 Plants 1-4 (10) cm tall; leaves carinate; margin finely crenulated ...................Hymenostylium recurvirostrum (n.s.)

- $\quad$ Plants to $1 \mathrm{~cm}$ tall; leaves not carinate; margin dentate at apex ................. Hennediella heimii (Desmatodon heimii) (rr)

14 Annulus of capsule persistent, of large cells; stems rarely branched

Gyroweisia tenuis ( $\mathrm{rr}$ )

- Annulus of capsule persistent or caducous, of small cells; stems branched.

Gymnostomum (p.170)

Group 18 Acrocarps with exserted capsule, striate or sulcate when dry and peristome well developed

1 Costa with a central layer of green cells surrounded by hyaline cells (cross section); plants whitish or glaucous.

- $\quad$ Costa not as above; plants glaucous or not ............................... 2

2 Plants very small, to $3.5 \mathrm{~mm}$ tall.

- $\quad$ Plants more than $3.5 \mathrm{~mm}$ tall ..................................................... 3

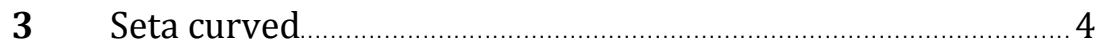

- Seta straight

4 Costa occupying 1/3 or more of leaf base.

Campylopus (p.133)

- Costa occupying less than $1 / 3$ of leaf base.

5 Leaves ovate-lanceolate; upper lamina cells rectangular or hexagonal, 30-50 $\mu \mathrm{m}$ wide, thin-walled 
- Leaves lanceolate; upper lamina cells quadrate or rounded, to $20 \mu \mathrm{m}$ wide, thick-walled. Grimmia (p.175)

6 Peristome teeth in pairs or groups of 4 (Orthotrichaceae pp.)

- $\quad$ Peristome teeth free, not forming groups ................................... 12

$7 \quad$ Capsule shortly exserted $\ldots$

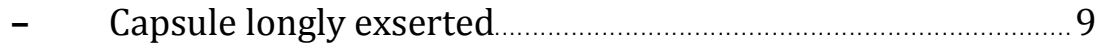

8 Stomata cryptopore .................................... Orthotrichum (p.203)

- Stomata phaneropore......................................... Lewinskya (p.203)

9 Marginal cells at leaf base rectangular, with thickened transverse walls, ascending up margin, basal cells linear.

Ulota (p.203)

- Marginal basal cells elongate, similar to the rest of basal cells

10 Lamina cells smooth; calyptra cucullate, glabrous

Codonoblepharon forsteri (Zygodon forsteri) (r)

- Lamina cells mostly papillose; calyptra mitrate, often hairy...

11 Stomata cryptopore Orthotrichum s.l. (incl. Lewinskya) pp 11

- Stomata phaneropore Orthotrichum (p.203)

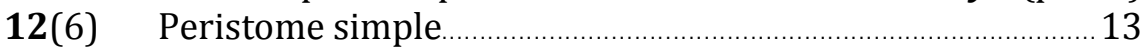

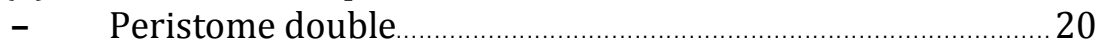

13 Peristome of 16 teeth, entire or slightly and irregularly divided.

- $\quad$ Peristome of 16 teeth, divided to halfway or more................16

14 Capsule cylindrical, covered completely by the calyptra.

Encalypta (p.130)

- $\quad$ Capsule ovoid or shortly cylindrical, not completely covered by the calyptra.

15 Leaf margin recurved ………………...... Cnestrum schisti (n.s.)

- Leaf margin flat. Rhabdoweisia (p.142)

16 Peristome teeth divided to base..

- Peristome teeth divided to halfway

17 Plants glaucous.

Saelania glaucescens (rr)

- Plants not glaucous. Ceratodon (p.143)

18 Alar cells \pm differentiated Dicranum (p.139) Alar cells not differentiated

19 Lamina cells quadrate. Cynodontium (p.142)

- Lamina cells rectangular. Dicranella (p.135) 
20(12) Median cells of lamina linear, smooth

Orthodontium lineare (rr)

- Median cells of lamina rounded, quadrate or hexagonal, mammilose or papillose

21 Leaves with dentate margins and sheathing base; marginal cells narrower and longer than median cells; plants without gemmae.

Timmia (p.130)

- Leaves with entire or denticulate margins and the base not sheathing; marginal cells similar to median cells; gemmae in groups at the end of pseudopodia.

Aulacomnium (p.211)

Group 19 Acrocarps with exserted erect capsule, peristome teeth 16, entire or slightly and irregularly divided

1 Lamina cells more than $20 \mu \mathrm{m}$ wide, smooth

Entosthodon (p.131)

- Lamina cells less than $20 \mu \mathrm{m}$ wide, smooth or papillose.........2

2 Leaf apex acuminate or subulate, very rarely obtuse ................ 3

- $\quad$ Leaf apex obtuse, acute or rounded, rarely acuminate............. 7

3 Alar cells differentiated, orange, brownish red

Blindia acuta (n.s.)

- $\quad$ Alar cells not differentiated................................................... 4

4 Leaves fragile; margin sinuose-undulate, notched

Chionoloma tenuirostre (Oxystegus tenuirostris) (r)

- Leaves not fragile; margin not sinuose, not notched ………....5

5 Plants minute; growing on calcareous or siliceous rocks .......6

- $\quad$ Plants medium-sized; growing on acid, volcanic rocks or tree trunks.

Dicranoweisia cirrata $(\mathrm{w})$

6 Seta arcuate when moist, straight when dry; plants growing on siliceous rocks or small calcareous stones

Blindiadelphus (p.174)

- Seta straight when moist and dry; plants growing on calcareous rocks.

Seligeria (p.174)

7(2) Leaves lingulate or spathulate; calyptra covering completely the capsule

Encalypta (p.130)

- Leaves not as above; calyptra not completely covering the

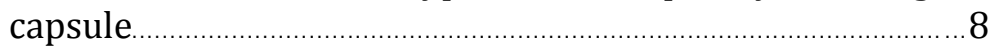

8 Costa excurrent

- Costa percurrent ................................................ Didymodon (p.147) 
9 Leaf margin with reflexed teeth at base.

- Leaf margin without reflexed teeth at base.

Eucladium verticillatum $(\mathrm{w})$

10 Lamina bistratose or pluristratose in the upper part

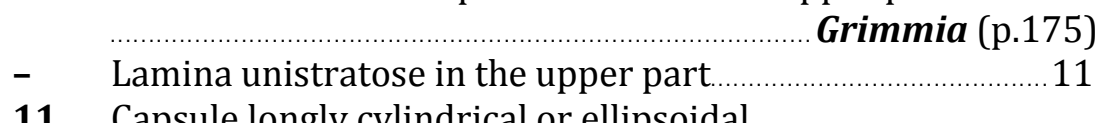

11 Capsule longly cylindrical or ellipsoidal

Trichostomum (p.172)

- $\quad$ Capsule shortly cylindrical or ovoid.

12 Leaves linear-lanceolate or lanceolate, strongly incurved at the apex

Weissia (p.173)

- Leaves ovate-lanceolate, ovate, obovate or lingulate.

13 Lid conical.

Microbryum starckeanum (Pottia starckeana) (rr)

- Lid rostrate. Tortula pp. (p.166)

Group 20 Acrocarps with exserted erect capsule, peristome teeth 16 , divided halfway or to the base (32 teeth)

1 Peristome teeth slightly or strongly spirally twisted .............. 2

- $\quad$ Peristome teeth straight or curved. 10

2 Basal lamina cells hyaline, forming a well-delimited group......

- Basal lamina cells hyaline or not, not forming a welldelimited group...

3 Basal hyaline cells of leaf ascending up margin in a Vshape.

- Basal hyaline cells of leaf forming an ovate group, not ascending up margin.

Syntrichia (p.156)

$4 \quad$ Peristome with well-developed basal membrane .....................5

- Peristome without or with low basal membrane.......................6 6

5 Leaf margin conspicuously revolute; basal membrane of peristome to $45 \mu \mathrm{m}$. Hilpertia velenovskyi $(\mathrm{r})$

- Leaf margin not revolute; basal membrane more than 300 $\mu \mathrm{m}$.

Tortula (inermis, mucronifolia, schimperi, subulata) (p.166)

6 Axillary hairs with 1-2(3) brown basal cells.

Didymodon (p.147)

- $\quad$ Axillary hairs hyaline throughout 
7 Margin plane or recurved; costa with elongate cells on ventral side

- Margin recurved to strongly revolute; ventral cells of costa elongate or quadrate to shortly rectangular.

8 Costa excurrent in a thick point; leaf margin recurved from base to apex; perichaetial leaves not much different from vegetative leaves

Barbula unguiculata (cc)

- Leaf apex at most with some hyaline cells forming a short apiculus, costa not excurrent; leaf margin plane or slightly recurved at leaf base; inner perichaetial leaves with sheathing base, conspicuously different from vegetative leaves

Streblotrichum convolutum (p.169)

9 Ventral cells of costa long rectangular, smooth; margin conspicuously revolute; costa excurrent in hyaline awn.

Hilpertia velenovskyi (r)

- Ventral cells of costa quadrate to shortly rectangular; margin recurved to strongly revolute; costa percurrent or excurrent in a short mucro.

10(1) Lamina cells longer than wide. Pseudocrossidium (p.155)

- Lamina cells \pm quadrate

11 Peristome teeth divided to base

Ditrichum s.l. (incl. Flexitrichum) (p.143)

- Peristome teeth divided halfway.

12 Leaves squarrose when moist.

Dichodontium pellucidum $(\mathrm{w})$

- Leaves not squarrose.

Dicranella (p.135)

13(10) Peristome teeth irregularly divided to base or nearly so.....14

- $\quad$ Peristome teeth regularly divided to base or nearly so.........17

14 Lamina cells $15-20 \mu$ m wide.

Tortula (p.166) Lamina cells to 14 um wide.

15 Costa excurrent in apiculus Trichostomum (p.172)

- Costa ending in or below apex

16 Plants to $5 \mathrm{~mm}$ tall; lamina cells smooth

Campylostelium saxicola (rr)

- $\quad$ Plants more than $5 \mathrm{~mm}$ tall; lamina cells mamillose on both surfaces.

Cynodontium (p.142)

17(13) Leaf margin entire or crenulate or slightly dentate near apex; lamina cells pluripapillose

Bryoerythrophyllum recurvirostrum (w) 
- $\quad$ Leaf margin strongly dentate in upper third; lamina cells mamillose Dichodontium pellucidum (w)

Group 21 Acrocarps with exserted capsule, inclined or pendulous, peristome simple

1 Seta curved at least when moist

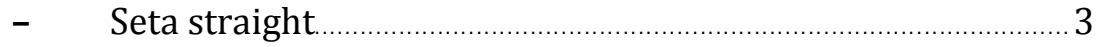

2 Plants minute; leaves not deciduous; growing on siliceous rocks or calcareous small stones......... Blindiadelphus (p.174)

- Plants medium-sized to robust; leaves deciduous, plants growing on humus-rich soil or dead wood.

3 Alar cells differentiated.

Dicranodontium denudatum $(\mathrm{rr})$

- Alar cells not differentiated. Dicranum (p.139)

4 Median lamina cells rectagular, long and narrow, smooth

Dicranella (p.139)

- $\quad$ Median lamina cells quadrate, papillose or mamillose $\ldots \ldots \ldots \ldots . . .5$

5 Lamina cells papillose, sometimes only faintly so; costa excurrent …….....Tortula cernua (Desmatodon cernuus) (rr)

- Lamina cells mamillose; costa percurrent

\section{Dichodontium pellucidum (w)}

Group 22 Acrocarps with exserted capsule, inclined to pendulous, peristome double

1 Plants bluish when dry (and dead) or with bluish to golden

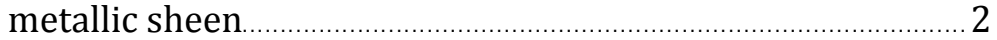

- $\quad$ Plants not bluish when dry .......................................................... 3

2 Plants bluish when dry and dead; lamina cells hexagonal, 20-24 $\mu$ m wide. Mnium stellare $(\mathrm{w})$ Plants with metallic sheen; lamina cells linear, 8-12 $\mu \mathrm{m}$ wide. Pohlia cruda (w)

3 Costa 1/3 or more of leaf base

- $\quad$ Costa less than $1 / 3$ of leaf base ……………………………...... 5

4 Upper leaves linear, subulate......Leptobryum pyriforme (w)

- Upper leaves oblong-lanceolate, not linear. Amblyodon dealbatus (n.s.)

5 Leaves distinctly 3-ranked, patent to squarrose, carinate, triangular-lanceolate. Meesia triquetra (n.s.) 
- Leaves not as above.

6 Leaves strongly imbricate, plants julaceous.

Ptychostomum zieri (Plagiobryum zieri) (r)

- Leaves not strongly imbricate, plants not julaceous.

7 Peristome teeth sigmoid; capsule asymmetrical.

Entosthodon (p.131)

- $\quad$ Peristome teeth straight; capsule symmetric, cylindrical to pyriform.

8 Leaves linear-lanceolate, more than 7 times as long as wide...

Orthodontium lineare ( $\mathrm{rr}$ )

- $\quad$ Leaves (except perichaetial leaves) less than 7 times as long as wide, lanceolate to ovate.

9 Leaves narrowly ovate to lanceolate, unbordered or with a weak border of narrow cells, distinctly denticulate above; perichaetial leaves longer than vegetative leaves; costa rarely excurrent and then only shortly so, in section with large median guide cells; lamina cells linear to narrowly hexagonal, 5 or more times as long as wide; basal cells not differentiated.

Pohlia (p.198)

- Leaves suborbicular to ovate, rarely lanceolate, usually with a distinct (sometimes thickened) border of narrow cells; margins entire or finely denticulate above, rarely distinctly so; perichaetial leaves hardly longer than vegetative leaves; costa often excurrent, sometimes as a long hair, in section with large ventral superficial cells; lamina cells rhomboidal to hexagonal, to 4 times as long as wide; basal cells quadrate or rectangular.

Bryum s.l. (incl. Imbribryum, Ptychostomum) (p.190)

\section{Group 23 Acrocarps with propagules on stems, leaves or in receptacles}

1 Plants with axillary bulbils

- Plants without axillary bulbils.................................................. 3

2 Leaves narrowly ovate to lanceolate, unbordered or with a weak border of narrow cells, distinctly denticulate above; perichaetial leaves longer than vegetative leaves; costa rarely excurrent and then only shortly so, in section with large median guide cells; lamina cells linear to narrowly hexagonal, 5 or more times as long as wide; basal cells not differentiated.

Pohlia (p.198) 
- $\quad$ Leaves suborbicular to ovate, rarely lanceolate, usually with a distinct (sometimes thickened) border of narrow cells; margins entire or finely denticulate above, rarely distinctly so; perichaetial leaves hardly longer than vegetative leaves; costa often excurrent, sometimes as a long hair, in section with large ventral superficial cells; lamina cells rhomboidal to hexagonal, to 4 times as long as wide; basal cells quadrate or rectangular.

Bryum s.l.

(incl. Imbribryum, Ptychostomum) (p.190)

3 Plants with foliose propagules in leaf axils.

Syntrichia laevipila $(\mathrm{rr})$

- Plants with gemmae............................................................ 4

$4 \quad$ Gemmae crowded at ends of stems ………………………...... 5

- Gemmae in leaf axils or on leaves …………………………......6 6

5 Gemmae globose, ovoidal or fusiform, in globose clusters on ends of leafless prolongations of stems.

Aulacomnium (p.211)

- Gemmae lenticular or discoid, in the centre of a rosette of apical leaves.

Tetraphis pellucida (w)

6 Gemmae globose or ellipsoidal on axillary filaments...............7

- Gemmae globose or ellipsoidal, sessile, or filamentous.......... 9

7 Leaves with hair point

(dissimulata, lisae, muehlenbeckii, trichophylla) (p.175)

- $\quad$ Leaves without hair point

8 Gemmae clavate, few-celled, or ovoid, many-celled

Hydrogonium (p.171)

- Gemmae spherical, sometimes irregularly so and with protruding cells......Didymodon (cordatus, glaucus, rigidulus)

9 Gemmae globose, at tips of leaves, more than $80 \mu \mathrm{m}$.

Grimmia hartmanii (w)

- Gemmae on costa, on leaf or in leaf axils, if at tips of leaves, then not globose or less than $70 \mu \mathrm{m}$.

10 Gemmae irregularly globose, on ventral side of costa

Syntrichia (latifolia, papillosa, virescens) (p.156)

- Gemmae filamentous, fusiform, ovoid or ellipsoidal, on lamina, at tips of leaves or in leaf axils..................................... 11

11 Gemmae filamentous, branched or not ………………......... 12

- Gemmae fusiform, shortly cylindrical, vermiform, ellipsoidal or ovoid. 
12 Basal cells hyaline, forming a well-delimited group.

Encalypta streptocarpa $(\mathrm{w})$

- Basal cells hyaline or not, not forming a well-delimited group

13 Leaves bordered, with 1-3 rows of elongate cells; lamina cells rectangular-hexagonal, smooth, more than $15 \mu \mathrm{m}$ wide..

Ptychostomum (moravicum, pallens, pseudotriquetrum)

- Leaves unbordered; lamina cells rounded, papillose, to 14 $\mu \mathrm{m}$ wide

Orthotrichum s.l.

(incl. Lewinskya, Nyholmiella, Pulvigera) (p.203)

14(11) Calyptra cucullate, smooth, hairless; capsule much exserted on a thin seta; gemmae in leaf axils and in the tomentum of the stem

- Calyptra mitrate, plicate, with or without hairs; capsule immersed to exserted on a strong seta; gemmae on the surface of leaves.

15 Lamina cells papillose.

- Lamina cells smooth

Zygodon rupestris $(\mathrm{r})$

Codonoblepharon forsteri (Zygodon forsteri) (r)

16 Leaves concave, with erect incurved or involute margins; apex obtuse or rounded

Nyholmiella (p.203)

- $\quad$ Leaves \pm keeled, rarely concave, with recurved, revolute or plane margins; apex obtuse, acute or acuminate, rarely rounded.

17 Marginal cells at leaf base hyaline, rectangular, with thickened walls, ascending up margin, basal cells linear.

Ulota (p.203)

- $\quad$ Marginal basal cells elongate, similar to the rest of basal cells Orthotrichum s.l. (incl. Lewinskya, Pulvigera) (p.203)

\section{Group 24 Acrocarps with costa 1/3 or more width of leaf base}

1 Costa excurrent in a hyaline hair point

Campylopus introflexus $(\mathrm{w})$

- Costa percurrent or excurrent in a coloured hair point........... 2

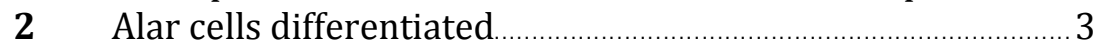

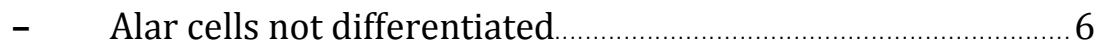

3 Costa consisting of green cells and hyaline cells (cross section) Paraleucobryum longifolium (w) 
- $\quad$ Costa consisting of stereids and guide cells (cross section).....

4 Lamina partly bistratose near costa ..... Dicranum fulvum (r)

- Lamina unistratose.

5 Costa with dorsal stereids only or without stereids.

- Costa with dorsal and ventral stereids

Campylopus (p.133)

Dicranodontium denudatum (rr)

6(2) Costa with a central layer of green cells surrounded by hyaline cells (cross section); plants whitish or glaucous.

Leucobryum (p.135)

- Costa with a central layer of guide cells or not, not with outer layers of hyaline cells (cross section); plants green or brownish.

7 Lamina cells papillose .........Gymnostomum aeruginosum (r)

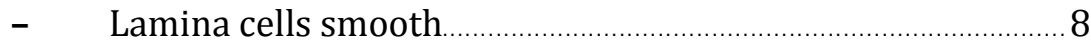

8 Leaves oblong-lanceolate; lamina cells longly hexagonal; costa without guide cells..............Amblyodon dealbatus (n.s.)

- Leaves linear to lanceolate; lamina cells rectangular to linear; costa with guide cells................................................. 9

9 Leaves linear, flexuose, lamina cells linear, 45-55 $\mu \mathrm{m}$ long; rhizoidal tubers abundant ...........Leptobryum pyriforme $(\mathrm{w})$

- $\quad$ Lamina cells less than $45 \mu \mathrm{m}$ long; rhizoidal tubers lacking or rare...

10 Costa wider than $180 \mu \mathrm{m}$ at leaf base......Campylopus (p.133)

- $\quad$ Costa less than $180 \mu \mathrm{m}$ wide at leaf base.................................11

11 Costa 80-110 $\mu$ m wide at leaf base.........Flexitrichum (p.133)

- $\quad$ Costa to $30 \mu \mathrm{m}$ wide at leaf base.

Dicranella (heteromalla, cerviculata) (p.135)

\section{Group 25 Acrocarps with lamina cells $18 \mu \mathrm{m}$ wide or more}

1 Leaves bordered by elongate cells, denticulate (sometimes very faintly so); plants often with creeping sterile shoots

Plagiomnium (p.198)

- $\quad$ Leaves not bordered; sterile shoots erect, not creeping ..........2

2 Lamina cells quadrate, rounded or shortly polygonal............. 3

- Lamina cells longly polygonal or elliptical................................10

3 Costa ending below leaf apex …………………...................... 4

- Costa excurrent in apiculus or hair point .................................... 5 
$4 \quad$ Leaf margin irregularly denticulate, plants bluish when dry (and dead)... Mnium stellare (w)

- $\quad$ Leaf margin entire; plants not bluish when dry Orthotrichum sprucei (rr)

5 Leaves apiculate, with reflexed, brownish yellow apiculus formed by a single elongate cell; margin irregularly denticulate above. Chenia leptophylla (Phascum leptophyllum, Leptophascum leptophyllum) (r)

- Leaves not as above; margin entire.

6 Capsule immersed 6

(Aphanorrhegma patens, Physcomitrella patens) (w)

- $\quad$ Capsule exserted or emergent

$7 \quad$ Calyptra small, cucullate; spores less than $40 \mu \mathrm{m} \ldots \ldots \ldots \ldots \ldots \ldots \ldots . . .8$

- $\quad$ Calyptra large, inflated, cucullate, distinctly 4-angled; spores 50-65 $\mu \mathrm{m}$. Pyramidula tetragona $(\mathrm{r})$

8 Capsule dehiscent

- Capsule indehiscent. Tortula protobryoides

(Pottia bryoides, Protobryum bryoides) (w)

9 Peristome single, teeth 16, irregularly divided; plants growing on soil........... Tortula pp. (cernua, lindbergii) (p.166)

- $\quad$ Peristome double, exostome teeth united in 8 pairs; plants growing in knot-holes.

Codonoblepharon forsteri (Zygodon forsteri) (r)

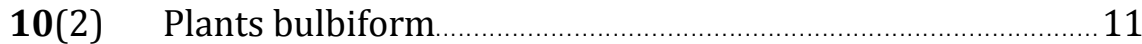

- Plants not bulbiform ............................................................... 12

11 Margin plane; costa excurrent in short apiculus

Acaulon (p.145)

- Margin strongly revolute, with papillose cells (median lamina cells smooth); costa excurrent in hyaline hair point....

Hilpertia velenovskyi (r)

12 Plants rhizomatous; leaves crowded in terminal rosette.

Rhodobryum (p.190)

- Plants not rhizomatous; leaves crowded in terminal rosette or evenly arranged along the stem............................................13

13 Leaf apex rounded ..................................................................... 14

- Leaf apex obtuse, acute or acuminate, but not rounded ........15

14 Costa percurrent; leaves 2-3 times as long as wide, decurrent, bordered by several rows of narrow, long cells

.Ptychostomum pseudotriquetrum fo. neodamense (Bryum neodamense) (n.s.) 
- $\quad$ Costa ending several cells below leaf apex; leaves 2 times as long as wide, not decurrent, unbordered

15 Capsule sulcate; peristome teeth fused at apices

Splachnobryum obtusum (n.s.)

Funaria hygrometrica $(\mathrm{w})$

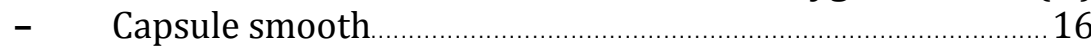

16 Capsule immersed, indehiscent (gymnostomous).

Physcomitrium patens

(Aphanorrhegma patens, Physcomitrella patens) (w)

- Capsule exserted, dehiscent ...................................................17

17 Capsule asymmetrical and curved …………..........................18

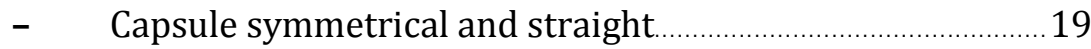

18 Capsule horizontal to pendulous; peristome teeth not sigmoid ………...Ptychostomum zieri (Plagiobryum zieri) (r)

- Capsule inclined to horizontal; peristome teeth sigmoid.

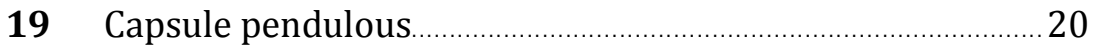

- Capsule erect or inclined ........................................................ 21

20 Leaves narrowly ovate to lanceolate, unbordered or with a weak border of narrow cells, distinctly denticulate above; perichaetial leaves longer than vegetative leaves; costa rarely excurrent and then only shortly so, in section with large median guide cells; lamina cells linear to narrowly hexagonal, 5 or more times as long as wide; basal cells not differentiated.

Pohlia (p.198)

- Leaves suborbicular to ovate, rarely lanceolate, usually with a distinct (sometimes thickened) border of narrow cells; margins entire or finely denticulate above, rarely distinctly so; perichaetial leaves hardly longer than vegetative leaves; costa often excurrent, sometimes as a long hair, in section with large ventral superficial cells; lamina cells rhomboidal to hexagonal, to 4 times as long as wide; basal cells quadrate or rectangular.

Bryum s.l.

(incl. Imbribryum, Ptychostomum) (p.190)

21 Exothecial cells elongate. Entosthodon

(hungaricus, muhlenbergii, pulchellus) (p.131)

- Exothecial cells isodiametric.

22 Calyptra mitriform; lid apiculate or rostellate; spores echinate. Physcomitrium (p.131) 
- $\quad$ Calyptra cucullate or mitriform; lid convex or plane, without apiculus; spores not echinate.....Entosthodon fascicularis (r)

\section{Group 26 Acrocarps with alar cells differentiated}

1 Costa with stereids

Dicranum (p.139)

- Costa without stereids

2 Leaves rigid, fragile, mostly broken.

- $\quad$ Leaves different; capsule symmetrical, smooth

Dicranum tauricum (w)

Blindia acuta (n.s.)

Group 27 Acrocarps with lamina cells isodiametric and leaf margins denticulate or dentate, at least near apex or base

1 Leaf margin denticulate near base with reflexed, hyaline teeth Eucladium verticillatum $(\mathrm{w})$

- Leaves not as above. 2

2 Plants glaucous. Saelania glaucescens (rr)

- Plants not glaucous. 3

3 Leaves squarrose

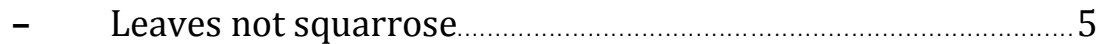

$4 \quad$ Basal cells hyaline, ascending up margin; leaf margin dentate above; frequent plants on open, dry calcareous soil

Tortella squarrosa (Pleurochaete squarrosa) (w)

- $\quad$ Basal cells not as above; leaf margin sharply serrate; very rare plants on peaty soils. Meesia triquetra (n.s.)

5 Stem with dense brownish tomentum and usually with clusters of gemmae at the tip. Aulacomnium (p.211)

- Stem not as above.

6 Leaves linear-lanceolate, fragile, notched; margin dentate at the tip in young leaves. Didymodon sinuosus (w)

- $\quad$ Leaves not as above.

7 Leaves lanceolate to lingulate, with wide, acute or obtuse apex.

- Leaves ovate or linear lanceolate, with gradually acuminate apex.

8 Lamina cells smooth Rhabdoweisia (p.142)

- Lamina cells mamillose.

9 Leaf margin plane or incurved Dichodontium pellucidum (w) 10 
- $\quad$ Leaf margin recurved

10 Marginal cells with slightly thicker walls than the rest of lamina cells, some longer, but not forming a distinct border; lid attached to columella after dehiscence; lamina cells not mamillose on ventral surface of leaf.

Hennediella heimii (Desmatodon heimii) (rr)

- Marginal cells similar to the rest of lamina cells; lid not attached to columella after dehiscence; lamina cells mamillose on ventral surface of leaf .................Timmia (p.130)

11 Leaves crisped when dry ................................................... 12

- $\quad$ Leaves flexuose, slightly twisted or straight when dry.........16

12 Leaves lanceolate, acuminate, with unistratose margins; lamina cells mamillose or finely papillose-striate.

- Leaves linear-lanceolate, acute, often with bistratose margins; lamina cells smooth or mamillose .............................14

13 Plants pale green; median lamina cells mamillose; stem circular in cross section. Bartramia (p.189)

- Plants dark green; median lamina cells finely papillosestriate; stem triangular in cross section...

Plagiopus oederianus (r)

14 Lamina cells smooth.. Cynodontium tenellum (rr)

- Lamina cells mamillose. 15

15 Leaves tristichous. Cnestrum schisti (n.s.)

- Leaves spirally arranged ………………..... Cynodontium (p.142)

16(11) Leaves with papillose-dentate margins, at least in upper half

Bartramia (p.189)

- Leaves with denticulate margins only at apex.

17 Leaf margin crenulate or papillose; apex denticulate, with few hyaline teeth; lamina cells papillose; capsule erect, smooth, not strumose.

Bryoerythrophyllum recurvirostrum (w)

- Leaf margin not crenulate or papillose; apex slightly denticulate; lamina cells smooth; capsule inclined, striate, strumose

Ceratodon (p.143)

\section{Group 28 Acrocarps with lamina cells isodiametric and excurrent costa}

1 Basal cells of leaf hyaline, ascending up margins in a V-shape Tortella (p.171) 
- $\quad$ Basal cells of leaf hyaline or not, not ascending up margins.....

2 Basal cells of leaf hyaline, forming a well-delimited group on

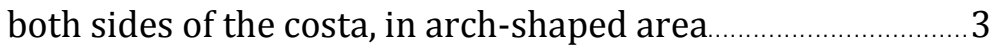

- Basal cells of leaf hyaline or not, transition to cells above gradual.

3 Peristome teeth spirally twisted; calyptra partially covering the capsule

Syntrichia (p.156)

- $\quad$ Peristome teeth not twisted or lacking; calyptra covering the whole capsule; basal hyaline lamina cells with pale orange cross walls distinctly thickened.

$4 \quad$ Leaves partially bistratose in upper part

Encalypta (p.130)

Schistidium (p.175)

- $\quad$ Leaves unistratose or with bistratose margins ............................ 5

$5 \quad$ Lamina cells smooth or mamillose

- Lamina cells papillose $\quad$............................................................ 7

6 Costa excurrent in hyaline or yellowish hair point, rarely in apiculus; capsule indehiscent, or if dehiscent then leaf margin indistinctly bordered by longer cells.

Tortula pp. (p.166)

- Costa ending below apex, percurrent or shortly excurrent; capsule dehiscent and leaf margin not bordered.

Didymodon (p.147)

7 Leaf margin revolute or recurved on one or both sides, at least partially.

- $\quad$ Leaf margin plane or incurved .......................................................... 15

8 Leaf margins strongly revolute …………………................... 9

- Leaf margins recurved on one or both sides ..............................10

9 Leaves lanceolate to ovate-lanceolate, triangular or lingulate Pseudocrossidium (p.155)

- Leaves oblong, ovate, elliptical or obovate......Tortula (p.166)

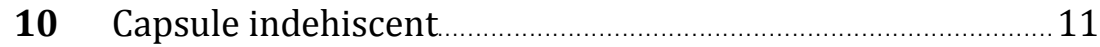

- Capsule dehiscent ............................................................................. 13

11 Lid differentiated, persistent ................ Tortula protobryoides (Pottia bryoides, Protobryum bryoides) (w)

- $\quad$ Lid not differentiated ............................................................... 12

12 Stereids numerous, in 3-5 (6) layers; capsule immersed or emergent. Tortula pp. (T. acaulon, Phascum cuspidatum) (p.166) 
- $\quad$ Stereids few, in 1-2 layers or lacking; capsule emergent, rarely immersed.

Microbryum (p.151)

13(10) Peristome teeth erect, rudimentary or lacking...... Tortula pp.

- $\quad$ Peristome teeth filiform, spirally twisted.

14 Cells of axillary hairs hyaline.

Barbula unguiculata (cc)

- Basal cells of axillary hairs brown

15(7) Capsule immersed to emergent. Didymodon (p.147)

- $\quad$ Capsule exserted

Weissia (longifolia, rostellata) (p.173)

16 Leaves 3-4 (6) mm long; margins plane, sinuose, notched, papillose-crenulate; apex formed by a group of smooth, hyaline cells twice as long as papillose cells below.

Chionoloma tenuirostre (Oxystegus tenuirostris) (r)

- Leaves 0.4-3 (4.5) mm long; margin plane or incurved, entire.

17 Leaf margin plane or incurved, apex occasionally cucullate; capsule longly cylindrical or ellipsoidal; peristome teeth straight or twisted, perforated.

Trichostomum (p.172)

- Leaf margin incurved, at least in upper part, sometimes plane; capsule shortly cylindrical or ovoid; peristome teeth straight, entire or lacking.

Weissia (p.173)

Group 29 Acrocarps with isodiametric lamina cells, leaf apex obtuse or rounded, apiculate or not and costa not excurrent

1 Lamina cell walls sinuouse or incrassate with \pm stellate lumen

- Lamina cell walls neither sinuouse nor incrassate with stellate lumen...

2 Lamina cell walls incrassate with \pm stellate lumen.

Aulacomnium (p.211)

- Lower lamina cell walls sinuose.

Grimmiaceae (p.175)

3 Leaf margins plane or incurved.

- Leaf margins recurved.

4 Lamina bistratose; capsule ovoid, asymmetric, immersed; perichaetial leaves ciliate. Diphyscium foliosum (w)

- Lamina unistratose; capsules and perichaetial leaves not as above 
5 Basal lamina cells narrowly rectangular, (14) 16-40 (50) $\times$ (5) 6-7 $\mu \mathrm{m}$; costa 20-40 $\mu \mathrm{m}$ wide at mid-leaf; leaves only 0.5 mm long, erect; capsule with annulus of large persistent cells. Gyroweisia tenuis (rr)

- $\quad$ Basal lamina cells short or long rectangular, 14-18 $\mu \mathrm{m}$ long, or if longer then costa 50-70 (90) $\mu \mathrm{m}$ wide at mid-leaf; leaves various; plants sometimes taller; annulus of small cells, persistent or falling.

Gymnostomum (p.170)

6(3) Costa homogeneous in cross section …….... Orthotrichum s.l. (incl. Lewinskya, Nyholmiella, Pulvigera) (p.203)

- $\quad$ Costa heterogeneous in cross section 7

7 Leaves ovate-lanceolate; axillary hairs of 2-8 cells, 1-2 (3) basal cells brown Didymodon (p.147)

- $\quad$ Leaves obovate, lingulate or elliptical; axillary hairs of 4-5 cells, all hyaline.

Tortula (p.166)

Group 30 Acrocarps with isodiametric cells, apex acute, subacute or acuminate, margins recurved at least on one side, costa not excurrent or lacking

1 Costa lacking. Hedwigia (p.188)

- $\quad$ Costa present

2 Upper lamina cells mamillose on both sides.

Cynodontium (p.142)

- Upper lamina cells smooth or papillose on one or both sides.

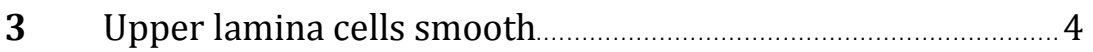

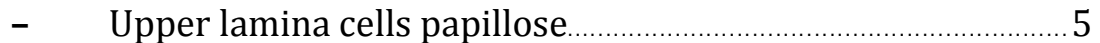

4 Leaves acute or acuminate; capsule \pm cylindrical, sulcate, strumose.

Ceratodon (p.143)

- Leaves longly acuminate; capsule ellipsoidal, smooth, not strumose. Dicranoweisia cirrata (w)

5 Marginal cells at leaf base hyaline, quadrate to shortly rectangular, with thickened walls, ascending up margin, basal cells linear. Ulota (p.203)

- Marginal basal cells different

6 Capsule immersed to emergent; calyptra glabrous or hairy.....

- $\quad$ Capsule exserted; calyptra glabrous 7

7 Stomata cryptopore. 8 Orthotrichum (p.203) 
- $\quad$ Stomata phaneropore

Lewinskya (p.203)

8 Leaves ovate, elliptical or oblong; axillary hairs completely hyaline Tortula (p.166)

- Leaves linear-lanceolate to ovate-lanceolate; axillary hairs completely hyaline or with brown basal cells

9 Axillary hairs with brown basal cells........ Didymodon (p.147)

- Axillary hairs completely hyaline.

10 Clavate or ovoid gemmae in leaf axils Hydrogonium (p. 171)

- $\quad$ Axillary gemmae lacking Streblotrichum convolutum (Barbula convoluta) (p.169)

Group 31 Acrocarps with isodiametric cells, apex acute, subacute or acuminate, margins plane or recurved at base only, costa not excurrent

1 Leaf margin entire 2

- Leaf margin crenulate or papillose-crenulate ............................. 7

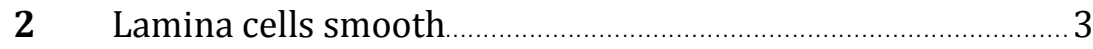

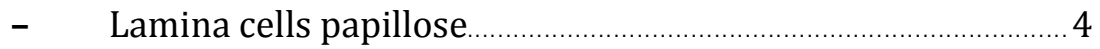

3 Peristome double; lamina cells (7) 11-20 (23) $\mu \mathrm{m}$ wide. Codonoblepharon forsteri (Zygodon forsteri) (r)

- $\quad$ Peristome simple; lamina cells 6-16 $\mu \mathrm{m}$ wide; plants to 5 $\mathrm{mm}$ tall. Campylostelium saxicola ( $\mathrm{rr}$ )

$4 \quad$ Plants rusty brown in lower part; lamina cells with c-shaped papillae. Bryoerythrophyllum recurvirostrum (w)

- Characters not as above ......................................................... 5

5 Lamina cells incrassate with \pm stellate lumen; gemmae in groups at the end of pseudopodia........Aulacomnium (p.211)

- Lamina cells not incrassate with \pm stellate lumen; without gemmae in groups at the end of pseudopodia. 6

6 Lamina cells rounded or hexagonal, strongly papillose; gemmae fusiform, pluricellular. Zygodon rupestris ( $\mathrm{r}$ )

- Lamina cells quadrate or rounded, papillose and finely longitudinally striate; gemmae lacking.

Amphidium mougeotii (r)

7(1) Leaves fragile, upper part often lost in older leaves; leaf margin irregularly erose, notched, \pm undulate or sinuose, dentate-denticulate or distinctly papillose-crenulate. 8

- $\quad$ Leaves not fragile; leaf margin neither sinuose, undulate nor notched, irregularly erose or dentate-denticulate. 
8 Leaf apex formed by a group of smooth, hyaline cells, twice as long as papillose cells below.

Chionoloma tenuirostre (Oxystegus tenuirostris) ( $\mathrm{r}$ )

- $\quad$ Leaf apex not formed by smooth, hyaline cells; dentate in young leaves or not

Didymodon

(tophaceus subsp. erosus, D. sinuosus) (p.147)

9 Leaves carinate or keeled.

- Leaves not carinate..

Hymenostylium recurvirostrum (n.s.)

10 Leaf margin bistratose above

- Leaf margin unistratose. Cynodontium (p.142) Rhabdoweisia (p.142)

Group 32 Acrocarps with lamina cells elongate, leaves acuminate or subulate and apex consisting largely or entirely of costa

1 Lamina cells mamillose. Bartramia (p.189)

- Lamina cells smooth.

2 Capsule indehiscent. 3

- Capsule dehiscent

3 Capsule exserted; neck distinct, about half the length of the urn. Bruchia flexuosa (rr)

- Capsule immersed; neck indistinct Pleuridium (p.143)

$4 \quad$ Plants to $2.5 \mathrm{~mm}$ tall; saxicolous. 5

- Plants larger; terricolous or saxicolous. 6

5 Seta arcuate when moist, straight when dry; plants growing on siliceous rocks or small calcareous stones.

Blindiadelphus (p.174)

- Seta straight when moist and dry; plants growing on calcareous rocks.

Seligeria (p.174)

6 Plants without capsules, leaves with expanded sheathing base, clasping the stem, and suddenly contracted into a narrow subula which is often squarrosely reflexed .................. 7

- $\quad$ Plants with capsules; leaves as above or otherwise _..................8

7 Subula made up of prorate cells, therefore mamillose all around, not just at margin

Trichodon cylindricus

(Ditrichum cylindricum) $(\mathrm{w})$

- Subula cells not prorate, mamillae only at margin, not all around. Dicranella schreberiana (w) 
8 Peristome teeth divided to base with filiform segments. Ditrichum, Trichodon cylindricus

(Ditrichum cylindricum) (p.143)

- Peristome teeth divided to middle. Dicranella (p.135)

Group 33 Acrocarps with lamina cells elongate, leave apex obtuse to acuminate, costa percurrent or excurrent, short or lacking

1 Protonema persistent; plants minute, to $2.7 \mathrm{~mm}$ tall

Ephemerum (p.169)

- $\quad$ Protonema not persistent; plants small to robust

2 Lamina cells mamillose; leaves dentate or serrate from base to apex (Bartramiaceae pp.).

- Lamina cells smooth or mamillose; leaves with entire margins or denticulate at apex only.

3 Leaves narrowly or linear lanceolate, with sheathing base; margin with simple teeth.

Bartramia (p.189)

- Leaves lanceolate to ovate-lanceolate, without sheathing base; margin with simple or geminate teeth.

Philonotis (p.189)

4 Lamina cells quadrate to rectangular.

- $\quad$ Lamina cells elongate hexagonal, rhomboidal or linear...........6

5 Capsule dehiscent, exserted.

Dicranella (p.135)

- Capsule indehiscent, immersed

Pseudephemerum nitidum $(\mathrm{w})$

6 Leaves appressed to erect when dry, imbricate.

Ptychostomum zieri (Plagiobryum zieri) (r)

- $\quad$ Leaves erecto-patent to spreading, rarely imbricate ................. 7

7 Lamina cells hexagonal or rhomboidal-hexagonal; costa percurrent or excurrent in long or short point

Bryum s.l. (incl. Imbribryum, Ptychostomum) (p.190)

- Lamina cells linear-hexagonal or linear-rhomboidal to vermicular; costa mostly not reaching leaf apex, rarely excurrent.

8 Leaves (except perichaetial leaves) less than 7 times as long as wide; capsule inclined or horizontal to pendulous.

Pohlia (p.198)

- $\quad$ Leaves more than 7 times as long as wide; capsule slightly inclined. Orthodontium lineare (rr) 


\section{Group 34 Pleurocarps with long costa and lamina cells short, at least at margins}

1 Leaf apex rounded Leptodon smithii (rr)

- Leaf apex obtuse, acute or acuminate.

2 Branch leaves strongly dentate; plants \pm dendroid

Thamnobryum (p.229)

- Branch leaves entire or denticulate; plants pinnately or irregularly branched ............................................................. 3

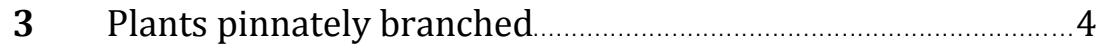

- Plants irregularly branched ...................................................... 5

4 Stem 1-pinnate ....................................... Abietinella abietina

(Thuidium abietinum) (c) (p.219)

- $\quad$ Stem 2-3-pinnate............................................ Thuidium (p.219)

5 Leaf cells smooth

- $\quad$ Leaf cells papillose or prorate ................................................... 7

6 Leaves with 2 longitudinal plicae at base, one on each side of the costa; leaf margin entire or denticulate; plants slender, often with propaguliferous branchlets at the tips of stems and branches, growing on rock or tree bark; capsules rare.......

Pseudoleskeella (p.219)

- $\quad$ Leaves not plicate; leaf margin entire; plants small, dark green, without propaguliferous branchlets, growing around water-filled knot-holes; capsules frequent, constricted below mouth when empty.

Anacamptodon splachnoides $(\mathrm{w})$

Note: For an account of this species in Hungary, see Németh and Erzberger (2015).

7 Costa extending to $1 / 2-2 / 3$ up leaf

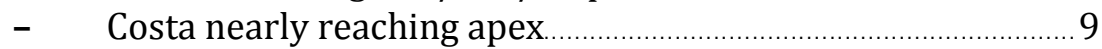

8 Stem and branch leaves strongly dimorphic; stem leaves reflexed, abruptly contracted from broad base; branch leaves slightly concave, ovate, obtuse or shortly acute.

Heterocladiella dimorpha (Heterocladium dimorphum) (rr) Note: For an account of this species in Hungary, see Baráth et al. (2016).

- $\quad$ Stem and branch leaves similar in shape, but differing in size; stem leaves erecto-patent to patent, not reflexed, gradually narrowed to acute apex.... Heterocladium heteropterum (rr) Note: For an account of this species in Hungary, see Baráth and Erzberger (2019). 
9 Leaf without longitudinal plicae; alar cells not differentiated. Anomodon s.l. (incl. Claopodium rostratum, Pseudanomodon attenuatus) (p.230)

- Leaf with 1-2 longitudinal plicae near base; alar cells differentiated

10 Leaf cells smooth or prorate

Lescuraea saviana (Pseudoleskea saviana) (rr)

- Leaf cells with a single central papilla each on the dorsal side

Leskea polycarpa (cc)

Group 35 Pleurocarps with longitudinally plicate leaves, costa long and lamina cells elongate

1 Plants dendroid Climacium dendroides $(\mathrm{w})$

- Plants irregularly or pinnately branched 2

2 Branch leaves with reflexed teeth at apex

- Branch leaves without reflexed teeth at apex............................ 3

3 Stem with paraphyllia

- Stem without paraphyllia $\quad$........................................................ 6

4 Stems regularly pinnately branched; alar cells inflated or not

- Stems irregularly branched, alar cells not inflated, not hyaline............ Lescuraea saviana (Pseudoleskea saviana) (rr)

5 Paraphyllia linear to linear-lanceolate; alar cells inflated, hyaline Palustriella (p.214)

- Paraphyllia branched; alar cells not differentiated.

Helodium blandowii (n.s.)

6 Stem leaves straight or only slightly falcate.............................

- Stem leaves strongly falcate................................................... 12

7 Plants very small and slender; leaves with two superficial longitudinal plicae near base..............Pseudoleskeella (p.219)

- $\quad$ Plants medium-sized to robust.

8 Stem with reddish or brownish tomentum of papillose rhizoids. Tomentypnum nitens ( $\mathrm{rr}$ )

- $\quad$ Stem without tomentum.

9 Stem leaves triangular, gradually tapering into long fine point ....................................................... Homalothecium (p.222)

- Stem leaves ovate to lanceolate, gradually or abruptly tapering into long or short point. 
10 Stem leaves ovate-lanceolate, gradually acuminate; costa of branch leaves ending in a dorsal projection or not; lid conical...... Brachythecium s.l. (incl. Sciuro-hypnum) (p.223)

- $\quad$ Stem leaves ovate to lanceolate, sometimes cordate at base; costa usually ending in a projection at dorsal side of branch leaves; lid longly rostrate.

11 Alar cells quadrate, incrassate, opaque, reaching costa.

. Plasteurhynchium striatulum

(Eurhynchium striatulum) (w)

- $\quad$ Alar cells rectangular, thin-walled, not reaching costa.

12(6) Stem with hyalodermis; alar cells inflated, hyaline

Eurhynchium (p.220)

Sanionia uncinata $(\mathrm{r})$

- Stem without hyalodermis; alar cells not differentiated

Hamatocaulis vernicosus $(\mathrm{rr})$

Group 36 Pleurocarps with squarrose or falcate leaves, long costa and elongated lamina cells

1 Leaves conspicuously transversely undulate.

Rhytidium rugosum (w)

- Leaves not transversely undulate.

2 Leaf apex acute or obtuse.

Hygrohypnum luridum $(\mathrm{w})$

- Leaf apex acuminate

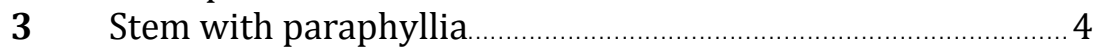

- $\quad$ Stem without paraphyllia ………………………………………. 5

4 Alar cells well developed, inflated, hyaline.

- $\quad$ Alar cells neither inflated nor hyaline.

Cratoneuron filicinum $(\mathrm{w})$

Lescuraea saviana (Pseudoleskea saviana) (rr)

5 Leaf acumen channelled.

- $\quad$ Leaf acumen not channelled .................................................... 7

6 Plants growing in dry calcareous habitats; stem leaves to 1.7 mm long; alar cells slightly inflated, the widest cells 10.517.5 (21) $\mu \mathrm{m}$ wide Campyliadelphus chrysophyllus (Campylium chrysophyllum) (w)

- $\quad$ Plants growing in wetlands; stem leaves at least 1.3-1.6 mm long; alar cells strongly inflated, the widest cells 17-31.5 $\mu \mathrm{m}$ wide.

Drepanocladus polygamus (Campylium polygamum) (r) 
7 Leaf margin distinctly denticulate, at least near apex Sarmentypnum exannulatus (Warnstorfia exannulata) (rr)

- $\quad$ Leaf margin entire or obscurely denticulate. 8

8 Group of alar cells large, of 2-4 rows of cells, ascending up margin and sometimes reaching costa.

Drepanocladus (p.215)

- $\quad$ Group of alar cells small, of 2-10 cells, not ascending up margin and not reaching costa.

Scorpidium cossonii (Drepanocladus cossonii) (rr)

Group 37 Pleurocarps with long costa, elongated lamina cells and rounded, obtuse, or obtuse and apiculate apex

1 Costa more than $40 \mu$ m wide.

Hygroamblystegium fluviatile (Amblystegium fluviatile) (r)

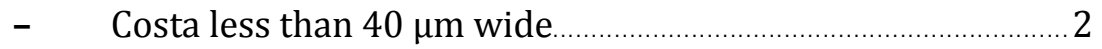

2 Group of alar cells well differentiated............................... 3

- Group of alar cells not or hardly differentiated .......................5

3 Alar cells small, opaque................................. Isothecium (p.229)

- $\quad$ Alar cells large, inflated and hyaline ........................................... 4

4 Leaves ovate-cordate; costa reaching apex or nearly so; group of alar cells triangular, nearly reaching costa, not ascending up margins; axillary hairs frequent, long, with 2-5 apical hyaline cells......................................... Calliergon (p.218)

- $\quad$ Leaves oblong or ovate; costa reaching 3/4 up leaf; group of alar cells ovate, extending up margin; axillary hairs scarce and short, with 2-3 apical hyaline cells; leaf apex often with rhizoids.

Straminergon stramineum (Calliergon stramineum) (rr)

5 Stems pinnately branched; lid conical.

Pseudoscleropodium purum (Scleropodium purum) (c)

- Stems irregularly branched; lid longly rostrate.

Rynchostegium (p.220) 


\section{Group 38 Pleurocarps with long costa, elongated lamina cells and acute or acuminate apex}

1 Branch leaves with reflexed teeth at apex

- Branch leaves without reflexed teeth at apex.

Antitrichia curtipendula (r)

2 Leaf margins dentate to ciliate or laciniate..Fabronia (p.214)

- $\quad$ Leaf margins entire to denticulate............................................. 3

3 Lamina cells 2-6 (7) times as long as wide ............................ 4

- $\quad$ Lamina cells more than 7 times as long as wide ........................ 9

4 Alar cells hyaline, inflated, forming a distinct group.

- $\quad$ Alar cells forming a poorly differentiated group ........................ 5

$5 \quad$ Margins at leaf base with \pm recurved teeth; sometimes with rhizoids on dorsal side of costa; plants small.

Conardia compacta (r)

- Margins at leaf base without recurved teeth; never with rhizoids on dorsal side of costa; plants small to mediumsized

6 Costa ending in conspicuous projection at the dorsal side of branch leaves; plants small.......Microeurhynchium pumilum

(Eurhynchium pumilum) (r)

- Costa not ending in projection at the dorsal side of branch leaves

7 Costa 25-75 (100) $\mu \mathrm{m}$ wide, reaching mid-leaf or above

Hygroamblystegium (p.216)

- $\quad$ Costa 15-35 (40) $\mu \mathrm{m}$ wide, reaching above mid-leaf or not....

8 Costa reaching mid-leaf or shorter (in A. serpens often longer), sometimes double or lacking, capsules not constricted below mouth when empty; habitat various (incl. knot-holes).

Amblystegium group (p.216)

- Costa reaching to leaf apex; plants small, dark green, growing around water-filled knot-holes; capsules frequent, constricted below mouth when empty.

Anacamptodon splachnoides (w)

Note: For an account of this species in Hungary, see Németh and Erzberger (2015).

9(3) Alar cells hyaline, inflated. 10

- $\quad$ Alar cells neither hyaline nor inflated 
10 Leaves acuminate. Drepanocladus (p.215)

- Leaves acute Brachythecium (p.223)

11 Alar cells small, opaque, incrassate; branches usually curved Isothecium (p.229)

- $\quad$ Alar cells different; branches \pm straight

12 Leaf acumen channelled. Campyliadelphus (p.215)

- Leaf acumen not channelled or leaves acute. 13

13 Stem and branch leaves differentiated (heteromorphous) 14

- $\quad$ Stem and brach leaves similar (homomorphous) 15

14 Stem regularly pinnately branched; seta rough.

Kindbergia praelonga (Eurhynchium praelongum) (r)

- $\quad$ Stem irregularly branched; seta smooth.

Eurhynchiastrum pulchellum

(Eurhynchium pulchellum) (w)

15 Costa ending in conspicuous projection at the dorsal side of branch leaves.

Note: In Oxyrrhynchium speciosum this character is only occasionally developed.

- Costa not ending in projection at the dorsal side of branch leaves or projection inconspicuous..

16 Leaves ovate to ovate-lanceolate, shortly acuminate; lid longly rostrate.

Oxyrrhynchium (p.221)

- $\quad$ Leaves lanceolate to ovate-lanceolate, longly acuminate; lid conical.

Brachythecium s.l.

(incl. Brachytheciastrum, Sciuro-hypnum) (p.223)

17 Leaves abruptly contracted or gradually narrowed into large, filiform acumen; axillary hairs with 3 short basal and 2 longer apical cells.

Cirriphyllum (p.221)

- Leaves not abruptly contracted into large acumen; axillary hairs with 1-2 basal cells

18 Plants small; leaves linear-lanceolate or narrowly oblonglanceolate.

Rhynchostegiella (p.222)

- Plants medium-sized or large; leaves lanceolate, ovate, oblong or triangular.

19 Shoots subcomplanate; plants aquatic

Leptodictyum riparium (c)

- Shoots not subcomplanate; plants aquatic or not.

20 Lid longly rostrate.

Rhynchostegium (p.220)

- Lid conical.

Brachythecium s.l. (incl. Sciuro-hypnum) (p.223) 


\section{Group 39 Pleurocarps with short or lacking costa, short lamina cells at least at margin}

1 Leaves longitudinally plicate. Leucodon sciuroides (c)

- Leaves with two short longitudinal plicae at base or not longitudinally plicate.

2 Lamina cells papillose; small to medium-sized plants.............. 3

- $\quad$ Lamina cells smooth; slender plants

Pseudoleskeella (p.219)

3 Plants \pm dendroid; upper branches curved when dry Nogopterium gracile (Pterogonium gracile) (n.s.)

- $\quad$ Plants not dendroid; branches not curved when dry ............... 4

4 Stem leaves very concave, imbricate; plants julaceous Myurella julacea $(\mathrm{r})$

- Stem leaves plane or slightly concave, patent to squarrose, not imbricate; plants not julaceous.

$5 \quad$ Stem and branch leaves strongly dimorphic; stem leaves reflexed, abruptly contracted from broad base; branch leaves slightly concave, ovate, obtuse or shortly acute. Heterocladiella dimorpha (Heterocladium dimorphum) (rr) Note: For an account of this species in Hungary, see Baráth et al. (2016).

- Stem and branch leaves similar in shape, but differing in size; stem leaves erecto-patent to patent, not reflexed, gradually narrowed to acute apex

Heterocladium heteropterum (rr)

Note: For an account of this species in Hungary, see Baráth and Erzberger (2019).

Group 40 Pleurocarps with short or lacking costa, elongated lamina cells and rounded, obtuse or apiculate apex

1 Lamina cells prorate on dorsal side; plants small.

Pterigynandrum filiforme $(\mathrm{w})$

- $\quad$ Lamina cells smooth; plants \pm robust

2 Stem and branch tips conspicuously cuspidate.

Calliergonella cuspidata $(\mathrm{w})$

- Stem and branch tips not conspicuously cuspidate................... 3

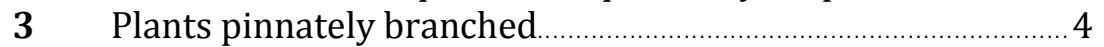

_ Plants irregularly branched ..................................................... 5 
4 Stems reddish; alar cells orange to brown

Pleurozium schreberi (w)

- Stems greenish, yellowish or light brown; alar cells hyaline or greenish

Entodon concinnus (rr)

5 Leaves longly decurrent; plants not aquatic.

- Leaves not or scarcely decurrent; aquatic plants

Plagiothecium (p.212)

6 Plants robust, turgid; alar cells hyaline, large, forming a welldelimited small group; plants growing on water-logged soil...

Scorpidium scorpioides ( $\mathrm{rr}$ )

- Plants small to medium-sized, not turgid; alar cells not hyaline, not in well-delimited group; plants on rock or stones in streams.

Hygrohypnum luridum (w)

Group 41 Pleurocarps with distinctly falcate or squarrose leaves, short or lacking costa, elongated lamina cells and acute or acuminate apex

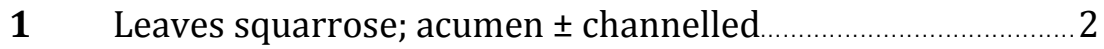

- $\quad$ Leaves not squarrose; acumen flat …………………………..... 4

2 Stems reddish ...................................... Rhytidiadelphus (p.228)

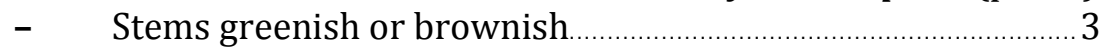

3 Plants medium-sized to robust; margins entire to finely denticulate; alar cells inflated, well-differentiated

Campylium (p.215)

- Plants small; margins dentate; alar cells poorly differentiated.

\section{Campylophyllopsis calcarea (Campylium calcareum) (w)}

4(1) Leaf apex acute; aquatic plants ..........................................5

- Leaf apex acuminate; plants not aquatic .................................. 6

5 Plants robust, alar cells hyaline, large, forming a welldelimited small group; plants growing on water-logged soil...

Scorpidium scorpioides ( $\mathrm{rr}$ )

- Plants small to medium-sized, not turgid; alar cells not hyaline, not in well-delimited group; plants on rock or stones in streams.

Hygrohypnum luridum (w)

6 Leaves wide and shortly acuminate; stems with hyalodermis Calliergonella lindbergii (Hypnum lindbergii) (w)

- Leaves narrowly and longly acuminate; stems without hyalodermis. 
7 Leaves strongly longitudinally plicate; plants pinnately branched. Ptilium crista-castrensis (rr)

- $\quad$ Leaves not or weakly longitudinally plicate; plants pinnately branched or not

8 Leaves cordate at base; branch leaves differing from stem leaves; plants pinnately branched

Ctenidium molluscum (w)

- Leaves not cordate at base, branch leaves similar to stem leaves; plants irregularly or pinnately branched.

Hypnum s.l. (incl. Buckia vaucheri) (p.227)

Group 42 Pleurocarps with straight, slightly falcate or squarrose leaves, costa single, short, long and double, or lacking, elongated lamina cells and acute or acuminate apex

1 Lamina cells distinctly papillose or prorate on dorsal side.......

- Lamina cells smooth or only slightly prorate on dorsal side....

2 Plants slender, filiform...... Pterigynandrum filiforme $(\mathrm{w})$

- Plants robust, not filiform. 3

3 Stems regularly bi-tripinnate, costa double, reaching $1 / 2$ of leaf length. Hylocomium splendens $(\mathrm{w})$

- $\quad$ Stems irregularly branched; costa double, reaching 3/4 of leaf length. Hylocomiadelphus triquetrus (Rhytidiadelphus triquetrus) (w)

4(1) Plants aquatic; leaves carinate or not ..........Fontinalis (p.211)

- Plants not aquatic; leaves not carinate $\quad$................................... 5

5 Lamina cells 2-5 times as long as wide; slender plants..........6

- $\quad$ Lamina cells more than 5 times as long as wide; plants small to robust.

6 Leaves with 2 longitudinal plicae at base, on each side of the costa; lamina cells shorter at margin.

Pseudoleskeella (p.219)

- Leaves not plicate; lamina cells \pm homogeneous.

7 Leaf margin entire.

Amblystegium group (p.216)

- Leaf margin denticulate, dentate or ciliate.

8 Leaf margin denticulate Platydictya jungermannioides ( $\mathrm{rr}$ )

- Leaf margin distinctly dentate or ciliate......Fabronia (p.214)

9(5) Leaves squarrose or spreading to reflexed. 
- $\quad$ Leaves erect to patent.

10 Plants small; leaves to $1 \mathrm{~mm}$ long, spreading to reflexed

Campylophyllopsis calcarea (Campylium calcareum) (w)

- $\quad$ Plants robust, leaves 2.7-3.7 mm long, squarrose.

11 Stem with branched paraphyllia

Rhytidiadelphus squarrosus (w)

Loeskeobryum brevirostre (Hylocomium brevirostre) (n.s.)

- Stem without paraphyllia, but sometimes with linear

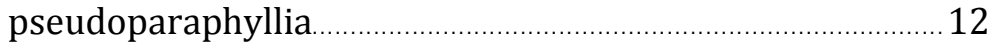

12 Alar cells poorly or not differentiated ……………………...13

- $\quad$ Alar cells \pm well developed, at least in small group of (2) 3-6 cells.

13 Plants robust, julaceous, glossy; leaves ovate, shortly pointed, concave; leaf margin distinctly denticulate, particularly near apex.

Taxiphyllum densifolium (w)

- $\quad$ Plants small to robust, not julaceous, glossy; leaves linear lanceolate, longly acuminate, not or slightly concave; leaf margin entire or slightly denticulate, sometimes near base only...

14 Basal cells usually porose, often brownish; axillary hairs with hyaline basal cell.

Orthothecium (p.214)

- Basal cells not or slightly porose, concolorous with the rest of cells; axillary hairs with brown basal cell.

15 Alar cells inflated.

Isopterygiopsis pulchella $(\mathrm{r})$

- Alar cells not inflated

16 Stem with hyalodermis. 18

- $\quad$ Stem without hyalodermis

Calliergonella (p.228)

17 Plants medium-sized to robust; capsule erect to slightly inclined, curved below mouth; lid conical to shortly rostrate, 0.8-1 mm long; linear pseudoparaphyllia in leaf axils.

\section{Callicladium haldanianum (rr)}

- $\quad$ Plants small; capsule \pm erect; lid including beak 0.5-0.6 mm long, very longly rostrate, beak $0.28-0.36 \mathrm{~mm}$ long, longer than conical basal part of lid; without pseudoparaphyllia.

\section{Sematophyllum adnatum (rr)}

18 Alar cells small, opaque; branches usually curved Isothecium (p.229)

- $\quad$ Alar cells different; branches straight. 
19 Group of alar cells concave, of incrassate cells

Hypnum s.l. (incl. Buckia vaucheri) (p.227)

- Group of alar cells not concave, of thin-walled or incrassate cells.

20 Leaf margin denticulate from base to apex

Herzogiella seligeri $(\mathrm{w})$

- $\quad$ Leaf margin entire or denticulate only near apex

21 Central strand distinct; external surface of exostome teeth smooth at base; corticole, rarely saxicole.

Pylaisia polyantha (cc)

- Central strand indistinct; external surface of exostome teeth papillose or striate-papillose at base; corticole or saxicole.

22 Leaf margin narrowly recurved in lower 2/3; plants usually with propaguliferous branchlets at the tip of branches; capsule straight; corticole.

Platygyrium repens $(\mathrm{cc})$

- Leaf margin plane; plants without propaguliferous branchlets; capsule curved; saxicole.

Homomallium incurvatum (w) 


\section{PART II: SPECIAL KEYS}

\section{KEYS TO SPECIES OF LIVERWORTS}

\section{Key to species of Barbilophozia group, incl. Neoorthocaulis floerkei}

See also key to Lophoziaceae group below

1 Lateral leaves mostly 3-4 (5)-lobed (occasionally 2-lobed leaves may occur).................................................................. 2

- Lateral leaves mostly 2-lobed, apex lobed only to 1/3; underleaves present, small, entire, often difficult to detect; lateral leaves rounded, sinus semi-lunate; gemmae reddishbrown, walls \pm solid; leaves sometimes with erosed margins caused by the production of gemmae; on non-calcareous rocks and soil

Barbilophozia sudetica (Lophozia sudetica) (rr) Note: This species can be recognised by clusters of red-brown ripe gemmae in combination with shallowly notched, concave leaves and small leaf cells 24-25 × 18-20 $\mu \mathrm{m}$ with (4) 6-9 (15) oil bodies per cell. Lophoziopsis excisa, which also produces red gemmae, differs by larger leaf cells, 30-35 (40) × (27) 28-30 (32) $\mu \mathrm{m}$ and more numerous oil bodies, 11-24 (28) per cell. Lophoziopsis longidens, another species with clusters of red gemmae at the tip of the leaf lobes, has also large cells, 28$35 \times 23-27(30) \mu \mathrm{m}$, but fewer oil bodies, 4-10 (14) per cell.

2 Postical margins of lateral leaves with basal cilia; underleaves present

- $\quad$ Postical margins of lateral leaves without cilia; underleaves absent; leaves (2) 4 (5)-lobed, lobes unequal; trigones small; shoots 3-8 $\mathrm{cm}$ long and up to $5 \mathrm{~mm}$ wide, procumbent.

Barbilophozia barbata $(\mathrm{w})$

3 Cells of cilia subquadrate, 15-30 (38) $\mu \mathrm{m}$ long; lateral leaves lobed to $1 / 3$ with (2) 3 (4) obtuse or acute lobes; shoots mostly ascending to erect; rarely with gemmae

Neoorthocaulis floerkei (Barbilophozia floerkei) Note: excluded - the voucher was collected in Austria.

- Cells of cilia on underleaves and base of lateral leaves elongate, 20-80 $\mu \mathrm{m}$ long or more; gemmae usually present.... 


\section{Key to species of Cephaloziaceae}

Based mainly on Damsholt (2002)

1 Lateral leaves asymmetrical, with 2 long acuminate lobes (47 uniseriate cells); postical margin strongly inflexed and forming inflated water sac; on rotting wood

Nowellia curvifolia $(\mathrm{w})$

- Lateral leaves not or only slightly asymmetrical; postical margin not inflexed, not forming sac ......................................... 2

2 Leaves longer than wide, divided $0.5-0.7$ of length, not decurrent, almost transversely inserted or not.

- $\quad$ Leaves as wide as long, divided 0.25-0.5 of length, often decurrent, obliquely to horizontally inserted; stem on mature leafy shoots with antical leaf-free zone 2 cells wide....

3 Leaves obliquely to horizontally inserted, 4-7 cells wide; cells at base of lobes $40-50 \times 20-45 \mu \mathrm{m}$; plants whitish, small, shoots $0.4-0.6 \mathrm{~mm}$ wide; perianth mouth laciniate; dioicous

Cephalozia lacinulata (n.s.)

- Leaves almost transversely inserted, non-decurrent, 8-16 cells wide; cells at base of lobes 30-70 $\times 25-50 \mu \mathrm{m}$; plants often with secondary pigmentation, large to medium-sized, shoots 0.6-1.2 mm wide; perianth mouth denticulate, with teeth formed by 1-3 superimposed cells; autoicous; stem with antical end of leaf insertion extending to median cortical cells, sometimes almost to the antical mid-line (except in fertile or gemmiferous shoots); flagelliform shoots often present ....................Cephalozia bicuspidata $(\mathrm{w})$

4 Cells at base of lobes 18-36 × 16-35 $\mu \mathrm{m}$, thin- or thickwalled; stolons lacking

- $\quad$ Cells at base of lobes (35) 40-55 (70) × (28) 33-48 $\mu \mathrm{m}$, thin-walled; plants often with stolons; leaves usually $12-25$ cells wide; apical cell on leaf lobes with wall not thickened at apex; autoicous; perianth mouth crenulated

Fuscocephaloziopsis pleniceps (Cephalozia pleniceps) (n.s.)

5 Leaves decurrent, lobes strongly connivent; cells at base of lobes 26-32 (40) × 20-28 (32) $\mu \mathrm{m}$; plants green, stem concolorous; leaves mostly (7) 9-14 (16) cells wide; apical cell on leaf lobes with wall thicker at apex than on margins; dioicous; female bracts entire; perianth mouth shortly lobed, 
the lobules crenulate-dentate with teeth 1-2 cells long. Fuscocephaloziopsis lunulifolia (Cephalozia lunulifolia) (n.s.)

- Leaves shortly decurrent, not or barely connivent; cells at base of lobes 20-35 × 15-30 $\mu \mathrm{m}$; plants green to olive-green or yellowish brown, stem often also somewhat yellowish brown; leaves (12) 13-16 cells wide or wider

6 Cells at base of lobes 20-25 × 15-18 $\mu$ m, thick-walled; apical cell on leaf lobes with wall not thickened at apex; dioicous; perianth mouth laciniate.....Fuscocephaloziopsis catenulata

(Cephalozia catenulata) (n.s.)

- $\quad$ Cells at base of lobes 28-35 × 20-30 $\mu$ m, thin-walled; apical cell on leaf lobes with wall thicker at apex than on margins; dioicous; female bracts dentate; perianth mouth dentate, not laciniate

Fuscocephaloziopsis macrostachya

(Cephalozia macrostachya) (n.s.)

\section{Key to species of Cephaloziella}

Important literature: Meinunger and Schröder (2007): Vol. 1: 176-200

1 Gemmae 2-celled, cubic, angulate or with warty elevations. Cephaloziella integerrima (n.s.)

- Gemmae 2-celled, elliptical, smooth or gemmae lacking .........2

2 Dioicous, often sterile; underleaves distinct; leaf cells small, 8-12 $\mu \mathrm{m}$ Cephaloziella divaricata $(\mathrm{w})$ Note: C. divaricata var. scabra (M. Howe) Haynes (rr) is doubtfully distinct from the typical variety and can be recognized by denticulate leaf margins, a verruculose cuticula and \pm strong papilla-like outgrowths below the sinus on the abaxial surface of upper leaves.

- $\quad$ Monoicous, mostly fertile

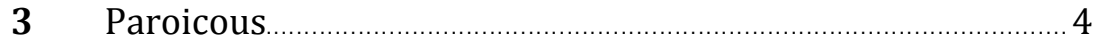

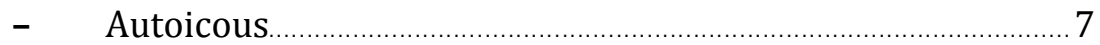

4 Sterile shoots with distinct, often large and 2-lobed underleaves. Cephaloziella stellulifera (n.s.).......................... 5

- Sterile shoots without underleaves, but occasionally with rudimentary underleaves consisting of 2 or 3 cell rows towards the shoot apex; cells 10-16 $\mu \mathrm{m}$ wide, in lower part of leaf lobes cells of regular rectangular shape; leaf lobes only 4-5 cells wide at base. Cephaloziella rubella agg. (w) pp. 
5 Cells large, 14-20 $\mu \mathrm{m}$ wide; leaves entire, patent to squarrose; female bracts partly in stellate arrangement.

Cephaloziella stellulifera var. stellulifera

- $\quad$ Cells smaller, narrower, 10-15 $\mu$ m wide; leaf lobes 4-9 cells wide at base; underleaves small and indistinct except in gametangiophores; plants light to yellowish green, in insolated situations also brownish, only perianths and male bracts occasionally with a light reddish hue; similar to $C$. varians, but paroicous.

Cephaloziella stellulifera var. limprichtii

6 Female bracts often connate forming a ring around perianth base, urn-like and extending far upward

Cephaloziella rubella var. rubella

- Female bracts more deeply divided nearly to base, not forming an urn around the base of the perianth (Boros 1968: on rotting wood, Bükk, Vértes)

Cephaloziella rubella var. sullivantii

7 Sterile shoots without underleaves

- $\quad$ Sterile shoots with distinct underleaves, at least towards shoot apex; cells medium-sized to small, 7-14 $\mu$ m wide.......13

8 Cells large, 14-20 $\mu \mathrm{m}$ wide.

- Cells medium-sized, 10-15 mm wide.

9 Female bracts with rounded, entire, often somewhat undulate lobes; perianth pyriform, free.

Cephaloziella integerrima (n.s.)

- $\quad$ Female bracts with acute, \pm dentate lobes.................................10

10 Plants light to pale green, in insolated places \pm brownish; cell walls always thin to moderately thickened; leaf lobes 6-10 cells wide at base. Cephaloziella hampeana var. subtilis

- $\quad$ Plants at least partly red, especially the male bracts often deeply purplish to blackish red; cells thin- or thick-walled; female bracts often coarsely to squarrosely dentate; cells of perianth mouth conspicuously elongate; leaf lobes 4-6 cells wide at base ............. Cephaloziella rubella var. pulchella (rr)

11 Plants in calcareous habitats; [perhaps to be expected in Hungary, but not yet recorded].

Cephaloziella baumgartneri

- $\quad$ Calcifuge species.......................................................................... 12

12 Plants pale green, in open places partly brownish; cells always thin-walled; leaf lobes $6-10$ cells wide at base; in well 
developed plants cells of perianth mouths free for half their length, perianth mouth therefore denticulate

\section{Cephaloziella hampeana (rr)}

- $\quad$ Plants \pm reddish, especially male bracts mostly strongly red brown; cell walls partly distinctly to strongly thickened; leaf lobes 4-6 cells wide at base; even in well developed plants cells of perianth mouth fused together for nearly all their length, perianth mouth therefore crenulated.

Cephaloziella rubella var. bifida

13(7) Leaf lobes mostly 2-5 cells wide at base, mostly long and narrow, occasionally with a few teeth; cells mostly distinctly, sometimes strongly thickened, often papillose; older and insolated parts of plants often conspicuously coppercoloured; calcifuge, in bogs, on peat and humid, lime-free sand (Boros 1968: on rotting wood, Zemplén, Bükk)

Cephaloziella spinigera (n.s.)

- $\quad$ Leaf lobes 6-12 cells wide at base, shorter and wider than in the preceding species, mostly entire; cells mostly thin-walled to moderately thickened; plants green, yellowish, brown or red, not conspicuously copper-coloured; in base-rich, \pm calcareous habitats. Cephaloziella varians agg.

14 Stem at apex partly with a few hyaline teeth; leaves partly denticulate; cells at leaf base with conical mamilla on the dorsal side Cephaloziella varians var. scabra

- Stem and leaves smooth, without such outgrowths 15

15 Leaf lobes ovate, rounded at apex; male inflorescences julaceous, club-shaped. Cephaloziella varians var. arctica

- $\quad$ Leaf lobes pointed, often with two uniseriate cells at apex; male inflorescences mostly with homomallous leaves.

Cephaloziella varians var. varians $(\mathrm{rr})$

Key to Lophoziaceae group (incl. Barbilophozia, Isopaches, Lophozia, Lophoziopsis, Mesoptychia, Neoorthocaulis, Obtusifolium, Schistochilopsis, Trilophozia and Tritomaria)

Important references: Meinunger and Schröder (2007), Bakalin (2016)

1 Lateral leaves mostly 3-4 (5)-lobed (occasional 2-lobed leaves may occur in some species). 
- $\quad$ Lateral leaves mostly 2-lobed, apex rarely emarginate or only shallowly 2-lobed (occasional 3-4 (5)-lobed leaves may occur in some species).

2 Lateral leaves obliquely inserted, mostly symmetrical or only weakly asymmetrical, (2) 3-4 (5)-lobed with sinus (1/8) 1/4-1/3 leaf length; postical leaf margins with or without basal cilia; underleaves distinctly and deeply divided into 2 lobes or absent or minute except on fertile shoots; gemmae rare, mostly absent. Barbilophozia

- Lateral leaves \pm transversely inserted, distinctly asymmetrical, (2) 3-lobed with sinus to 1/4 leaf length; postical leaf margins without basal cilia; underleaves mostly absent or undivided; postical surface of stem sometimes brown or red (in Trilophozia quinquedentata).......................... 5

3 Postical margins of lateral leaves with basal cilia; underleaves present. 4

- $\quad$ Postical margins of lateral leaves without cilia; underleaves absent; leaves (2) 4 (5)-lobed, lobes unequal; trigones small; shoots 3-8 $\mathrm{cm}$ long and up to $5 \mathrm{~mm}$ wide, procumbent.

\section{Barbilophozia barbata (w)}

4 Cells of cilia subquadrate, 15-30 (38) $\mu \mathrm{m}$ long; lateral leaves lobed to $1 / 3$ with (2) 3 (4) obtuse or acute lobes; shoots mostly ascending to erect; rarely with gemmae

Neoorthocaulis floerkei (Barbilophozia floerkei) Note: excluded - the voucher was collected in Austria.

- Cells of cilia on underleaves and base of lateral leaves elongate, 20-80 $\mu \mathrm{m}$ long or more; gemmae usually present....

Barbilophozia hatcheri ( $\mathrm{rr}$ )

5 Leaf lobes mostly narrowly triangular; leaf cells with equally thickened walls; reddish gemmae nearly always present, often abundant and conspicuous 6

- Leaf lobes mostly broadly ovate-triangular; leaf cells with coarse trigones; lateral leaves as long as wide, 3-lobed in unequal lobes; lobes acute to acuminate or apiculate; gemmae rare, often sparse and inconspicuous

Trilophozia quinquedentata

(Tritomaria quinquedentata) ( $\mathrm{r}$ )

6 Mid-leaf cells averaging 19-22 $\mu$ m wide; gemmae obtusely angled or pyriform, 14-22 $\mu \mathrm{m}$ wide, $16-28 \mu \mathrm{m}$ long..

Tritomaria exsectiformis (n.s.) 
- $\quad$ Mid-leaf cells averaging 10-14 $\mu \mathrm{m}$ wide; gemmae ellipsoid, smooth, 8-12 $\mu \mathrm{m}$ wide, 12-19 (22) $\mu \mathrm{m}$ long

Tritomaria exsecta ( $\mathrm{r}$ )

7(1) Perianths often present, plicate in the upper 1/3; gemmae often present, angulate in Hungarian species; underleaves mostly absent; plants generally on non-calcareous substrates (but Obtusifolium obtusum and Lophoziopsis excisa tolerating lime or base-rich substrates).........................8

- $\quad$ Perianths absent, or without plicae; gemmae absent or if present then smooth (in Mesoptychia heterocolpos with attenuate shoots); underleaves present or if absent then lateral leaves with blunt to rounded lobes (Gymnocolea inflata: calcifuge; Mesoptychia badensis: calciphile)...

8 Cells of lateral leaves mostly equally thick-walled; capsule wall 2-layered; paroicous; lateral leaves closely imbricate, 2lobed to 1/5-1/3; plants smelling of cedar oil when crushed; frequently with abundant gemmae, reddish yellow to reddish brown; on sandy or peaty acid soil, occasionally on rocks. Isopaches bicrenatus (Lophozia bicrenata) (w) Note: This species often produces abundant perianths with a long-dentate mouth, cilia to 3-4 cells long, whereas the perianth mouth of Lophoziopsis excisa, with which it might be confused, is crenulate, at most with short finger-shaped marginal cells.

- $\quad$ Cells of lateral leaves mostly thin-walled; trigones present or not; capsule-wall 3-4-layered; plants not aromatic.

9 Lobes of lateral leaves mostly obtuse, sinus gibbous; young stems with lanceolate or 2-lobed underleaves; gemmae rare, mostly 2-celled, polygonous; lime-tolerant

Obtusifolium obtusum (Lophozia obtusa) (n.s.)

- Plants lacking this combination of characters; leaf lobes acute, rarely obtuse (in Lophozia wenzelii).

10 Lateral leaves 2-3 (5)-lobed to $1 / 3-1 / 2$, lobes dentate to spinose dentate; upper lateral leaves somewhat plicate and crispate; underleaves absent on sterile shoots; gemmae usually abundant, 1-2-celled; bright to pale green plants on rotting wood and acid soil, peat, in rock crevices and among other bryophytes

Schistochilopsis incisa (Lophozia incisa) (n.s.)

- $\quad$ Plants lacking this combination of characters 
11 Underleaves present, small, entire, often difficult to detect; lateral leaves rounded, lobed only to $1 / 3$; sinus semi-lunate; gemmae reddish-brown, walls \pm solid; leaves sometimes with erosed margins caused by the production of gemmae; on non-calcareous rocks and soil

Barbilophozia sudetica (Lophozia sudetica) (rr) Note: This species can be recognised by clusters of red-brown ripe gemmae in combination with shallowly notched, concave leaves and small leaf cells 24-25 × 18-20 $\mu \mathrm{m}$ with (4) 6-9 (15) oil bodies per cell. Lophoziopsis excisa, which also produces red gemmae, differs by larger, thin-walled leaf cells, 30-35 (40) $\times(27) 28-30$ (32) $\mu \mathrm{m}$ and more numerous oil bodies, 11-24 (28) per cell. Lophoziopsis longidens, another species with clusters of red gemmae at the tip of the leaf lobes, has also large cells, 28-35 × 23-27 (30) $\mu \mathrm{m}$, but fewer oil bodies, 4-10 (14) per cell.

- Underleaves absent on sterile stems; lateral leaves 2-lobed, occasionally 3-lobed; mid-leaf cells 20-30 (40) $\mu \mathrm{m}$; oilbodies 4-8 (9) $\mu \mathrm{m}$, smooth or granular, 8-24 per cell; lobes of female bracts mostly entire (except in Lophoziopsis excisa); stems 10-24 cells high in cross section; cells of medulla clearly differentiated, with antical band of wide hyaline cells and postical band of small cells infected with mycorrhiza; epidermal (cortical) cells often larger than cells of medulla.

12 Plants small, 3-6 (8) $\mathrm{mm}$ long and $0.8 \mathrm{~mm}$ wide, suberect, decumbent and ascending; apical leaves constantly with pale green, angulate gemmae 18-20 $\mu \mathrm{m}$; lateral leaves ovate to oblong, with narrow, often horn-like lobes; trigones triangular, colourless; on rotting wood.

\section{Lophozia ascendens $(\mathrm{rr})$}

- Plants larger; mostly on soil, humus, peat, rocks, occasionally on wood.

13 Apical leaves often imbricate; shoot apex resembling miniature lettuce; lateral leaves asymmetrical, lobed to $1 / 4$; leaf cells thin-walled, trigones small or absent; paroicous; perianths common, mouth dentate, but cilia absent; gemmae frequent, reddish, angulate, on young leaves.

Lophoziopsis excisa (Lophozia excisa) (w) Note: See the notes under Barbilophozia sudetica and Isopaches bicrenatus above.

- $\quad$ Plants lacking this combination of characters 14 
14 Lower lateral leaves often somewhat reflexed, upper with narrow horn-like lobes bearing globose clusters of reddishbrown gemmae; trigones small.

Lophoziopsis longidens (Lophozia longidens) (r) Note: See note under Barbilophozia sudetica above.

- Plants lacking this combination of characters. 15

15 Cross section of stem in postical half with 5-20 layers of small cells reaching or extending beyond the middle

- Cross section of stem in postical half with 0-4 layers of small cells reaching at most to lower third

16 Group of small cells infected by mycorrhiza yellowish brown to brown, mostly only the postical cortex cells purplish-red; sometimes also the lower cell layers purplish-red, but always surrounded by a "halo" of brownish cells at the transition towards the larger hyaline medulla cells above; leaves rectangular to oval, widest below mid-leaf; gemmae mostly frequent. Lophozia ventricosa s.l. (r)

- Group of small cells infected by mycorrhiza always dark purplish-red, without a "halo" of brownish cells; leaves often widest above mid-leaf, distinctly narrowed towards the base, sometimes nearly cuneate (wedge-shaped); gemmae sparse to lacking. Lophozia longiflora Note: excluded, specimens revised to L. guttulata.

17 Oil bodies homogeneous, uniformly granular

Lophozia ventricosa s.str. (r) Oil bodies biconcentric, finely granular with \pm central, glistening homogeneous globule, immediately fugacious, the globule fragmenting on drying

Lophozia silvicola $(\mathrm{rr})$

18 Cortex cells of stem mostly yellowish brown to brown, partly tinged red; medulla cells mostly \pm infected by mycorrhiza and therefore appearing grey; leaves orbicular, oval to broadly oval, often \pm concave, lobe apices inflexed, leaves thus appearing imbricate or shoots appearing succulent; gemmae mostly abundant; teeth of perianth mouth consisting of 1-2 cells; on soil, rocks and among bryophytes of siliceous substrates in open to shaded habitats. Lophozia wenzelii (n.s.) 
- Postical cortex cells vigorously purplish-red, forming a sharp contrast of colour to the adjoining wide, hyaline, transparent medulla cells mostly not infected by mycorrhiza; leaves elongate ovate to rectangular, not concave, patent to slightly squarrose; trigones mostly bulging; shoots mostly flattened; gemmae lacking or sparse; perianth mouth always distinctly spinosely dentate to ciliate, teeth mostly of 1-4 cells; on permanently moist rotting wood ............................................ Lophozia guttulata (rr)

19(7) Trigones small or absent; underleaves absent or only few and subulate; gemmae absent; perianth clavate; female bracts similar in size and shape to lateral leaves; plants 1-3 $\mathrm{cm}$ long, green to blackish; lateral leaves obtuse to rounded; sterile perianths abundant, mostly caducous; plants calcifuge.

Gymnocolea inflata $(\mathrm{r})$

- Trigones present; underleaves present, entire or 2-lobed, often difficult to detect, or absent (Mesoptychia badensis); gemmae present in Mesoptychia heterocolpos, otherwise absent; perianth cylindrical to pyriform, abruptly contracted at mouth; female bracts mostly larger than lateral leaves; plants calciphile.

Mesoptychia (p.103)

\section{Key to species of Diplophyllum and the genus Scapania}

1 Postical lobe 3-4 times as long as wide, narrowly lingulate to lingulate, \pm parallel-sided, nearly at right angles to stem, slightly secund; antical lobe elliptical-lingulate, forming more acute angle with stem than postical lobe (compare also Scapania umbrosa); median leaf cells rectangular or linear and forming a vitta; gemmae angulate or stellate; perianth ovate, plicate above, narrowed to mouth; small to mediumsized plants 1-6 cm long.

- Postical lobe up to twice as long as wide, variously shaped, rarely lingulate or parallel-sided, not secund; antical lobe variously shaped, antical and postical lobes at similar angle to stem (except $S$. umbrosa); median leaf cells isodiametric, not differentiated; gemmae ovoid to elliptical; perianth \pm compressed, mostly not plicate, truncate at mouth..Scapania 
2 Leaf lobes with conspicuous vitta of elongate cells (3-8 times as long as wide); cuticle almost smooth; stem with (2) 3-4 (5) layers of distinct, thick-walled cortical cells; dioicous Diplophyllum albicans (r)

- Vitta in leaf lobes short and only poorly defined or absent; cells in middle and lower part of postical lobe 2-4 times as long as wide; cuticle papillose; postical lobe mostly 1.6-2.3 times as long as wide; stem with 1-2 layers of cortical cells hardly distinct from medullary cells; paroicous; gemmae rare. Diplophyllum obtusifolium (r)

\section{Key to species of Scapania}

Based on Damsholt (2002), Meinunger and Schröder (2007)

1 Postical lobe of leaves not conspicuously decurrent or only decurrent to the level of the insertion of the keel, or in some cases with a decurrent strip only 1 cell wide, gradually tapering and visible below the insertion of the keel..

- Postical lobe of leaves distinctly decurrent, with the decurrent strip several cells wide, gradually tapering and visible for $c a$ half of the length of the segment below the insertion of the keel; leaves often dentate.

2 Antical lobe (0.6) 0.7-0.8 the length of the postical lobe; gemmae 2-celled; usually both lobes standing away from each other; cuticle with hemispherical papillae; calcicole.

Scapania aequiloba $(\mathrm{rr})$

- $\quad$ Antical lobe 0.3-0.65 the length of the postical lobe; gemmae 1-2-celled.

3 Postical lobes narrow, 1.3-2 times as long as wide; plants $0.5-3 \mathrm{~mm}$ wide and $2-18 \mathrm{~mm}$ long

- $\quad$ Postical lobes ovate to almost rotundate, 0.8-1.3 times as long as wide; plants $1.8-5 \mathrm{~mm}$ wide and $20-100 \mathrm{~mm}$ long; gemmae greenish.

Scapania irrigua $(\mathrm{r})$

4 Leaves bordered by (1) 2-4 rows of equally thick-walled cells lacking trigones.

- Marginal cells of lobes not differing from median leaf cells and thus not forming a border, except at the base of the postical lobe, where 1-2 rows of thick-walled cells may occur. 
5 Gemmae greenish to brownish; base of postical lobe never with vinaceous secondary pigmentation; cuticle with hemispherical papillae; calcicole..........Scapania calcicola (r)

- $\quad$ Gemmae greenish, 2-celled; base of postical lobe often with vinaceous secondary pigmentation; leaves keeled almost to the base (sect. Curtae)

6 Postical lobe rounded at apex; marginal cells of the leaves (15) 16-22 $\mu \mathrm{m}$; perianth mouth with teeth 1-3 cells long, wide entire sections between teeth lacking; keel 0.5-0.6 the length of the postical lobe; antical lobe not directed towards shoot apex.

Scapania curta (r)

- $\quad$ Postical lobe often acute; marginal cells of the leaves 12-18 $\mu \mathrm{m}$; perianth mouth entire; keel to $0.3-0.4$ the length of the postical lobe; antical lobe directed towards shoot apex.

Scapania parvifolia $(\mathrm{rr})$

7(4) Gemmae 1-celled, black or reddish-brown, formed at apex of erect shoots with reduced leaves; shoots to $1 \mathrm{~mm}$ wide and 2-3 mm long; only on decaying logs.

Scapania apiculata (n.s.)

- $\quad$ Gemmae (1) 2-celled, greenish, vinaceous or brown; shoot mostly more than $1 \mathrm{~mm}$ wide and more than $3 \mathrm{~mm}$ long........8

8 Cells with 2-5 (6) large, persistent oil-bodies, 10-14 × 8-11 $\mu \mathrm{m}$; gemmae green to brownish at maturity, $16-24 \mu \mathrm{m}$ wide; perianth inflated and plicate towards the mouth; antical lobe large, 0.4-0.6 the size of the postical lobe, often distantly dentate; cuticle with hemispherical papillae; calcicole

Scapania calcicola $(\mathrm{r})$

- Cells with smaller, non-persistent oil-bodies, of which the largest are $9-10 \times 5 \mu \mathrm{m}$, gemmae colourless or greyish or reddish to vinaceous, rarely yellow-brown (sect. Curtae)......9

9 Plants pale green or reddish to purplish brown, when exposed; postical lobes mostly rounded at apex, antical lobes almost always acute; cells with 2-6 often large greyish oilbodies, occluding lumen; gemmiparous leaves strongly dentate; perianth mouth entire (or with single, distant small teeth: var. argutedentata).

Scapania scandica (rr)

- $\quad$ Plants with brownish secondary pigmentation, never with vinaceous or reddish postical lobe bases or gemmiparous leaves; leaves edentate or only dentate near gemmiparous areas or distantly dentate, but the dentition never reaches 
the basal 0.2 of the leaf; perianth mouth laciniate to dentate.

10 Postical lobe rounded, lingulate; marginal cells of lobes 19$25 \mu \mathrm{m}$; leaves often with scattered teeth; cells of leaf middle with 6-12 oil-bodies; perianth mouth with teeth of 1-7 superimposed cells; gemmiparous lobes often dentate.

Scapania lingulata $(\mathrm{r})$

- Postical lobe apiculate, rarely rounded, marginal cells of lobes 13-20 $\mu \mathrm{m}$; leaves edentate or only denticulate near gemmiparous areas; cells of leaf middle with 2-6 oil-bodies; perianth mouth with teeth of (1) 2-6 superimposed cells, terminating lobules $2-5$ cells wide at base.

11 Gemmae greenish, rarely reddish, 16-29 × 8-14 $\mu \mathrm{m}$; antical lobe $c a$ half as large as postical lobe; leaves entire; perianth mouth laciniate-dentate. Scapania mucronata $(\mathrm{r})$

- Gemmae yellowish-brown when ripe, 18-36 × 10-19 $\mu$ m; antical lobe $c a 0.65$ the size of the postical lobe; leaves occasionally with minute dentition; perianth mouth with many teeth, each with several superimposed cells.

Scapania praetervisa $(\mathrm{r})$

12(1) Antical lobe longly or shortly decurrent ...............................13 Antical lobe not decurrent, transversely inserted ..................14

13 Antical lobe longly decurrent; cuticle verruculose, especially at marginal teeth; gemmae 1-celled, brown.

Scapania nemorea $(\mathrm{w})$

- $\quad$ Antical lobe shortly decurrent; cuticle coarsely verruculose, with hemispherical papillae; gemmae 1-2-celled, whitish green.

Scapania aspera $(\mathrm{r})$

14 Shoot 5-12 mm long; gemmae reddish brown; leaf lobes elliptical-lanceolate, dentate; keel winged; on decaying logs or humus

Scapania umbrosa (n.s.)

- Shoot 15-100 mm long; gemmae yellow-green or pinkish, sometimes totally lacking, on wet or submerged stones in streams.

Scapania undulata $(\mathrm{r})$ 


\section{Supplementary 'key' according to habitats}

Based on Nebel and Philippi (2005)

1 wet habitats (swamps, springs, streams):

- $\quad$ S. irrigua: leaf lobes not decurrent, plants green

- $\quad$ S. undulata: postical lobe long decurrent, antical lobe not decurrent, plants sometimes pigmented

2 limestone rocks:

- S. aequiloba: antical lobe crossing stem; lobes entire

- $\quad$ S. aspera: antical lobe crossing stem; lobes mostly dentate

- $\quad$ S. calcicola: antical lobe not crossing stem; lobes edentate to serrate-dentate

3 soil:

- $\quad$ S. nemorea: robust species with dentate lobes and mostly conspicuous brown gemmae

- S. curta, S. mucronata, S. scandica, S. lingulata: small species, difficult to distinguish, see key 6 and $9-11$

4 decaying wood:

- S. apiculata: small plants with erect attenuate-leaved gemmiparous shoots

- $\quad$ S. umbrosa: small plants with dentate leaf lobes

- $\quad$ (S. nemorea): large plants, usually on soil, see above

\section{Key to species of Calypogeia}

1 Leaves bidentate with divergent and usually very acute teeth; cuticle striolate-verruculose.....Calypogeia arguta ( $\mathrm{rr}$ ) Note: missing in Erzberger and Papp (2020).

- Leaves rounded at apex or bidentate, but teeth not divergent; cuticle smooth ..................................................... 2

2 Underleaves 2-lobed to 0.5-0.75, with 1-4 rows of cells between sinus and rhizoid area.

- Underleaves entire, emarginate or 2-lobed to $1 / 3$, with 4-14 rows of cells between sinus and rhizoid area

3 Mature shoots rarely more than $2 \mathrm{~mm}$ wide; on decaying coniferous wood and raw conifer humus, rarely on peat; lateral leaves imbricate; underleaves 2-3.5 times as wide as stem, 2-lobed, outer margins often with small obtuse tooth.... 
- Mature shoots often more than $2 \mathrm{~mm}$ wide; on loamy or sandy-loamy soil, non-calcareous rocks, humus, peat, and in swampy or boggy habitats; if on wood then underleaves to 2.5 times as wide as stem, lacking lateral teeth.

4 Oil-bodies colourless; lateral leaves \pm acute, bidentate or lobed to $1 / 3$ with acute lobes; leaves widest $c a 1 / 3$ from base except on attenuate shoots. Underleaves divided in 2 triangular lobes, outer margin often with a knob or tooth

Calypogeia fissa (w)

- Oil-bodies azure blue (when fruiting, seta therefore bluehyaline). Lateral leaves obtuse to rounded, mostly widest near base. Underleaves divided into 2 mostly obtuse, triangular lobes, outer margins without knobs or teeth

Calypogeia azurea (r)

5 Lateral leaves mostly as long as wide, \pm translucent; underleaves with (2) 4-6 rows of cells between sinus and rhizoid area, these cells 30-80 $\mu \mathrm{m}$ long; oil-bodies present in all underleaf cells; shoots 1.5-3.5 (4) mm wide.

Calypogeia muelleriana $(\mathrm{r})$

- Lateral leaves 1-1.3 times as long as wide, rather opaque, often with translucent margins; underleaves with 7-14 rows of cells between sinus and rhizoid area, these cells 20-50 $\mu \mathrm{m}$ long; oil-bodies soon lost from all or most underleaf cells; shoots not $>3 \mathrm{~mm}$ wide 6

6 At least some lateral leaves with tangentially elongated marginal cells forming a continuous border; underleaves decurrent at base; rhizoid area shallowly linear; oil-bodies present only in 1-3 marginal cell rows of lateral leaves, stem cells lacking oil-bodies; shoots 0.7-1.8 (2.5) mm wide.

Calypogeia neesiana (n.s.)

- Marginal cells of lateral leaves not tangentially elongated or rectangular and forming a discontinuous, ill-defined border; underleaves not or slightly decurrent; rhizoid area deeply oval or suborbicular; oil-bodies present in nearly all cells of lateral leaves and in stem cells; shoots 1.5-3.0 mm wide.

Calypogeia integristipula (n.s.) 


\section{Key to species of Marsupella}

1 Plants robust, (0.5) 1-5 cm long; lateral leaves boat-shaped, when flattened rounded-quadrate to \pm orbicular; lobed to $1 / 20-1 / 5(1 / 4)$, basal part of leaf not sheathing stem; orientation of leaf sinus parallel to stem when viewed from side; leaf lobes obtuse or rounded and apiculate; leaf margin usually narrowly recurved or revolute on one or both sides below; polymorphic.

Marsupella emarginata (rr)

- $\quad$ Plants small, up to $1(1.5) \mathrm{cm}$ long, lateral leaves bilobed to (1/5) 1/4-1.2; lobes of apical leaves acute; leaf margins plane.

2 Paroicous, plants mostly with sporophytes; lateral leaves increasing in size towards apex of stem; fertile plants clavate; plants 1-5 (7) $\mathrm{mm}$ long; lateral leaves erectspreading, without sheathing base, rounded-quadrate when flattened; sinus acute to rectangular.

Marsupella sprucei (rr)

- $\quad$ Dioicous, plants rarely fertile; lateral leaves of \pm equal size; plants larger, shoots 5-15 mm long; trigones scarcely developed; sinus acute.

Marsupella funckii (r)

\section{Key to species of Nardia}

- Plants green, light-green to brown-green, lateral leaves rounded, orbicular, not lobed or incised, not erectappressed; oil-bodies hyaline, glistening, homogeneous, persisting several years after drying, mostly 2 per cell, often segmented; perigynium not bulbous or sac-like; trigones small to medium-sized and bulging; shoots 0.5-3 (6) cm long; dioicous.

Nardia scalaris (rr)

- Plants green, brown to red-brown, lateral leaves nearly orbicular, retuse to emarginate or entire; oil-bodies granular, opaque, not persisting; perigynium bulbous or saclike, forming marsupium (but sometimes not); underleaves only rudimentary, except at apex of fertile shoots; paroicous

Nardia geoscyphus (rr) 
Key to Jungermanniaceae group (including Endogemma, Jungermannia, Liochlaena, Nardia, Solenostoma, Syzygiella)

1 Lateral leaves rounded-rectangular, flat (not concave), spreading in lower part of stem, appressed towards apex; perianth mouth longly ciliate; male bracts with small dentate antical lobe; plants in green to dark green, often reddish or copper-coloured turfs, also on rotting wood

Syzygiella autumnalis (Jamesoniella autumnalis) (r)

- Leave arrangement different; perianth mouth at most crenulate; male bracts entire.

2 Underleaves lanceolate, distinct, usually restricted to younger parts of stem; oil-bodies large, homogeneous, weakly segmented, or granular, 1 to several per cell; perianth very short, immersed in bracts.

- Underleaves absent (stems of Solenostoma hyalinum and Endogemma caespiticia occasionally with a few underleaves); oil-bodies granular, not homogeneous, few or many per cell; perianth exserted from female bracts.

3 Plants green, light-green to brown-green, lateral leaves rounded, orbicular, not lobed or incised, not erectappressed; oil-bodies hyaline, glistening, homogeneous, bean- or sausage-shaped, persisting several years after drying, mostly 2 per cell, often segmented; perigynium not bulbous or sac-like; trigones small to medium-sized and bulging; shoots 0.5-3 (6) cm long; dioicous.

Nardia scalaris (rr)

- Plants green, brown to red-brown, lateral leaves nearly orbicular, retuse to emarginate or entire; oil-bodies granular, opaque, not persisting; perigynium bulbous or saclike, forming marsupium (but sometimes not); underleaves only rudimentary, except at apex of fertile shoots; paroicous

Nardia geoscyphus (rr)

$4 \quad$ Female bracts and perianth arising from well-developed perigynium 0.2-0.6 length of perianth bearing 1 pair of bracts; perianth conical, plicate above, emergent to about $1 / 2$ from bracts, cells in upper part 2-3 times as long as wide; at least some rhizoids purple or violet, sometimes brownish or colourless; underleaves absent, occasionally 
single at stem apex, lanceolate; leaves reniform to semicircular, rounded to weakly retuse; plants procumbent; dioicous; leaf cells 25-40 $\mu \mathrm{m}(30-40 \times 25-35 \mu \mathrm{m})$

Solenostoma hyalinum (Jungermannia hyalina) (r)

- $\quad$ Perigynium absent, or, if present, short; perianth cylindrical to ovate, with or without plicae above, exceeding bracts, cells in upper part not elongate, similar to leaf cells; rhizoids colourless to brownish, not violet; underleaves absent on sterile shoots.

5 Lateral leaves \pm lingulate, distinctly longer than wide (1.21.7 times); perianth emergent, cylindrical, smooth, abruptly contracted to beaked mouth.

- Lateral leaves orbicular, ovate to reniform, cordate, as long as wide or slightly longer (1.3 times); perigynium absent or only short; perianth emergent, plicate above, not beaked (Jungermannia) or contracted to beaked mouth (Solenostoma, Endogemma)

6 Plants 4-6 mm wide, nearly always with cylindrical perianths, gemma-bearing shoots very rare or completely lacking; paroicous; on shaded, humid, limefree, but base-rich to moderately acidic substrates

Liochlaena lanceolata (Jungermannia leiantha) (r) Note: According to Meinunger and Schröder (2007), the following characters are not reliable for the distinction between L. lanceolata and $L$. subulata: L. lanceolata - only rarely with gemma-bearing shoots; leaf cells up to 50 (65) $\mu \mathrm{m}$ wide; leaves in situ resembling those of Plagiochila, vs. $L$. subulata - gemma-bearing shoots more frequent; leaf cells up to 40 (50) $\mu \mathrm{m}$ wide.

- $\quad$ Plants 2-3 mm wide, usually sterile or with young pyriform perianths not emerging from bracts; gemma-bearing shoots very frequent; dioicous.

Liochlaena subulata (Jungermannia subulata) (rr)

$7 \quad$ Plants with many small-leaved innovations (often only these are found), well-developed lateral leaves bordered with one row of somewhat larger, thick-walled cells, orbicular, concave (leaves of small plants and of small distant-leaved innovations are often unbordered); dioicous; trigones small or absent; plants up to $1 \mathrm{~mm}$ wide.

Solenostoma gracillimum (Jungermannia gracillima) (r) 
- $\quad$ Plants without small-leaved innovations; margins of lateral leaves unbordered or only indistinctly bordered, marginal cells not larger than adjoining leaf cells; dioicous or paroicous; trigones mostly present

8 Lateral leaves elliptical, ovate, cordate, mostly slightly longer than wide (up to 1.3 times); perianth weakly plicate, not beaked, mouth eventually divided into 4 short, toothed lobes; perigynium lacking.

- Lateral leaves as wide as long or slightly wider than long, reniform to orbicular; perianth with 4-5 plicae above, \pm abruptly contracted to beaked mouth, mouth eventually divided into 4-5 entire lobes; perigynium present.

9 Dioicous; plants to $0.5-4$ (5) $\mathrm{cm}$ long; lateral leaves ovate, 0.6-1.8 $\mathrm{mm}$ long and $0.6-1.5 \mathrm{~mm}$ wide.

Jungermannia atrovirens ( $\mathrm{rr}$ )

- $\quad$ Paroicous; plants 0.3-1 (2) cm long; lateral leaves 0.3-1.2 $\mathrm{mm}$ long and $0.3-1 \mathrm{~mm}$ wide; perianth clavate to cylindrical, plicate above, \pm acute; lateral leaves on fertile stems broadly elliptical to broadly ovate; mid-leaf cells 16-28 (32) $\mu \mathrm{m}$ wide. Jungermannia pumila (rr)

10 Dioicous; gemmae frequent, 1-celled, forming dense mass at shoot apices; trigones absent; oil-bodies only 1 (2) per cell, fugacious; small plants, shoots $<1 \mathrm{~cm}$ long, in yellowish green patches; usually ephemeral, with many perianths

Endogemma caespiticia (Jungermannia caespiticia) (n.s.)

- Paroicous; gemmae absent; trigones present, usually distinct; several oil-bodies per cell; without perigynium; plants dark green, in green to greenish-black tufts, without small-leaved innovations

Solenostoma sphaerocarpum (Jungermannia sphaerocarpa) (rr)

\section{Key to species of Mesoptychia}

1 Brown smooth gemmae mostly present, 1-2-celled, usually on margins of appressed leaves on attenuate small-leaved shoots; lateral leaves with acutely angulate, occasionally semi-orbicular sinus; trigones large, bulging; underleaves subulate, entire or with 1-2 cilia at base or 2-lobed

.Mesoptychia heterocolpos (Leiocolea heterocolpos) (n.s.) 
- Plants lacking both gemmae and attenuate shoots with appressed leaves; underleaves absent or with 1 to several marginal cilia.

2 Underleaves absent; plants not aromatic; lateral leaves in middle part of stem $0.3-0.7 \mathrm{~mm}$ long; mid-leaf cells $24-32$ (36) $\mu \mathrm{m}$ wide; trigones distinct; cortical stem cells 16-32 $\mu \mathrm{m}$ wide; perianths pyriform, abruptly contracted to shortly beaked mouth; on calcareous substrates

Mesoptychia badensis (Leiocolea badensis) (r) Note: Trigones may be inconspicuous in lateral leaves, but usually are more pronounced in bracts and perianths.

- $\quad$ Underleaves present, but hidden among the rhizoids, small and often difficult to detect; plants usually strongly aromatic; lateral leaves mostly $0.5-1.3 \mathrm{~mm}$ long, 2-lobed to $1 / 5$ (1/3); mid-leaf cells 20-32 $\mu \mathrm{m}$ wide; on calcareous substrates, damp soil, rocks, loess

.Mesoptychia collaris (Leiocolea collaris) (r)

\section{Key to species of Lophocoleaceae}

1 At least lowest lateral leaves 2-lobed or, if all lateral leaves rounded to retuse, antical margin not or hardly decurrent; perianth well developed, apical on main stems or on \pm fullsized branches; calyptra shorter than perianth; paroicous or dioicous; underleaf lobes mostly divergent; underleaves free or connate with a lateral leaf; strongly aromatic. Lophocolea.

- Mature lateral leaves rounded to retuse, rectangular, rarely lateral leaves of side branches 2-lobed, antical margin decurrent; perianth on short side branches; calyptra protruding beyond perianth; autoicous; underleaf lobes generally nearly parallel; underleaves free; not strongly aromatic. Chiloscyphus.

2 Apical leaves distinctly 2-lobed or apex 2-dentate; mid-leaf cells 25-50 $\mu \mathrm{m}$ wide; caducous flagelliform branches absent; leaf insertion not or scarcely arcuate postically; plants 1-6 $\mathrm{cm}$ long, whitish, bright or yellowish green; autoicous or dioicous. Lophocolea bidentata s.l. conditions, it is perhaps appropriate to deal with the collective taxon. 
- $\quad$ Apical leaves \pm rectangular, ovate; apex rounded, retuse, emarginate or only shortly 2-lobed; paroicous.

3 Stems branched; shoots 1-3 cm long; leaf lobes ending in (2) 3-7 uniseriate cells; dioicous.

Lophocolea coadunata (Lophocolea bidentata auct.) (w) Note: According to Köckinger (2017) and Damsholt (2002), the correct nomenclature (based on the types) implies, that the common dioicous taxon must be called L. coadunata (Sw.) Mont., whereas the rare autoicous taxon must be called L. bidentata (L.) Dumort.

- Stems hardly branched; leaf lobes ending in 1-5 (6) uniseriate cells; autoicous. Lophocolea bidentata Note: Development of antheridia appears to depend strongly on environmental conditions, which makes assessment of the sexual condition very difficult if not impossible; the gametophytic characters used in this key are probably not reliable.

4 Paroicous, perianths usually abundant; lowermost lateral leaves and leaves of branches 2-lobed to 1/3, apical leaves retuse or emarginate; gemmae rare, mostly 1 -celled.

Lophocolea heterophylla (c)

- $\quad$ Dioicous (or paroicous), but perianths rare; all lateral leaves shortly 2-lobed to $1 / 4-1 / 3$, with abundant marginal gemmae................................................ Lophocolea minor $(\mathrm{w})$

5(1) Plants dark to greyish green; median leaf cells 30-35 (40) $\times$ (21) 24-30 $\mu \mathrm{m}$; each cell with (1) 2-4 (5) oil bodies; each oil body $7-12 \times 4-7 \mu \mathrm{m}$; lateral leaves broadly rounded to truncate or weakly retuse, those of branches rarely 2-lobed; lobes of perianth mouth entire or obscurely dentate; calyptra long emergent from perianth apex; plants closely appressed to mostly siliceous rocks by running water.

Chiloscyphus polyanthos (w)

- Plants pale to yellowish green, rarely dark green (in submerged forms); leaf cells 45-60 × (32) 35-40 $\mu \mathrm{m}$ or larger; each cell with (3) 4-6 (12) oil bodies; each oil body 8-9 (11) $\times 4-5 \mu \mathrm{m}$; lateral leaves more narrowly rounded or frequently retuse, those of branches often 2-lobed; lobes of perianth mouth often dentate; calyptra little or hardly emergent from perianth apex; plants in lax turfs, mostly in neutral mires, also on calcareous substrates.

Chiloscyphus pallescens $(\mathrm{w})$

Note: According to Meinunger and Schröder (2007), the best differentiating character between the two species is cell size. According to Damsholt (2002), the differences in the dentition of the perianth mouth 
are not significant. Cell size is variable in both species, small leaves have small cells, larger leaves have larger cells.

\section{Key to species of Plagiochilaceae}

1 Lateral leaves \pm plane, margin entire or retuse or with 2-4 apical teeth; underleaves small, filiform, limited to young shoots; shoots usually with rhizoids \pm to apex; monoicous; leaves not inserted to the antical stem mid-line, but with a leaf-free zone 2-4 cells wide; leaves often variable in size or shape even on a single stem.

Pedinophyllum interruptum $(\mathrm{w})$

- $\quad$ Lateral leaves usually convex, usually dentate; underleaves absent or only present at apex as cell filaments; rhizoids rare or absent; dioicous; leaves inserted to antical mid-line 2

2 Plants up to $10 \mathrm{~cm}$ long and 5-9 $\mathrm{mm}$ wide; lateral leaves 3$4.5 \times 2.5-4.5 \mathrm{~mm}$, mostly dentate with numerous teeth, sometimes \pm entire; mid-leaf cells 30-33 (35) $\mu \mathrm{m}$ wide, trigones very small or absent; flagella absent.

Plagiochila asplenioides $(\mathrm{w})$

- $\quad$ Plants 2-5 cm long and 1.5-5.5 mm wide; lateral leaves $3 \times$ $2.5 \mathrm{~mm}$, dentate to nearly entire; mid-leaf cells 25-30 (33) $\mu \mathrm{m}$ wide; trigones small to medium-sized; flagella present.

Plagiochila porelloides $(\mathrm{w})$

\section{Key to species of Frullania}

1 Postical lobes (water sacs) 1.8-2.5 times as long as wide; antical lobes rounded or apiculate, antical lobes with ocelli, these either scattered or arranged in a line, sometimes only few; mid-leaf cells of antical lobe (on main stems) 12-20 $\mu \mathrm{m}$ wide; perianth trigonous, smooth; growth form variable; sometimes with a smell of roses.

- Postical lobes as long as wide or evolute-lanceolate; antical lobes always rounded, without ocelli; mid-leaf cells of antical lobe (on main stems) 20-33 $\mu \mathrm{m}$ wide; perianth 3-5-gonous, smooth or tuberculate; growing in patches often not neatly delimited but with individual branches outside the dense

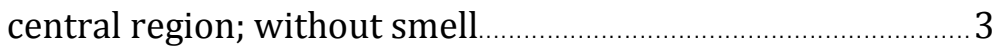

2 Antical lobes \pm acute to apiculate (at least on branch leaves), 
concave when moist, with generally long line of ocelli, additional ocelli often present, scattered or forming small discrete group; underleaves on main stems decurrent, margin recurved, base auriculate to crispate; leaves not caducous; lobe cells (10) $12-23 \mu \mathrm{m}$ wide; plants up to $10 \mathrm{~cm}$ long, reddish brown to copper coloured.

Frullania tamarisci (r)

- Antical lobes (even of branch leaves) always rounded, plane when moist; ocelli of antical lobes scattered, at most short line present at base of lobe, ocelli often pale brown; underleaves on main stems not decurrent, divided to $1 / 3-$ $2 / 5$, often with lateral tooth on both sides, margins plane, entire; lateral leaves sometimes caducous; lobe cells 16-22 (25) $\mu \mathrm{m}$ wide; delicate species growing in neatly delimited patches; with the smell of roses when rubbed with a moist finger.

Frullania fragilifolia $(\mathrm{r})$

3 Underleaves on main stem reniform, much wider than long, 2.5-3.5 times as wide as stem, entire or retuse; mid-leaf cells with strongly bulging trigones, colourless

Frullania jackii (n.s.)

- $\quad$ Underleaves on main stem longer than wide, at most twice as wide as stem, narrowly incised with an acute sinus; lobes acute...

4 Dioicous, but perianths common, trigonous, tuberculate; antical base of antical lobes on main stem auriculate; midleaf cells of antical lobes mostly with strongly bulging trigones and intermediary thickenings; postical lobe helmetshaped or evolute, as long as wide or wider than long; stylus (triangular flap between lobule and stem) mostly large, lanceolate, 3-10 cells wide at base; underleaves with acute lobes and 1-2 blunt teeth on lateral margins.

Frullania dilatata $(\mathrm{cc})$

- $\quad$ Autoicous, perianth with 5 plicae, smooth externally; antical base of antical lobes on main stem not auriculate; mid-leaf cells of antical lobes with small trigones and generally without intermediary thickenings; postical lobes evolute, lanceolate, < 1/2 width of antical lobe; antical lobes (on main stems) plane, mostly broadly ovate to ovate; leaf cell walls thin, colourless; plants mostly green.

Frullania cleistostoma (Frullania inflata auct.) (r) 


\section{Key to species of Lejeuneaceae}

1 Leaf cells smooth; oil-bodies simple, numerous, persistent..... Lejeunea cavifolia $(\mathrm{w})$

- $\quad$ At least cells of antical lobe distinctly conically mamillose....2

2 Postical lobe with smooth cells.......Cololejeunea calcarea (r)

- Postical lobe with cells conically mamillose. Cololejeunea rossettiana $(\mathrm{r})$

\section{Key to species of Porella}

1 Leaves in situ with antical margin neatly appressed, margins of postical lobes and underleaves \pm spinose-dentate, at least on branches; antical lobes ovate, apex acute; plants with strong metallic sheen, glossy; tasting acrid.

Porella arboris-vitae (r)

- Leaves in situ with antical margin of at least some leaves elevated or recurved, postical lobes of lateral leaves and underleaves entire or only weakly dentate and distantly toothed (sometimes with toothed decurrent wings); antical lobes mostly not acute; plants dull; not tasting acrid..

2 Postical lobe of lateral leaves tapering to acute apex, small, not more than 0.2 times as wide as antical lobe, narrower than stem; underleaves dentate at base, longly decurrent; mid-leaf cells of antical lobe 28-40 $\mu$ m wide.

Porella cordaeana $(\mathrm{r})$

- $\quad$ Postical lobe rounded at apex, mostly (0.2) 0.3-0.6 times as wide as antical lobe, as wide or hardly wider than stem, to about $1 / 2$ as wide as underleaves; shoots irregularly 2-3pinnately branched; plants dull, not glossy.

3 Postical lobes and underleaves longly decurrent; cells in the middle of the antical lobe (36) 38-40 $\mu \mathrm{m}$ in diameter; perianth mouth long-dentate to densely short-ciliate; female bracts dentate.

Porella baueri (r)

- $\quad$ Postical lobes and underleaves not longly decurrent; cells in the middle of the antical lobe 32-35 $\mu \mathrm{m}$ in diameter; perianth mouth somewhat dentate; female bracts almost edentate.

Porella platyphylla (c) 


\section{Key to species of Radula}

- $\quad$ Paroicous, perianths common; male bracts saccate at base in (1) 2-4 pairs below female bracts.... Radula complanata (cc)

- Dioicous, perianths very rare; male inflorescences spicate, closely imbricate, with 10-20 leaf pairs (but male plants rare) Radula lindenbergiana (n.s.)

\section{Key to species of Aneuraceae}

1 Thallus 2-6 cm long and (2) 3-7 (10) mm wide; greasy in appearance; in cross section (7) 9-12 (15)-layered centrally, simple, or sparsely and irregularly pinnately branched; oilbodies 8-15 (40) per epidermal cell, breaking down rapidly when dry Aneura pinguis $(\mathrm{w})$

- Thallus 0.5-3 cm long and 0.3-1.2 (2.6) mm wide; not greasy; in cross section (3) 4-8 (9) cell layers thick centrally; irregularly branched, pinnately or palmately lobed; oil-bodies 0-3 per epidermal cell. Riccardia.

2 Thallus light-green, strap-like, irregularly pinnately branched, 1-2 cm long and $0.5 \mathrm{~mm}$ wide; dorsal side of thallus flat to concave, typically channelled, semi-orbicular in section; gemmae often present; dioicous.

Riccardia incurvata (n.s.)

- Thallus light or dark green, palmately lobed, fan-like or \pm regularly 1-3-pinnate, rarely simple, $1-3 \mathrm{~cm}$ long and $0.2-2$ $\mathrm{mm}$ wide, biconvex in section or dorsal side \pm plane, not channelled; monoicous or dioicous

3 Thallus palmate; thallus branches dark green, $0.2-0.3 \mathrm{~mm}$ wide, densely arranged; dioicous......... Riccardia palmata (r)

- Thallus \pm regularly 1-3-pinnate, fan-like or palmate; monoicous.

4 Upper part of thallus \pm regularly 2-3-pinnate, branches strap-like, $0.3-1 \mathrm{~mm}$ wide, biconvex in section; thallus margins unistratose, translucent, 2-3 cells wide; epidermal and marginal cells without oil-bodies (in fresh material)

Riccardia multifida (rr) 
- $\quad$ Upper part of thallus irregularly pinnate or palmate, dorsal surface flat to weakly convex in section; thallus branches 1$2 \mathrm{~mm}$ wide; unistratose margins mostly absent or only 1-2 cells wide; epidermal and marginal cells with or without oilbodies.

5 Thallus irregularly 1-2 (3)-pinnate; branch apices rounded; oil-bodies 1-2 per cell. Riccardia chamedryfolia (rr)

- Thallus irregularly branched, branches narrowed at base; branch apices with heart-shaped incision; oil-bodies absent.

Riccardia latifrons $(\mathrm{r})$

\section{Key to species of Metzgeria}

1 Thallus densely covered with hairs on both sides, without gemmae or adventive thalli

Metzgeria pubescens (Apometzgeria pubescens) (r)

- Thallus without hairs or hairs confined to margins and ventral surface of midrib; with or without gemmae and adventive thalli.

2 Thallus 2-3 cm long and 1-2 mm wide; margins strongly down-curved; adventive gemmae not present on thallus margins; hairs of ventral surface of midrib bristly; hairs of thallus margins \pm straight, often in pairs; thallus cells $45-65$ $\mu \mathrm{m}$; monoicous.

Metzgeria conjugata

(Metzgeria conjugata subsp. conjugata) (w)

- $\quad$ Thallus up to 1 (2.5) cm long and 0.4-1.0 (1.5) mm wide; adventive thalli and / or gemmae present or not; ventral surface of thallus not or hardly hairy; hairs of thallus margins single or absent; dioicous.

3 Thallus branches linear, of equal width throughout; margins \pm plane when moist; thallus margins sometimes with adventive thalli; thallus never blue........Metzgeria furcata (c)

- $\quad$ Thallus branches attenuate towards apices, bearing gemmae on both faces of thallus as well as on margins; margins recurved when moist; midrib mostly 4-5 cells wide on each surface; thallus becoming blue upon drying.

.Metzgeria violacea (Metzgeria fruticulosa auct.) (excluded) 


\section{Key to species of Fossombronia}

1 Spores with 5-7 alveolae across the convex face; alveolae 8$12 \mu \mathrm{m}$ wide, regular. Fossombronia foveolata (n.s.)

- Spores not alveolate, ornamented with lamellae free or anastomosing in the centre, \pm parallel at least on the sides even if reticulate towards the centre.

2 Spores in side view with 5-7 lamellae 6-10 $\mu$ m apart; spore margin with 15-19 spines in profile; wing often translucent. Fossombronia pusilla $(\mathrm{w})$

- $\quad$ Spores in side view with 10-13 lamellae 6-10 $\mu \mathrm{m}$ apart and with 25-35 (40) spines in profile.

\section{Fossombronia wondraczekii (r)}

\section{Key to species of Pelliaceae}

1 Slime papillae restricted to ventral side of costa near apex, on stalk 1-5 (6) cells long; thalli with miniature apical branches proliferating in autumn; dioicous; involucres subhorizontal to erect, tubular, with dentate-ciliate lobes; male tubercles $c a 200 \mu \mathrm{m}$ wide, cells surrounding aperture not papilliform; calcicole

Apopellia endiviifolia (Pellia endiviifolia) (w)

- $\quad$ Slime papillae on stalk 1 cell long, on both ventral and dorsal side of costa near apex; caducous branches absent; dioicous or monoicous; calcifuge.

2 Monoicous and normally paroicous; involucres nearly horizontal, flap-like, subentire or irregularly lobed; male tubercles to $400 \mu \mathrm{m}$ wide, aperture surrounded by papilliform cells

Pellia epiphylla (r)

- Dioicous; involucres tubular (but sometimes distally incomplete and then resembling those of $P$. epiphylla), with irregularly rounded lobes, margin subentire or crenulate or with an occasional tooth; male tubercles to $500 \mu \mathrm{m}$ wide, with conspicuous papilliform cells surrounding the aperture

Pellia neesiana (rr) 
Key to Marchantiales pp. (incl. Asterella, Clevea, Conocephalum, Lunularia, Mannia, Marchantia, Reboulia)

1 Dorsal side of thallus nearly always with gemmae cups, distinctly reticulate; female receptacles stellate, on stalks (archegoniophores).

- $\quad$ Thalli without gemmae cups, reticulate or not .......................... 4

2 Gemmae cups semi-lunate; air-pores volcano-shaped, simple; female receptacles cruciate, 4-rayed.

Lunularia cruciata $(\mathrm{r})$

- Gemmae cups goblet-shaped, circular; air-pores barrelshaped, each composed of 4 (6) rings of superimposed cells; female receptacles at apex of thallus, stellate, deeply divided with usually (5) 8-9 (11) terete lobes; thallus dark green, often with \pm distinct blackish median band on dorsal surface; ventral scales colourless, not conspicuous, of 3 different forms; spores 9-13 $\mu \mathrm{m}$ in diameter.

3 Thallus prostrate, 6-9 $\mathrm{mm}$ wide, densely branched; with a discontinuous, dark median band on dorsal surface of thallus; appendages of median scales sharply toothed; gametangiophores frequent; dorsal epidermis usually at least partly verruculose; gemma cups with 7-13 gemmae, each with 50-60 marginal oil cells.

Marchantia polymorpha subsp. ruderalis (w)

- Thallus usually growing erect, > $9 \mathrm{~mm}$ wide, distantly branched; with a long, conspicuous, dark median band (lacking air-chambers) on dorsal surface of thallus; margins of appendages of median scales entire or crenulate; gametangiophores infrequent; dorsal epidermis smooth; gemma cups with 22-25 gemmae, each with 70-75 marginal oil cells........Marchantia polymorpha subsp. polymorpha (r)

4(1) Air-pores barrel-shaped; archegonia and antheridia born on stalked receptacles; air-chambers with branched chlorenchyma (chlorophyllose filaments); female receptacle a disc with 4 ridges (if with 8-9 lobes, see Marchantia polymorpha), with stalk 5-10 cm long, male receptacles with stalk 1-2 cm long; thallus \pm carinate; ventral scales purplish, soon vanishing; taste pepperish (after initial sweetness).

Marchantia quadrata (Preissia quadrata) (r) 
- $\quad$ Air-pores elevated and volcano-shaped, or simple, or absent, not barrel-shaped; antheridia on sessile receptacles or immersed in the thallus; female receptacles stalked, rarely nearly sessile. 5

5 Air-chambers with chlorenchyma (chlorophyllose filaments); thallus very large, up to $1-2 \mathrm{~cm}$ wide and $15 \mathrm{~cm}$ long, regularly dichotomously branched, distinctly reticulate, green to dark green, with a strong smell of turpentine; air-pores elevated, volcano-shaped, simple, with 5-6 concentric rings, each ring with 7-8 cells; female receptacles conical, stalk to $6(10) \mathrm{cm}$ long, arising at the apices of the thallus branches.

- Air-chambers without chlorenchyma (chlorophyllose filaments), but often with secondary walls, or air-chambers absent; if air-chambers with chlorenchyma, then thallus small and air-pores not elevated.

6 Dorsal surface of moist thallus distinctly glossy, to the naked eye the pores are more prominent than the lines; hyaline margin of thallus 3-4 cells wide; air-chambers between costa and thallus margin usually in 6-7 rows; boundaries of air-chambers on surface of thallus level with the surface (not recessed); epidermis of air-chambers of archegoniophore heads mostly bistratose Conocephalum conicum $(\mathrm{w})$

- Dorsal surface of moist thallus dull, to the naked eye the lines are more prominent than the pores; hyaline margin of thallus 1-2 cells wide; air-chambers between costa and thallus margin usually in 4-5 rows; boundaries of airchambers on surface of thallus recessed (forming furrows); epidermis of air-chambers of archegoniophore heads unistratose.

Conocephalum salebrosum (w)

7 Radial walls of air-pores thin (partially thickened in Reboulia hemisphaerica); stalk of female receptacle with 1 rhizoid furrow; each receptacle with (2) 3-8 sporophytes... 8

- Radial walls of air-pores thickened, air-pores therefore appearing stellate; stalk of female receptacle without rhizoid furrow; each receptacle with (1) 2-6 sporophytes; archegoniophores arising from middle part of dorsal surface of thallus; thallus not coriaceous, mostly $<5 \mathrm{~mm}$ wide, not glaucous; ventral side of thallus pale green; ventral scales large, hyaline. Clevea hyalina (Athalamia hyalina) (r) 
8 Air-pores with 4-5 rings of 6-9 guard cells, radial walls \pm thickened; female receptacles 4-7-lobed; thallus coriaceous; ventral scales with 2-4 elongated appendages at least when young; air-chambers in several layers, with plate-like outgrowths; taste slightly aromatic, not pepperish (compare Marchantia quadrata). Reboulia hemisphaerica $(\mathrm{w})$

- $\quad$ Air-pores with (1) 2-4 rings of 4-8 (9) guard cells; cells thin-walled; female receptacles spherical to conical.

9 Female receptacles hemispherical to conical with 3-4 bellshaped involucres (involucral skirts), each with 1 sporophyte; archegonia and sporophytes not surrounded by a laciniate pseudoperianth; thalli mostly 2-3 (4) mm wide, linear and dichotomously branched; stalk of female receptacles (archegoniophores) sometimes with linear, colourless scales; cells of thallus epidermis thick-walled, rounded, or thallus epidermis delicate becoming slightly lacunose with age.

- $\quad$ Female receptacles \pm conical; each sporophyte surrounded by involucre and laciniate pseudoperianth; colourless ventral scales projecting beyond thallus margin at thallus apex; spores brown, not alveolate; thallus 2-3 mm wide; pseudoperianth divided into 6-8 lanceolate lobes, connected at tips; crushed fresh thallus with a faint smell of rotten fish; cells of thallus epidermis thin-walled, polygonate

Asterella saccata $(\mathrm{w})$

10 Thallus tough, strap-like, furcate, $2-3 \mathrm{~mm}$ wide; dorsal surface not reticulate; air-chambers narrow; walls of chlorenchyma bearing numerous, much-branched chlorophyllose filaments; ventral scales red-violet or reddish brown, with 2-3 appendages; ventral scales at apices of female thalli projecting far beyond margin; archegoniophores with numerous long scales at base and top of stalk; epidermal cells with thickened walls and trigones; distal face of spores areolate; crushed fresh and rehydrated thallus with smell of cedar oil.

Mannia fragrans $(\mathrm{w})$

- $\quad$ Thallus delicate; dorsal surface reticulate, becoming slightly lacunose with age; air-chambers broad; walls of chlorenchyma without lateral chlorophyllose filaments; ventral scales small, distant, light-green or hyaline; stalk of 
archegoniophores almost without scales; without smell of cedar oil Mannia triandra $(\mathrm{r})$

Key to species of Riccia group (incl. Oxymitra, Riccia, and Ricciocarpos)

Important references: Müller (1951-1958), Szweykowski and Mendelak (1964), Jovet-Ast (1986), Gradstein and van Melick (1996), Schumacker and Váňa (2000), Damsholt (2002), Meinunger and Schröder (2007), Hugonnot (2010)

1 Sporophytes in ovate colourless involucres sessile in the middle of the thallus lobes; ventral scales hyaline with lanceolate appendages projecting beyond thallus margins; margin of scales entire, air-pores surrounded by 6 cells with partially thickened radial walls......... Oxymitra incrassata $(\mathrm{r})$

- Sporophytes immersed in dorsal surface of thallus, scattered, released by decay of thallus tissue; ventral scales inconspicuous, rounded, or, if lanceolate, with serrulate margins; air pores absent or if present, surrounding cells without thickened walls.

2 Thalli floating on water; ventral scales large, in several illdefined rows, strap-shaped, with serrulate margins, pendent in water; plants sometimes also terricolous with small ventral scales; epidermis and ventral scales with scattered dark oil cells, chlorenchyma with large air-chambers; airpores present; sporophytes very rare

Ricciocarpos natans (w)

- Plants terricolous (thalli often in rosettes) or aquatic; ventral scales inconspicuous, rounded; without oil cells; chlorenchyma chambered or consisting of parallel columns of cells separated by air-spaces; air-pores present (Subgenus Ricciella), or air-spaces lacking sharply delimited air-pores, opening through gaps between terminal cells (Subgenus Riccia). Riccia.

3 Dorsal tissue of thallus similar to an epidermis, consisting of fully connected cells with chlorophyll, and with air-pores above air-chambers (aquatic forms partly without either), sometimes dorsal tissue spongiose, with air-chambers becoming exposed by decay of epidermal cells; chlorenchyma mostly chambered. Subgenus Ricciella. 
- Dorsal chlorenchyma consisting of cell columns with an upper epithelium of one or two layers of hyaline cells, without sharply delimited air-pores (air-spaces opening through gaps between hyaline cells); dorsal tissue of lobes compact. Subgenus Riccia.

4 Thallus not spongiose, with air-chambers; dorsal surface of older parts of thallus not lacunose; epidermis with inconspicuous pores; capsule protuberant and opening on

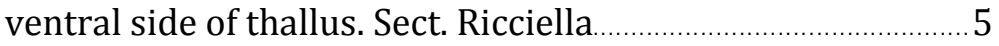

- $\quad$ Thallus spongiose, with \pm large cavities on dorsal surface, at least in older parts; capsule immersed, or \pm protuberant on ventral or dorsal surface and opening on dorsal side. Sect. Spongodes.

5 Dorsal surface of thallus conspicuously reticulate, at least at apex of lobes; thallus lobes 0.5-1.5 (2) mm wide, dorsal surface flat, in cross section 3-8 times as wide as high, apices somewhat enlarged; thallus without or with only inconspicuous ventral scales and rhizoids

- Dorsal surface of thallus inconspicuously reticulate; thallus lobes up to $0.5 \mathrm{~mm}$ wide, in cross section 1.5-2.5 times as wide as high, with a dorsal furrow (best seen in dry material), apices somewhat narrowed; ventral scales towards thallus apices distinctly 2-rowed; rhizoids abundant; on muddy soil.................... Riccia canaliculata (n.s.)

6 Dorsal surface of thallus often finely reticulate, at least towards apex; areolae up to $0.3 \mathrm{~mm}$ in diameter; thallus lobes in cross section 3-6 times as wide as high, $0.5-1.5 \mathrm{~mm}$ wide, forming an angle of $40^{\circ}$, somewhat enlarged at apex; marginal cells of thallus 30-45 × 12-20 $\mu \mathrm{m}$; almost always sterile; submerged in standing water, more rarely as a terricolous form on periodically inundated muddy soil.

Riccia fluitans (w)

- Dorsal surface of thallus more coarsely reticulate; thallus lobes in cross section 5-8 times as wide as high, up to $2 \mathrm{~mm}$ wide, forming angle of $90^{\circ}$, rounded at apex; marginal cells of thallus 40-50 × $25 \mu \mathrm{m}$; capsules unknown; in similar sites to $R$. fluitans.

Riccia rhenana $(\mathrm{r})$

7(4) Branches of young and adult thalli elongate, up to $1 \mathrm{~mm}$ wide, lobes up to 3 times as wide as high; thalli not in rosettes or rosettes indistinct; adult thalli vivid green, often 
tinged violet or completely violet; capsules protuberant on ventral surface of thallus and spores exiting through ventral epidermis; distal face of spores alveolate

Riccia huebeneriana (rr)

- $\quad$ Lobes up to $2 \mathrm{~mm}$ wide, 3-6 times as wide as high; thalli in rosettes, disc-shaped or fan-shaped, pale green to bluish green, sometimes tinged with pink; capsules protuberant on dorsal surface of thallus and spores exiting through dorsal epidermis; distal face of spores with \pm parallel to divergent ridges or irregularly alveolate.

8 Dioicous; heterothallic, male smaller than female; thallus lobes fan-shaped, in large $(\mathrm{ca} 2 \mathrm{~cm})$ deeply divided rosettes often tinged pink; cavities small, in older parts only; spores 40-65 $\mu \mathrm{m}$ in diameter; distal face with irregular ridges \pm parallel to divergent from the distal pole

Riccia frostii (w) (Figure 1, p.4)

- Monoicous; thallus often forming circular disc, green, rearly tinged pink; divided to half its length, with lobes 1-2 mm wide; cavities large; spores reddish brown, 60-120 $\mu \mathrm{m}$ in diameter, distal face with irregular ridges and alveolae.

Riccia cavernosa $(\mathrm{w})$

9(3) Thallus lobes winged, 4-8 mm long, 2.5-3 (4) mm wide, mostly nearly as wide as high; perennial, mostly dioicous taxa; thallus lobes short, transversely truncated; terminal cell of columns elongate, bottle-shaped.....

- Thallus lobes not winged, often narrower than $2.5 \mathrm{~mm}$, annual or perennial monoicous taxa, except $R$. papillosa, terminal cell of columns not bottle-shaped (but note pearshaped epidermal cells in $R$. crozalsii).

10 Thallus lobes bluish green, distal parts thickened and tuberous; spores $110-180 \mu \mathrm{m}$ in diameter, distal face with 5-7 \pm indistinct alveolae, restricted to polar region; cells of ventral scales 33-45 x 70-90 $\mu \mathrm{m}$ Riccia ciliifera $(\mathrm{w})$

- $\quad$ Thallus lobes green to yellowish green; thallus apices with stalked bulbils (not always present); spores $130-215 \mu \mathrm{m}$ in diameter; distal face of spore with 8-20 alveolae; cells of ventral scales 50-65 x 100-120 $\mu$ m......Riccia gougetiana (r) Note: Meinunger and Schröder (2007) doubt that R. gougetiana is a good species. According to them, difference in thallus colour between $R$. ciliifera ("female thallus bluish-green, deeply spotted with violet on all faces and 
on scales") and $R$. gougetiana ("female thallus yellow-green with brownish-yellow wings rarely spotted with violet on the faces and on scales" (Schumacker and Váňa 2000: 141) are considered unreliable since they probably are related to environmental conditions and different age of plants. In the sites, where both "species" occur in Germany, no significant ecological or sociological differences can be found (Marstaller in Meinunger and Schröder 2007). Spore size ( $R$. ciliifera: 110-180 $\mu \mathrm{m} ; R$. gougetiana: 130-220 $\mu \mathrm{m}$; Schumacker and Váňa 2000: 141) seems to vary continuously, the few fruiting German plants had spores 120-160 $\mu \mathrm{m}$. The only character that separates these entities seems to be cell size of ventral scales $(R$. ciliifera: 33-45 x 70-90 $\mu \mathrm{m}$; $R$. gougetiana: $50-65 \times 100-120$ $\mu \mathrm{m}$; Müller 1951-1958: 435, 439), a difference that remained constant in cultivation experiments (Szweykowski and Mendelak 1964).

Sporophytes are rarely produced in Hungary, but spore morphology seems to be sufficiently different, compare the illustrations in Jovet-Ast (1986).

11 Subepidermal cells incrassate (visible already in surface view of a crushed thallus), terminal cells of cell columns early collapsing. 12

- Subepidermal cells thin-walled .................................................... 13

12 Cross section of thallus semicircular; on dorsal surface and margins often with uncinate 'papillae' (bulging epidermal cells, not true papillae) to $145 \mu \mathrm{m}$ long, these often disappearing during the summer; dioicous; sporophytes rare, spores $60-84 \mu \mathrm{m}$, with 5-8 alveolae across the distal face. Riccia papillosa $(\mathrm{r})$

- Cross section of thallus not semicircular, thallus lobes up to 1.5 times as wide as high, flanks towards apex of thallus nearly vertical, but in older parts spreading laterally, median groove sharply acute, V-shaped, with sharp margins; 'papillae' lacking on dorsal side of thallus (but see var. heegii below); sporophytes frequent, spores 70-95 $\mu \mathrm{m}$, with 7-14 alveolae across the distal face, proximal side of mature spores rarely with indistinct alveolae, mostly dissolved into a vermicular pattern Riccia sorocarpa $(\mathrm{w})$ Note: Riccia sorocarpa var. heegii is doubtfully distinct from the typical variety, it is characterized by solitary or scattered straight, finger- or pearshaped papilliform epidermal cells to $85 \mu \mathrm{m}$ long, similar to but shorter than the 'papillae' of $R$. papillosa, on the dorsal side of the thallus.

13 Thallus with numerous cilia, cilia often crossing one another above the surface of the thallus when dry)

Note: taxa with sparse cilia are not keyed out here; compare also R. ciliata var. epilosa, which lacks cilia. 
- Thallus normally glabrous, but sparse short cilia may be rarely present in $R$. glauca var. ciliaris, $R$. warnstorfii var. ciliaris, $R$. subbifurca and $R$. bifurca var. subinermis.

14 Thallus glistening when fresh (not visible in herbarium specimens); margin of lobes \pm densely ciliate with cilia up to $1000 \mu \mathrm{m}$ long; spores very finely papillose (difficult to see in light microscope), dark brown to blackish; distal face with 7-12 alveole across the diameter, each (6) 8-12 (14) $\mu \mathrm{m}$ wide, wing (at the margin of the spores) narrow or lacking....

Riccia ciliata (Riccia crinita auct.) (w)

Note: $R$. ciliata var. epilosa: Thallus lobes without cilia.

- Thallus dull when fresh, margins mainly on the apex of the lobes with cilia up to $550 \mu \mathrm{m}$ long; distal face of spores with (6) 8-10 (12) alveolae across the diameter, each 12-16 $\mu \mathrm{m}$ wide, wing 3.5-7.5 $\mu \mathrm{m}$ wide. Riccia crozalsii (rr) Note: According to Meinunger and Schröder (2007), additional characters for the identification of $R$. crozalsii are: (i) plants small, thallus lobes 3-6× $0.4-1 \mathrm{~mm}$, growing in mostly irregular rosettes; (ii) thallus margin distinctly purple; (iii) lobe apex very thick, turgid, almost cushion-like; (iv) epidermal cells pear-shaped; (v) spores often remaining light yellowish or light brown for a long period, but mature spores always very dark to nearly black, often all shades mixed.

15 Robust plants, thallus $1.8-3 \mathrm{~mm}$ wide; often with cilia; spores $95-130 \mu \mathrm{m}$, brown, wing mostly papillose-crenulate; thallus not decaying after ripening of spores.

Riccia beyrichiana

Note: doubtfully recorded from Hungary.

- $\quad$ Plants medium-sized to small; spores mostly less than 100 $\mu \mathrm{m}$, wing smooth or notched; internal thallus tissue mostly soon decaying after spore ripening. 16

16 Thallus (seen in transverse section) 3-5 times as wide as high; margins thin, sharp, curved downward; thallus lobes green or bluish green without a trace of purple; ventral scales colourless, quickly vanishing; cilia mostly lacking; spores $80-100 \mu \mathrm{m}$, deep reddish-brown, small alveolate on proximal face, with distinct wing; medium-sized plants

Riccia glauca var. glauca (w)

- $\quad$ Thallus in transverse section 1-3 (4) times as wide as high; margins rounded or bulging, not decurved. 17 
17 Spores 60-80 $\mu \mathrm{m}$, diffusely sculptured on proximal face, mostly without distinct alveolae; distal face with 5-7 alveolae across; ripe spores translucent brown, with conspicuous yellowish wing $c a 5 \mu \mathrm{m}$ wide; medium-sized plants with bulging thallus margins. Riccia bifurca (w) Notes: (i) the plants described and illustrated in Paton (1999) under this name belong to R. subbifurca agg. according to Meinunger and Schröder (2007).

(ii) From $R$ glauca, which also has a rather wide thallus with a \pm flat groove, in section 3-5 times as wide as high, $R$. bifurca can be distinguished by being only 3 (4) times as wide as high in section and having raised, convex margins forming small tumid ridges (sharp, \pm deflexed margins in R. glauca). Spores of R. glauca are larger (80-100 $\mu \mathrm{m}$ in diameter vs. 60-80 $\mu \mathrm{m}$ in $R$. bifurca) and also differ in having usually well delimited alveolae on the proximal faces, and 6-8 (12) alveolae 6-12 $\mu \mathrm{m}$ wide across the distal face. The spores of $R$. bifurca are light brown and translucent even when old, whereas the spores of $R$ glauca are darker red brown to brown, blackish when old, opaque to hardly translucent (but light brown translucent when just ripe).

(iii) R. bifurca var. subinermis: Thallus apex with a few cilia.

- $\quad$ Spores with closed alveolae on proximal face; distal face with > 6 alveolae; marginal wing of spores distinct or indistinct; mostly small plants.

18 Spores 80-100 $\mu \mathrm{m}$, sometimes even larger, brown to dark brown, with 8-12 alveolae across distal face, red brown to dark brown, without any pink tinge, marginal wing of spores very narrow, mostly only weakly developed; thallus green to glaucous on dorsal side, margins and ventral side vigorously purple, regularly with some cilia; plants of calcareous rocky grassland, growing in irregular small patches or incomplete rosettes.

Riccia subbifurca $(\mathrm{r})$

Notes: (i) According to Meinunger and Schröder (2007) the plants in the drawings under this name in Gradstein and van Melick (1996), Paton (1999), Damsholt (2002) and Siebel and During (2006) apparently represent Riccia glauca var. subinermis (= var. ciliaris).

(ii) Cilia, papillose in their upper part, 70-120 (200) $\mu \mathrm{m}$, are not infrequently found near the thallus margin (in $R$. bifurca, smooth cilia, $120-340 \mu \mathrm{m}$, may be sometimes found).

- $\quad$ Spores 60-80 $\mu \mathrm{m}$, wing mostly distinct to well-developed...19

19 Distal face of spores with 10-12 alveolae across, proximal face with fine reticulate pattern; mature spores reddish brown; cilia few, but regularly present; thallus 1-3 times as wide as high, margins mostly with reddish tinge, otherwise resembling $R$. glauca

Riccia glauca var. ciliaris (rr) 
See the note under R. subbifurca.

- Distal face of spores with 6-10 alveolae across, reticulate pattern on proximal face similar, with wider and therefore less numerous alveolae; mature spores coffee brown; thallus mostly without cilia; thallus 1.2-2 (3) times as long as high, lobes pure green, linear, resembling terrestrial form of $R$. fluitans.

Riccia warnstorfii (n.s.)

Note: $R$. warnstorfii var. ciliaris: Thallus margins with short, single cilia. 


\section{KEYS TO SPECIES OF MOSSES}

\section{Key to sections and species of Sphagnum}

Branch leaves means leaves of spreading branches unless stated otherwise.

References: Dierssen (1996), Hill in Smith (2004), Szurdoki (2000, 2003), Szurdoki and Nagy (2002), Szurdoki et al. (1999-2000, 2014), Laine et al. (2011, 2018), Hassel et al. (2018)

1 Hyalodermis of stems (mostly) and branches (always) with spiral fibrils, best seen on pendent branches; branch leaves large, concave, 1.5-2 times as long as wide (Subgen. Sphagnum).

- Hyalodermis of stems and branches without spiral fibrils; branch leaves smaller, less concave, usually more than twice as long as wide

2 Branch leaves 2-3 mm, stem leaves smaller, < $0.7 \mathrm{~mm}$ long; apex of branch leaves broadly truncate; upper branches often pointing upwards; chlorocysts completely enclosed between hyalocysts (like in S. divinum); hyalodermis of branches of uniform cells with 1 apical pore each (Subgen. Rigida).

- $\quad$ Stem leaves usually $>0.7 \mathrm{~mm}$ long, often longer than branch leaves (if stem leaves small, $0.7 \mathrm{~mm}$ or less, then branch leaves with acute or cuspidate apex); apex of branch leaves narrowly truncate; chlorocysts not completely enclosed between hyalocysts; hyalodermis of branches consisting of 2 types of cells, short poreless cells and long "retort cells" with apical pore.

3 Chlorocysts of branch leaves exposed on ventral side in transverse section (or exposed on both sides, but more so on ventral side); branch leaves small, lanceolate; plants often with red colours (Subgen. Acutifolia Sect. Acutifolia) .........12

- Chlorocysts of branch leaves with a wider exposure on the dorsal side or \pm equally exposed on both sides in transverse section; branch leaves small or large; plants never with red colours, green, yellow-green, yellow or brown

4 Chlorocysts of branch leaves \pm equally exposed on both sides in transverse section; hyalocysts of branch leaves mostly with numerous small ringed pores on dorsal side arranged in rows along commissures; spreading and 
pendent branches weakly differentiated, branches in capitulum often homomallous, horn-like; plants often with yellow and brown colours (Subgen. Subsecunda). 8

- Chlorocysts of branch leaves more exposed on dorsal than on ventral side; pores on dorsal side of hyalocysts of branch leaves few or numerous, but not arranged in rows; spreading and pendent branches strongly differentiated, branches in capitulum not homomallous, not horn-like.......... 5

5 Stem leaves with border of several rows of elongate cells; branch leaves undulate when dry, 3-7 times as long as wide; stem hyalodermis sometimes not clearly distinguishable from sclerodermis (Subgen. Cuspidata).

- $\quad$ Stem leaves with few rows of elongate cells at leaf base only; branch leaves shorter, not undulate when dry, often with apices reflexed; stem hyalodermis sharply differentiated from sclerodermis (Subgen. Acutifolia Sect. Squarrosa)... 24

6(1) Plants usually purplish red or tinged with red; chlorocysts elliptical in transverse section, completely enclosed by hyalocysts, centrally placed.

Sphagnum divinum

(Sphagnum magellanicum auct. pp.) (rr)

- $\quad$ Plants green, brown, not red; chlorocysts exposed on ventral side or if enclosed between hyalocysts then placement not central.

7 Chlorocysts in transverse section narrowly triangular, exposed on ventral side. Sphagnum palustre $(\mathrm{r})$

- Chlorocysts in transverse section centered but very narrowly exposed on both sides, lenticular or spindleshaped to narrowly triangular with broader side close to ventral surface, cell walls thickened.

Sphagnum centrale (rr)

8(3) Hyalodermis of stem (1) 2-3-layered in transverse section.....

- $\quad$ Hyalodermis of stem unistratose, stem often \pm dark .............10

9 Hyalodermis of stem 1-2-layered; stem leaves to $2.5 \mathrm{~mm}$ long, broadly lingulate...............Sphagnum platyphyllum (rr)

- $\quad$ Hyalodermis of stem 2-4-layered, stem leaves < $1 \mathrm{~mm}$ long, triangular-lingulate Sphagnum contortum (rr)

10 Stem leaves 0.4-0.6 (0.9) mm long; plants slender, yellowish to brownish green Sphagnum subsecundum (r)

- $\quad$ Stem leaves at least $0.9 \mathrm{~mm}$ long 
11 Stem leaves 0.9-1.5 mm long, triangular-lingulate, widest at leaf base, fibrillose in upper third; spreading branches not or only weakly homomallous.

Sphagnum inundatum (rr)

- $\quad$ Stem leaves to $2.5 \mathrm{~mm}$ long, lingulate to spathulate, widest above leaf base, sometimes fibrillose to base; branches often homomallous, horn-like

Sphagnum auriculatum (Sphagnum denticulatum) (rr)

12(4) Stem leaves spathulate, broadly truncate, fringed at apex; plants with distinct terminal bud; plants always green, never red..

- Stem leaves triangular to lingulate, not fringed at apex; plants red or green.

13 Stem leaves expanded at apex, margins fringed from apex to lower half of leaf.

Sphagnum fimbriatum $(\mathrm{r})$

- $\quad$ Stem leaves not expanded, fringed only at apex

Sphagnum girgensohnii (rr)

14 Stem leaves lingulate, apex broadly rounded, the sides \pm parallel, flat, not incurved.

- $\quad$ Stem leaves triangular, with acute or obtuse apex, the sides tapering slightly at base, more strongly towards apex, flat or incurved towards apex.

15 Outer cells of stem hyalodermis with scattered pores, not more than 1 pore per cell; branch leaf hyalocysts with numerous pores on both sides; stem leaves broadly lingulate, slightly denticulate-fringed at rounded apex.

Sphagnum russowii (rr)

- $\quad$ Outer cells of stem hyalodermis without pores; branch leaf hyalocysts with numerous pores on dorsal side only. 16

16 Branch leaves in 5 distinct ranks, their hyalocysts towards apex with many small ( $c a 5 \mu \mathrm{m})$ ringed pores on dorsal side; branch leaf apices pointing outward when dry; plants reddish violet. Sphagnum warnstorfii (n.s.)

- $\quad$ Branch leaves not in 5 ranks, their hyalocysts with larger, elliptical, less distinctly ringed pores on dorsal side; branch leaf apices not pointing outward when dry; plants reddish.....

Sphagnum capillifolium $(\mathrm{r})$

17 Branch leaves distinctly 5-ranked in and below capitulum; fascicles with 4-5 branches in total, of which 2-3 are spreading; stem leaves triangular-acuminate, with wide zone of elongate cells at base; stem hyalodermis with 
scattered pores or pseudopores; sclerodermis green with red spots. Sphagnum quinquefarium (rr)

- Branch leaves not distinctly 5-ranked outside capitulum; fascicles with 3-4 branches in total, of which rarely more than 2 are spreading; stem hyalodermis without pores, but sometimes with pseudopores; sclerodermis reddish or brownish even in otherwise green plants.

18 Stem leaves 1.5-1.7 mm long, contracted into tubulose apex, at base with narrow to moderately widened zone of elongate cells, hyalocysts usually without fibrils, several times septate; plants lustrous when dry, violet reddish.

Sphagnum subnitens (n.s.)

- $\quad$ Stem leaves 0.9-1.4 mm long, not contracted into tubulous apex, triangular to triangular-lingulate, often rounded at apex, at base with widened zone of elongate cells, hyalocysts usually with fibrils in apical part of stem leaf, \pm septate, but rarely more than once; plants not lustrous when dry, reddish, often in compact tufts...Sphagnum capillifolium (r)

19(5) Stem leaves to $1.6 \mathrm{~mm}$ long, at apex with a cleft of $1 / 3$ of leaf length; branch leaves to $3 \mathrm{~mm}$ long; very robust, green plants. Sphagnum riparium $(\mathrm{rr})$

- $\quad$ Stem leaves without apical cleft .............................................20

20 Stem leaves triangular-lingulate to lingulate, rounded at apex

- $\quad$ Stem leaves triangular, narrowed above, rounded or acute at apex 23

21 Branch leaf hyalocysts with numerous dorsal pores arranged in 1 or 2 rows, pores often indistinct and visible only after extensive staining; stem leaves > $1 \mathrm{~mm}$ long; robust plants.

Sphagnum obtusum (rr)

- Branch leaf hyalocysts with few pores in the cell corners only...

22 Stem leaves $1 \mathrm{~mm}$ long or little longer, longer than wide; axes of branches and stems pale; robust plants

Sphagnum flexuosum (rr)

- $\quad$ Stem leaves mostly $<1 \mathrm{~mm}$ long, as long as wide; axes of branches and stems often pink; small to medium sized plants.

Sphagnum angustifolium (r)

23 Stem leaves 1-2 mm long, triangular, longer than wide; branch leaves $>4$ times as long as wide; chlorocysts 
trapezium-shaped in transverse section, exposed on both sides

Sphagnum cuspidatum (rr)

- $\quad$ Stem leaves $<1 \mathrm{~mm}$ long, triangular, as long as wide, apex cuspidate; chlorocysts in transverse section widely exposed on dorsal side, narrowly exposed on ventral side.

Sphagnum fallax $(\mathrm{r})$

Note: A useful way to distinguish $S$. fallax from $S$. cuspidatum in the field is to tear off a capitulum and inspect the pendent branches at its underside: these are in pairs, whitish and downwards pointing in S. fallax, whereas in $S$. cuspidatum they are greener and stick out sideways (Godfrey and Hill 2012).

24(5) Plants mostly bright green to greenish yellow; branch leaves with apices distinctly reflexed, 1.7-3.1 × 1.0-1.8 mm; hyalocysts elongate throughout the leaf, distinctly wider in basal part Sphagnum squarrosum (r)

- $\quad$ Plants yellowish brown, rarely pure green; branch leaves usually imbricate, apices rearly reflexed, 1.0-2.3 × 0.5-1.2 $\mathrm{mm}$, hyalocysts shorter towards apex, of equal width throughout leaf.

Sphagnum teres (rr)

\section{Key to the varieties of Andreaea rupestris}

References: Murray $(1987,1988)$

- Leaves shortly and bluntly apiculate, 0.7-1.5 mm long; plants to $2 \mathrm{~cm}$ high; papillae on dorsal side of leaves less than twice as high as wide.

Andreaea rupestris var. rupestris

- $\quad$ Leaves narrow, longly pointed, to $2 \mathrm{~mm}$ long; plants to $3 \mathrm{~cm}$ high; papillae on dorsal side of leaves more than twice as high as wide Andreaea rupestris var. papillosa

\section{Key to species of Polytrichaceae}

For an auxiliary key for sterile plants of Polytrichastrum, Polytrichum and Pogonatum, see below

1 Costa narrow (< 1/5 leaf width), leaves therefore translucent, crispate when dry, bordered by long narrow cells, transversely undulate when moist; capsule usually inclined (nearly erect in A. flavisetum), with long operculum and cucullate, hairless calyptra. Atrichum. 
- Costa wide, filling upper part of leaf, leaves therefore opaque, not changed when dry, whithout border of narrow long cells, never transversely undulate; usually leaf base sheathing; capsule with campanulate, usually hairy calyptra..

2 Leaves about $1 \mathrm{~mm}$ wide; lamina cells 10-16 (20) $\mu \mathrm{m}$ in diameter; leaves \pm taut, not much transversely undulate; lamellae 5-6 (7) in number, 6-9 cells high; spores 12-14 $\mu \mathrm{m}$

Atrichum angustatum (w)

- Leaves 1.5-2 mm wide; lamina cells 20-30 (50) $\mu \mathrm{m}$ in diameter; leaves distinctly transversely undulate; lamellae 4-5 (6) in number, to 5 cells high; spores $16-20 \mu \mathrm{m}$. 3

3 Autoicous (antheridia terminal on first year's growth, archegonia terminal on second year's growth); sporophytes mostly single, seta red, capsule red brown, inclined.

Atrichum undulatum (c)

- Paroicous (antheridia terminal, archegonia outside perigonial leaves, stem continuing growth for 2 or more years, so that persistent setae appear lateral); often several sporophytes in a single perichaetium, seta yellowish (strawcoloured to reddish-yellow), capsule dark purple to reddish, narrow, almost erect.

Atrichum flavisetum (Atrichum haussknechtii, A. undulatum var. gracilisetum) (rr)

4(1) Capsule without apophysis and stomata, terete. Pogonatum

- $\quad$ Capsule with apophysis and stomata, 4-6-angled or terete...7

5 Plants bluish-green, $>2 \mathrm{~cm}$ tall, often branched or with subterranean stolons; protonema not persistent; uppermost cells of lamellae papillose, wider than tall in cross section.

Pogonatum urnigerum (w) Note: for the difference between this species and Polytrichastrum alpinum, see the note under that species.

- Plants dark green, $<2 \mathrm{~cm}$ tall, unbranched; protonema persistent; uppermost cells of costal lamellae smooth.............6

6 Leaf margins serrate to mid-leaf or along whole blade; capsule (without lid) (1.8) 2.8-3.2 (3.8) mm long, shortly cylindrical, 2-3 times as long as wide, exothecial cells with coarse prominent mamillae.

Pogonatum aloides (w) 
- $\quad$ Leaf margins serrate only at apex; capsule (without lid) to $2.3 \mathrm{~mm}$ long, ovoid to almost globose, 1-1.5 times as long as wide, exothecial cells finely papillose

Pogonatum nanum $(\mathrm{r})$

7 Capsule cylindrical, rounded; uppermost cells of costal lamellae papillose, taller than wide in cross section

Polytrichastrum alpinum (Polytrichum alpinum) (n.s.) Note: Pogonatum urnigerum also has papillose end cells of lamellae, but these are wider than tall. Other differences between these two species which share also round, not angled capsules, are: (i) colour: dull green in $P$. alpinum, glaucous green in Pogonatum urnigerum; (ii) length of sheathing part of leaf: $24-30 \%$ of total leaf length in P. alpinum, to $22 \%$ in Pogonatum urnigerum; (iii) stomata lacking in capsules of $P$. urnigerum, stomata present at base of urn in P. alpinum.

- $\quad$ Capsule angled; uppermost cells of costal lamellae smooth. Polytrichum.

8 Leaf margins sharply serrate in upper part of leaf, plane when moist.

- Leaf margins almost entire (except at tip), involute when moist.

9 Uppermost cells of costal lamellae furrowed or flat in transverse section, at least in part.

- Uppermost cells of costal lamellae all rounded........................11

10 Uppermost cells of costal lamellae all grooved.

Polytrichum commune (r)

- Uppermost cells of costal lamellae variable in shape, some asymmetric, some grooved, some flat-topped (especially in median part of costa), some rounded (especially in marginal part of costa).

Polytrichum perigoniale (P. commune var. perigoniale) $(\mathrm{r})$

11 Lamina in upper part of leaf consisting of 3-5 rows of cells; teeth 1-celled; lamina cells 10-15 $\mu$ m wide; capsule with 4-6 sharp edges; spores 12-16 $\mu$ m....Polytrichum formosum (c) Notes: (i) Fully developed leaves of $P$. formosum have a V-shaped ridge at their back formed by the prominent costa, whereas the dorsal side of the leaf is rounded in $P$. commune. (ii) The basal sheathing part of the leaf is dull in $P$. formosum, but shiny in $P$. commune, (iii) Young leaves of $P$. formosum may be indistiunguishable from $P$. longisetum.

- $\quad$ Lamina in upper part of leaf consisting of 6-15 rows of cells; teeth formed of 1-2 cells; lamina cells 15-20 $\mu \mathrm{m}$ wide, capsule with 5-6 blunt edges; spores 18-26 $\mu \mathrm{m}$ 
12(8) Excurrent part of costa hyaline, $1 / 4-1 / 3$ as long as leaf; lamellae crenulate with crenulae directed towards leaf apex

Polytrichum piliferum $(\mathrm{w})$

- $\quad$ Excurrent part of costa brownish; crenulae of lamellae \pm erect.

13 Plants to $7 \mathrm{~cm}$ tall, leaves patent when moist, stems not or slightly tomentose; capsule $c a 5 \mathrm{~mm}$ long; on dry soil.

Polytrichum juniperinum (w)

- Plants to $20 \mathrm{~cm}$ tall, leaves erect-spreading when moist, stems densely tomentose with whitish rhizoids; capsule $c a 3$ mm long; in bogs.

Polytrichum strictum (rr)

Auxiliary key for sterile plants of Polytrichum, Polytrichastrum and Pogonatum

1 Leaf margin inflexed over blade, partly covering lamellae, appearing entire (except at leaf tip).

Polytrichum piliferum, $P$. juniperinum, $P$. strictum

- $\quad$ Leaf margin sharply serrate, not inflexed.................................. 2

$2 \quad$ End cell of lamellae papillose

- $\quad$ End cell of lamellae not papillose ................................................ 4

3 Sheathing part of leaf relatively short, to $22 \%$ of total leaf length, plants glaucous; end cell of lamellae wider than high..

Pogonatum urnigerum

- $\quad$ Sheathing part of leaf longer, $24-30 \%$ of total leaf length, plants dull green; end cell of lamellae higher than wide

Polytrichastrum alpinum

4 End cell of lamellae grooved, at least in part of lamellae.

Polytrichum commune, $P$. perigoniale

- $\quad$ End cell of lamellae rounded.................................................. 5

5 Plants small, to $2 \mathrm{~cm}$ high, with persistent protonema; costa not excurrent.

Pogonatum aloides, $P$. nanum

- Plants mostly much higher than $2 \mathrm{~cm}$, robust; without persistent protonema; costa excurrent as apiculus.

Polytrichum formosum, P. longisetum 


\section{Key to species of Buxbaumia}

References: Deme et al. (2020), Erzberger et al. (2018)

- $\quad$ Sporophyte reddish brown, glossy, capsule ovoid, strongly flattened, with a sharp edge; capsule epidermis not peeling off on dorsal side, or only to a mostly small extent at capsule mouth; peristome teeth uniseriate; stomata (at neck of capsule) deeply immersed (cryptopore); on soil.

\section{Buxbaumia aphylla $(\mathrm{w})$}

- $\quad$ Sporophyte greenish or greenish brown, not glossy when brownish and ripe; capsule elliptic, hardly flattened; epidermis in ripe capsules peeling off partly, remaining parts conspicuous ("indusium"); peristome teeth in 4 rows; stomata only shallowly immersed, appearing phaneropore; on soil, on rotting wood

Buxbaumia viridis $(\mathrm{w})$

\section{Key to species of Timmia}

Reference: Mastracci (1993)

- Sheathing part of leaf orange or red brown; dorsal surface of costa in upper part of leaf serrate to obtusely dentate; costa of sheathing part of lamina without stereids; endostome cilia without appendages; dioicous, capsules rare

Timmia austriaca (rr)

- $\quad$ Sheathing part pale or yellow throughout; dorsal surface of costa in upper part of leaf smooth; costa at centre of leaf sheath with stereids; endostome cilia appendiculate; monoicous, capsules frequent.

Timmia bavarica (rr)

\section{Key to species of Encalypta}

References: Nyholm (1998), Meinunger and Schröder (2007)

1 Plants with clusters of brownish filamentous gemmae in leaf axils; plants dioicous, rarely with sporophytes; urn spirally striate, spirally furrowed when dry; uppermost leaves obtuse or subacute; costa not excurrent.

Encalypta streptocarpa $(\mathrm{w})$

- $\quad$ Plants without gemmae in leaf axils; urn smooth or with longitudinal stripes or furrows. 
2 Peristome absent; calyptra smooth or erose at base; spores coarsely papillose; leaves bluntly pointed, costa ceasing below leaf apex (rarely shortly excurrent).

Encalypta vulgaris $(\mathrm{w})$

Note: In Encalypta vulgaris var. apiculata ( $\mathrm{rr}$ ) the costa is shortly excurrent or ending in a more or less long hairpoint.

- $\quad$ Peristome present, single; costa excurrent as short apiculus or longer hair point. 3

3 Leaf apex with short apiculus; calyptra lobed ("ciliate") at base, shiny, smooth; seta yellow; capsule smooth; spores with numerous radial plicae on the proximal surface and with 5-7 plicae on the distal surface, not papillose.

Encalypta ciliata (r)

- $\quad$ Leaf apex mostly with long hair point; calyptra smooth or erose at base, papillose throughout; seta red; capsule with prominent longitudinal red-brown striae, when dry deeply furrowed; spores on distal surface with large hemispherical papillae.

Encalypta rhaptocarpa (n.s.)

\section{Key to species of Funariaceae}

References: Erzberger (2002), Guerra et al. (2010)

1 Seta only 1-2 mm long, capsule immersed in leaves; capsule indehiscent, without lid, globose with short apiculus; plants $<5$ mm high

Physcomitrium patens

(Aphanorrhegma patens, Physcomitrella patens) (w)

- $\quad$ Seta longer, capsule exserted, dehiscent 2

2 Calyptra persistent, inflated, contracted at base, with four angles; capsule emergent to exserted, not reached by upper leaves, ovoid to subglobose, as long as seta; spores 45-70 $\mu \mathrm{m}$

Pyramidula tetragona (r)

- Calyptra caducous, small, not inflated; capsule clearly exserted; subglobose or not; spores less than $45 \mu \mathrm{m}$.

3 Capsule furrowed when dry and empty; seta cygneous; peristome sigmoid, teeth fused apically in a disc; calyptra cucullate. Funaria hygrometrica $(\mathrm{w})$

- Capsule smooth, not furrowed; seta not cygneous; peristome teeth not fused apically in a disc or peristome lacking or rudimentary; calyptra cucullate or mitrate. 
3 Peristome present; capsule obovoid or pyriform, inclined; exothecial cells rectangular; calyptra cucullate.

- Peristome lacking or rudimentary; capsule subglobose or pyriform, erect; exothecial cells rectangular or isodiametric; calyptra cucullate or mitrate..

4 Leaf margins sharply serrate in upper half of leaf by projecting cells; marginal cells usually longer and narrower than adjacent cells; seta 7-11 mm long; capsule curved, $c a 3$ $\mathrm{mm}$ long, with ca 70 stomata; spores coarsely papillose.

Entosthodon muhlenbergii (Funaria muhlenbergii) ( $\mathrm{r}$ )

- Leaf margins entire to bluntly denticulate by slightly projecting cell ends; marginal cells similar to adjacent cells; seta 5-8 mm long; capsule curved, ca $2 \mathrm{~mm}$ long, with ca 30 stomata; spores finely papillose.

Entosthodon pulchellus (Funaria pulchella) (w)

5 Calyptra of ripe capsule cucullate; lid without apiculus; exothecial cells isodiametric, incrassate.

Entosthodon fascicularis (r)

- Calyptra of ripe, fully developed capsules mitrate, usually trilobed at base; lid with a short apiculus to rostrate; exothecial cells \pm isodiametric, thin-walled or rectangular and strongly incrassate.

6 Capsule pear-shaped to club-shaped, with a long neck; exothecial cells long and narrow, nearly linear, incrassate; peristome present, but rudimentary, slightly protruding from the mouth of the urn and soon disappearing after dehiscence; leaves entire; spores coarsely papillose...

Entosthodon hungaricus (w)

- Capsule semiglobose to pear-shaped, usually with a short, indistinct neck; exothecial cells lax, predominantly rounded quadrate to hexagonal; peristome absent; leaf margin \pm entire to crenulate or distinctly denticulate by protruding cells longer and often narrower than adjacent lamina cells; spores densely echinate. Physcomitrium pp.

7 Capsule pear-shaped, gradually narrowed into seta; plants (including seta) 5-10 mm tall; spores 24-35 $\mu \mathrm{m}$; leaf margin distinctly denticulate by protruding narrow and long cells......

Physcomitrium pyriforme $(\mathrm{w})$

Note: Young capsules, green and still covered by the calyptra, of this species have a rostrate lid (from a conical base gradually narrowed to a 
beak), whereas young capsules in the same state of $E$. hungaricus have a low conical, but not rostrate lid, through which the peristome is visible; in the process of ripening and drying, the lid of E. hungaricus becomes flat and shortly rostrate.

- Capsule globose or semiglobose, empty capsule hemispherical, wide-mouthed; plants 3-7 $\mathrm{mm}$ tall; leaf margin entire or denticulate ........................................................ 8

8 Leaf margin distinctly denticulate above; costa percurrent or excurrent; seta 2-5 mm long; spores 30-40 $\mu \mathrm{m}$; plant (including sporophyte) 5-7 $\mathrm{mm}$ tall.

Physcomitrium eurystomum (r)

- Leaf margin \pm entire, \pm inrolled towards blunt, slightly cucullate apex; costa ending below leaf apex; seta 1-2 mm long; spores 24-32 $\mu \mathrm{m}$; plant (including sporophyte) 2-5 $\mathrm{mm}$ tall

Physcomitrium sphaericum (n.s.)

\section{Key to species of Flexitrichum}

- Costa in transverse section not projecting dorsally, transition to lamina continuous, cross section forming a smooth ring; basal paracostal cells narrow, elongate, distinctly porose to nodulose; plants $4-11 \mathrm{~cm}$ tall, leaves 4$11 \mathrm{~mm}$ long.. Flexitrichum gracile (Ditrichum crispatissimum, D. flexicaule var. sterilis; D. gracile) (rr) Note: For an account of this species in Hungary, see Erzberger (2001).

- $\quad$ Costa in transverse section projecting dorsally, transition to lamina discontinuous; often pseudopapillose with projecting cross walls ('Pfeilerpapillen') seen in cross section; basal paracostal cells wider, rectangular, not or only indistinctly porose; plants $1-5 \mathrm{~cm}$ tall, leaves 1-3.5 mm long.

Flexitrichum flexicaule (Ditrichum flexicaule s.str.) (w)

\section{Key to species of Campylopus}

References: Erzberger and Németh (2014), Csiky et al. $(2014,2015)$

Note: transverse sections of the costa should be made at about 1/4 of leaf length above the base

1 Leaves piliferous due to hyaline excurrent costa (which may be reduced in shaded habitats), hair points reflexed when dry; dorsal surface of costa ribbed; ventral cells wide, empty, occupying ca $25-50 \%$ of total costa thickness, about as 
many or slightly more numerous than median guide cells (cross section); seta cygneous before capsule maturation, calyptra fringed at base. Campylopus introflexus (w)

- Leaves without hyaline apices, not piliferous; dorsal surface of costa smooth or ribbed.

2 Costa without stereids in transverse section; vegetative propagation by caducous shoot tips with long, erecto-patent leaves; mostly small plants

(stunted forms of) Campylopus pyriformis

- Costa with stereids 3

3 Ventral cells smaller and more numerous than median cells in transverse section of costa, occupying ca 16-36\% of total costa thickness; alar cells forming conspicuous hyaline or more often brown auricles; vegetative propagation by caducous branches, small-leaved at base, but with a longleaved apex, at stem tips.

Campylopus flexuosus $(\mathrm{r})$ Note: Dicranum flagellare produces similar caducous branches, which are, however, uniformly small-leaved to the tip.

- Ventral cells of at least equal size as and not more in number than median cells in costa cross sections; alar cells variable, vegetative propagation mostly by caducous leaves.. 4

4 Leaves widest at or almost at base; ventral cells usually smaller than guide cells (but larger in slender plants: Smith (2004: Fig. 65,7)), occupying ca 32-54\% of total costa thickness; alar cells usually undifferentiated, hyaline or pale red, rarely forming distinct auricles; leaf apex canaliculate, denticulate; vegetative propagation by broadly oval brood leaves at stem tips Campylopus pyriformis (rr)

- Leaves widest $1 / 8$ to $1 / 4$ distance from base, tapering downwards; ventral cells larger than median cells and about equal in number, occupying between $1 / 3$ and $2 / 3$ of total costa thickness, dorsal groups of stereids distinct; basal cells hyaline, not forming auricles, conspicuously shining whitish in dry and moist plants; vegetative propagation by bundles of caducous minute, linear leaves in axils of normal leaves at shoot apex.

Campylopus fragilis (rr) 


\section{Key to species of Leucobryum}

Reference: Zündorf (1988)

- $\quad$ Most cells in the middle of the leaf base $>30 \mu \mathrm{m}$ wide; hyaline marginal cells (=lamina cells) mostly in 5-8 rows, at extreme margin narrow and elongate cells with an abrupt transition; capsule distinctly strumose; pores of hyalocysts (transverse section!) 15-20 $\mu \mathrm{m}$ wide, many large; basal expanded part of leaf usually longer than narrowly triangular tubular apical part, transition usually \pm gradual; cushions higher, more swelling than in the following species

Leucobryum glaucum (w)

- $\quad$ Most cells in the middle of the leaf base $<30 \mu \mathrm{m}$ wide; hyaline marginal cells in 9-14 rows, towards extreme margin gradually more elongate; capsule weakly strumose; pores of hyalocysts (transverse section!) predominantly small, 10-12 (15) $\mu \mathrm{m}$ wide; basal part of leaf usually shorter than \pm parallel-sided apical tubular part, transition \pm abrupt; cushions and plants usually smaller than in preceding species Leucobryum juniperoideum ( $\mathrm{r}$ )

\section{Key to species of Dicranella}

1 Leaves crispate when dry; leaf base sheathing, contracted into a squarrose acumen.

- Leaves erect-spreading, or homomallous, at most weakly contorted when dry, not crispate, not squarrose, leaf base not sheathing.

2 Capsule erect, symmetric, striate; lamina cells 4-6 $\mu$ m wide; rhizoidal tubers absent; autoicous, always with sporophytes

Dicranella crispa (n.s.)

- $\quad$ Capsule inclined, asymmetric, smooth; lamina cells 6-14 $\mu \mathrm{m}$ wide; rhizoidal tubers often present; dioicous, not often with sporophytes

Dicranella schreberiana (w) Note: For the difference between this species and Trichodon cylindricus, see the note under the latter.

3 Plants almost always sterile, always with irregularly shaped, brownish rhizoidal tubers; leaves erect-spreading, shortly acuminate from broadly lanceolate base, margin plane, denticulate at apex; lamina cells $9-14 \mu \mathrm{m}$ wide; plants to 5 
$\mathrm{mm}$ tall

Dicranella staphylina $(\mathrm{w})$

- Plants often with sporophytes, different combination of characters

4 Seta yellow; costa filling 1/3 of leaf width at base or more...5 Note: compare also $D$. howei with costa indistinctly delimited at leaf base (9).

- $\quad$ Seta red; costa filling up to $1 / 5$ of leaf base

5 Capsule strumose, brown; leaves suberect to secund, entire except at apex; basal cells 70-115 $\mu$ m long

\section{Dicranella cerviculata (rr)}

- Capsule not strumose, reddish brown; leaves falcate, dentate; basal cells 30-50 $\mu \mathrm{m}$ long.

Dicranella heteromalla (c)

6 Perichaetial leaves differentiated from normal leaves, suddenly contracted into acumen from sheathing base; leaves erect or secund; leaf margins almost entire; capsule striate, lid longly rostrate; rhizoidal tubers often present, dark brown; plants 5-20 mm tall...Dicranella subulata (n.s.)

- $\quad$ Perichaetial leaves not differentiated from lower leaves, not sheathing, gradually narrowed into acumen

7 Capsule erect, symmetric; leaves mostly homomallous, reddish; stems and setae reddish; leaf margin plane, very weakly denticulate in upper part of leaf...

Dicranella rufescens $(\mathrm{r})$

Note: When sterile, this species can be recognized by its mostly reddish stems and \pm homomallous leaves, which appear cross-striated, since the chloroplasts tend to crowd in the cell corners and the cells are arranged in transverse rows. It often grows together with Pohlia lescuriana, from which it can be distinguished by the marginal cells which are wider than median leaf cells (narrower in P. lescuriana).

- Capsule curved, asymmetric; leaves erect or weakly homomallous; margins recurved or plane, entire or weakly denticulate only near the tip, plants not reddish.

8 Leaf margins recurved; leaves erect when dry, stiff; longitudinal walls of exothecial cells more heavily thickened than transverse walls; plants in tufts to $1 \mathrm{~cm}$ tall.

Dicranella varia $(\mathrm{w})$

- $\quad$ Leaf margins \pm plane.

9 Lamina cells irregularly bistratose; costa strong, filling 1/3 leaf base, indistinctly differentiated from lamina; longitudinal walls of exothecial cells hardly wider than 
transverse walls

Dicranella howei (w)

- Lamina cells unistratose; costa narrower, clearly differentiated ........................................ Dicranella humilis (n.s.)

\section{Key to species of Fissidens}

Reference: Erzberger (2016)

1 Leaves with a border of elongate cells (limbidium), at least in sheathing part of lamina.

Note: Fissidens arnoldii, which has elongate marginal cells resembling a border on the sheathing part of perichaetial leaves, is keyed out in both alternatives.

- Leaves without a border of elongate cells.

2 Lamina cells twice as long as wide; plants 1-3 mm long with 3-5 pairs of leaves; leaves narrowly lanceolate, tapering to apex from below middle; terricolous.

Fissidens curvatus (Fissidens algarvicus) (n.s.)

- $\quad$ Lamina cells as long as wide; leaves tapering only at apex.....3

3 Limbidium mostly confined to sheathing part of perichaetial leaves, sometimes variously reduced on cauline leaves; apex rounded to obtuse, cells below apex often in concentric rows; margin slightly crenulate by protruding cell ends; plants growing on limestone or other base-rich rock in or near water.

Fissidens arnoldii $(\mathrm{r})$

- Limbidium well developed on all laminae and all leaves except sometimes the lowermost.

$4 \quad$ Leaf cells conspicuously small, usually not longer than $8 \mu \mathrm{m}$ and not wider than $6 \mu \mathrm{m}$; leaves oblong to ovate-lanceolate, $>2.5$ times as long as wide, median lamina cells distinctly protuberant on both sides, higher than wide (transverse section)................ Fissidens crispus (Fissidens limbatus) (n.s.)

- $\quad$ Leaf cells not conspicuously small, usually larger.....................5

5 Limbidium confluent with excurrent or percurrent costa; antheridia often in bud-like perigonia or naked in leaf axils....

- Limbidium not confluent with costa; antheridia not axillary..

6 Antheridia terminal in dwarf male plants; capsule asymmetric, strongly inclined................Fissidens incurvus $(\mathrm{r})$

- $\quad$ Antheridia axillary, not in dwarf male plants; capsule erect 
or inclined

7 Antheridia nearly always naked in leaf axils; plants mostly growing on periodically inundated, silt-covered tree trunks or roots (rarely also rocks or stones; in other European countries often on silt-covered stones of artificial riverbank enforcements along great rivers).

Fissidens gymnandrus $(\mathrm{w})$

- Antheridia in axillary bud-like perigonia, rarely naked; plants growing on moist loamy soil usually away from water

Fissidens bryoides $(\mathrm{w})$

8 Limbidium bi- to pluristratose on vaginant laminae; sheathing part often with intramarginal limbidium; costa ceasing below leaf apex; median lamina cells (10)12-18(20) $\mu \mathrm{m}$ long; plants 5-30 mm long; mostly on calcareous or base-rich rocks near or in water. Fissidens crassipes (incl. Fissidens crassipes subsp. warnstorfii) (w)

- $\quad$ Limbidium 1-2-stratose on vaginant laminae; plants often <

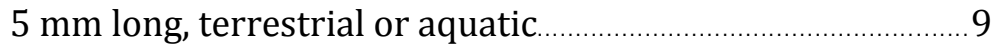

9 Terricolous plants ................................................................ 10

- Plants growing on moist siliceous or calcareous rock or in streams.

10 Capsules symmetric, erect.

Fissidens viridulus (incl. F. bambergeri) (w)

- Capsules asymmetric, inclined

Fissidens incurvus $(\mathrm{r})$

11 Perichaetial leaves 4-6 times as long as wide, lanceolate, rather broad, suddenly narrowed to a short and wide, somewhat obtuse or \pm acute apex; plants hydrophilous, growing on siliceous rock often close to flowing water or inundated.

Fissidens pusillus $(\mathrm{w})$

- Perichaetial leaves to 6-7 (9) times as long as wide, narrower, more gradually narrowed to slightly cuspidate point; plants growing on moist to wet calcareous rock

Fissidens gracilifolius $(\mathrm{w})$

12(1) Mature plants small, 1-4 (6) mm long ..................................13

_ $\quad$ Mature plants $>1 \mathrm{~cm}$ long ................................................. 14

13 Leaves in 2-4 pairs, plants procumbent; margin at apex finely crenulate, margin on sheathing part of perichaetial leaves often coarsely dentate; dorsal lamina not extending to leaf base; terricolous, nearly always with capsules.

Fissidens exilis (w) 
- $\quad$ Leaves in 4-5 (10) pairs, increasing in length towards stem apex, plants erect; margin at apex entire or indistinctly crenulate by protruding cells, sheathing part of leaves entire; dorsal lamina reaching leaf base; plants growing on limestone or other base-rich rock and stones in or near water.

Fissidens arnoldii $(\mathrm{r})$

14 Leaf margin dentate with large and smaller teeth alternating, particularly near apex; several rows of cells near margin forming pale band

- Leaf margin entire to crenulate, sometimes with 2-3 teeth near apex; leaf margin without pale band or just one marginal cell row paler; costa excurrent as a short apiculus; upper lamina cells 6-10 $\mu \mathrm{m}$ long, distinctly bulging to mamillose; perichaetia at the base of shoots

Fissidens taxifolius (c)

15 Lamina cells (10) 12-20 $\mu \mathrm{m}$ wide, lamina unistratose, \pm translucent; plants $2-10 \mathrm{~cm}$ tall...Fissidens adianthoides $(\mathrm{r})$

- Lamina cells (5) 6-12 $\mu \mathrm{m}$ wide; lamina irregularly bistratose, opaque; plants 1-3 cm long. Fissidens dubius. 16

16 Costa ending shortly below leaf apex in uppermost leaves....... Fissidens dubius var. dubius $(\mathrm{w})$

- Costa shortly excurrent as mucro in uppermost leaves. Fissidens dubius var. mucronatus (r)

\section{Key to species of Dicranaceae}

References: Erzberger (1999), Hedenäs and Bisang (2004)

1 Costa broad, 1/3-4/5 leaf width at base or more …................ 2

- $\quad$ Costa narrower, < $1 / 3$ leaf width ............................................... 4

2 Costa in transverse section with large hyaline cells (hyalocysts) present on both the dorsal and ventral sides; costa filling 1/2-2/3 leaf width, ridged on dorsal surface; leaf apex denticulate; lamina at leaf base consisting of $c a 13$ cell rows; leaves hamate, plants in tufts to $4 \mathrm{~cm}$ tall.

Paraleucobryum longifolium (w)

- Costa in transverse section with a ventral and a dorsal layer of stereids, separated by the guide cells.

3 Leaves stiff and fragile, at least in upper part of shoot straight and erect when moist, upper leaf portions very narrow and tips frequently broken (touch cushion with 
moistened finger and inspect finger for broken tips); capsules straight and erect or nearly so

- $\quad$ Leaves in upper part not at the same time fragile, straight and erect, upper leaf portions not markedly narrow................5

4 Costa in basal portion lacking stereid bands, with up to 1-2 cell layers above and below guide cells (transverse section); basal lamina cells narrowly rectangular to linear (35-120 $\mu \mathrm{m}$, most cells $>40 \mu \mathrm{m}$ long), eporose; alar cells unistratose; dark green glossy dense tufts.

Dicranum tauricum (w)

- Costa in basal portion with stereid bands, sometimes weak, with up to 2-3 (4) layers of cells above and below guide cells; basal lamina cells quadrate to short-rectangular (16$50 \mu \mathrm{m}$, most cells $<30 \mu \mathrm{m}$ long), not or hardly porose, alar cells mostly bistratose, at least partially, rarely entirely unistratose; lamina above partially bistratose; plants light green, to $4 \mathrm{~cm}$ tall, leaves slightly curled when dry.

Dicranum viride ( $\mathrm{r}$ )

5 Cells in upper leaf mainly prosenchymatous, elongate and porose; usually robust plants.

- Cells in upper leaf mainly parenchymatous, quadrate or rectangular, rarely elongate-rectangular, with or without pores.

6 Costa above with 2 dorsal lamellae or ridges; leaves \pm transversely undulate.

- Costa above with 4 dorsal lamellae; leaves transversely undulate or not; variable species.....Dicranum scoparium (c)

7 Leaves at stem apex erect, further down spreading; leaf lamina strongly transversely undulate; costal lamellae tall; margin in upper part spinosely denticulate or dentate; margins recurved at leaf base; plants to $>10 \mathrm{~cm}$ high, densely whitish tomentose.

Dicranum polysetum $(\mathrm{w})$

- Orientation of apical leaves and leaves further down not clearly different; leaf lamina \pm transversely undulate (at least in some leaves); costal lamellae low or weakly developed; margin obtusely to sharply denticulate; margins flat at leaf base; plants to $10 \mathrm{~cm}$ high

Dicranum bonjeanii (r)

8 Upper leaf lamina in at least some leaves rugose, or \pm transversely undulate; scattered cells of lamina and costa on upper dorsal surface of leaf with conical mamillae; plants in 
loose tufts, to $6 \mathrm{~cm}$ high; leaves curled when dry, appressed to the stem in basal portion and suddenly narrowed to short acumen. Dicranum spurium (r)

- Leaves smooth, neither rugose nor undulate.

9 Small plants (rarely above $3 \mathrm{~cm}$ high, leaves up to $4 \mathrm{~mm}$ long and up to $0.5 \mathrm{~mm}$ wide); dry leaves strongly crisped; upper lamina cells mamillose, normally unistratose; costa occupying 1/5 leaf base; leaf margins denticulate from apex down to mid-leaf

Dicranum montanum (w)

Notes: (i) D. montanum can be distinguished from Dicranoweisia cirrata occurring in the same habitat (tree bark, siliceous rock) in the field by the size distribution of leaves: whereas in D. cirrata all leaves are of approximately the same size, in D. montanum leaves occur in a wider size range within one cushion, larger and in particular many smaller leaves mixed. (ii) When growing on rock, D. montanum could also be confused with species of Cynodontium, which are somewhat similar in habit (leaves crisped when dry), but distinguished by bistratose leaf margins (except the rare $C$. tenellum).

- Different combination of characters.

10 Small plants that almost invariably have numerous easily detached erect small-leaved flagellae from upper leaf axils; alar cells unistratose; costa occupying $1 / 3$ leaf base; leaf margins denticulate only at apices....Dicranum flagellare $(\mathrm{r})$ Note: For the difference to Campylopus flexuosus, see the note under that species.

- $\quad$ Plant size variable; if flagellae present, then never several on each plant; alar cells at least partially bistratose.

11 Upper leaf lamina bistratose in large portions; costa very broad, $1 / 3$ of basal leaf width; leaves crispate when dry; leaf margin denticulate in upper part of leaf; plants dark green, to $5 \mathrm{~cm}$ tall.

Dicranum fulvum (r)

- $\quad$ Upper leaf lamina unistratose; costa narrower, filling < 1/4 leaf width; upper leaf tubular (cross section with circular outline); leaves strongly curled when dry; leaf margin near apex irregularly and coarsely denticulate to dentate; robust, usually tomentose plants in tufts to $6 \mathrm{~cm}$ tall, leaves erectspreading, 5-7 mm long........ Dicranum muehlenbeckii (n.s.) 


\section{Key to species of Rhabdoweisiaceae}

1 Lamina cells smooth

- Lamina cells mamillose; upper leaf margin \pm bistratose, mamillae of marginal cells forming double teeth.

2 Capsules striate when dry and empty, less than 3 times as long as wide; leaf margin denticulate in upper part of leaf, sometimes only very slightly so.

- $\quad$ Capsules smooth, more than 3 times as long as wide; leaf margin entire; often with elliptical to cylindrical gemmae on basal part of lamina. Dicranoweisia cirrata (w) Note: For the difference between this species and Dicranum montanum see the note under the latter species.

3 Leaves not with parallel margins, tapering from lower third; peristome teeth divided to base; annulus formed of small cells, persistent, not separating...Cynodontium tenellum (rr)

- $\quad$ Leaves with \pm parallel margins, tapering only in upper $1 / 3$ to $1 / 5$; peristome teeth undivided; annulus not

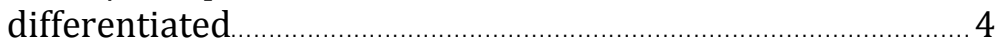

4 Peristome teeth from broad base suddenly narrowed to a filiform, fragile tip; leaves almost entire or weakly denticulate; lamina mostly 3-4 cell rows wide on either side of the costa at $220 \mu \mathrm{m}$ below apex; upper lamina cells 7-12 $\mu \mathrm{m}$ wide

Rhabdoweisia fugax $(\mathrm{r})$

- $\quad$ Peristome teeth gradually narrowed, linear-lanceolate, not fugacious; leaves mostly distinctly denticulate; lamina mostly 5-6 cell rows wide on either side of the costa at 220 $\mu \mathrm{m}$ below apex; upper lamina cells 9-12 (14) $\mu \mathrm{m}$ wide.

Rhabdoweisia crispata (rr)

5(1) Peristome teeth undivided; perigonia on short stalks below perichaetium; capsule short, $<3$ times as long as wide

Cnestrum schisti (n.s.)

- $\quad$ Peristome teeth divided halfway or below; perigonia sessile; capsules $>3$ times as long as wide 6

6 Capsules erect, symmetric, not strumose

Cynodontium polycarpon (w)

- Capsules curved, asymmetric, strumose.

Cynodontium strumiferum (rr) 
Key to species of Ditrichaceae s.l. incl. Saelania and Flexitrichum

1 Plants bluish green with waxy surface, $2-3 \mathrm{~cm}$ tall; leaves lanceolate, the upper longer; costa percurrent; lamina cells quadrate or shortly rectangular.....Saelania glaucescens (rr)

- Plants not glaucous, without waxy surface. 2

2 Upper leaves squarrose, from sheathing base \pm abruptly tapering to long, flexuose subula consisting of costa, cells prorate, therefore subula denticulate all around, not just at margins.. Trichodon cylindricus (Ditrichum cylindricum) (w)

- Upper leaves not squarrose, not abruptly narrowed to subula......

3 Capsules indehiscent, enclosed by the leaves; seta hardly a few millimeters long.

- Capsules with dehiscent lid, exserted above the leaves, seta longer than capsule, or capsules lacking.

4 Perichaetial leaves slightly differentiated from stem leaves, lanceolate; costa ending below leaf apex; plants without comal tuft, 2-4 mm tall; sometimes with yellowish-orange rhizoidal gemmae Pseudephemerum nitidum (w)

- $\quad$ Perichaetial leaves strongly differentiated, leaves ending in subulate apex, costa excurrent; upper leaves crowded in comal tuft.

5 Antheridia 1-3, enclosed in buds in leaf axils; lamina unistratose at shoulder; costa in basal part clearly delimited from lamina.

Pleuridium subulatum (w)

- $\quad$ Antheridia single, naked in axils of comal leaves; lamina irregularly bistratose at shoulder; costa weakly delimited from lamina in basal part of leaf.

Pleuridium acuminatum (w)

6(3) Upper lamina cells quadrate; capsule ribbed, inclined ........... 7 Upper lamina cells elongate; capsule smooth, erect. Ditrichum s.l.

7 Peristome teeth with pale translucent border; costa percurrent, rarely excurrent; capsule strumose, inclined; leaf shape very variable, leaf apex usually with some blunt teeth..

Ceratodon purpureus (cc) 
- $\quad$ Peristome teeth unbordered; costa longly excurrent; capsule ovoid, scarcely inclined, not or indistinctly strumose.

Ceratodon conicus (excluded)

8 Plants 1-8 cm tall, densely tomentose; leaves with long subula; upper lamina cells unistratose, predominantly oval to rounded, cells at shoulder irregularly quadrate, triangular or short rectangular; on calcareous soil. Flexitrichum …....... 9

- $\quad$ Plants to $1.5 \mathrm{~cm}$ tall, not tomentose; upper lamina cells quadrate to rectangular, more regular; leaves not subulate or if subulate, then upper lamina partially 2-stratose; on acidic soil. Ditrichum.

9 Costa in transverse section not projecting dorsally, transition to lamina continuous, cross section forming a smooth ring; basal paracostal cells narrow, elongate, distinctly porose to nodulose; plants $4-11 \mathrm{~cm}$ tall, leaves 4$11 \mathrm{~mm}$ long..

Flexitrichum gracile (Ditrichum crispatissimum, D. flexicaule var. sterilis, D. gracile) (rr)

- $\quad$ Costa in transverse section projecting dorsally, transition to lamina discontinuous; often pseudopapillose with projecting cross walls ('Pfeilerpapillen') seen in cross section; basal paracostal cells wider, rectangular, not or only indistinctly porose; plants $1-5 \mathrm{~cm}$ tall, leaves $1-3.5 \mathrm{~mm}$ long.

Flexitrichum flexicaule (Ditrichum flexicaule s.str.) (w)

10 Leaves erect to \pm appressed to stem, in 3 ranks, 2-4 times as long as wide, margins entire, recurved on one or both sides; capsule and seta yellowish brown, peristome yellowish.

Ditrichum lineare $(\mathrm{rr})$

- $\quad$ Leaves $>4$ times as long as wide

11 Leaf margin partially recurved, occasionally 2-stratose (transverse section!); leaves spreading, with somewhat channelled acumen, weakly denticulate at margins; capsule and seta reddish, peristome reddish; sterile plants with yellowish brown rhizoidal gemmae 100-150 $\mu$ m in diameter

\section{Ditrichum pusillum (r)}

- Leaf margin plane; leaves from ovate base narrowed to long, canaliculate subula.

12 Seta red at least in lower part; leaves homomallous; leaf apex entire or with few teeth; leaf margin partially bistratose in subulate part of leaf (cross section!); rhizoids brown; rhizoidal gemmae dark red-brown, consisting of 5-7 
thick-walled cells arranged in a curved or helical line, rare; costa clearly delimited; plants to $1 \mathrm{~cm}$ tall; spores light in colour, \pm smooth Ditrichum heteromallum (r)

- Seta yellowish, long; leaf apex denticulate, in subula all around, not just at margins, often down to mid-leaf; lamina 2-stratose in lower part near costa and in subulate upper part (transverse section!); rhizoids yellow; rhizoidal gemmae pale yellow to yellowish-brown, in shape similar to those of $D$. heteromallum; costa very broad, indistinctly delimited; plants to $5 \mathrm{~mm}$ tall; spores brown, coarsely papillose.

Ditrichum pallidum (w)

\section{Key to species of Acaulon}

- $\quad$ Costa ending in the leaf apex or shortly excurrent; leaves not carinate; plants rounded in appearance from above

Acaulon muticum (r)

- $\quad$ Costa clearly excurrent; leaves carinate; plants triangular in appearance from above Acaulon triquetrum $(\mathrm{w})$

\section{Key to species of Aloina}

1 Basal marginal leaf cells elongate, thin-walled, forming distinct hyaline border of 2-3 (4) cell rows, which differ conspicuously from adjacent leaf cells; annulus of inflated cells, separating; peristome teeth twisted 1-3 times. 2

- Basal marginal leaf cells quadrate or rectangular, not significantly elongate, not forming distinct membranaceous border; annulus of small cells, \pm persistent; peristome teeth twisted through one turn..

2 Leaves 1-2 mm long, very short and almost orbicular, only 2-3 times as long as wide; costa in transverse section with 1-2 layers of dorsal stereids; spores papillose, (15) 18-22 (33) $\mu \mathrm{m}$ in diameter; seta 5-10 mm long; lid conical or shortly rostrate, $0.5 \mathrm{~mm}$ long, $<1 / 2$ as long as capsule; synoicous, rarely dioicous. Aloina brevirostris Note: This species was reported from Hungary, but the voucher specimens did not represent this species.

- $\quad$ Leaves 4-6 times as long as wide; costa in cross section with 3-6 (8) layers of dorsal stereids; spores 11-15 (22) $\mu \mathrm{m}$ in 
diameter; lid half as long as the capsule; dioicous

Aloina rigida $(\mathrm{w})$

3 Leaf apex apiculate or mucronate, acute or obtuse, cucullate or not; spores 14-25 $\mu \mathrm{m}$ in diameter; basal membrane of peristome 1-2 cells high, not projecting above mouth of capsule; peristome teeth united in pairs at base, erect or slightly twisted; capsule slightly curved......Aloina aloides (r)

- Leaf apex neither apiculate nor mucronate, rounded, cucullate; spores (12) 17.5-24 (27.5) $\mu \mathrm{m}$ in diameter; basal membrane of the peristome to 5 cells high, projecting above mouth of capsule; peristome teeth not united in pairs at base, usually distinctly twisted

Aloina ambigua $(\mathrm{w})$

\section{Key to species of Cinclidotus including Dialytrichia}

1 Leaf cells strongly papillose, leaves opaque; dorsal surface of costa not covered by epidermis, stereid cells therefore exposed; leaf margin recurved below; peristome segments free. Dialytrichia mucronata (excluded)

- Leaf cells smooth or weakly papillose, translucent; dorsal surface of costa covered by quadrate to short rectangular cells 20 (100) x 10-15 $\mu \mathrm{m}$ in upper $2 / 3$ of leaf; leaf margin plane; peristome segments linked and often with crossbars, therefore lattice-like at least towards the base

2 Leaves widest at middle, elliptical, to 3 times as long as wide; costa 100-140 $\mu \mathrm{m}$ wide at leaf base, $c a 1 / 10$ of maximal leaf width; leaf margins moderately thickened, border internally uniform; lamina cells 8-10 $\mu \mathrm{m}$; leaves appressed when dry, spreading when wet; setae 3-6 mm long, terminal

Cinclidotus riparius $(\mathrm{w})$

- Leaves widest shortly above insertion, gradually narrowed towards apex or with nearly parallel margins in lower third, mostly $>4$ times as long as wide; costa 100-200 $\mu$ m wide at leaf base, $c a 1 / 10$ of maximal leaf width or wider, 1/6-1/5; leaf margin moderately to strongly thickened, sometimes with internal cells differentiated, lamina cells 8-15 $\mu \mathrm{m}$; leaves slightly or strongly curled when dry; setae very short, sporophytes lateral, immersed or sporophytes very rare (found only once). 
3 Leaf border 2-5 layers thick, with differentiated internal stereids (long, thick-walled narrow cells with oblique apical walls); leaf cells 7.5-10 (12.5) $\mu \mathrm{m}$; costa 100-140 $\mu \mathrm{m}$ wide at leaf base, $c a 1 / 10$ of maximal leaf width, rarely excurrent as a mucro; leaves strongly flexuose when dry; setae very short, sporophytes lateral, immersed

Cinclidotus fontinaloides $(\mathrm{w})$

- Leaf border usually 2 layers thick, without differentiated internal cells (in cross section all cells of equal thickness); leaf cells 12-15 (19) $\mu \mathrm{m}$; costa 150-200 $\mu \mathrm{m}$ wide at leaf base, often excurrent as mucro; leaves slightly flexuose when dry; sporophytes usually absent (found only once).

Cinclidotus danubicus (rr)

\section{Key to species of Crossidium}

1 Leaf margins plane to incurved, hyaline; upper lamina cells and end cells of filaments heavily incrassate; leaves with very long hair points. Crossidium squamiferum ( $\mathrm{rr}$ )

- $\quad$ Leaf margins recurved, not hyaline; upper lamina cells and end cells of filaments thin-walled; hair points of variable length

2 Terminal cells of filaments smooth or almost so; peristome $350 \mu \mathrm{m}$ long; cells at capsule mouth 5-10 $\mu \mathrm{m}$ wide.

\section{Crossidium laxefilamentosum ( $\mathrm{rr}$ )}

- $\quad$ Terminal cells of filaments papillose; peristome teeth long, > $400 \mu \mathrm{m}$ to $800 \mu \mathrm{m}$; cells at capsule mouth 9-15 $\mu \mathrm{m}$ wide.

\section{Crossidium crassinervium (rr)}

\section{Key to species of Didymodon}

This key includes 2 taxa of doubtful status in Hungary: D. austriacus and D. validus. For a key to infraspecific taxa of $D$. tophaceus, see below. References: Kučera (2000), Jiménez (2006), Müller (2017), Kučera et al. (2018)

1 Leaf apex fragile. Didymodon sinuosus (w)

- Leaf apex not fragile

2 Leaf margins in upper part distinctly erose, irregularly notched; plants with rhizoidal tubers

Didymodon tophaceus subsp. erosus (rr) 
- $\quad$ Leaf margins in upper part entire or papillose-crenulate, not erose or notched; plants with or without rhizoidal tubers..... 3

3 Ventral surface of costa with elongate cells above mid-leaf, narrower than adjacent lamina cells (near apex sometimes isodiametric).

- Ventral surface of costa with quadrate, rarely short rectangular cells (cells of lamina extending over costa) ......... 7 Note: See also Didymodon tophaceus subsp. sicculus with short rectangular ventral costa surface cells.

4 Leaves strongly reflexed when moist, often distinctly 3ranked, to $2 \mathrm{~mm}$ long; stem in transverse section with weak central strand and thick-walled parenchyma; plants in lax brown-green tufts, to $2.5 \mathrm{~cm}$ tall (or taller in wet habitats)..

Didymodon ferrugineus $(\mathrm{r})$

- Leaves erect-spreading to recurved when moist, not arranged in distinct rows; stem in transverse section with mostly thick central strand and thin-walled parenchyma..... 5

5 Leaves lingulate to ovate with obtuse to subacute apex; costa usually ending below leaf apex; plants to $1 \mathrm{~cm}$ high, in wet places to $6 \mathrm{~cm}$, olive- or brown-green

Didymodon tophaceus $(\mathrm{w})$

Note: For a key to infraspecific taxa of $D$. tophaceus see below.

- $\quad$ Leaves acute, lanceolate, recurved when moist; costa ending in leaf apex or shortly excurrent.

6 Peristome spirally twisted, mostly more than $800 \mu \mathrm{m}$ high; leaf margins mostly recurved to broadly recurved at $2 / 3-$ $4 / 5$ of leaf length (less in dry habitats); archegonia mostly 400-500 $\mu \mathrm{m}$ long; small to robust plants, leaves 0.8 to more than $3.5 \mathrm{~mm}$ long. Didymodon fallax (w)

- $\quad$ Peristome straight or nearly so, mostly $<500 \mu \mathrm{m}$ high; leaf margins mostly not or only weakly recurved in upper half of leaf; archegonia mostly 700-800 $\mu \mathrm{m}$ long; robust plants, leaves mostly $>1.7 \mathrm{~mm}$ long. Didymodon spadiceus (r)

7(3) Costa in transverse section (in lower third of leaf in well developed plants) without ventral stereids, dorsal stereids mostly in 2 or more layers; guide cells mostly in 2 layers...... 8

- Costa in transverse section with ventral and dorsal stereids, guide cells usually in a single layer (if in 2 layers then ventral stereids well developed) 
8 Cells on dorsal surface of costa elongate in $4 / 5$ of leaf length or more, narrower than adjacent lamina cells.

- Dorsal surface cells of costa isodiametric at least in upper half of leaf, equally wide as lamina cells

9 Basal lamina cells hyaline, sharply differentiated from upper lamina cells; lamina cells mostly strongly papillose and mamillose, papillae large, covering \pm all of cells; leaves (1.3) 1.7-2.6 (3.8) mm long; costa (45) 60-90 (120) $\mu \mathrm{m}$ wide; leaf margins nearly always recurved; axillary gemmae mostly present

Didymodon glaucus (rr)

- $\quad$ Basal lamina cells coloured, but mostly lighter than upper lamina cells, indistinctly differentiated; upper lamina cells densely papillose, papillae small, several per cell, thus obscuring cell areolation; axillary gemmae lacking

Didymodon insulanus $(\mathrm{w})$

10 Lamina cells (or at least isodiametric cells on ventral side of costa) densely papillose, papillae small, several per cell, thus obscuring cell areolation, lamina opaque; leaf apex often with one or three pellucid cells.

- $\quad$ Lamina cells smooth, if papillose than only 1 papilla per cell; lamina translucent and areolation clearly visible.

11 Leaves mostly longly linear-lanceolate (margins nearly parallel in upper half of leaf); margins recurved only to \pm $1 / 2$ of leaf length; lamina cells nearly always thin-walled, densely papillose, opaque. Didymodon insulanus (w)

- Leaves mostly from ovate base triangular-lanceolate (margins towards apex forming an angle); margins recurved at $2 / 3$ or $4 / 5$ of leaf length; lamina cells sometimes incrassate and weakly papillose (papillae often only visible in section)

Didymodon vinealis $(\mathrm{w})$

12(7, 10) Leaf margin unistratose .......................................................... 13 Leaf margin bistratose; leaves lanceolate with thick, subacute apex formed from costa and thickened leaf margins; upper lamina cells smooth to weakly papillose; plants to $2 \mathrm{~cm}$ tall (usually shorter), usually with nearly spherical but somewhat irregularly-shaped axillary gemmae

Didymodon rigidulus $(\mathrm{w})$

13 Plants with gemmae on modified rhizoids in leaf axils.........14

- Plants without axillary gemmae 17 
14 Leaf margins spirally revolute in well developed plants; costa very broad and strong, 60-120 $\mu \mathrm{m}$ wide; axillary gemmae regularly spherical; plants in brown-green cushions to $5 \mathrm{~cm}$ high.

- Leaf margins recurved, not revolute; costa narrower; axillary gemmae of irregular shape, with protuberant cells.

15 Lamina cells at mid-leaf and above small, 6-8 $\mu \mathrm{m}$ wide; gemmae regularly present. Didymodon cordatus (w) (cell width according to Kučera, pers. comm.)

- $\quad$ Lamina cells wider, ca $12 \mu \mathrm{m}$ wide; leaves shorter, margin less strongly recurved; gemmae sometimes missing.

Didymodon austriacus

16 Ventral stereids of costa in one layer; leaves (0.8) 1.0-1.4 (2.1) mm long; costa (30) 45-65 (80) $\mu \mathrm{m}$ wide; gemmae very rarely present

Didymodon acutus $(\mathrm{w})$

- Ventral stereids of costa mostly in two layers; leaves (1.3) 1.8-2.7 (4) mm long; costa (40) 60-85 (120) $\mu \mathrm{m}$ wide.

Didymodon validus

17(13) Leaves ovate-triangular (1.6-2.8 times as long as wide); costa mostly ending below or in leaf apex; peristome very short, mostly < $150(290) \mu \mathrm{m}$

- $\quad$ Leaves longer triangular (2-5 times as long as wide); costa excurrent, with excurrent part 1/6-1/8 leaf length; perichaetial leaves with acute apex and excurrent costa; peristome $>300 \mu \mathrm{m}$

$18 \mathrm{~K}+$ red; plants $0.2-2 \mathrm{~cm}$ tall; lamina cells smooth; perichaetial leaves with rounded apex and costa ending below apex; leaf margins recurved nearly to apex, leaves therefore not curled when dry but straight

Didymodon luridus $(\mathrm{w})$

- $\quad \mathrm{K}+$ greenish-yellowish; plants 0.2-0.4 (0.7) cm tall; lamina cells strongly papillose.

Didymodon tophaceus subsp. sicculus (rr)

19 Ventral stereids of costa in one layer; leaves (0.8) 1.0-1.4 (2.1) mm long; costa (30) 45-65 (80) $\mu \mathrm{m}$ wide.

Didymodon acutus $(\mathrm{w})$

- Ventral stereids of costa mostly in two layers; leaves (1.3) 1.8-2.7 (4) mm long; costa (40) 60-85 (120) $\mu \mathrm{m}$ wide. 


\section{Key to infraspecific taxa of Didymodon tophaceus}

From Kučera et al. (2018)

The key works for well-developed plants growing in non-extreme habitats in most, certainly not all cases. In particular, large hygrophytic plants of subsp. erosus might key out to subsp. tophaceus, hygrophytic morphs of subsp. sicculus might key out to subsp. erosus, while weak morphs of subsp. tophaceus might key out to subsp. sicculus. Sporophytic characters have only been observed in single cases for subsp. sicculus and subsp. erosus, respectively. Hence, barcoding using one of the molecular markers described in Kučera et al. (2018) is advisable in ambiguous cases.

1 Ventral superficial costa cells on all leaves elongate ( $>3: 1$ ), costa on leaves of well-developed plants often $>100 \mu \mathrm{m}$ wide, leaf base markedly and widely decurrent; rhizoidal gemmae not known subsp. tophaceus 2

- Ventral superficial costa cells on most leaves shortrectangular to irregularly quadrate $(<1.5: 1)$, costa on leaves of well-developed plants mostly $<70 \mu \mathrm{m}$ wide, leaf base shortly, not conspicuously decurrent; rhizoidal gemmae often present (sufficient amount of substrate to be checked!)

2 Costa ending below apex var. tophaceus $(\mathrm{w})$

- Costa excurrent. var. anatinus

3 Leaves ovate, ovate-lanceolate to ovate-lingulate, to 1.45 $\mathrm{mm}$ long, costa $<85 \mu \mathrm{m}$ wide; peristome present. subsp. sicculus $(\mathrm{rr})$

- $\quad$ Leaves lanceolate to lingulate, to $1.9 \mathrm{~mm}$ long, costa $<100$ $\mu \mathrm{m}$ wide; peristome absent (observation on plants from Ecuador) subsp. erosus (rr)

\section{Key to species of Microbryum}

1 Capsule immersed; plants only $1 \mathrm{~mm}$ tall, brownish; costa excurrent as a brownish cusp; leaf margins crenulate at apex; spores $27-30 \mu \mathrm{m}$.

Microbryum floerkeanum (Phascum floerkeanum) (r)

- $\quad$ Capsule emergent or exserted.................................................. 2

2 Capsule exserted to side of leaves, seta arcuate; leaves to 1 $\mathrm{mm}$ long; plants conspicuously reddish brown.

Microbryum curvicollum (Phascum curvicolle) (w)

- $\quad$ Capsule erect, exserted, seta straight; leaves longer.................. 3 
3 Peristome teeth present, well developed; lid bluntly conical or mamillate; spores raspberry-like, with coarse warts but otherwise smooth walls; calyptra distinctly papillose in upper part; upper lamina cells densely and strongly papillose.

Microbryum starckeanum (Pottia starckeana) (rr)

- $\quad$ Peristome teeth absent or rudimentary; lid bluntly conical.. 4

4 Capsule short, empty capsule wide-mouthed, widest at mouth, not (or only slightly) longer than wide; peristome seemingly absent (reduced to a basal membrane not protruding above the capsule mouth); lid bluntly conical, with a short (erect) mamilla; spores echinate; leaf margins distinctly recurved; upper lamina cells distinctly papillose...... Microbryum davallianum (Pottia davalliana) (r) Note: M. davallianum shares with M. muticum the bluntly conical capsule lid, but differs in capsules not contracted at mouth (widest at mouth), strongly widened at mouth when dry and empty, and the tip of the lid appearing more like a beak when capsules are dry, whereas in M. muticum the capsules are widest some distance below the mouth, in empty capsules the mouth remains narrow, and the lid of dry capsules takes up a more hemispherical shape upon drying, without differentiated mamilla or beak. The spores of both species can be echinate, but the spines are shorter in M. muticum, and spore ornamentation is sometimes a mixture of spines and warts. Spores of M. muticum are normally warty with hemispherical papillae $2.5 \mu \mathrm{m}$ high and placed rather distantly $(4 \mu \mathrm{m}$ apart), whereas spores of $M$. davallianum have spines up to $5 \mu \mathrm{m}$ long, also on average $4 \mu \mathrm{m}$ distant from each other. Spores of M. davallianum are often larger, $22-42 \mu \mathrm{m}$, often about $35 \mu \mathrm{m}$, spores of M. muticum are 16-32 $\mu \mathrm{m}$, often about $25 \mu \mathrm{m}$ (Erzberger, unpublished).

- $\quad$ Capsule longer, ovoid, ellipsoid or shortly cylindrical, empty capsule not wide-mouthed, widest at middle, distinctly longer than wide; peristome rudimentary, protruding above the capsule mouth; calyptra papillose; upper lamina cells 6$15 \mu \mathrm{m}$ wide, densely and strongly papillose; capsule mouth distinctly narrowed, with (1) 2-4 rows of small, rounded incrassate cells, annulus absent; rudimentary peristome teeth whitish.

Microbryum muticum

(Pottia mutica, P. starckeana var. brachyoda, Microbryum starckeanum var. brachyodus) (w)

Note: For the difference between this species and M. davallianum, see the note under that species. Capsules of M. muticum have longitudinal stripes caused by large spherical cells between the capsule wall and the spore sac that are arranged in longitudinal rows, best seen in fresh capsules just 
before dehiscence, but detectable also in dry specimens and older capsules. Capsules of $M$. davallianum seem to lack these stripes (Limpricht 1890: 529).

Key to Pottia s.l. (including Hennediella heimii, Microbryum davallianum, M. muticum, M. starckeanum, Tortula caucasica, T. lindbergii, T. protobryoides, T. truncata, but without species formerly in Phascum: Microbryum curvicollum, M. floerkeanum)

1 Capsule indehiscent; peristome teeth differentiated but united with the indehiscent lid; costa excurrent; capsule elongate-ovoid, reddish brown like the seta; plants to $10 \mathrm{~mm}$ tall, brownish green

Tortula protobryoides

(Pottia bryoides, Protobryum bryoides) (w)

- $\quad$ Capsule with dehiscent lid .......................................................... 2

$2 \quad$ Peristome teeth absent or rudimentary ................................... 3

- $\quad$ Peristome teeth present, well developed................................... 7

3 Leaf margins denticulate in upper part of leaf; costa ending in leaf apex; lid remaining attached to ripe capsule by columella; brownish green plants to $1 \mathrm{~cm}$ tall and with seta 5-10 mm long; on soil in saline habitats.

..Hennediella heimii (Pottia heimii, Desmatodon heimii) (rr)

- $\quad$ Leaf margins entire, costa mostly excurrent ............................... 4

4 Capsule short, empty capsule wide-mouthed, widest at mouth, not (or only slightly) longer than wide; peristome seemingly absent (reduced to a basal membrane not protruding above the capsule mouth)

- Capsule longer, ovoid, ellipsoid or shortly cylindrical, empty capsule not wide-mouthed, widest at middle, distinctly longer than wide; peristome rudimentary, protruding above the capsule mouth

5 Lid obliquely rostrate; plants (with sporophyte) mostly more than $5 \mathrm{~mm}$ tall; calyptra smooth; spores papillose; leaf margins mostly flat, occasionally slightly recurved; upper lamina cells smooth or slightly papillose; rhizoidal gemmae unknown Tortula truncata (Pottia truncata) $(\mathrm{w})$ Note: For the difference to Tortula caucasica see note under the latter.

- Lid bluntly conical, with a short (erect) mamilla; plants (with sporophyte) often less than $5 \mathrm{~mm}$ tall; spores echinate; leaf margins distinctly recurved; upper lamina 
cells distinctly papillose

Microbryum davallianum (Pottia davalliana) (r)

Note: M. davallianum shares with $M$. muticum the bluntly conical capsule lid, but differs in capsules not contracted at mouth (widest at mouth), strongly widened at mouth when dry and empty, and the tip of the lid appearing more like a beak when capsules are dry, whereas in M. muticum the capsules are widest some distance below the mouth, in empty capsules the mouth remains narrow, and the lid of dry capsules takes up a more hemispherical shape upon drying, without differentiated mamilla or beak. The spores of both species can be echinate, but the spines are shorter in M. muticum, and spore ornamentation is sometimes a mixture of spines and warts. Spores of M. muticum are normally warty with hemispherical papillae $2.5 \mu \mathrm{m}$ high and placed rather distantly $(4 \mu \mathrm{m}$ apart), whereas spores of $M$. davallianum have spines up to $5 \mu \mathrm{m}$ long, also on average $4 \mu \mathrm{m}$ distant from each other. Spores of $M$. davallianum are often larger, $22-42 \mu \mathrm{m}$, often about $35 \mu \mathrm{m}$, spores of $M$. muticum are 16-32 $\mu \mathrm{m}$, often about $25 \mu \mathrm{m}$ (Erzberger, unpublished).

6 Lid obliquely rostrate; plants (with sporophyte) mostly more than $5 \mathrm{~mm}$ tall; calyptra smooth; annulus present; upper lamina cells $12-25 \mu \mathrm{m}$ wide, smooth or weakly papillose; costa in upper third with or without wide, smooth ventral cells; leaf margins meeting at acute angle at apex; rhizoidal gemmae sometimes present.

Tortula caucasica (Pottia intermedia) (w) Note: The presence (in T. caucasica) or absence (in T. truncata) of an annulus (recommended for separation of these species by Meinunger and Schröder (2007) and others, e.g. Smith (2004) and Chamberlain in Smith (1978)) appears not to be a reliable character (Ros and Werner in Guerra et al. 2006); however, the degree of development of the peristome (rudimentary in $T$. caucasica with usually several papillose segments prodruding above the capsule mouth; missing or reduced to a basal membrane not exceeding $20 \mu \mathrm{m}$ and not protruding beyond the capsule mouth in $T$. truncata) appears to be more reliable; see illustrations in Guerra et al. (2006).

- $\quad$ Lid bluntly conical; plants (with sporophyte) often less than $5 \mathrm{~mm}$ tall; calyptra papillose; upper lamina cells 6-15 $\mu \mathrm{m}$ wide, densely and strongly papillose; capsule mouth distinctly narrowed, with (1) 2-4 rows of small, rounded incrassate cells, annulus absent; rudimentary peristome teeth whitish. Microbryum muticum (Pottia mutica, P. starckeana var. brachyoda, Microbryum starckeanum var. brachyodus) (w)

Note: For the difference between this species and $M$. davallianum, see the note under that species. Capsules of M. muticum have longitudinal stripes caused by large spherical cells between the capsule wall and the spore sac 
that are arranged in longitudinal rows, best seen in fresh capsules just before dehiscence, but detectable also in dry specimens and older capsules. Capsules of M. davallianum seem to lack these stripes (Limpricht 1890: 529).

7(2) Plants small, (with sporophyte) often less than $5 \mathrm{~mm}$ tall; lid bluntly conical or mamillate; spores raspberry-like, with coarse warts but otherwise smooth walls; calyptra distinctly papillose in upper part; upper lamina cells densely and strongly papillose.

Microbryum starckeanum (Pottia starckeana) (rr)

- $\quad$ Plants taller, (with sporophytes) mostly more than $5 \mathrm{~mm}$; lid tall, conical, mostly obliquely and often indistinctly rostrate; spores finely papillose; calyptra mostly smooth, rarely weakly papillose; upper lamina cells weakly papillose to smooth, 13-17 $\mu \mathrm{m}$, thin-walled; costa in upper third covered by large, papillose ventral cells; peristome teeth well developed, divided, yellowish-white; capsule reddish brown, shortly cylindric; leaves \pm spirally twisted when dry, erectopatent when moist, with recurved margins and excurrent costa. ..................... Tortula lindbergii (Pottia lanceolata) (w) Note: var. gasilienii with conspicuous, large ventral costa cells with 1-2 papillae.

\section{Key to species of Pseudocrossidium}

- Leaves narrowly lanceolate to lingulate, obtuse, apiculate; stalked multicellular gemmae present in leaf axils; plants brownish green, in dense tufts

Pseudocrossidium revolutum (w)

- $\quad$ Leaves lanceolate, the apex acute; plants dull green, without gemmae Pseudocrossidium hornschuchianum (w)

\section{Key to species of Pterygoneurum}

1 Capsule globose, without peristome, on short seta, immersed in the leaves; calyptra mitrate; costa excurrent in long spinose hyaline hair point almost twice as long as leaf; lamina cells papillose; plants low, to $2 \mathrm{~mm}$ tall

Pterygoneurum subsessile $(\mathrm{w})$ 
- $\quad$ Capsule exserted above leaves; calyptra cucullate; hyaline hair point smooth or only faintly denticulate, as long as leaf; lamina cells smooth.

2 Plants to $1 \mathrm{~cm}$ high, seta to $10 \mathrm{~mm}$ long; peristome present (but fugacious); cells of lid in spirally twisted rows; lamellae towards leaf apex often dissolved into filaments with papillose end cells; spores 16-20 $\mu \mathrm{m}$.

Pterygoneurum lamellatum (r)

- $\quad$ Plants low, $<3 \mathrm{~mm}$ high, seta short, hardly exceeding $5 \mathrm{~mm}$; peristome absent; cells of lid in straight rows; spores 25-30 $\mu \mathrm{m}$.

Pterygoneurum ovatum (w)

\section{Key to species of Syntrichia}

(see also combined key to Syntrichia and Tortula below)

References: Gallego (2005), Gallego et al. (2018), Homm (2017), Hedenäs et al. (2019)

1 Leaves without hair point, with or without mucro …………...2

- $\quad$ Leaves with hyaline or sometimes coloured hair point ...........4

2 Costa ending in or below leaf apex, not excurrent; leaves contracted at the middle; plants often with spherical gemmae on the ventral surface of the leaf lamina.

Syntrichia latifolia (Tortula latifolia) (w)

- $\quad$ Costa excurrent as a short mucro..................................................... 3

3 Costa with hydroids in transverse section; leaves \pm contracted in the middle; margin plane in upper third; mucro consisting of stereids only.

\section{Syntrichia montana var. calva}

(Tortula crinita var. calva) (rr)

- $\quad$ Costa without hydroids; leaves not contracted in the middle; margin recurved to near apex; mucro consisting of stereids and papillose outer cells similar to lamina cells

Syntrichia ruralis var. epilosa (rr)

4(1) Hair point spinulose to spinose, often strongly so..................5

- Hair point smooth or if very weakly spinulose then costa smooth on dorsal surface.

5 Lamina irregularly bistratose in upper third; leaves not contracted at mid-leaf; dorsal surface of costa strongly papillose, with simple or bifurcate papillae 2.5-5 $\mu \mathrm{m}$ long in the lower half, and pedicellate and branched papillae 12.5- 
$37.5 \mu \mathrm{m}$ long near the apex; leaf margin recurved from base to apex; costa in section generally with substereids; hair point strongly spinose, $0.3-2.6 \mathrm{~mm}$ long.

Syntrichia caninervis var. gypsophila

(Tortula caninervis subsp. spuria) (rr)

- Lamina unistratose in upper third. 6

6 Costa in section without hydroids; leaves contracted at the middle or not.

- Costa in section with hydroids; leaves contracted at the middle.

7 Hair point brownish red or orange, sometimes hyaline at apex; dorsal superficial costa cells in upper third similar to lamina cells......Syntrichia norvegica (Tortula norvegica) (rr) Note: Many species of Syntrichia have hair points that are hyaline throughout except at the base, where they are often brownish. This is not to be confused with the hair point of S. norvegica, which is coloured throughout except sometimes at extreme apex. The leaf apex in $S$. norvegica is acuminate, acute to obtuse, and sometimes ascending the base of the hair point, a character also known in $S$. ruraliformis and $S$. subpapillosissima.

- $\quad$ Hair point hyaline; dorsal superficial costa cells (stereids) in upper third different from lamina cells.

8 Costa in section with 1-2 (3) layers of dorsal stereids; leaves contracted at mid-leaf; margins plane or weakly recurved from base to mid-leaf; mid-leaf cells with 4-6 (8) papillae, papillae bifurcate, not pedicellate, $2.5 \mu \mathrm{m}$ long; sometimes with spherical gemmae on ventral side of costa

Syntrichia virescens (Tortula virescens) (c)

- $\quad$ Costa in section with (2) 3-6 layers of dorsal stereids; leaves not contracted at mid-leaf; margins recurved from base to upper third or apex..

9 Margins recurved from base to upper third, rarely only to mid-leaf; mid-leaf cells 12.5-17.5 $\mu \mathrm{m}$ wide; leaves erectopatent, not recurved when moist

Syntrichia calcicola (Tortula calcicolens) (w)

Note: Additional characters of $S$. calcicola are: (i) a rather short hair point (0.2-1.7 mm), (ii) the short extent of the basal hyaline area (ca 25\%), (iii) areolation of lamina cells hardly obscured by papillae, due to the predominantly central position of papillae and mamillosely-bulging cell walls on ventral and dorsal leaf surface. S. subpapillosissima is similar in that respect (mamillose cells with \pm centrally placed papillae), however, that species has pedicellate and not sessile papillae. 
S. calcicola with few stereid layers could be confused with $S$. virescens. However, apart from the characters mentioned in the key, S. calcicola differs (i) in relative length of the hyaline area formed by basal paracostal cells (19-25 (33)\% in S. calcicola, 20-45\% in S. virescens), (ii) in habitat (S. calcicola is saxi-terricolous, $S$. virescens mainly corticolous). Additional characters which may be used to avoid confusion with $S$. montana and $S$. ruralis are: (i) the size of mid-leaf cells (up to $17.5 \mu \mathrm{m}$ wide in S. calcicola, 5-10 $\mu$ m wide in S. montana, (5) 7.5-10 (15) $\mu \mathrm{m}$ wide in S. ruralis), (ii) the extent of the basal hyaline area (19-25 (33)\% in S. calcicola, $27-45 \%$ in $S$. ruralis), (iii) the form of moist leaves in situ (patent in $S$. calcicola, squarrose in $S$. ruralis), (iv) the armation and length of the hair point (spinulose, $0.2-1.7 \mathrm{~mm}$ in $S$. calcicola, strongly spinose, $0.4-2.8 \mathrm{~mm}$ in $S$. ruralis, spinose, (0.3) 0.7-2.4 $\mathrm{mm}$ in S. montana).

- Margins recurved from base to apex, sometimes to upper third; mid-leaf cells (5) 7.5-12.5 $\mu \mathrm{m}$ wide; leaves mostly squarrosely recurved when moist.

10 Papillae of mid-leaf cells not pedicellate, $2.5 \mu \mathrm{m}$ long, (4) 6

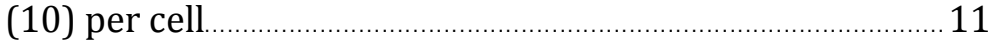

- $\quad$ Papillae of mid-leaf cells pedicellate, (5) 7.5-10 $\mu$ m long; (2) 3-4 (6) papillae per cell, bifurcate, rarely branched and stellate at apex; papillae on dorsal surface of costa simple, 2.5-5 $\mu \mathrm{m}$ long.

Syntrichia subpapillosissima

(Tortula papillosissima var. submamillosa) (w) Note: $S$. subpapillosissima resembles $S$. ruraliformis in the acuminate apex, sometimes hyaline or dentate, ascending the base of the hair point. (Compare also Hilpertia velenovskyi.) It differs, however, in the structure and size of the constantly pedicellate papillae of lamina cells.

11 Leaf apex not hyaline, rounded in general, not ascending the base of the hair point.

Syntrichia ruralis (Tortula ruralis) (cc) Note: Differs from S. montana in the following characters: (i) leaves not contracted at middle, (ii) margin recurved to near apex (iii) lack of hydroids.

- Leaf apex in general hyaline, acuminate, ascending the base of the hair point

Syntrichia ruraliformis (Tortula ruraliformis) (r)

Note: According to some authors $S$. ruraliformis has smaller mid-leaf cells than S. ruralis (Nyholm (1990): ruraliformis (6) 8-12 $\mu$ m wide versus ruralis 11-14 (16) $\mu \mathrm{m}$ wide, Nebel and Philippi (2000): ruraliformis 8-14 $\mu \mathrm{m}$, ruralis 11-18 (20) $\mu \mathrm{m})$. 
12(6) Hair point smooth or only weakly spinulose, (0.2) 0.4-0.9 (1.6) $\mathrm{mm}$ long; dorsal surface of costa smooth; stem with large central strand of cells becoming incrassate and brownish with age; plants usually corticolous.

Syntrichia laevipila (Tortula laevipila) (rr) Note: S. laevipila shares with $S$. virescens (i) the predominantly epiphytic habitat, (ii) the leaves contracted at the middle, (iii) degree of margin recurvature, (iv) lamina cell size; however, they can be separated by the following characters: (i) hair point smooth to weakly and indistinctly spinulose in $S$. laevipila, vs. distinctly spinulose in $S$. virescens, (ii) costa cross section with hydroids and 3-5 (7) layers of dorsal stereids in $S$. laevipila, lack of hydroids and only 1-2 (3) layers of stereids in $S$. virescens, (iii) leaf margin in S. laevipila may appear as a border of 2-5 rows of incrassate and less papillose cells, whereas this is not observed in S. virescens, (iv) if present, the different structure of gemmae (leaf-like in S. laevipila, spherical in $S$. virescens).

- $\quad$ Hair point spinulose, (0.3) 0.7-2.4 mm long; dorsal surface of costa papillose, rarely smooth; stem without central strand or central strand weakly developed; plants usually saxicolous Syntrichia montana var. montana

(Tortula crinita var. crinita) (w) Note: S. montana has the smallest lamina cells of all species with spinulose hair point, only 5-10 (12.5) $\mu \mathrm{m}$ wide.

13(4) Plants with gemmae. 14

Plants without gemmae; leaves contracted at the middle; hair point smooth or slightly spinulose, (0.2) 0.4-0.9 (1.6) $\mathrm{mm}$ long; costa in cross section with hydroids; mostly corticolous; dioicous or autoicous

Syntrichia laevipila (Tortula laevipila) (rr)

14 Gemmae in the form of leaves, papillose, near the stem apex or at the base of the upper leaves; lamina cells with 4-6 (8) bifurcate papillae, on both the ventral and dorsal surface; leaf margins plane or weakly recurved to mid-leaf.

Syntrichia laevipila (Tortula laevipila) (rr)

- Gemmae globular, smooth, at the ventral face of leaves; lamina cells with 1-2 simple (sometimes bifurcate) papillae, on the dorsal surface only; leaf margins plane or incurved.....

Syntrichia papillosa (Tortula papillosa) (c) 
Key to species of Syntrichia and Tortula pp. (excl. T. acaulon, T. caucasica, T. lindbergii, T. protobryoides, T. truncata, incl. Tortula cernua, Hilpertia velenovskyi)

1 Leaves without hair point, costa percurrent or excurrent in a

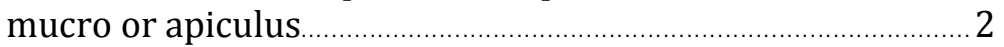

- $\quad$ Leaves with hyaline or sometimes coloured hair point.........12

2 Costa ending in or below leaf apex, not excurrent; leaves contracted at the middle; plants often with spherical gemmae on the ventral surface of the leaf lamina.

Syntrichia latifolia (Tortula latifolia) (w)

- $\quad$ Costa percurrent or excurrent, if ending in leaf apex then leaves not contracted at the middle; plants without gemmae.

3

3 Costa widened towards leaf apex, with large, papillose ventral cells; leaf margin revolute from base to apex.............. 4

- Costa not widened towards apex; ventral costa cells not conspicuously large.

4 Leaves > 3 times as long as wide; mid-leaf cells 8-11 $\mu \mathrm{m}$ wide; dorsal superficial costa cells differentiated from stereids; marginal lamina cells not different from median lamina cells.

Tortula muralis subsp. obtusifolia (Tortula obtusifolia) (r)

- Leaves 2.5-3 times as long as wide; mid-leaf cells 9-15 (17.5) $\mu \mathrm{m}$ wide; dorsal superficial costa cells not conspicuously different from stereids; $2-6$ rows of marginal lamina cells less papillose and more incrassate than median lamina cells, but not forming distinct border

Tortula atrovirens $(\mathrm{r})$

5 Upper and median lamina cells smooth or inconspicuously papillose; marginal cells in upper half of leaf quadrate, similar to other lamina cells (but in general with more incrassate transverse walls).

Tortula mucronifolia ( $\mathrm{rr}$ )

Note: The lack of papillae in this species is best seen in transverse sections of leaves; this should avoid confusion with weakly papillose forms of other species, e.g. T. subulata.

- Upper and median lamina cells papillose $\quad$.................................. 6

6 Costa percurrent or excurrent in short mucro, 10-200 $\mu \mathrm{m}$ long

- $\quad$ Costa excurrent in longer apiculus 
7 Central strand distinct; marginal cells differentiated from median lamina cells by being less papillose and having thicker walls, often oblate; costa ending in or below apex or excurrent in a short mucro, 10-40 $\mu \mathrm{m}$ long; autoicous; peristome with conspicuous tubular basal membrane making up about half of peristome length; peristome teeth strongly spirally twisted; plants of warm, dry, open habitats on base-rich soil or limestone. Tortula inermis (n.s.)

- $\quad$ Central strand indistinct; marginal leaf cells \pm from base to apex similar to median lamina cells with respect to shape, papillosity and wall thickness, not forming border; costa excurrent in short mucro 20-200 $\mu \mathrm{m}$ long. 8

8 Costa with hydroids in transverse section; leaves \pm contracted in the middle; margin plane in upper third; mucro 20-60 $\mu \mathrm{m}$ long, consisting of stereids only.

Syntrichia

montana var. calva (Tortula crinita var. calva) (rr)

- $\quad$ Costa without hydroids; leaves not contracted in the middle; margin recurved to near apex; mucro 70-200 $\mu \mathrm{m}$ long, consisting of stereids and papillose outer cells similar to lamina cells. Syntrichia ruralis var. epilosa (rr)

9 Leaf border conspicuous, formed by elongate to linear cells, at least in lower half of leaf.

- Marginal cells differentiated from median lamina cells by being larger and less papillose, but not forming distinct border; costa excurrent in short, yellowish awn or rarely ending in leaf apex; dioicous; peristome with low basal membrane, sometimes not visible above capsule mouth; peristome teeth not or weakly spirally twisted; plants of shady moist habitats.

Tortula muralis subsp. muralis var. aestiva (w)

10 Capsule ovoid-cylindric, asymmetric, horizontal; peristome without conspicuous tubular basal membrane; leaves bordered in lower $2 / 3$ by elongate, yellowish bistratose cells; central strand absent.

Tortula cernua (Desmatodon cernuus) (rr)

- Capsule cylindric, 4-6 mm long, erect; peristome with conspicuous tubular basal membrane making up about half of peristome length; leaves bordered in lower $2 / 3$ by rectangular to linear cells in one layer or if bistratose then reaching near apex; central strand distinct. 
11 Leaves narrowly lanceolate, acuminate, irregularly denticulate near apex; border of linear cells strongly developed, extending almost to apex, in at least one cell row bistratose Tortula schimperi $(\mathrm{w})$

- Leaves narrowly lingulate to ovate-lanceolate, obtuse to acuminate; border extending $1 / 2-3 / 4$ way up leaf, unistratose. Tortula subulata $(\mathrm{w})$

12(1) Hair point spinulose to spinose, often strongly so..................13

- Hair point smooth or if very weakly spinulose then costa smooth on dorsal surface.

13 Lamina irregularly bistratose in upper third; leaves not contracted at mid-leaf; dorsal surface of costa strongly papillose, with simple or bifurcate papillae 2.5-5 $\mu \mathrm{m}$ long in the lower half, and pedicellate and branched papillae 12.5$37.5 \mu \mathrm{m}$ long near the apex; leaf margin recurved from base to apex; costa in section generally with substereids; hair point strongly spinose, $0.3-2.6 \mathrm{~mm}$ long.

Syntrichia caninervis var. gypsophila

(Tortula caninervis subsp. spuria) (rr)

- $\quad$ Lamina unistratose in upper third ............................................ 14

14 Costa in section without hydroids; leaves contracted at the middle or not.

- Costa in section with hydroids; leaves contracted at the middle. 20

15 Hair point brownish red or orange, sometimes hyaline at apex; dorsal superficial costa cells in upper third similar to lamina cells.......Syntrichia norvegica (Tortula norvegica) (rr) Note: Many species of Syntrichia have hair points that are hyaline throughout except at the base, where they are often brownish. This is not to be confused with the hair point of $S$. norvegica, which is coloured throughout except sometimes at extreme apex. The leaf apex in $S$. norvegica is acuminate, acute to obtuse, and sometimes ascending the base of the hair point, a character also known in $S$. ruraliformis and $S$. subpapillosissima.

- $\quad$ Hair point hyaline; dorsal superficial costa cells (stereids) in upper third different from lamina cells.

16 Costa in section with 1-2 (3) layers of dorsal stereids; leaves contracted at mid-leaf; margins plane or weakly recurved from base to mid-leaf; mid-leaf cells with 4-6 (8) papillae, papillae bifurcate, not pedicellate, $2.5 \mu \mathrm{m}$ long; sometimes with spherical gemmae on the ventral face of the costa. 
Syntrichia virescens (Tortula virescens) (w)

- $\quad$ Costa in section with (2) 3-6 layers of dorsal stereids; leaves not contracted at mid-leaf; margins recurved from base to upper third or apex.

17 Margins recurved from base to upper third, rarely only to mid-leaf; mid-leaf cells 12.5-17.5 $\mu \mathrm{m}$ wide; leaves erectopatent, not recurved when moist.

Syntrichia calcicola (Tortula calcicolens) (w)

Note: Additional characters of $S$. calcicola are: (i) a rather short hair point $(0.2-1.7 \mathrm{~mm})$, (ii) the short extent of the basal hyaline area ( $c a 25 \%)$, (iii) areolation of lamina cells hardly obscured by papillae, due to the predominantly central position of papillae and mamillosely-bulging cell walls on ventral and dorsal leaf surface. S. subpapillosissima is similar in that respect (mamillose cells with \pm centrally placed papillae), however, that species has pedicellate and not sessile papillae.

$S$. calcicola with few stereid layers could be confused with S. virescens. However, apart from the characters mentioned in the key, S. calcicola differs (i) in relative length of the hyaline area formed by basal paracostal cells (19-25 (33)\% in S. calcicola, 20-45\% in S. virescens), (ii) in habitat ( $S$. calcicola is saxi-terricolous, $S$. virescens mainly corticolous). Additional characters which may be used to avoid confusion with $S$. montana and $S$. ruralis are: (i) the size of mid-leaf cells (up to $17.5 \mu \mathrm{m}$ wide in $S$. calcicola, 5-10 $\mu \mathrm{m}$ wide in S. montana, (5) 7.5-10 (15) $\mu \mathrm{m}$ wide in S. ruralis), (ii) the extent of the basal hyaline area (19-25 (33)\% in S. calcicola, $27-45 \%$ in $S$. ruralis), (iii) the form of moist leaves in situ (patent in S. calcicola, squarrose in $S$. ruralis), (iv) the armation and length of the hair point (spinulose, $0.2-1.7 \mathrm{~mm}$ in $S$. calcicola, strongly spinose, $0.4-2.8 \mathrm{~mm}$ in $S$. ruralis, spinose, (0.3) 0.7-2.4 $\mathrm{mm}$ in $S$. montana).

- $\quad$ Margins recurved from base to apex, sometimes to upper third; mid-leaf cells (5) 7.5-12.5 $\mu \mathrm{m}$ wide; leaves mostly squarrosely recurved when moist.

18 Papillae of mid-leaf cells not pedicellate, $2.5 \mu \mathrm{m}$ long, (4) 6 (10) per cell.

- $\quad$ Papillae of mid-leaf cells pedicellate, (5) 7.5-10 $\mu \mathrm{m}$ long; (2) 3-4 (6) papillae per cell, bifurcate, rarely branched and stellate at apex; papillae on dorsal surface of costa simple, 2.5-5 $\mu \mathrm{m}$ long. Syntrichia subpapillosissima (Tortula papillosissima var. submamillosa) (w) Note: S. subpapillosissima resembles $S$. ruraliformis in the acuminate apex, sometimes hyaline or dentate, ascending the base of the hair point. (Compare also Hilpertia velenovskyi.) It differs, however, in the structure and size of the constantly pedicellate papillae of lamina cells. 
19 Leaf apex not hyaline, rounded in general, not ascending the base of the hair point.

Syntrichia ruralis (Tortula ruralis) (cc) Note: Differs from S. montana in the following characters: (i) leaves not contracted at middle, (ii) margin recurved to near apex (iii) lack of hydroids.

- $\quad$ Leaf apex in general hyaline, acuminate, ascending the base of the hair point

Syntrichia ruraliformis (Tortula ruraliformis) (r)

Note: According to some authors $S$. ruraliformis has smaller mid-leaf cells than $S$. ruralis (Nyholm 1990: S. ruraliformis (6) 8-12 $\mu$ m wide versus $S$. ruralis 11-14 (16) $\mu \mathrm{m}$ wide, Nebel and Philippi 2000: $S$. ruraliformis 8-14 $\mu \mathrm{m}$, S. ruralis 11-18 (20) $\mu \mathrm{m})$.

20(14) Hair point smooth or only weakly spinulose, (0.2) 0.4-0.9 (1.6) $\mathrm{mm}$ long; dorsal surface of costa smooth; stem with large central strand of cells becoming incrassate and brownish with age; plants usually corticolous.

Syntrichia laevipila (Tortula laevipila) (rr)

Note: $S$. laevipila shares with $S$. virescens (i) the predominantly epiphytic habitat, (ii) the leaves contracted at the middle, (iii) degree of margin recurvature, (iv) lamina cell size; however, they can be separated by the following characters: (i) costa cross section with hydroids and 3-5 (7) layers of dorsal stereids in S. laevipila, lack of hydroids and only 1-2 (3) layers of stereids in $S$. virescens, (ii) leaf margin in $S$. laevipila may appear as a border of 2-5 rows of incrassate and less papillose cells, whereas this is not observed in $S$. virescens, (iii) if present, the different structure of gemmae (leaf-like in S. laevipila, spherical in $S$. virescens).

- $\quad$ Hair point spinulose, (0.3) 0.7-2.4 mm long; dorsal surface of costa papillose, rarely smooth; stem without central strand or central strand weakly developed; plants usually saxicolous.............................Syntrichia montana var. montana

(Tortula crinita var. crinita) (w)

Note: $S$. montana has the smallest lamina cells of all species with spinulose hair point, only 5-10 (12.5) $\mu \mathrm{m}$ wide.

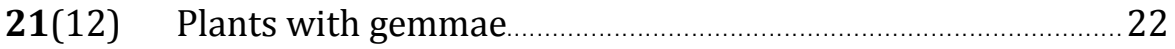

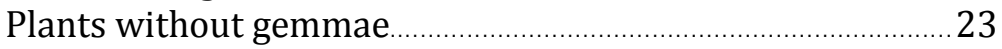

22 Gemmae in the form of leaves, papillose, near the stem apex or at the base of the upper leaves; lamina cells with 4-6 (8) bifurcate papillae, on both the ventral and dorsal surface; leaf margins plane or weakly recurved to mid-leaf.

Syntrichia laevipila (Tortula laevipila) (rr)

- Gemmae globular, smooth, at the ventral face of leaves; lamina cells with 1-2 simple (sometimes bifurcate) papillae, 
on the dorsal surface only; leaf margins plane or incurved ............. Syntrichia papillosa (Tortula papillosa) (c)

23 Costa widened in upper third of leaf; cells on ventral surface of costa 20-25 × (17.5) 20-25 $\mu \mathrm{m}$, subglobose, arranged in 1-2 layers; costa in transverse section with 2-3 layers of stereids; leaves strongly concave; hair point flexuose when dry, less so when moist. Tortula brevissima (r)

- $\quad$ Costa not thickened in upper third of leaf; ventral superficial cells of costa inconspicuous, smooth or if papillose then similar to lamina cells; costa with 3-6 (7) layers of dorsal stereids; leaves slightly to strongly concave; hair point not flexuose. 24

24 Leaf margins strongly revolute (to 2 times) from \pm base to apex, entire or broadly toothed at or near the base of the awn, margins ascending the awn and thereby forming a \pm hyaline triangle; cells of leaf apex rhomboidal to fusiform, epapillose; plants bud-like, leaves crowded, ovate to circular, 1.3-2 mm long (including the awn); costa in transverse section with a single layer of epapillose \pm wide cells at the ventral surface. Hilpertia velenovskyi $(\mathrm{r})$

- Leaf margins plane or weakly recurved to mid-leaf or recurved to revolute from base to apex; leaf apex not hyaline, rounded to obtuse or emarginate, not ascending the base of the awn, made up of isodiametric papillose cells; plants not bud-like, leaves lingulate to spathulate, or linear-lingulate to ovate-lingulate, to $3.8 \mathrm{~mm}$ long; costa in transverse section with guide cells in 1-2 layers, and in addition with a ventral layer of \pm wide papillose cells similar to lamina cells. 25

25 Leaf margins plane or weakly recurved to mid-leaf; leaves contracted at the middle; hair point smooth or slightly spinulose, (0.2) 0.4-0.9 (1.6) mm long; costa in cross section with hydroids; plants sometimes with leaf-like gemmae; mostly corticolous; dioicous or autoicous.

Syntrichia laevipila (Tortula laevipila) (rr)

- $\quad$ Leaf margins recurved to revolute from base to near apex; leaves not contracted at the middle; hair point smooth, 0.3-2 mm long; costa in cross section without hydroids; gemmae unknown; plants mostly saxicolous; monoicous

Tortula muralis subsp. muralis var. muralis (cc) 


\section{Key to species of Tortula}

References: Erzberger (1998), Košnar and Kolář (2009)

1 Costa percurrent or excurrent in mucro or in greenish or yellowish hair point ................................................................ 2

- Costa excurrent in hyaline hair point $\quad$........................................16

2 Costa widened towards leaf apex, with large, papillose ventral cells; leaf margin revolute from base to apex; costa percurrent to very shortly excurrent.

- Costa not widened towards apex; ventral costa cells not conspicuously large; costa percurrent or excurrent ................. 4

3 Leaves $>3$ times as long as wide; mid-leaf cells 8-11 $\mu \mathrm{m}$ wide; dorsal superficial costa cells differentiated from stereids; marginal lamina cells not different from median lamina cells.

Tortula muralis subsp. obtusifolia (Tortula obtusifolia) (r)

- $\quad$ Leaves 2.5-3 times as long as wide; mid-leaf cells 9-15 (17.5) $\mu \mathrm{m}$ wide; dorsal superficial costa cells not conspicuously different from stereids; 2-6 rows of marginal lamina cells less papillose and more incrassate than median lamina cells, but not forming distinct border.

Tortula atrovirens ( $\mathrm{r}$ )

4 Costa percurrent, in transverse section with hydroids, dorsal and ventral cells differentiated ............... Tortula inermis (n.s.)

- Costa excurrent in short or long point $\quad$.....................................

5 Lamina cells smooth or very faintly papillose ……................... 6

- Lamina cells conspicuously papillose..........................................12

6 Capsule immersed or emergent, indehiscent ……………..... 7

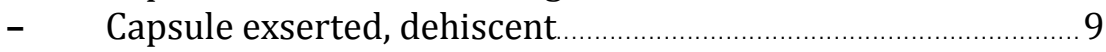

7 Capsule emergent, ellipsoid to ovoid...Tortula protobryoides

(Pottia bryoides, Protobryum bryoides) (w)

- $\quad$ Capsule immersed, ovoid to shortly ovoid.................................... 8

8 Lamina cells completely smooth, occasionally ventral costa cells very weakly papillose; hair point 300-600 $\mu \mathrm{m}$ or longer; spores small, $<25$ (28) $\mu \mathrm{m}$............ Tortula acaulon var. pilifera

(Phascum cuspidatum var. piliferum) (w) Note: Moderately small spores $(25 \mu \mathrm{m})$ and smooth lamina cells are sometimes also observed in var. acaulon, therefore the length of the hair point is diagnostic for var. pilifera. 
- Lamina cells weakly to moderately papillose; hair point inconspicuous, shorter; spores 25-35 $\mu \mathrm{m}$.

Tortula acaulon var, acaulon

(Phascum cuspidatum var. cuspidatum) (w)

Note: In the field, small plants of this species might be confused with Weissia longifolia. That species, however, has perichaetial leaves that from a sheathing, ovate base (hiding the capsule), are contracted to a long, \pm parallel-sided lamina with an acute to acuminate apex, whereas T. acaulon has ovate-oblong perichaetial leaves ending in a conspicuous mucro. When dry, confusion is precluded because the leaves of Weissia are strongly crisped.

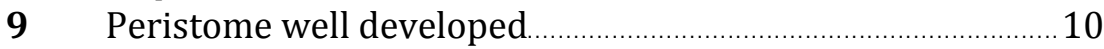

- $\quad$ Peristome rudimentary or lacking …………............................. 11

10 Peristome with inconspicuous basal membrane to $70 \mu \mathrm{m}$ high; upper lamina cells weakly papillose to smooth, 13-17 $\mu \mathrm{m}$, thin-walled; costa in upper third covered by large, papillose ventral cells

Tortula lindbergii (Pottia lanceolata) $(\mathrm{w})$

- $\quad$ Peristome with conspicuous basal membrane 400-800 $\mu \mathrm{m}$ high. Tortula mucronifolia ( $\mathrm{rr}$ )

Note: The lack of papillae in this species is best seen in transverse sections of leaves; this should avoid confusion with weakly papillose forms of other species, e.g. T. subulata var. graeffii.

11 Capsule short, empty capsule wide-mouthed, widest at mouth, not (or only slightly) longer than wide; peristome seemingly absent (reduced to a basal membrane not protruding above the capsule mouth)

Tortula truncata (Pottia truncata) (w)

- $\quad$ Capsule longer, ovoid, ellipsoid or shortly cylindrical, empty capsule not wide-mouthed, widest at middle, distinctly longer than wide; peristome rudimentary, protruding above the capsule mouth; annulus present; upper lamina cells 12$25 \mu \mathrm{m}$ wide, smooth or weakly papillose; costa in upper third with or without wide, smooth ventral cells; leaf margins meeting at acute angle at apex; rhizoidal gemmae sometimes present.

Tortula caucasica (Pottia intermedia) (w) Note: The presence (in T. caucasica) or absence (in T. truncata) of an annulus (recommended for separation of these species by Meinunger and Schröder (2007) and others, e.g. Smith (2004) and Chamberlain in Smith (1978) appears not to be a reliable character (Ros and Werner in Guerra et al. (2006)); however, the degree of development of the peristome (rudimentary in T. caucasica with usually several papillose segments prodruding above the capsule mouth; missing or reduced to a basal 
membrane not exceeding $20 \mu \mathrm{m}$ and not protruding beyond the capsule mouth in T. truncata) appears to be more reliable; see illustrations in Ros and Werner in Guerra et al. (2006).

12(5) Capsule immersed

Tortula acaulon var. papillosa

(Phascum cuspidatum var. papillosum, P. cuspidatum var. mitraeforme) (r)

- $\quad$ Capsule exserted 13

13 Capsule ovoid, cernuous to horizontal; leaves bordered below..................... Tortula cernua (Desmatodon cernuus) (rr)

- $\quad$ Capsule cylindrical, erect; leaves bordered or not .................14

14 Peristome with conspicuous basal membrane 400-1600 $\mu \mathrm{m}$ high, visible above the capsule mouth as a long tube...............15

- $\quad$ Peristome without conspicuous basal membrane

Tortula muralis subsp. muralis var. aestiva (w)

15 Leaves narrowly lanceolate, acuminate, irregularly denticulate near apex; border of linear cells strongly developed, extending almost to apex, in at least one cell row bistratose.

Tortula schimperi $(\mathrm{w})$

- Leaves narrowly lingulate to ovate-lanceolate, obtuse to acuminate; border extending $1 / 2-3 / 4$ way up leaf, unistratose............................................. Tortula subulata (w)

16(1) Costa widened in upper third of leaf; cells on ventral surface of costa 20-25 × (17.5) 20-25 $\mu \mathrm{m}$, subglobose, papillose, arranged in 1-2 layers; costa in transverse section with 2-3 layers of stereids; leaves strongly concave; leaf margin recurved at leaf base and revolute at apex; hair point flexuose when dry, less so when moist.

Tortula brevissima (r)

- $\quad$ Costa not thickened in upper third of leaf; ventral superficial cells of costa $10-20 \times 8.8-17.5 \mu \mathrm{m}$, papillose, arranged in a single layer; costa with 3-6 (7) layers of dorsal stereids; leaves slightly to strongly concave; hair point not flexuose.......

Tortula muralis subsp. muralis var. muralis (cc) 


\section{Key to varieties of Streblotrichum convolutum}

Concerning the characters differentiating the two varieties of $S$. convolutum, $S$. convolutum var. convolutum and $S$. convolutum var. commutatum, there are contradictory statements in the literature. Although Frahm and Ahmed (2004), Frey et al. (2006) and Smith (2004) state that a central strand is lacking in the typical variety, other sources claim its presence in both varieties (Limpricht 1890, Guerra et al. 2006, and own observations). According to Kučera et al. (2013), rhizoidal tubers are present in both varieties, contrary to statements in Smith (2004) and Frey et al. (2006). Therefore, the following key is based only on the confirmed morphological differences.

- Leaves small, < $1 \mathrm{~mm}$ long; basal leaf cells quadrate, incrassate; leaf margins flat, not undulate.

Streblotrichum convolutum var. convolutum

(Barbula convoluta var. convoluta) (c)

- $\quad$ Leaves > $1 \mathrm{~mm}$ long; basal leaf cells rectangular, thin-walled; leaf margins undulate

Streblotrichum convolutum var. commutatum (Barbula convoluta var. commutata, B. convoluta var. sardoa) (r)

\section{Key to species of Ephemerum}

Reference: Ellis and Price (2015)

1 Leaves costate; leaf margin denticulate, sometimes in upper

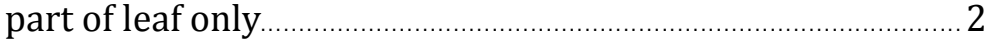

- Leaves ecostate; leaf margins serrate $\quad$.......................................... 4

2 Upper leaves lanceolate to oblong-lanceolate, with 1-2 asymmetric shoulders; branches of chloronema in fascicles; leaf margin denticulate in upper part.

\section{Ephemerum cohaerens $(\mathrm{r})$}

Note: According to Infante et al. in Guerra et al. (2010), the costa may end below or in the leaf apex, or be excurrent. Orientation of leaf cells (diagonal rows vs. parallel rows) is not distinct according to the illustrations in Guerra et al. (2010).

- Upper leaves lanceolate to linear-lanceolate, without shoulders; branches of chloronema divergent.

3 Capsule with straight apiculus; stomata all over the capsule surface; upper leaves erect; tuberous parts of rhizoid system packed with lipid drops and having oblique cross walls; leaf margin denticulate in upper part.

Ephemerum crassinervium subsp. sessile

(Ephemerum sessile) (rr) 
- $\quad$ Capsule with curved apiculus; stomata confined to capsule base; upper leaves recurved; tuberous parts of rhizoid system packed with starch grains and having transverse cross walls; leaf margin denticulate.

Ephemerum recurvifolium (rr)

4 Ripe spores finely papillose, each covered by a whitish veil...

Ephemerum serratum

(Ephemerum minutissimum Lindb.) (w)

Note: This is not what was hitherto named E. serratum, but what was named E. minutissimum.

- $\quad$ Ripe spores warty, not covered by veil

Ephemerum stoloniferum

(=Ephemerum serratum auct. in traditional, but incorrect use) (rr)

\section{Key to species of Gymnostomum group}

1 Basal lamina cells narrowly rectangular, (14) 16-40 (50) $\times$ (5) 6-7 $\mu \mathrm{m}$, costa $20-40 \mu \mathrm{m}$ wide at mid-leaf; leaves only 0.5 $\mathrm{mm}$ long, erect; plants tiny, only $2 \mathrm{~mm}$ tall; annulus of large inflated cells, persistent; peristome absent; brownish ovoid to elongate rhizoidal gemmae present among the tomentum

Gyroweisia tenuis (rr)

- Basal lamina cells short or long rectangular, 14-18 $\mu \mathrm{m}$ long, or if longer then costa 50-70 (90) $\mu \mathrm{m}$ wide at mid-leaf; leaves various; plants sometimes taller; annulus of small cells, persistent or falling.

2 Plants $>5 \mathrm{~mm}$ high; leaves 5-7 times as long as wide ............. 3

- $\quad$ Plants 2-5 mm high; leaves very short, 0.4-0.5 mm long, broadly ovate to oblong, sometimes lingulate or spathulate, rarely ovate-lanceolate; 2-4 times as long as wide; multicellular gemmae present in leaf axils; margins of upper leaves unistratose; plants dull green

Gymnostomum viridulum (r)

3 Plants vivid green, fresh green; costa in transverse section with dorsal band of stereids only, 25-45 $\mu \mathrm{m}$ wide at leaf base; lamina cells 4-10 $\mu \mathrm{m}$; leaves $1 \mathrm{~mm}$ long; plants usually only a few millimeters (to $2 \mathrm{~cm}$ ) tall; leaf scarcely tapered, and broadly rounded or obtuse at the apex

Gymnostomum calcareum (w) 
- $\quad$ Plants dark green to brownish green or olive green; costa in transverse section with dorsal and ventral group of stereids, 45-70 (100) $\mu \mathrm{m}$ wide at leaf base; lamina cells 7-14 (16) $\mu \mathrm{m}$; plants $0.5-8 \mathrm{~cm}$ tall; leaf tapered to a rather narrow, blunt to acute tip..................Gymnostomum aeruginosum (r)

\section{Key to species of Hydrogonium}

References: Limpricht (1890), Nyholm (1989), Ahrens in Nebel and Philippi (2000), Garilleti in Guerra et al. (2006)

- $\quad$ Axillary gemmae numerous, clavate, consisting of few (ca 10) cells; dorsal side of costa with cells prorate at distal and proximal ends, appearing like paired mamillae.

Hydrogonium consanguineum (Barbula indica auct.) (n.s.)

- $\quad$ Axillary gemmae few, ovoid, pointed at both ends, consisting of many ( $\mathrm{ca}$ 100) cells; dorsal side of costa with simple papillae, without doubly prorate cells.

Hydrogonium croceum (Barbula crocea) (rr)

Note: missing in Erzberger and Papp (2020), recently discovered by Németh and Schmotzer in a single site in Bükk Mts.

\section{Key to species of Tortella}

References: Köckinger and Hedenäs (2017), Erzberger and Papp (2018)

1 Leaf margin denticulate in upper third; leaves squarrosely reflexed from sheathing base when moist; plants growing in turf on soil mostly in calcareous grassland

Tortella squarrosa (Pleurochaete squarrosa) (w)

- $\quad$ Leaf margin entire; leaves not squarrose when moist; plants forming \pm well defined cushions on soil or calcareous rock. 2

2 Cells of ventral surface of costa linear, smooth, not covered by isodiametric papillose lamina cells; leaf apex broadly acute, cucullate. Tortella inclinata $(\mathrm{w})$

- Ventral surface of costa covered by isodiametric papillose lamina cells, at least in upper part of leaf; leaves tapering to long, narrowly lanceolate apex; leaves undulate when moist, much contorted when dry.

3 Plants to $5 \mathrm{~cm}$ tall; leaves sometimes fragile; cells on dorsal surface of costa near leaf apex elongate and smooth (stereids), rarely papillose; stem mostly without central 
strand; peristome teeth twisted 1.5-3 times to the left.

Tortella tortuosa $(\mathrm{w})$

- $\quad$ Plants usually smaller; leaves fragile with most tips broken off transversely; cells on dorsal surface of costa near intact leaf apex quadrate and papillose; stem mostly with central strand; peristome teeth twisted $1 / 2$ turn to the left.

4 Leaves when dry curled up to the apex, intact leaf tip often like a cork-screw; individual shoots of cushion well discernible from above and shaped like a ball of wool; marginal cells transversely elongate (wider than long) or quadrate, with bulging outer walls causing the margin to be neatly crenulate; thermophilic plants growing at low elevations.

Tortella fasciculata ( $\mathrm{r}$ )

Note: see illustrations and details in Köckinger and Hedenäs (2017).

- $\quad$ Dry leaves straight or slightly flexuose in their apical third and mostly oriented perpendicular to the shoot axis ('lying on the cushion surface'); individual shoots of cushion thereby less well discernible from above; marginal cells elongate (longer than wide) or quadrate, outer walls only slightly bulging; cryophilic plants of higher elevations

Tortella pseudofragilis (r)

\section{Key to species of Trichostomum}

- $\quad$ Leaf apex cucullate, cuspidate; costa slightly excurrent; basal lamina cells rectangular, incrassate, upper lamina cells rounded, papillose; capsule elliptical, brownish, on a red seta; plants 1-2 cm tall; dioicous

Trichostomum crispulum (w)

Note: $T$. viridulum $=T$. crispulum var. angustifolium might merit specific rank; it produces often sporophytes and has very narrow, longly acuminate leaves (Meinunger and Schröder 2007: as species; illustrated in Schlüsslmayr 2005); taxonomic status controversial (Caspari et al. 2018).

- $\quad$ Leaf apex not cucullate; costa usually excurrent as a mucro; capsule reddish brown, on a yellow seta.

Trichostomum brachydontium (r) 


\section{Key to species of Weissia}

1 Capsule immersed in perichaetial leaves, on very short seta,

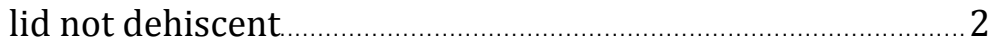

- $\quad$ Capsule clearly exserted above the leaves.................................. 3

2 Seta shorter than the capsule; spores coarsely papillose; leaves narrow lanceolate from a broad sheathing base, with incurved margins and excurrent costa, strongly crispate when dry.

Weissia longifolia $(\mathrm{w})$

- Seta ca $1 \mathrm{~mm}$ long, longer than the capsule, mostly 2 capsules in a single perichaetium, clearly overtopped by the comal leaves; capsule without a peristome, closed by an epiphragm; lid differentiated but usually not dehiscent; plants to $5 \mathrm{~mm}$ tall.

Weissia rostellata $(\mathrm{rr})$

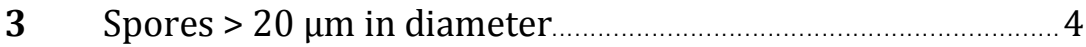

- $\quad$ Spores $<20 \mu \mathrm{m}$ in diameter.................................................... 5

4 Capsule with peristome (but peristome mostly rudimentary); upper leaf margins hardly involute; capsule shortly cylindric, sulcate when dry (similar to Cynodontium)

Weissia rutilans $(\mathrm{r})$

- Capsule without a peristome, closed by an epiphragm, sometimes incomplete; exothecial cells with incrassate walls

Weissia brachycarpa $(\mathrm{w})$

Note: Attention should be paid to var. obliqua with leaves strongly incurved above and capsule oblong-ovate on short seta, when young often just emergent.

5 Peristome well developed, reddish-brown to yellowish brown (but may become pale with age); costa 30-80 $\mu \mathrm{m}$ wide.....................Weissia controversa var. controversa $(\mathrm{w})$

- $\quad$ Peristome rudimentary and pale or lacking ..............................6

6 Peristome rudimentary, always pale, often not extending above capsule mouth; costa 70-100 $\mu$ m wide near leaf base..

Weissia controversa var. crispata (Weissia fallax) $(\mathrm{r}$ )

- Peristome completely lacking, capsule closed by an

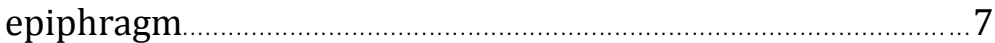

7 Costa 70-130 $\mu \mathrm{m}$ wide near leaf base Weissia condensa $(\mathrm{w})$ Note: The leaf apex in $W$. condensa is cucullate like in Trichostomum crispulum, however, in that species the leaf margin is plane and not strongly inrolled as in $W$. condensa. T. crispulum is also a larger plant.

- $\quad$ Costa up to $50 \mu \mathrm{m}$ wide near leaf base; spores 17-34 $\mu \mathrm{m}$.

Weissia brachycarpa $(\mathrm{w})$ 


\section{Key to species of Seligeriaceae}

References: Nyholm (1987), Blockeel et al. (2000), Brugués and Guerra (2015)

1 Plants commonly $>1 \mathrm{~cm}$ tall; leaves with distinct alar cells....

Blindia acuta (n.s.)

- $\quad$ Plants usually $<1 \mathrm{~cm}$ tall, often minute; alar cells not distinct

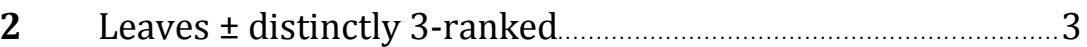

- $\quad$ Leaves not 3-ranked ..................................................................... 4

3 Plants 2-5 (6) mm, blackish; leaves distinctly to indistinctly trifarious, with long, smooth to nearly smooth subula, \pm secund; peristome reduced; spores large, (16) 20-33 (40) $\mu \mathrm{m}$, coarsely papillose; ventral costa superficial cells in section 8-11 $\mu \mathrm{m}$, dorsal superficial costa cells in section 6-8 $\mu \mathrm{m}$.

Seligeria trifaria var. longifolia ( $\mathrm{rr}$ )

- $\quad$ Plants 1-2.5 mm, light green; leaves indistinctly trifarious, with \pm scabrous subula, \pm recurved; peristome teeth lanceolate-triangular, 70-100 $\mu \mathrm{m}$ long, not reduced; spores ca $18 \mu \mathrm{m}$, smooth to slightly papillose; ventral costa superficial cells in section 6-9 $\mu \mathrm{m}$, dorsal superficial costa cells in section 4-6 $\mu \mathrm{m}$.

Seligeria patula (n.s.)

4 Capsules without peristome, widened at mouth; leaf margins denticulate in lower third; seta to $2 \mathrm{~mm}$ long

Seligeria donniana $(\mathrm{r})$

- $\quad$ Capsules with peristome.

5 Seta arcuate when moist; mature capsules ovoid to shortly cylindrical, narrowed at mouth when dry and empty. Blindiadelphus.

- Seta straight when moist; mature capsules semiglobose, becoming wide-mouthed when dry and empty.

6 Leaves abruptly narrowed into long, fine subula completely filled by the excurrent costa; costa usually $45-65 \mu \mathrm{m}$ wide at base; plants mostly in crevices of moist siliceous rock protected by overhangs

Blindiadelphus recurvatus (Seligeria recurvata) (r)

- $\quad$ Leaves gradually narrowed to broad acumen; costa ending in leaf apex, lamina extending into the leaf apex; costa usually 20-30 (40) $\mu \mathrm{m}$ wide at base; plants exclusively on small dolomitic stones at ground level below shaded rock walls in Corno-Quercetum

Blindiadelphus campylopodus (Seligeria campylopoda) (rr) 
$7 \quad$ Narrow and linear leaves mixed with broader leaves; spores (9) $10-14 \mu \mathrm{m}$

- Leaves from ovate-lanceolate base narrowed into stout point, formed by excurrent costa; leaf lamina opaque in upper part; spores 14-18 $\mu \mathrm{m} \ldots \ldots \ldots \ldots \ldots . . .$. Seligeria calcarea $(\mathrm{rr})$

8 Perichaetial leaves long, reaching or almost reaching capsule, longly excurrent costa filling subula; seta surface cells short rectangular, mostly 15-26 $\mu \mathrm{m}$ long, 2-4 times as long as wide Seligeria acutifolia (rr)

- $\quad$ Seta much longer than perichaetial leaves, percurrent costa not filling subula, lamina extending to apex; seta surface cells narrow, linear, mostly 28-50 $\mu \mathrm{m}$ long, 4-8 times as long as wide.

Seligeria pusilla $(\mathrm{w})$

\section{Key to species of Grimmiaceae}

(Coscinodon: 3; Grimmia: 24-64; Racomitrium: 4-9; Schistidium: 10-23)

References: Blom (1996), Blom in Nyholm (1998), Erzberger and Schröder (2008), Erzberger (2009), Maier (2010), Erzberger et al. (2016)

1 Basal leaf cells elongate, with incrassate nodulose-sinuose walls; seta elongate (capsules exserted), mostly dextrorse (forming a right-handed helix like a normal screw) when dry (sinistrorse in $R$. canescens, $R$. lanuginosum); stem without central strand. Racomitrium …........................................... 4

- Basal leaf cells never at the same time elongate and incrassate nodulose-sinuose; seta often short, untwisted or sinistrorse; stem with or without central strand. 2

2 Costa in transverse section nearly homogeneous, composed of cells of \pm equal size; seta short, capsule immersed; columella attached to operculum, both fall off the capsule together; stem (of sporophyte-bearing plants) often with central strand (central strand lacking or narrow and indistinct in $S$. apocarpum, $S$. brunnescens subsp. griseum, $S$. elegantulum, S. flaccidum, S. lancifolium, S. papillosum). Schistidium.

- Costa in transverse section composed of cells of different size, usually with large guide cells, often with stereids or hydroids; capsules immersed to exserted; columella not attached to lid, remaining in the urn when the capsule opens; stem mostly with central strand 
3 Leaves plicate, often at leaf base with additional costa-like structures of several layers; calyptra large, campanulatemitrate, covering nearly all of ripe urn; peristome teeth cribrose (extensively perforated); stem with a central strand of few cells. Coscinodon cribrosus (rr)

- Leaves plicate or not, rarely with additional costa-like structures; calyptra smaller, mostly mitrate (cucullate in $G$. ovalis, G. montana, G. crinita, G. orbicularis), peristome teeth usually not or only slightly perforated; stem with central strand (absent in G. hartmanii and sometimes G. elatior). Grimmia

4(1) Hair point present, papillose; seta sinistrorse when dry........5

- Hair point absent or present, not papillose, but often denticulate; seta dextrorse when dry.

5 Lamina smooth; hair point papillose and sinuose-erose dentate, decurrent at margins; seta strongly papillose

Racomitrium lanuginosum (rr)

- Lamina papillose; hair point not sinuose-erose dentate, decurrent or not; seta smooth.

Racomitrium canescens (Niphotrichum canescens) (w)

6 Hair point absent; lamina cells papillose, but papillae flat and inconspicuous (best seen in cross section). Subgenus Codriophorus.

- $\quad$ Hair point usually present, but sometimes lacking; lamina cells not papillose (but sometimes pseudopapillose with projecting cell walls). Subgenus Bucklandiella.

7 Leaves broadly lanceolate; leaf apex broadly rounded with distant teeth; alar cells forming distinct \pm decurrent auricles; supra-alar cells not differentiated.

Racomitrium aciculare (Codriophorus acicularis) (n.s.)

- Leaves narrow lanceolate with obtuse apex, without teeth, at most very slightly denticulate by prominent cell corners; alar cells not differentiated; supra-alar cells hyaline or yellowish-hyaline, incrassate and esinuose, forming a distinct marginal band.

Racomitrium aquaticum (Codriophorus aquaticus) (rr)

8 Basal lamina cells nodulose; ventral surface of costa in cross section flat towards base, not canaliculate; 4-8 guide cells free at ventral surface in the median part; hair point (if present) with wide insertion, often slightly decurrent. 
- Basal lamina cells thick-walled and porose, but not nodulose; ventral side of costa in cross section canaliculate (with a \pm rounded profile); 2-4 guide cells free at ventral surface; costa in mid-leaf mostly bistratose, narrow (60-80 $\mu \mathrm{m}$ ) in lower part (costa 2 (3)-stratose with 3-4 ventral cells in basal part, 2-stratose with 2-3 ventral cells in mid-leaf, 2stratose with 2 ventral cells in upper part); hair point lacking or short $(<0.4 \mathrm{~mm})$; marginal supra-alar cells in conspicuous row consisting of 10-15 hyaline or yellowishhyaline, thin-walled, pellucid esinuose cells.

Racomitrium microcarpon

(Bucklandiella microcarpa) (n.s.)

9 Costa predominantly bistratose, weakly convex on dorsal side; reaching to hair point; 4-8 guide cells free at ventral surface; hair point usually well developed and flexuose, but absent in some Hungarian populations; leaf margin unistratose, narrowly revolute to $3 / 4$ leaf length; innermost perichaetial leaf ovate, rarely brevipilose, hyaline

Racomitrium heterostichum

(Bucklandiella heterosticha) (rr)

- Costa predominantly 3-4-stratose, prominently convex on the dorsal side; (3) 4 (5) guide cells free at ventral surface; hair point often short; leaf margin recurved on both sides towards the apex, in upper part with or without bistratose spots or sometimes predominantly bistratose; innermost perichaetial leaf epilose, usually hyaline, apex obtuse with lax, wide, smooth cells.

Racomitrium affine (Bucklandiella affinis) (rr)

10(2) Leaf lamina with scattered papillae on one or both sides....11

- Leaf lamina not papillose, but dorsal side of costa and / or margins sometimes papillose or denticulate with projecting cell ends.

11 Leaf lamina unistratose; plants often with red spots in insolated parts; ventral side of leaf not or only weakly papillose; central strand absent or indistinct; usually $>8$ stomata per capsule.

Schistidium papillosum $(\mathrm{r})$

- Leaf lamina usually with bistratose patches; plants never with red spots; papillae nearly equally frequent on ventral and dorsal sides of leaf or not; central strand distinct; up to 8 stomata per capsule. 
12 Perichaetial leaves broadly elliptical to broadly ovate, distinctly wider than upper stem leaves; lamina cells small, rounded, 6-9 $\mu \mathrm{m}$ in upper part of leaf; central strand of 3-10 cells; papillae frequent on dorsal and ventral sides of lamina; plants of siliceous substrates.......Schistidium pruinosum (r)

- Perichaetial leaves not distinctly wider than upper stem leaves; lamina cells larger, \pm sinuose, $10-12 \mu \mathrm{m}$ in upper part of leaf; central strand of 20-30 cells; papillae usually more frequent on dorsal than on ventral side of lamina; plants of usually calcareous substrates.

Schistidium confusum (rr)

13(10) Exothecial cells in lower third of capsule predominantly isodiametric, but sometimes mixed with patches of elongate cells; urn length : width ratio often less or equal to 1.3; leaf margins or back of costa mostly denticulate with papillae or projecting cells in upper third of leaf.

- $\quad$ Exothecial cells predominantly elongate; urn length : width ratio usually $>1.3$; leaf margins and dorsal side of costa smooth or denticulate (S. crassipilum, S. helveticum; for $S$. dupretii see 15).

14 Spores 16-24 $\mu \mathrm{m}$; hair point lacking or consisting of few hyaline cells only; plants on stones near running water (Danube). Schistidium platyphyllum (rr)

- $\quad$ Spores smaller, 8-13 $\mu \mathrm{m}$; hair point various, but usually present; plants not specifically riverine.

15 Exothecial cells irregular in size and shape, forming an irregular pattern; perichaetial leaves narrow, 0.5-0.6 mm wide, hardly concealing the urn; hair point narrow at insertion, consisting of few cells, up to $0.15(0.25) \mathrm{mm}$ long; at least some leaves with smooth margins; plants small.

Schistidium dupretii $(\mathrm{w})$

- Exothecial cells usually isodiametric, often quadrate, but sometimes with patches of elongate cells, forming a \pm regular to very regular pattern; perichaetial leaves narrow or wide, usually concealing major part of the urn; hair point various, but not conspicuously narrower than the chlorophyllose part of the leaf apex; margins usually distinctly to conspicuously denticulate-papillose. 16

16 Urn 0.7-1.0 $\mathrm{mm}$ long and 0.5-0.65 $\mathrm{mm}$ wide; leaves narrowly lanceolate, margins and back of costa strongly 
papillose down to below mid-leaf, with size of papillae increasing towards apex; exothecial cells arranged in neat vertical rows; peristome teeth $320-400 \mu \mathrm{m}$ long; perichaetial leaves $0.5-0.8 \mathrm{~mm}$ wide; plants small.

Schistidium Iancifolium (w)

- Urn 0.9-1.35 mm long and 0.5-0.85 mm wide; leaves broader, with costa and margins less distinctly papillose; exothecial cells less neatly arranged; peristome teeth 400$700 \mu \mathrm{m}$ long; perichaetial leaves $0.8-1.5 \mathrm{~mm}$ wide; plants medium-sized.

Schistidium apocarpum (w)

17(13)

$\mathrm{K}+$ yellow.

$\mathrm{K}+\mathrm{red}$

18 Peristome usually lacking; hair point usually long, 0.15-0.85 $\mathrm{mm}$, finely denticulate; perichaetial leaves plicate; lid mamillate; plants small to medium sized

Schistidium flaccidum (rr)

- Peristome well developed; hair point short, 0-0.45 mm, coarsely spinulose; lid rostrate, but beak sometimes short; plants small..

Schistidium confertum (rr)

19 Leaf margins or back of costa denticulate with papillae or projecting cells; peristome teeth 350-400 $\mu \mathrm{m}$ long, in freshly deoperculate capsules stellate-straight, scarcely twisted, orange; urn usually with 0-4 (6) stomata at base, but sometimes more, pores often rudimentary or lacking; central strand distinct, $>6$ cells Schistidium crassipilum (c)

- Leaf margins and dorsal side of costa smooth (few papillae may occur at leaf apex immediately below the hair point, in $S$. helveticum also further down).

20 Stomata absent (absent to few in forms of $S$. crassipilum with smooth margins and costa, see 19); plants small, in compact cushions. 21

- $\quad$ Stomata present, (3) 6-10 per urn; plants medium-sized to large with conspicuous hair points.

21 Plants usually black, glossy; hair point absent or short $(<0.2$ $\mathrm{mm}$ ) on all leaves, coarse and coarsely spinulose with short and broad, patent to squarrose spinulae, terete, not decurrent; exothecial cells forming an irregular pattern.

Schistidium helveticum (Schistidium singarense) (w)

- $\quad$ Plants brownish; hair point absent or short in lower leaves, conspicuous in perichaetial leaves, $0.15-1.0 \mathrm{~mm}$ long, coarse 
and terete, but flattened towards insertion, not or shortly decurrent, but embracing parts of upper lamina; exothecial cells up to 50-80 $\mu \mathrm{m}$ long, forming a regular pattern. Schistidium brunnescens.

22 Leaves ovate-lanceolate to ovate triangular, often with shoulder, $1.85-2.6 \mathrm{~mm}$ long, usually with longitudinal bistratose ridge-like striae on one or both sides of costa; costa 58-90 $\mu \mathrm{m}$ wide in central part of leaf.

Schistidium brunnescens subsp. griseum (r)

- $\quad$ Leaves oblong, ovate or short ovate-triangular, 1.1-2.0 mm long, shoulders and ridge-like striae absent; costa 38-60 $\mu \mathrm{m}$ wide in central part of leaf.

Schistidium brunnescens subsp. brunnescens (w)

23(20) Hair point erect, terete, narrow throughout, not decurrent, hyaline, but often brownish at insertion; central strand absent; urn usually ovate in shape; upper lamina cells isodiametric, not sinuose, not distinctly incrassate; lamina with irregular bistratose patches; plants in mats or decumbent tufts on \pm shaded calcareous rocks.

Schistidium elegantulum subsp. elegantulum (w)

- Hair point stiff and straight, usually flattened at base, decurrent; central strand always distinct ( $>20$ cells); urn usually cylindrical in shape; upper and especially lower lamina cells strongly sinuose, distinctly incrassate (similar to cells of Racomitrium); lamina rarely with bistratose patches; plants in hoary tufts on exposed or moderately shaded calcareous rocks. Schistidium robustum $(\mathrm{r})$

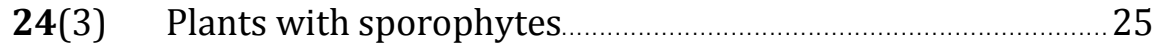

Plants without sporophytes...................................................... 44

25 Seta short, not longer than capsule, capsule immersed to

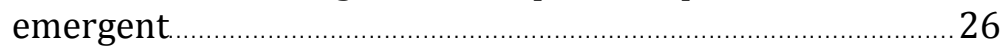

- $\quad$ Seta longer than capsule, capsule exserted above the cushion 31

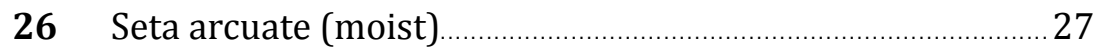

- $\quad$ Seta straight (moist) ................................................................... 30

27 Lamina bistratose from apex to widest part of leaf, semicircular in section; costa only slightly prominent on dorsal side; peristome present.........Grimmia tergestina $(\mathrm{w})$

- Lamina unistratose or with bistratose patches, margins unistratose or bistratose; leaves \pm concave; costa \pm 
prominent on dorsal side; peristome present or absent .....28

28 Peristome absent; leaves concave in basal part only, obtusely keeled towards apex; lamina unistratose with bistratose margin and bistratose patches.

Grimmia anodon $(\mathrm{r})$

- $\quad$ Peristome present; lamina completely unistratose (margins sometimes locally bistratose)

29 Leaves spathulate, widest above mid-leaf; hair point long to very long, broadly inserted; margin completely unistratose; seta as long as capsule

Grimmia crinita (rr)

- Leaves not spathulate, widest at or below mid-leaf; hair point not particularly long, with narrow insertion; margin partly bistratose; seta shorter than capsule.

Grimmia plagiopodia $(\mathrm{r})$

30(26) Leaves plicate; costa recessed in deep ventral groove; some plicae pluristratose at base, resembling additional costae; calyptra wide, campanulate, plicate, nearly enclosing the urn; peristome cribrose.................... Coscinodon cribrosus ( $\mathrm{rr}$ )

- $\quad$ Leaves not plicate, semicircular in section; other characters different.

Grimmia tergestina $(\mathrm{w})$

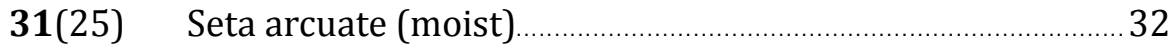

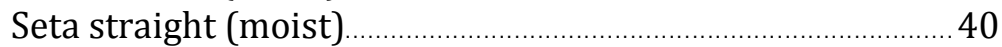

32 Lamina bistratose in upper part of leaf; costa recessed in a deep grove, prominent on dorsal side, in transverse section without hydroids but with an additional layer of wide cells on the dorsal side of the guide cells; lamina and costa usually with scattered hemispherical papillae; central strand absent in weak stems and branches

Grimmia elatior (rr) Note: Compare also G. trichophylla with guide cells in 2 layers.

- $\quad$ Lamina usually unistratose in upper part of leaf, sometimes with bistratose margins or striae; costa not grooved; in transverse section with hydroids, without additional wide cells (except in G. trichophylla); lamina and costa epapillose; stems with central strand. 33

33 Leaves ovate, widest at or shortly above mid-leaf, apex \pm broad; lamina usually unistratose, margins unistratose or bistratose in 1 or more cell rows; gemmae unknown .............34

- Leaves lanceolate, from ovate base tapering to acuminate apex; lamina unistratose or with bistratose patches, margins unistratose or bistratose; gemmae sometimes present........35 
34 Basal paracostal cells usually elongate, 4-8 times as long as wide; capsule ovate, lid mamillate, flat; leaf margins unistratose or bistratose in 1 cell row at one side of leaf only, not thickened, recurved on both sides at mid-leaf; costa slightly attenuate towards leaf base, mamillose dorsally at insertion.

Grimmia orbicularis (w)

- Basal paracostal cells mostly shortly rectangular to quadrate, 2-4 times as long as wide; capsule oblong, lid usually rostrate; leaf margins pluristratose, thickened, recurved on both sides, on one side from base, on the other side from above base to above widest part of leaf; costa not attenuate towards leaf base. Grimmia pulvinata (cc)

35 Leaves strongly asymmetric, one side rounded in outline, opposite side straight; margin of straight side recurved; costa S-shaped, towards apex not median, but approaching one of the margins; in cross section at mid-leaf with two narrowly elliptical guide cells arranged obliquely with respect to leaf plane; rope-like young shoots present in the interior of the cushion; gemmae unknown; narrow central strand of thin-walled cells contrasting sharply with the incrassate orange-tinged stereid-like cortical cells.

Grimmia funalis (rr)

- Leaves symmetric to slightly asymmetric, costa not Sshaped, median at leaf apex; young shoots of different shape or absent; short-stalked gemmae sometimes present at leaf base.

36(35; Costa above mid-leaf rectangular in section, with edges 64) angulate to winged; hair point conspicuously denticulate; lamina sometimes partly bistratose; gemmae sometimes present. Grimmia muehlenbeckii (w) Note: G. hartmanii also can have an angulate costa, but lacks a central strand.

- $\quad$ Costa in section rounded, not angulate or winged; hair point denticulate or smooth; gemmae present or absent.

37(36; Lamina cells at leaf apex longer than wide, slightly sinuose;

52) costa very wide at leaf base, sometimes $>80 \mu \mathrm{m}$, with 6 (8) guide cells at insertion; leaf margin revolute on one side, recurved on opposite side; hair point denticulate; gemmae unknown Grimmia decipiens (r) 
- $\quad$ Lamina cells at leaf apex rounded; costa usually less wide; hair point nearly smooth; gemmae sometimes present........38

38 Costa in transverse section at leaf insertion and leaf base with two layers of enlarged cells, i.e. 1-2 (3) cells in addition to ventral guide cells, in size and position intermediate between guide cells and other costal cells; plants of siliceous substrates.

Grimmia trichophylla $(\mathrm{r})$

- $\quad$ Guide cells at leaf base in one layer; substrate various..........39

39 Guide cells 4 at leaf insertion; leaves erecto-patent to spreading when moist; plants usually on calcareous substrates. Grimmia dissimulata $(\mathrm{w})$

- Guide cells 6 at leaf insertion; leaves erecto-patent to squarrose when moist; plants of siliceous substrates, often near water.

Grimmia lisae (r)

40(31) Leaves semicircular in transverse section \pm from base to apex.

- $\quad$ Leaves \pm keeled, not semicircular in transverse section $(G$. longirostris has leaves keeled in basal and semicircular in apical part)

41 Leaves ovate, usually with rounded apex; detached leaves lie flat on a slide; margin unistratose in bistratose upper part of leaf; most basal cells oblate, incrassate, few elongate paracostal cells. Grimmia laevigata $(\mathrm{w})$

- $\quad$ Leaves from ovate base lanceolate, tapering from distinct shoulder to narrow apex; detached leaves on a slide usually fold along the costa and appear in lateral view; margin bistratose; most basal cells elongate, some nodulose, towards margin shorter Grimmia ovalis (w)

42 Costa in transverse section recessed in a deep groove in upper part of leaf; leaves with distinct shoulder; basal cells short rectangular to quadrate with incrassate transverse walls; hair point denticulate. Grimmia montana (rr)

- $\quad$ Costa not recessed in groove; leaves without shoulder; basal cells elongate-rectangular with thin transverse walls; hair point smooth, sometimes short $(<0.4 \mathrm{~mm})$

43 Stem without central strand; plants usually with numerous short branches; basal lamina cells with strongly thickened longitudinal walls, porose, cells from leaf base to mid-leaf elongate and nodulose; ventral side of costa in cross section canaliculate (with a \pm rounded profile); $2-4$ guide cells free 
at ventral surface, bistratose at mid leaf composed of 2 types of cells; hair point lacking or short $(<0.4 \mathrm{~mm})$, marginal supra-alar cells in conspicuous row consisting of 10-15 hyaline or yellowish-hyaline, thin-walled, pellucid esinuose cells; margins recurved to revolute on both sides.

Racomitrium microcarpon (Bucklandiella microcarpa)(n.s.)

- $\quad$ Stem with central strand; plants sparsely branched; basal lamina cells not conspicuously incrassate or porose, towards margin usually short but neither widened nor hyaline; costa at mid-leaf usually 3-5-stratose composed of 3 different types of cells (guide cells, substereids and larger dorsal cells); margin recurved on one side.

\section{Grimmia longirostris (rr)}

44(24) Leaf apex without any hyaline cell; leaves strongly asymmetric, costa towards apex not median, but approaching one of the margins; rope-like young shoots present in the interior of the cushion (muticous leaves can occur in G. anodon, too)(male plants of)

Grimmia funalis (rr) (see also 35)

- Leaf apex with hair point or at least with some hyaline cells.

45 Central strand absent; hair point lacking or short $(<0.4$ $\mathrm{mm}$ ), or with cell lumina clearly visible, denticulate; globular multicellular gemmae sometimes present at leaf tips 46

- $\quad$ Central strand present (lacking in weak stems and branches of $G$. elatior); cells of hair point with very narrow, hardly visible lumen; globular multicellular gemmae at leaf tips lacking...

46 Plants sparsely branched; basal lamina cells not conspicuously incrassate or porose, towards margin usually short but neither widened nor hyaline; costa at mid-leaf usually 3-5-stratose; cells of leaf apex with cell lumen clearly visible; hair point denticulate; globular multicellular gemmae often present at leaf tips (or some leaf tips deformed due to gemma production)

Grimmia hartmanii (w)

- $\quad$ Plants usually with numerous short branches; basal lamina cells with strongly thickened longitudinal and thin transverse walls, porose, cells from leaf base to mid-leaf elongate and nodulose; ventral side of costa in cross section 
canaliculate (with a \pm rounded profile); $2-4$ guide cells free at ventral surface; hair point lacking or short $(<0.4 \mathrm{~mm})$, marginal supra-alar cells in conspicuous row consisting of 10-15 hyaline or yellowish-hyaline, thin-walled, pellucid esinuose cells; costa at mid-leaf mostly bistratose.

\section{Racomitrium microcarpon}

(Bucklandiella microcarpa) (n.s.)

47 Lamina usually unistratose in upper part of leaf, margin unistratose or pluristratose in one or several rows.

- Lamina bistratose in upper part of leaf or lamina unistratose with some bistratose cell rows, margin pluristratose in several rows.

48 Lamina unistratose, margin unistratose (or at one side of leaf a single marginal row bistratose).

- Lamina usually unistratose, margin pluristratose in one or several rows.

49 Leaves spathulate, widest above mid-leaf; margin completely unistratose, plane ................... Grimmia crinita (rr)

- $\quad$ Leaves not spathulate, widest at or below mid-leaf; margin unistratose or partly bistratose, plane or recurved.

50 Leaves spoon-like, concave; margin unistratose to partly bistratose, plane; basal cells short Grimmia plagiopodia $(\mathrm{r})$

- $\quad$ Leaves not spoon-like, not concave, with an obtuse keel, leaf halves forming a right or obtuse angle in transverse section; margins unistratose or on one side of leaf a single unthickened bistratose row of cells, recurved on both sides around mid-leaf; costa slightly attenuate towards leaf base, mamillose dorsally at insertion; basal paracostal cells usually elongate, 4-8 times as long as wide.

\section{Grimmia orbicularis (w)}

51 Leaves strongly asymmetric, one side rounded in outline, opposite side straight; margin of straight side recurved; costa S-shaped, towards apex not median, but approaching one of the margins; in cross section at mid-leaf with two narrowly elliptical guide cells arranged obliquely with respect to leaf plane; rope-like young shoots present in the interior of the cushion; gemmae unknown; narrow central strand of thin-walled cells contrasting sharply with the incrassate orange-tinged stereid-like cortical cells. 
- $\quad$ Leaves \pm symmetric, costa not S-shaped, median towards apex; young shoots of different shape or absent; shortstalked gemmae sometimes at leaf base

52 Leaves ovate, widest at or shortly above mid-leaf; apex \pm broad; leaf margins pluristratose, thickened, recurved on both sides, on one side from base, on the other side from above base to above widest part of leaf; leaf halves forming approximately a right angle in transverse section; basal cells mostly shortly rectangular to quadrate, 2-4 times as long as wide; gemmae unknown...................... Grimmia pulvinata (cc)

- Leaves lanceolate, from ovate base tapering to acuminate apex; gemmae sometimes present

53(47) Lamina continuously bistratose at least in upper part of leaf (in G. laevigata margin in part unistratose)

- $\quad$ Lamina unistratose even in upper part of leaf, with some cell rows bistratose; margin bistratose in several rows ................ 62

54 Leaves semicircular in transverse section ………………......55

- $\quad$ Leaves not semicircular in transverse section..........................58

55 Costa biconvex, prominent on ventral and dorsal sides, with a centrally placed group of hydroids, guide cells indistinct; plants of exposed calcareous rocks.

Grimmia teretinervis (Schistidium teretinerve) (n.s.)

- Costa not biconvex, guide cells distinct; substrate calcareous or siliceous.

56 Leaves from ovate base lanceolate, tapering from distinct shoulder to narrow apex; detached leaves on a slide usually fold along the costa and appear in lateral view; margin bistratose; most basal cells elongate, some nodulose, towards margin shorter. Grimmia ovalis (w)

- $\quad$ Leaves ovate, usually rounded or obtuse at apex; detached leaves lie flat on a slide; margin bistratose or unistratose; basal cells short or long

57 Margin towards leaf base unistratose in a widening zone; guide cells in a shallow groove with incrassate ventral walls in mid-leaf; most basal cells oblate, incrassate, few paracostal cells elongate; hair point strongly denticulate.

Grimmia laevigata $(\mathrm{w})$

Note: G. laevigata is usually confined to siliceous rocks (Erzberger 2009). Its tufts disintegrate easily. 
- Margin bistratose throughout bistratose part of lamina; costa not grooved, guide cells hardly discernible, ventral walls not incrassate; basal paracostal elongate cells usually extending far towards margin, where cells are shorter; hair point smooth or faintly denticulate..Grimmia tergestina (w)

58(54) Costa in transverse section of upper part of leaf appearing recessed in a \pm deep groove; leaves with or without shoulder; basal cells with thin or \pm incrassate transverse walls

- Costa not grooved ventrally; leaves without shoulder; basal cells elongate with thin transverse walls.

59 Costa without hydroids, ventral side of pluristratose costa with 1 to several layers of wide cells of guide-cell-like appearance; lamina and costa usually with scattered hemispherical papillae, rarely smooth; a wide band of strongly elongate paracostal cells with thin transverse walls present at leaf base; leaves without distinct shoulder.

Grimmia elatior (rr)

- Costa with hydroids; costa and lamina without hemispherical papillae; basal cells with \pm incrassate transverse walls, paracostal basal cells shorter, elongate in few rows; leaves with \pm distinct shoulder 60

60 Leaves strongly plicate, some plicae pluristratose at base, resembling additional costae; shoulder poorly developed; hair point nearly smooth Coscinodon cribrosus (rr)

- Leaves faintly plicate, without additional costae; shoulder distinct; hair point denticulate. Grimmia montana (rr)

61(58) Costa above mid-leaf rectangular in section, edges angulate to winged; in cross section at insertion with 4 (6) guide cells; leaf margin thickened, recurved on one side and revolute on the other; hair point denticulate; capsule ribbed when dry; short-stalked gemmae sometimes at leaf base

\section{Grimmia muehlenbeckii $(\mathrm{w})$}

- $\quad$ Costa rounded at dorsal side, but occasionally unevenly so to somewhat angulate in lower part of leaf; in cross section at insertion with 6 , rarely only 4 guide cells; leaf margin not thickened, usually recurved on one side only; hair point smooth; capsule smooth when dry 
62(53) Costa biconvex, prominent on ventral and dorsal sides, with a centrally placed group of hydroids, guide cells indistinct; plants of exposed calcareous rocks

Grimmia teretinervis (Schistidium teretinerve) (n.s.)

- $\quad$ Costa not biconvex, guide cells distinct; substrate calcareous or siliceous.

63 Leaves strongly asymmetric, one side rounded in outline, opposite side straight; margin of straight side recurved; costa S-shaped, towards apex not median, but approaching one of the margins; in cross section at mid-leaf with two narrowly elliptical guide cells arranged obliquely with respect to leaf plane; rope-like young shoots present in the interior of the cushion; gemmae unknown; narrow central strand of thin-walled cells contrasting sharply with the incrassate orange-tinged stereid-like cortical cells.

Grimmia funalis (rr)

- Leaves symmetric to slightly asymmetric, costa median at leaf apex; young shoots of different shape or absent; shortstalked gemmae sometimes present at leaf base...

64 Leaves ovate, widest at mid-leaf; basal cells shortly rectangular, marginal cells incrassate; margins plane throughout; gemmae unknown................Grimmia anodon (r)

- Leaves lanceolate, from ovate base tapering to acuminate apex; margin recurved to revolute at least on one side; gemmae sometimes present. 36

\section{Key to species of Hedwigia}

References: Hedenäs (1994), Erzberger (1996)

1 Mid-leaf cells mostly with 1, rarely with 2 peltate papillae per cell on dorsal side; hyaline hair point usually reflexed when dry

Hedwigia stellata (rr)

- Mid-leaf cells predominantly with several, \pm branched papillae per cell on dorsal side; leaves straight or falcate...... 2

2 Hyaline hair point of sterile shoots conspicuously white, strongly contrasting with the leaf lamina, occupying 1/4$1 / 2$ of leaf length; median lamina cells often with 2 papillae placed near proximal and distal cell ends on dorsal side, the papillae of adjacent cells seemingly merging together, 
forming a regular pattern; hair points straight or curved to reflexed; spores 19.5-28 (30) $\mu \mathrm{m}$.

Hedwigia emodica (Hedwigia ciliata var. leucophaea) (w)

- Hyaline hair point of sterile shoots not conspicuously white, not strongly in contrast with lamina, occupying up to $1 / 3$ of leaf length; median lamina cells usually with more than 2 papillae per cell on the dorsal side, not forming a regular pattern; hair points usually falcate; spores (23) 25-35 $\mu \mathrm{m} . . . .$. Hedwigia ciliata (Hedwigia ciliata var. ciliata) (w)

\section{Key to species of Bartramiaceae}

Note on the examination of Philonotis: Since the species of this genus show a high degree of variability, it is advisable to examine well-grown plants and avoid juvenile stages. This also applies to the examination of leaves, which should be taken from the tomentose part of the stem, i.e. growth of the previous year, since the first leaves of a season tend to be untypical.

The shape of perigonial leaves (acuminate or obtuse) is not a reliable character for species identification: Meinunger and Schröder (2007) 3: 94.

References: Buryová (unpublished), Bergamini (2001), Frey et al. (2006)

1 Leaves lanceolate, not sheathing at base. Philonotis

- $\quad$ Leaves narrowly lanceolate to linear lanceolate, sheathing at base.

2 Lamina cells with striate cuticle; leaves curled or crispate when dry; seta about $1 \mathrm{~cm}$ long with erect, globose capsule

Plagiopus oederianus $(\mathrm{r}$ )

- Lamina cells mamillose. Bartramia

3 Leaves with whitish sheathing base, abruptly contracted into lanceolate limb; cells mostly elongate, rarely quadrate to shortly rectangular.

Bartramia ithyphylla (r)

- Leaf base weakly sheathing, not conspicuously whitish; cells shorter, at most shortly rectangular.

4 Capsule overtopping leaves on long straight seta; tufts to 5 cm tall. Bartramia pomiformis (w)

- Capsule immersed among leaves on short seta, appearing lateral; plants to $>10 \mathrm{~cm}$ tall..

Bartramia halleriana (rr)

5(1) All lamina cells with mamilla at distal end; leaves $1.2-2 \mathrm{~mm}$ long, 2.5-4 times as long as wide, margins plane, not recurved.

Philonotis marchica (rr) 
- $\quad$ Lamina cells only in upper half of leaf with mamillae at distal end, lower cells smooth, or at least some mamillae at proximal end (especially in lower part of leaf)

6

6 Lamina cells only in upper half of leaf with mamillae at distal end (some cells without mamilla), lower cells smooth; leaves short, 0.6-0.9 (1) mm long.

Philonotis capillaris (Philonotis arnellii) (r)

- Lamina cells with mamillae at proximal end, or some with mamillae in mid-cell, or cells with mamillae at distal end only in uppermost part of leaf or margin

7 Cells uniformly rectangular throughout, of \pm equal width; margin mostly plane with single teeth; leaves not plicate.

Philonotis caespitosa (r)

- $\quad$ Upper lamina cells \pm linear, distinctly narrower than basal rectangular cells; margin recurved, partly toothed with geminate teeth; leaves plicate or not. 8

8 Basal paracostal cells $>60 \mu \mathrm{m}$ long (at least some cells), conspicuously translucent, leaves distinctly homomallous, gradually tapering, hardly plicate below; costa very robust, 60-180 $\mu \mathrm{m}$ wide near base Philonotis calcarea (rr)

- $\quad$ Basal paracostal cells up to $50 \mu \mathrm{m}$ long, not conspicuously translucent; leaves rarely weakly homomallous, \pm abruptly tapering from broad base to narrow acumen, distinctly plicate below; costa usually only to $90 \mu \mathrm{m}$ wide near base.......

Philonotis fontana $(\mathrm{r})$

\section{Key to species of Bryaceae}

References: Demaret (1993), Nyholm (1993), Ahrens in Nebel and Philippi (2001), Guerra et al. (2010), Erzberger and Schröder (2013)

1 Plants with subterranean stolons and erect secondary stems with large terminal rosette and scale-like lower leaves, comal leaves in general $>5 \mathrm{~mm}$ long. Rhodobryum.

- Plants without a conspicuous terminal rosette and without subterranean stolons, leaves $<5$ mm long. Bryum s.l.

(incl. Imbribryum, Ptychostomum).

2 Leaf apex narrowly pointed; costa ceasing below apex; leaf rosette consisting of (11) 16-21 (27) leaves; costa with 1-2 (3) layers of dorsal stereids covered by 2-3 layers of wider superficial dorsal cells; margins weakly recurved; plants to 5 
cm tall, dark green, with leaves $9-10 \mathrm{~mm}$ long and patent whether wet or dry; usually on shady acid humus

Rhodobryum roseum $(\mathrm{r})$

- Leaf apex broadly pointed; costa excurrent; leaf rosette consisting of (18) 21-35 (52) leaves; costa with (3) 4-7 layers of dorsal stereids, superficial dorsal cells unistratose to irregularly bistratose; margins strongly recurved to revolute; plants to $3 \mathrm{~cm}$ high with leaves 5-6 $\mathrm{mm}$ long and incurved when dry; usually on base-rich soil over limestone..

Rhodobryum ontariense (w)

3 Plants whitish-green or silvery; shoots julaceous, leaves closely imbricate when moist and when dry, concave, broadly ovate to ovate. 4

- Plants not conspicuously whitish-green or silvery; shoots not or rarely julaceous.

4 Capsule gibbous on curved seta, with oblique mouth and long neck; leaves concave, imbricate; lamina cells 14-25 $\mu \mathrm{m}$ wide; plants in dense tufts with densely julaceous shoots, whitish or pale green above, usually vinaceous below; in crevices of basic rocks, often near waterfalls

Ptychostomum zieri (Plagiobryum zieri) (r)

- Capsules symmetrical or slightly asymmetrical; shoots julaceous, but not vinaceous below; lamina cells 8-16 $\mu \mathrm{m}$ wide.

5 Costa excurrent as short, stout apiculus, 60-100 $\mu \mathrm{m}$ wide at leaf base; upper leaf cells green (in young leaves); plants short and bud-like, julaceous; capsules elongate-ovate, lightbrown when ripe; seta 2-4 cm long; spores 16-20 $\mu \mathrm{m}$; bulbils in leaf axils lacking..

Ptychostomum funkii (Bryum funckii) (rr)

- Costa mostly ending distinctly below leaf apex, rarely percurrent or excurrent, less wide; upper leaf cells hyaline, without chlorophyll; plants slender, thin, often silvery white; capsules small, ovate or obovate to ellipsoidal, dark red when ripe, getting blackish later; seta shorter, to $2 \mathrm{~cm}$ long; spores 8-14 $\mu \mathrm{m}$; plants often with bulbils in leaf axils.

Bryum argenteum (cc)

6 Bulbils present in leaf axils, either foliate or with rudimentary leaf primordia. (Bryum dichotomum group)......7

- Bulbils in leaf axils lacking. 10 
$7 \quad$ Bulbils $<200 \mu \mathrm{m}$ long, several per leaf axil, leaf primordia either rudimentary or only in uppermost part $(<1 / 3)$ of bulbil.

- $\quad$ Bulbils $>200 \mu \mathrm{m}$ long, solitary or several per leaf axil, leaf primordia in upper third, half or two thirds of bulbil............. 9

8 Bulbils brilliant yellow, usually ca 5 per leaf axil; leaf primordia rudimentary..

Bryum gemmilucens (rr)

- Bulbils not brilliant yellow, often 20-30 per leaf axil; leaf primordia peg-like, incurved or erect

Bryum gemmiferum ( $\mathrm{r}$ )

9 Bulbils solitary (rarely 2) in leaf axils; leaf primordia acuminate, erect, not incurved, occurring in upper half or two thirds of bulbil; bulbils up to $400 \mu \mathrm{m}$ long (rarely more)

Bryum bicolor $(\mathrm{w})$

- Bulbils several per leaf axil; leaf primordia rounded to obtuse, incurved, occurring in upper third of bulbil.

Bryum barnesii (r)

10(6) Filiform gemmae present in leaf axils ...................................11

Filiform gemmae lacking .......................................................... 13

11 Leaves mostly abruptly narrowed to filiform acumen; leaves spirally twisted when dry; margin plane or recurved in lower part of leaf only.

Ptychostomum moravicum (Bryum moravicum) (cc)

- $\quad$ Leaves gradually narrowed to short acumen, flexuose, but not spirally twisted when dry; margin broadly or narrowly recurved from base to near apex.

12 Leaf base red, contrasting green part of leaf (discolorous); margin with distinct border of 3-5 (10) rows of narrow, incrassate cells, border distinctly decurrent along stem; usually \pm robust plants with conspicuous tomentum of red rhizoids, to $>4 \mathrm{~cm}$ tall (up to $10 \mathrm{~cm}$ ).

Ptychostomum pseudotriquetrum (incl. var. bimum)

(Bryum pseudotriquetrum) (w)

- Leaf base not contrasting rest of leaf, concolorous (either green or if red then whole leaf red); marginal border distinct, but narrower, to 3 rows, not decurrent; less robust plants, not tomentose

Ptychostomum pallens (fo. rutilans) (Bryum pallens) (r)

13(10) Leaves spathulate or ovate, widest at or above middle, suddenly contracted into long, filiform point; cells at leaf 
base reddish, discolorous; lamina cells $\pm 20 \mu \mathrm{m}$ wide.

- Leaves widest below middle, more gradually narrowed to short or long point; cells at leaf base concolorous or discolorous.

14 Leaves not spirally twisted when dry, closely imbricate and evenly arranged along \pm julaceous stem; border often indistinct, 1-2 (3) cells wide; capsules very rare.

- Leaves spirally twisted when dry; margin with distinct border 2-5 cells wide; capsules not infrequent, to $5 \mathrm{~mm}$ long

15 Leaves not decurrent, margins not recurved, except in lower part; stems julaceous; rhizoids coarsely papillose, papillae tall and to $5 \mu \mathrm{m}$ wide; lamina cells 15-20 $\mu \mathrm{m}$ wide.

Ptychostomum elegans (Bryum elegans) ( $\mathrm{r}$ )

- $\quad$ Leaves slightly decurrent, margins often recurved to apex; plants not julaceous; rhizoids less coarsely, but densely papillose; lamina cells 16-23 (30) $\mu$ m wide.

16 Plants dioicous; capsules brown when ripe, cernuous

Bryum stirtonii (r)

Ptychostomum capillare (Bryum capillare) (c)

- $\quad$ Plants synoicous; capsules dark red when ripe, cernuous to pendulous

Ptychostomum torquescens (Bryum torquescens) (r)

17(13) Robust plants, often with metallic sheen and reddish colour, stem evenly foliated, leaves stiff, densely imbricate when dry; costa ending below leaf apex or percurrent to shortly excurrent; marginal border indistinct.

- Characters different.

18 Plants glossy, with metallic sheen, mostly red to goldengreen; mid-leaf cells of older leaves elongate, narrow, 8-12 $\mu \mathrm{m}$ wide, incrassate; costa ending in or just below leaf apex, rarely shortly excurrent; rhizoidal tubers often present, 100-200 $\mu \mathrm{m}$ in diameter.

Imbribryum alpinum (Bryum alpinum) (w)

- $\quad$ Plants not glossy, not red; mid-leaf cells 10-18 (28) $\mu \mathrm{m}$ wide, not incrassate; costa stout, excurrent into short point; rhizoidal tubers absent, but fragile shoots sometimes developed in leaf axils.

Imbribryum mildeanum (Bryum mildeanum) (r) 
19 Plants with rhizoidal tubers

(Note: several other species occasionally or regularly also produce rhizoidal tubers, e.g. Imbribryum alpinum, Ptychostomum imbricatulum, Ptychostomum capillare, Ptychostomum elegans, Ptychostomum moravicum, Ptychostomum torquescens, Bryum bicolor, Bryum barnesii, Bryum gemmiferum. These are not keyed out here!)

- $\quad$ Plants lacking rhizoidal tubers (but compare Ptychostomum imbricatulum sometimes with rhizoidal tubers) ....................26

20 Fully developed rhizoidal tubers small, < $100(115) \mu \mathrm{m} . . . .21$

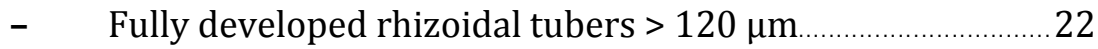

21 Rhizoids pale violet, finely papillose, tubers yellowish to orange or reddish-brown, $70-80 \mu \mathrm{m}$, cells not to slightly protuberant.

Bryum violaceum $(\mathrm{w})$

- $\quad$ Rhizoids pale yellowish brown, tubers bright crimson to reddish-brown, to $100 \mu \mathrm{m}$ long, irregularly spherical, cells distinctly protuberant.

Bryum klinggraeffii $(\mathrm{w})$

22 Rhizoids and tubers yellow to orange-yellow; costa becoming dark purple with age.

Imbribryum tenuisetum (Bryum tenuisetum) (r)

- $\quad$ Tubers red; rhizoids not yellow............................................... 23

23 Rhizoids usually deep violet (old rhizoids dark red and coarsely papillose, young rhizoids pale reddish and only weakly papillose); tubers red to reddish-brown or orange, at the end of long rhizoids, never axillary, to $200 \mu \mathrm{m}$, cells not to slightly protuberant

Bryum ruderale $(\mathrm{w})$

- $\quad$ Rhizoids paler, not violet 24

24 Leaves with distinct border of 2-3 (4) rows of elongate, narrow cells; median lamina cells $15-20 \mu \mathrm{m}$ wide; tubers glossy, bright crimson red, on short rhizoids at the stem base and frequently also in leaf axils above the soil, opaque in transmitted light, (130) $180-260 \mu \mathrm{m}$ in diameter, tuber cells 30-35 (45) $\mu \mathrm{m}$ in diameter, strongly protuberant, with 2-3 $\mu \mathrm{m}$ thick walls as seen in profile; plant of slightly acidic to highly basic habitats.

Ptychostomum rubens (Bryum rubens) (w)

- Leaves not or scarcely bordered; lamina cells 10-16 $\mu \mathrm{m}$ wide; tuber cells not protuberant; tubers never axillary ..... 25

25 Plants growing in dense, nearly cushion-like yellowish to brownish-green or green turfs, with numerous basal rhizoids forming a \pm dense felt; costa stout, in upper leaves 
excurrent in long, denticulate point; basal lamina cells beside the costa quadrate or shortly rectangular; mid-leaf cells 10-12 $\mu \mathrm{m}$ wide, incrassate; rhizoidal tubers 120-180 (220) $\mu \mathrm{m}$ in diameter, pale brownish to bright red, tuber cells usually $<45 \mu \mathrm{m}$ long, not protuberant; plants of drywarm calcareous habitats.

Bryum radiculosum (w)

- $\quad$ Plants growing in lax turf, mostly reddish-green, without conspicuous rhizoid felt; costa in upper leaves only shortly excurrent; basal lamina cells beside the costa rectangular; mid-leaf cells 10-14 (16) $\mu \mathrm{m}$ wide, slightly incrassate or thin-walled; rhizoidal tubers \pm spherical, (180) 190-260 (330) $\mu \mathrm{m}$, red, tuber cells usually not protuberant, (18) 2455 (65) $\mu \mathrm{m}$ long; plants growing on base-rich noncalcareous soil.

Imbribryum subapiculatum (Bryum subapiculatum) (w)

26(19) Plants growing in tufts usually $>4 \mathrm{~cm}$ tall, leaves often strongly decurrent, plants often with dense tomentum of reddish rhizoids.

- $\quad$ Plants smaller, leaves usually not or scarcely decurrent .....29

27 Leaf base concolorous, not contrasting with upper lamina; border often bistratose; lamina cells $16-24 \mu \mathrm{m}$ wide; rhizoid tomentum scarce or lacking; leaves conspicuously longly and broadly decurrent; soft plants to $10 \mathrm{~cm}$ tall, often pinkish to flesh-coloured

Ptychostomum weigelii (Bryum weigelii) (n.s.)

- $\quad$ Leaf base discolorous, reddish, contrasting with upper green lamina; border unistratose, conspicuous; laminal cells 12-14 $\mu \mathrm{m}$ wide; rhizoid tomentum often conspicuous. 28

28 Plants dioicous; sporophytes rare; spores usually 12-18 $\mu \mathrm{m}$. Ptychostomum pseudotriquetrum var. pseudotriquetrum (Bryum pseudotriquetrum var. pseudotriquetrum) (w)

- $\quad$ Plants synoicous, nearly always with sporophytes; spores usually $15-25 \mu \mathrm{m}$

Ptychostomum pseudotriquetrum var. bimum

(Bryum pseudotriquetrum var. bimum, Bryum bimum) (rr) 29(26) Leaf base not contrasting upper lamina in colour, concolorous, plants often reddish to pinkish; marginal border often partially bistratose, sometimes inconspicuous; capsule narrow-mouthed, lid with \pm acute mamilla ................30

- Leaf base red, in contrast with upper green lamina, 
discolorous (examine old leaves!); plants green or variegated red; border unistratose, conspicuous or indistinct to lacking; lid sharply or obtusely pointed.

30 Endostome cilia \pm long, nodose or with short appendages; spores (15) 18-24 (26) $\mu \mathrm{m}$; plants dioicous; often with wine-red to pinkish colour.

- $\quad$ Endostome cilia short to rudimentary, rarely longer and nodose; spores > $28 \mu \mathrm{m}$; plants autoicous; seta usually long; leaf border yellowish; plants green or sometimes pale reddish...

31 Capsule elongate pyriform, with curved neck, not conspicuously contracted below mouth when dry and empty; marginal border conspicuous, to 3 cells wide, often bistratose (in well developed plants).

Ptychostomum pallens (Bryum pallens) (r)

- $\quad$ Capsule short, symmetric, turbinate when dry and empty, with conspicuous contraction below mouth; marginal border inconspicuous, often only 1-2 cells wide.

Ptychostomum turbinatum (Bryum turbinatum) (r)

32 Exostome teeth usually with oblique cross-walls connecting lamellae, exostome partially united to endostome; spores usually > $40 \mu \mathrm{m}$; endostome segments with narrow, slit-like perforations; border less conspicuous, only locally bistratose; plants sometimes pale reddish.

Ptychostomum warneum (Bryum warneum) (n.s.)

- Exostome teeth without cross-walls between lamellae, endostome free; spores smaller, 28 (35) $\mu \mathrm{m}$; endostome segments with oval perforations; leaf margin with yellowish, conspicuous regularly bistratose border; seta to $5 \mathrm{~cm}$ long; plants green

Ptychostomum cernuum (Bryum uliginosum) (n.s.)

33(29) Leaf margin without border or border indistinct ..................34

- $\quad$ Leaf margin with distinct border...................................................36

34 Capsule with narrow mouth, elongate pyriform mostly slightly asymmetric, gibbous, red-brown to blackish when ripe; cilia of variable length, nodose, not appendiculate; plants synoicous; spores $18-25 \mu \mathrm{m}$.

Ptychostomum intermedium (Bryum intermedium) (rr)

- Capsule with wide mouth, cilia appendiculate, or plants without capsules, dioicous. 35 
35 Plants small, $0.5-1 \mathrm{~cm}$ tall, whitish-green, julaceous; leaves broadly ovate, strongly concave, imbricate, crowded at budlike apex; costa excurrent as short, but stout apiculus (of $c a$ $10 \%$ of total leaf length or less), $60-100 \mu \mathrm{m}$ wide at leaf base; lamina cells thin-walled, lax, 20-35 × $15 \mu \mathrm{m}$; marginal border lacking (or consisting of a single row of incrassate, hardly narrowed cells); capsule turbinate (strongly contracted below mouth) when dry and empty.

Ptychostomum funkii (Bryum funckii) (rr)

- $\quad$ Plants not bud-like, taller, $0.5-2 \mathrm{~cm}$; leaves ovate to ovatelanceolate, not strongly concave, gradually narrowed to long point formed by excurrent costa (of $c a 20-30 \%$ of total leaf length), entire or weakly denticulate; lamina cells longer, 40-70 $\mu \mathrm{m}$ long; leaves enlarged and crowded towards shoot apex; leaf margin recurved to revolute from base to near apex; margin with \pm indistinct border formed by 2-3 (4) rows of elongate, narrow cells; plants dioicous, but often with sporophytes; capsule wide-mouthed, pendulous; cilia long appendiculate; spores 10-12 $\mu \mathrm{m}$.

Ptychostomum imbricatulum (Bryum caespiticium) (c)

36(33) Plants without sporophytes.

plants cannot be identified without ripe capsules

- $\quad$ Plants with ripe capsules 37

37 Cilia short to rudimentary; spores large, usually $>20 \mu \mathrm{m}$ $(18-50 \mu \mathrm{m})$; plants usually synoicous; capsule narrowmouthed. 38

- $\quad$ Cilia long, nodose or appendiculate; spores small, usually < $20 \mu \mathrm{m}(10-24 \mu \mathrm{m})$; plants dioicous, synoicous, autoicous or polyoicous; capsule mouth wide or narrow.

38 Exostome teeth with oblique cross-walls between lamellae; endostome attached to exostome; lid with sharp point; costa longly excurrent.

Ptychostomum compactum (Bryum algovicum) (r) Note: Compare also P. warneum.

- Exostome teeth usually without cross-walls; endostome free; capsule obovate to pyriform; lid flat, mamilla indistinct; leaves ovate-lanceolate, upper leaves longly acuminate; costa excurrent into long, smooth or slightly denticulate cuspidate point; exostome teeth at tip with thickened cell wall remnants. Ptychostomum inclinatum 
(Bryum archangelicum, B. imbricatum) (rr)

39 Spores 15-25 $\mu$ m; capsule mouth wide or narrow................40

- $\quad$ Spores (at least majority) not exceding $16 \mu \mathrm{m}$; capsule largemouthed.

40 Capsules \pm gibbous, elongate pyriform, mostly somewhat curved and asymmetric, narrow-mouthed, cernuous to pendulous; leaf margin with indistinct border or 2-3 rows of narrow, elongate cells; plants synoicous.

Ptychostomum intermedium (Bryum intermedium) (rr)

- Capsules cylindrical to clavate pyriform or elongate pyriform, not curved, symmetric, large-mouthed, sometimes inclined; leaf margin with distinct border of 2-6 rows of elongate, narrow incrassate cells; plants autoicous or polyoicous

Ptychostomum pallescens

(Bryum pallescens agg., incl. B. lonchocaulon) (r)

41 Plants synoicous; red leaf base distinct, leaf margin with distinct border of narrow, elongate, incrassate cells

Ptychostomum creberrimum (Bryum creberrimum) (r)

- $\quad$ Plants dioicous; leaf base often concolorous to indistinctly red; leaf margin with few rows of narrow, elongate cells forming indistinct border.

Ptychostomum imbricatulum (Bryum caespiticium) (c)

\section{Key to species of Pohlia}

References: Erzberger (2005), Guerra in Guerra et al. (2010)

1 Plants rarely with sporophytes; usually with numerous axillary gemmae (bulbils) in leaf axils in upper part of stem, rarely bulbils solitary (in P. andalusica); lamina cells 8-10 times as long as wide; costa reaching leaf apex; leaf margin weakly denticulate at apex. (Pohlia annotina agg.)...................

- $\quad$ Plants without axillary bulbils. 2

2 Bulbils globose to slightly elongate, rarely more than twice as long as wide, mostly (70) 80-130 (175) $\mu \mathrm{m} \times 60-110$ (150) $\mu \mathrm{m}$, usually stalked, leaf primordia poorly formed, peg-like, incurved, consisting of only 1 (2) cell(s), never laminate; bulbils yellow-translucent, occasionally brown; plants dull when dry

Pohlia camptotrachela (n.s.)

- Bulbils oblong, obconic or elongate and vermicular; plants dull or glossy. 
3 Leaf primordia distinctly laminate in form; bulbils (including primordia) usually narrowed towards the apex and the base in outline, not larger than $600 \mu \mathrm{m}$, yellowish-green when young, red-brown when mature; leaf primordia 3-5 (8), laminate, erect, comprising $c a 1 / 2$ of total bulbil length, inserted at the same level at flattened bulbil apex; plants glossy, leaves straight, appressed to erect when dry...

Pohlia andalusica (rr)

- $\quad$ Leaf primordia peg-like, rarely becoming laminate on very large ovate bulbils; bulbils green, yellow, orange, red according to age; plants dull or glossy....................................... 4

$4 \quad$ Plants glossy when dry; bulbils mostly 150-300 (450) $\mu \mathrm{m}$ long and to $60 \mu \mathrm{m}$ wide, rather uniform in shape, oblonglinear to linear-vermicular; leaf primordia 1-2, reaching $1 / 4$ of total bulbil length.

Pohlia proligera $(\mathrm{rr})$

Note: The bulbils of this plant differ from those of P. annotina, which may be similar, by the following characters: body of the bulbil 1-2 cells wide, with 1-2 primordia consisting of 1-2 cells (P. annotina: bulbil body opaque, more than 2 cells wide, with 2-3 (4) leaf primordia mostly consisting of more than 2 cells. See photographs in Guerra et al. (2010), p. 192.

- $\quad$ Plants dull when dry; bulbils extremely variable in size and shape, obovate, obconic to elongate and narrowly turbinate, occasionally bulbiform, rarely vermicular, different forms often present on a single stem, mostly more than $80 \mu \mathrm{m}$ wide at the broadest point and 150-300 (550) $\mu \mathrm{m}$ long, opaque, with (2) 3-4 (5) peg-like, erect primordia (occasionally becoming laminate with age); leaves patent when dry; leaf cells uniformly wide from costa to margin.

Pohlia annotina (r)

5(1) Capsules longly cylindric, with neck as long as or longer than urn, horizontal; leaves narrowly lanceolate, margins recurved, denticulate; costa excurrent.

Pohlia elongata (n.s.)

- Capsules shortly cylindric to ovoid, with shorter neck, drooping, pendulous.

6 Lamina cells of upper leaves to 5-6 times as long as wide, mostly $>16 \mu$ m wide; vegetative leaves short, only 2-4 times as long as wide; stems and leaf base often reddish.

- $\quad$ Lamina cells of upper leaves longer, 6-14 $\mu$ m wide; leaves mostly $>4$ times as long as wide; leaf base reddish or not ....8 
7 Plants whitish green, with waxy water-repellent surface; leaves predominantly ovate (observe older stems), \pm distinctly decurrent; usually 1-3 cm high plants; rarely with sporophytes

Pohlia wahlenbergii $(\mathrm{w})$

- $\quad$ Plants brownish or pale green, not waxy, easily wetted; leaves lanceolate to ovate-lanceolate, hardly decurrent; plants only to $5 \mathrm{~mm}$ tall; occasionally with sporophytes.

Pohlia melanodon (c)

8 Plants with rhizoidal gemmae, usually sterile, rarely $>1 \mathrm{~cm}$ tall

- $\quad$ Plants without rhizoidal gemmae, usually $>1 \mathrm{~cm}$ tall...........10

9 Gemmae brownish, spherical to pyriform, with smooth surface, not knobbly, 75-150 × 70-90 $\mu \mathrm{m}$; plants very small, only to $5 \mathrm{~mm}$ high; lower leaves lanceolate with costa ending below leaf apex, upper leaves narrowly lanceolate with costa excurrent; lamina cells very narrow and elongate, $70-120 \times 9-12(15) \mu \mathrm{m}$

Pohlia lescuriana $(\mathrm{r})$

Note: rhizoidal gemmae must be well soaked when examining dried specimens, because when insufficiently hydrated they may have protuberant cells. Care must also be taken not to confuse this species with Dicranella rufescens. In $P$. lescuriana, the marginal cells are slightly narrower than median leaf cells, whereas in D. rufescens they are sometimes even wider.

- $\quad$ Gemmae yellowish, rounded, with protuberant cells giving a knobbly appearance, 50-70 × 40-50 $\mu \mathrm{m}$; leaf apices more strongly denticulate and lamina cells narrower and longer than in preceding species, $70-180 \times 6-10 \mu \mathrm{m}$, wider in lower leaves.

Pohlia lutescens (w)

10 Lamina cells very long and narrow, about 10 times as long as wide, 6-10 $\mu \mathrm{m}$ wide and up to $150 \mu \mathrm{m}$ long; plants conspicuously glaucous green with metallic sheen; leaf base, stem and costa reddish; capsules cernuous, ellipsoid, neck half as long as urn, pale brown

Pohlia cruda (w)

- $\quad$ Lamina cells shorter and wider, only 5-7 times as long as wide, $10-12 \mu \mathrm{m}$ wide and up to $70 \mu \mathrm{m}$ long; capsule yellowish brown, elongate pyriform to elliptical; leaves erect, lanceolate, denticulate at apex.

11 Plants paroicous, spores 20-25 $\mu \mathrm{m}$ in diameter; habitat various, also in wetlands.

Plants dioicous. spores $10-12 \mu \mathrm{m}$ in diameter, nearly smooth; growing exclusively in bogs............Pohlia sphagnicola 
Note: doubtfully recorded.

12 Plants dark green...................Pohlia nutans subsp. nutans (c)

- $\quad$ Plants with variegated red, dense shoots, leaves red or at least with red costa

Pohlia nutans subsp. schimperi (Pohlia schimperi) (r)

Key to species of Mnium (1; 4-7), Plagiomnium (8-13), Rhizomnium (2)

References: Koponen in Nyholm (1993), Sauer in Nebel and Philippi (2001)

1 Leaves unbordered, bluntly toothed down to mid-leaf

Mnium stellare $(\mathrm{w})$

- Leaves with a border of narrow elongate cells, often multistratose.

2 Leaf margins entire, leaves roundish oval; stems densely tomentose in lower part............ Rhizomnium punctatum (w)

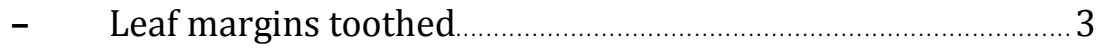

3 Teeth of leaf margins usually in pairs (geminate); sterile shoots erect, leaves spirally arranged. Mnium pp.................... 4

- $\quad$ Teeth of leaf margins simple; sterile shoots procumbent or arcuate, with complanate leaves. Plagiomnium.

$4 \quad$ Lamina cells 13-17 $\mu$ m wide .................. Mnium thomsonii (rr)

- Lamina cells wider................................................................ 5

5 Leaves $c a$ twice as long as wide, broadly lanceolate to obovate; lamina cells without collenchymatous thickenings, not arranged in distinct rows; stems with terminal rosettes; often more than 1 seta per perichaetium; synoicous; leaves flexuose when dry, nearly smooth and only very slightly undulate when moist; dorsal surface of costa usually without teeth, rarely with few teeth; peristome (exostome) dark red-brown.

Mnium spinulosum (n.s.)

- $\quad$ Leaves at least 3 times as long as wide, lanceolate; lamina cells with or without collenchymatous thickenings; leaves equal in size along stem, not forming rosette; only 1 seta per perichaetium; synoicous or dioicous; peristome (exostome) yellowish, greenish-yellow or brownish to golden-brown, not dark red-brown .

6 Dorsal surface of costa with teeth; dioicous ………………...... 7 
- Dorsal surface of costa without teeth (a few sometimes present in upper leaves); costa reaching into \pm cuspidate leaf apex; cell corners with distinct thickenings; marginal teeth small and blunt; stems and leaf base often brownish; synoicous. Mnium marginatum (w)

7 Leaf base not decurrent (or decurrent leaf bases not easily seen); costa usually ending below leaf apex (except sometimes in the uppermost leaves); lamina cells without collenchymatous thickenings.

Mnium hornum (r)

- $\quad$ Leaf base distinctly decurrent; costa ending in acute apex; lamina cells with collenchymatous thickenings; cells at costa much larger than cells at leaf margin; numerous sharp teeth usually present on dorsal side of costa of all well-developed leaves; marginal teeth sharp

Mnium lycopodioides ( $\mathrm{r}$ )

8(3) Leaves narrowly lingulate (except in immature plants), conspicuously decurrent; transversely undulate when wet and dry; leaf cells 10-16 $\mu \mathrm{m}$ wide

Plagiomnium undulatum (c)

- Leaves orbicular to oval or ovate, decurrent or not, not transversely undulate; leaf cells larger

9 Leaves serrate down to mid-leaf.

- $\quad$ Leaves serrate down to base ................................................... 10

10 Leaf base decurrent along stem ……………………….........11

- Leaf base not decurrent ......................................................... 13

11 Synoicous, often with sporophytes; lamina cells isodiametric, with thickenings...Plagiomnium medium (n.s.)

- $\quad$ Dioicous; lamina cells longer than wide, without thickenings

12 Leaves narrowly and often only shortly decurrent; sterile shoots prostrate; lamina cells 1.5-2 times as long as wide; costa weak, often ending below leaf apex; at least some teeth nearly perpendicular to margin, formed by 1-3 (4) cells

Plagiomnium affine (c)

- $\quad$ Leaves longly and broadly decurrent; sterile shoots arcuate; lamina cells twice as long as wide; costa strong apically, percurrent to excurrent; marginal teeth directed forward and formed by 1-2 cells

Plagiomnium elatum (w)

13 Synoicous; lid longly rostrate; lamina cells not porose, isodiametric to shortly elongate, $35-50 \times 20-32 \mu \mathrm{m}$, with 
trigones (collenchymatous thickenings); marginal teeth blunt. Plagiomnium rostratum $(\mathrm{w})$

- $\quad$ Dioicous; lid conical; lamina cells porose, elongate, 40-77 × 22-37 $\mu \mathrm{m}$; marginal teeth sharp.

Plagiomnium ellipticum (r)

\section{Key to species of Orthotrichaceae}

References: Schäfer-Verwimp in Nebel and Philippi (2001), Guerra et al. (2014), Caparrós et al. (2016), Blockeel (2017)

Codonoblepharon (2), Lewinskya (15-17), Nyholmiella (13), Orthotrichum (9-10; 18-25), Pulvigera (12), Ulota (4-8), Zygodon (2)

1 Plants with or without sporophytes, often with spindleshaped gemmae having exclusively transverse walls, in leaf axils; if plants fertile then calyptra cucullate; lamina cells papillose or smooth.

- Plants usually with sporophytes, or if sterile then gemmae occurring on leaf lamina or at leaf apex; calyptra large and conspicuous, mitriform or campanulate, often hairy, leaf cells papillose

2 Upper and median lamina cells smooth; autoicous, capsules frequent, with double peristome; gemmae very sparse, with pale walls; costa strong, 70-85 (100) $\mu \mathrm{m}$ wide in lower third of leaf, ending below apex or percurrent, sometimes slightly excurrent; leaves erect-spreading; rare blackish-green plants to $2 \mathrm{~cm}$ high, on trees (Fagus, Abies) particularly in knotholes and seapage areas on the trunk, in Hungary around water-filled knotholes on Quercus cerris, often together with Anacamptodon splachnoides.

Codonoblepharon forsteri (Zygodon forsteri) (r)

- $\quad$ Upper and median lamina cells papillose; dioicous, capsules rare, gymnostomous (without peristome); gemmae generally abundant, ovoid to ellipsoid, consisting of 3-6 cells with greenish to brownish walls, without longitudinal walls; costa weak, 30-40 (50) $\mu \mathrm{m}$ wide in lower third of leaf, ending below apex, rarely percurrent or slightly excurrent; leaves erect-appressed, \pm flexuose, usually curved and homomallous when dry; green plants, brownish below, on the bark of living trees, also saxicolous.

Zygodon rupestris $(\mathrm{r})$ 
3 Marginal cells at leaf base hyaline, median basal cells incrassate and usually linear; leaves usually crispate when dry (except Ulota coarctata and U. hutchinsiae); seta usually longer than capsule, and capsule therefore exserted (far) above leaves; calyptra conspicuosly hairy. Ulota. 4

- Marginal cells at leaf base not forming hyaline border, median basal cells rectangular, not incrassate; leaves not crispate when dry (but somewhat curled in some species not yet recorded in Hungary); seta usually not much longer than capsule, capsule therefore often immersed, emergent or shortly exserted above leaves (more conspicuously exserted in Orthotrichum anomalum and Lewinskya speciosa); calyptra hairy or not. Orthotrichum (s.l., including Lewinskya, Pulvigera, Nyholmiella).

4 Leaves straight and appressed when dry, in appearance much like Orthotrichum ..........................................................

- $\quad$ Leaves curled or crisped when dry

5 Capsule pale, elongate pyriform with contracted mouth and long neck, smooth and lacking striae when empty; on bark of deciduous trees.

Ulota coarctata $(\mathrm{rr})$

- Capsule ellipsoid to narrowly cylindrical, not contracted at mouth, sulcate when empty; on siliceous rocks

\section{Ulota hutchinsiae (rr)}

6 Capsules spindle-shaped (fusiform) when empty, not contracted below mouth; sum of capsule length + seta length ca 5-8 mm; endostomial segments 8 , linear, fragile, mostly uniseriate, ornamentation obliquely striate at base; leaves scarcely crisped when dry (each leaf is more strongly bent at its base than towards the tip, i.e. the radius of curvature increases from base to apex). Ulota bruchii (w)

- $\quad$ Capsules \pm contracted below mouth (urceolate) when dry and empty; sum of capsule length + seta length ca 3-5 mm; endostomial segments fragile or persistent, not striate at base; leaves strongly crisped or not when dry. Ulota crispa s.l. (w)...

7 Capsules when dry and empty conspicuously constricted below mouth, ribs very close to each other in upper half of urn (intercostal spaces can hardly be seen); exothecial bands 4-6 cells wide, reaching to mouth or nearly so; exostomial teeth pairs not easily splitting, usually bordered 
with a hyaline halo particularly apparent in lower half of tooth; endostomial segments 8, strong, persistent, shining, broad at base; leaf base wide, strongly concave, usually abruptly narrowing towards the leaf lamina; basal marginal leaf cells forming a broad band (7-15 cell rows) along the leaf base; leaves usually strongly crisped (with radius of curvature \pm constant from leaf base to apex, compare however $U$. bruchii); operculum without differentiated basal ring. Ulota crispa s.str. (r)

- Capsules when dry and empty only slightly or not constricted below mouth, ribs separated by \pm broad furrows in upper half of urn; exothecial bands 2-4 (5) cells wide, visibly separated from the mouth by a ring of small thinwalled cells in 2-6 rows; pairs of exostome teeth partially splitting in empty capsules, teeth not bordered by a hyaline halo; operculum with or without orange basal ring.

8 Endostome segments incurved when dry, uniseriate with incrassate and prominent transverse wall remnants, persistent, hardly fragile; all the cells of the exothecial bands hyaline with pale yellow incrassate lateral walls; leaves markedly crisped when dry, abruptly narrowing from a concave base; operculum without differentiated basal ring.....

Ulota intermedia $(\mathrm{r})$

- $\quad$ Endostome segments variably bent when dry, uniseriate or irregularly biseriate with thin transverse wall remnants, fragile, easily lost; cells of exothecial bands evenly pale yellow, at least in the two central rows; leaves slightly or moderately crisped when dry, gradually narrowing from a plane to slightly concave base; operculum usually with an orange to reddish basal ring.

Ulota crispula $(\mathrm{w})$

9(3) Leaves ending in hyaline point; capsule pale brown, smooth to weakly striate, almost immersed in leaves; peristome teeth separating at maturity.. Orthotrichum diaphanum (cc)

- $\quad$ Leaves without hyaline tip; peristome teeth separating or not.

10 Upper lamina cells large, 16-24 $\mu \mathrm{m}$ in diameter; leaves ovate-lingulate to elliptical with rounded apex (sometimes apiculate); plants $0.5-1 \mathrm{~cm}$ high, sometimes with leaf-borne gemmae; usually growing on wood or stones in the flood zone of rivers.

Orthotrichum sprucei (rr) 
Note: found only once in an artificial habitat in the Duna-Tisza-interfluve; see Erzberger and Papp (2000).

- Upper lamina cells smaller, 10-18 $\mu \mathrm{m}$ in diameter; leaves ovate to lanceolate with acute to obtuse apex, sometimes apiculate.

11 Plants dioicous, usually without capsules; margins plane to incurved; leaves sometimes covered with conspicuous brown gemmae; plants usually corticolous

- $\quad$ Plants autoicous, almost always with capsules; gemmae, if present, green and inconspicuous; leaf margins recurved; plants corticolous or saxicolous

12 Leaves lanceolate, densely covered with brown filamentous gemmae; leaf margins plane; large plants, $3-4 \mathrm{~cm}$ tall or more........................Pulvigera lyellii (Orthotrichum lyellii) (w)

- $\quad$ Leaves ovate-lingulate, with rounded apex, with few to many small greenish gemmae; margins plane to incurved; small plants. Nyholmiella.

13 Leaf margin plane; upper lamina cells with 1 papilla per cell (rarely 2); gemmae predominantly on ventral side of leaf lamina; capsule with double peristome.

Nyholmiella obtusifolia (Orthotrichum obtusifolium) (c)

- $\quad$ Leaf margin incurved from base to somewhat cucullate apex; upper lamina cells with (1) 2-3 papillae per cell; gemmae on both sides of leaf lamina; capsule without peristome.

Nyholmiella gymnostoma (Orthotrichum gymnostomum) (n.s.)

14(11) Capsules with superficial stomata (phaneropore). Lewinskya. 15

- Capsules with immersed stomata (cryptopore). Orthotrichum 19

15 Outer peristome teeth erect or spreading when dry, coarsely papillose, sometimes with preperistome; capsules with $8 \pm$ conspicuous striae, immersed to emergent, ovoid-obloid; outer peristome teeth in 8 pairs soon separating; calyptra strongly hairy, the hairs rising above apex of calyptra; lamina occasionally bistratose above and towards margins; leaf cells with simple papillae; $1.5-5 \mathrm{~cm}$ tall robust plants, commonly on (siliceous) rock but sometimes also on deciduous trees

Lewinskya rupestris (Orthotrichum rupestre) (r) 
Note: Ulota hutchinsiae might key out here, because it has superficial stomata, grows on siliceous rocks and has erect to spreading peristome teeth, sometimes with a preperistome, and a very hairy calyptra, and unlike other Ulota species, has the leaves not crisped, but straight and appressed when dry. However, its capsules are clearly exserted, strongly contracted and cylindrical when dry and empty, and careful examination of the coloured leaf base will reveal the characters typical of Ulota (hyaline marginal and incrassate median basal cells).

- $\quad$ Outer peristome teeth recurved when dry; capsules smooth or striate; plants corticolous or saxicolous.

16 Capsules yellowish, thin-walled, smooth or almost so when dry, immersed in the leaves or clearly exserted above the leaves; outer peristome teeth united in pairs or not, recurved but arcuate when dry, only the tips touching surface of capsule ('tea cup handle'); leaves mostly with a narrow, acute apex.

- Capsules pale, elongate-cylindrical, strongly sulcate when dry, hemi-emergent to shortly exserted; calyptra naked or with few short hairs; peristome teeth united in 8 pairs (or partly separating when old), regularly recurved when dry, touching surface of capsule throughout their length; inner peristome segments coarsely papillose (rarely nearly smooth); leaves mostly with a broad, short apex; mostly on trees, but also on rock

Lewinskya affinis (Orthotrichum affine) (cc) Note: Lewinskya fastigiata was distinguished from $L$. affinis as variety already by Boros (1968), but neglected during the last decades. It has been resurrected recently as a good species (Vigalondo et al. 2020), but is missing in the most recent Hungarian checklist (Erzberger and Papp 2020 ) pending verification of specimens. It can be distinguished from $L$. affinis inter alia by capsules immersed or hemi-emergent, and having broad exothecial bands 4 cells wide near capsule mouth (often 6-8 cell rows below) vs. narrow bands 2-3 cells wide near capsule mouth (sometimes 4-6 below) in L. affinis.

17 Capsule ovoid, without thickended longitudinal bands and completely smooth when dry, immersed in the leaves; peristome teeth yellowish, narrow, not united in pairs; inner peristome segments papillose, broad, 2 cells wide, with irregular margins; robust species, predominantly on bark.......

Lewinskya striata (Orthotrichum striatum) (c)

- $\quad$ Capsule cylindrical with long neck, weakly sulcate in upper half or total length, emergent to clearly exserted, gradually narrowed to the seta, seta $0.75-3 \mathrm{~mm}$ long; peristome teeth 
united in 8 pairs (or partly separating when old); inner peristome segments 8, papillose, with slightly irregular margins; calyptra usually densely hairy; plants forming tufts to $3 \mathrm{~cm}$ tall; on deciduous trees, rarely on rock

18 Seta (1) 1.5-2.5 (3) mm long, as long as or longer than the urn, capsule clearly exserted; capsule wall smooth or with short striae in upper half only; ripe calyptra conical or fusiform, with golden or colourless hairs

Lewinskya speciosa (Orthotrichum speciosum) (c) Note: When capsules are not strongly exserted, confusion with $L$. affinis might occur, especially when old capsules of $L$. speciosa sometimes are sulcate to near base. However, in a cushion of $L$. speciosa nearly always some smooth capsules will be present. Additional useful characters to separate L. speciosa from L. affinis: (i) strongly hairy calyptra (calyptra with only few or no hairs in L. affinis); (ii) peristome teeth arcuate, only the tips touching the capsule surface (regularly recurved in L. affinis); (iii) stomata confined to lower half of capsule ( $L$. affinis: stomata not too frequent, scattered all over the capsule, some occasionally close to capsule mouth).

- $\quad$ Seta 0.75-1 (1.3) mm long, as long as or less long than the urn, capsule half emergent; capsule wall with distinct striae in total length; ripe calyptra oblong-conical, with greenishyellowish hairs

Lewinskya breviseta

(Orthotrichum speciosum var. brevisetum)

19(14) Outer peristome teeth erect or spreading when dry, often with preperistome (prostome); plants mostly on rocks......20

- $\quad$ Outer peristome teeth recurved when dry, touching surface of empty capsule; prostome lacking; plants mostly on trees....

20 Vaginula with numerous golden-yellow hairs (also numerous golden-yellow paraphyses between the antheridia); calyptra campanulate, straw-coloured, with (moderately) numerous yellow, papillose hairs; capsule wide-ovoid to shortly urn-shaped; inner peristome segments 8 or 16, well developed; capsule wall with 8 pronounced striae, intermediate striae weak or lacking; plants densely tomentose, in tall lax cushions; on noncalcareous rocks. Orthotrichum urnigerum (r)

- $\quad$ Vaginula naked or with a few hyaline hairs (very rarely with numerous hairs); inner peristome lacking; capsule with $16 \pm$ equally strong striae (but intermediate striae often 
somewhat shorter); on base-rich rock

21 Capsules exserted above leaves, elongate-cylindrical, only very slightly constricted below mouth when dry; calyptra long conical to campanulate, with few to numerous papillose hairs; seta 2-4 mm long, as long as or longer than capsule, reddish brown; outer peristome teeth striate horizontally below, vertically above... Orthotrichum anomalum (c)

- $\quad$ Capsules immersed or only shortly exserted, wide ovoid or urn-shaped when empty, slightly constricted below mouth, \pm abruptly contracted into seta; seta shorter than the capsule, pale; outer peristome teeth striate, papillose-striate or papillose-reticulate; inner peristome segments usually lacking

22(19) Exothecial bands of capsule wall formed by 2 rows of welldifferentiated yellowish cells (locally 3-4 cells wide); vaginula with many long hairs; spores $15-23 \mu \mathrm{m}$.

Orthotrichum patens (c)

Note: Confusion with 0 . stramineum, the only other (Hungarian) corticole species with long vaginula hairs, can be avoided by taking into account the following characters: (i) spore size in just ripe capsules (O. patens: 16-20 (24) $\mu \mathrm{m}$, O. stramineum: mostly $12 \mu \mathrm{m}$ ); (ii) capsule shape (O. patens: wide ovoid, abruptly (often forming a $90^{\circ}$ angle) contracted into seta, dry empty capsules not longitudinally contracted, $O$. stramineum: capsule more cylindrical, gradually narrowed to seta, dry empty capsule always strongly contracted); (iii) width and length of capsule striae (O. patens: only 2-3 cells wide, $O$. stramineum: 4-6 cells wide and mostly longer); (iv) endostome sculpture (O. patens: papillose, O. stramineum: smooth); (v) apical openings in exostome teeth $(O$. patens: mostly lacking, $O$. stramineum: present); (vi) papillosity of upper lamina cells (O. patens: cells with 1-4 (6) simple or forked papillae, O. stramineum: less papillose, with small, mostly unbranched papillae); (vii) time of spore ripening (most easily observed, when both species occur together) - is 1 month ahead in 0 . patens. A hairy vaginula is also observed in 0 . urnigerum, a saxicole species with an erect exostome.

- $\quad$ Exothecial bands of capsule wall formed by 4 or more rows of well-differentiated cells; vaginula hairy or not; spores usually smaller (but $18-24 \mu \mathrm{m}$ in 0 . rogeri).

23 Vaginula with numerous long hairs (best seen near young capsules); capsule elongate-cylindrical, longitudinally contracted when dry; gradually narrowed into seta; empty capsule wall tough; capsule striae (3) 4-6 cells wide; inner peristome with 8 or 16 segments (the intermediate segments often consisting of few cells only); outer peristome 
teeth with apical window-like openings, extremely rarely splitting into 16 single teeth; spores mostly $12 \mu \mathrm{m}(10-15$ $\mu \mathrm{m})$; calyptra campanulate, with some smooth hairs, rarely naked, the tip conspicuously blackish far down.

Orthotrichum stramineum (w)

- Vaginula naked or with 1-3 hairs. 24

24 Plants with dimorphic leaves, leaves (of female shoots) from broad ovate base elongate-lanceolate-lingulate, often rounded at apex, margins recurved for the greater part of their length, leaves of male branches smaller, with the base not or slightly widened, and margins plane or nearly so; inner peristome at least with some segments completely erect when dry, smooth to finely papillose (slightly ornamented by longitudinal striae at base)

Orthotrichum rogeri ( $\mathrm{rr}$ )

- $\quad$ Plants with monomorphic leaves, leaves of all shoots similar, independent of sex; endostome segments incurved when dry, smooth or papillose, without longitudinal striae. 25

25 Upper leaves from ovate base lanceolate, widest at lower third, apex acute or obtuse, rarely rounded; capsule gradually narrowed to the seta, half emergent to almost exserted; neck and seta pale brown, contrasting with urn, with 8 striae 6-8 cells wide; stomata (mostly) 'pseudophaneropore', i.e. hardly covered by broadly rounded edges of surrounding cells; inner peristome with 8 or more often 16 segments ( 8 longer and 8 shorter, the latter sometimes reduced to 1-2 cells); calyptra short, to $1.4 \mathrm{~mm}$ long; gemmae unknown; exostome teeth yellowish, ornamented in upper part with papillae and lines.

Orthotrichum pallens (c)

Note: Orthotrichum moravicum is closely related to 0 . pallens, but differs in 16 inner peristome segments of \pm equal length (not 8 longer and 8 shorter as in 0 . pallens) and nearly as long as the exostome teeth; the endostome processes have conspicuous lateral appendages (Plášek et al. 2009). O. moravicum was described from the Czech Republic and might be expected in Hungary.

- Upper leaves frequently ovate-lanceolate (widest shortly below middle) to oblong-lanceolate, acuminate or obtusely rounded (sometimes apiculate with 1-2 hyaline end cells); capsule immersed to half emergent, suddenly or gradually narrowed to seta; stomata covered by surrounding cells to a 
variable extent, mostly in a single capsule some stomata hardly covered, some covered half or more by irregularly protruding mamillae of surrounding cells; inner peristome mostly with 8 segments; exostome orange, ornamentation various..

26 Capsule abruptly narrowed to the seta; exostome teeth in persistent pairs, ornamented with tall papillae (rarely some lines); endostome segments 8, with enlarged base, usually shorter than exostome teeth; gemmae very common

Orthotrichum schimperi $(\mathrm{w})$

- Capsule gradually narrowed to the seta; exostome teeth pairs splitting at tips, ornamented in upper part with low papillae and some fine lines; endostome segments 8 or 16 , long and narrow, not noticeably widened at base, as long as exostome teeth, gemmae rare...... Orthotrichum pumilum (c)

\section{Key to species of Aulacomnium}

- Stems tomentose; gemmae rare; cells at leaf base pluristratose, brownish; plants to $10 \mathrm{~cm}$ tall

Aulacomnium palustre $(\mathrm{w})$

- $\quad$ Stems not tomentose, nearly always with gemmae in stalked globose clusters at shoot apices; cells at leaf base unistratose; plants $1-3 \mathrm{~cm}$ high

Aulacomnium androgynum (r)

Key to species of Fontinalis

- $\quad$ At least lower stem leaves keeled; stem and branch leaves arranged in 3 rows Fontinalis antipyretica $(\mathrm{r})$

- $\quad$ All leaves plane, without border.....Fontinalis hypnoides (rr) 


\section{Key to species of Plagiothecium}

References: Erzberger and Baráth (2017), Erzberger et al. (2020)

1 Leaves whitish green, 2-5 mm long, imbricate, strongly transversely undulate; decurrent alar cells with straight outer walls; on forest soil......Plagiothecium undulatum (rr)

- Plants without this combination of characters...........................2

2 Median lamina cells narrow, $<10 \mu \mathrm{m}$ wide; small plants, usually only $2-3 \mathrm{~cm}$ long.

- $\quad$ Median lamina cells $>10 \mu \mathrm{m}$ wide; medium-sized to large plants

3 Leaves $0.9-1 \mathrm{~mm}$ long and ca $0.35 \mathrm{~mm}$ wide, symmetric, gradually acuminate to a long point, often with uniseriate gemmae and rhizoids at the tip; lamina cells 5 (8) $\mu$ m wide....

Plagiothecium latebricola $(\mathrm{rr})$

Note: For an account of this species in Hungary see Erzberger and Baráth (2017).

- Leaves longer and wider (mostly > $0.5 \mathrm{~mm}$ wide), asymmetric, apex less longly drawn out, usually without gemmae (but gemmae frequent in leaf axils); lamina cells wider.

4 Leaf apices plane; leaves asymmetric usually with one curved and one straight side, to $1.2 \mathrm{~mm}$ long, alar cells decurrent in 1-2 rows, not clearly delimited, not auriculate, with straight outer walls, rectangular.

Plagiothecium laetum (w)

- Leaf apices curved downward towards substrate when moist; leaves asymmetric with two curved sides, $>1.2 \mathrm{~mm}$ long, alar cells forming a distinct group, decurrent in 2-4 (5) rows, mostly somewhat auriculate, often with weakly bulging outer walls, isodiametric or rectangular; capsule horizontal to inclined, often gibbous

Plagiothecium curvifolium (w)

5 Decurrent alar cells inflated, oval to rounded, with bulging walls, sometimes only a few cells rounded and most cells rectangular or quadrate; lamina cells not wider than $16 \mu \mathrm{m} .$.

- Alar cells not inflated, the decurrent cells rectangular, not rounded; lamina cells wider than $16 \mu \mathrm{m}$ or not. 
6 Alar cells mostly rectangular or quadrate, forming a long triangular group decurrent in 2-4 rows along stem and often remaining on the detached leaf, at least some of the outer cells with rounded outlines; apical part of lamina usually with a group of thin-walled short cells (rhizoid initials) often eroded; some leaves only weakly asymmetric; large plants to $10 \mathrm{~cm}$ long.

Plagiothecium platyphyllum (rr) Note: For an account of this species in Hungary see Erzberger et al. (2020)

- Most alar cells strongly inflated, rounded, forming an oval group usually less long, often wider, decurrent in 3-4 (6) rows; leaves without rhizoid initials at apex; all leaves distinctly asymmetric; medium-sized plants. Plagiothecium denticulatum.

7 Lamina cells in \pm distinct transverse rows, therefore leaves sometimes transversely undulate when moist; margins at apex often completely without denticulations; leaves 2.5-4 $\mathrm{mm}$ long, strongly complanate, strongly asymmetric, at least some with one straight and one curved side; decurrent alar cells in 4-6 (8) rows; plants of wet habitats.

\section{Plagiothecium denticulatum var. undulatum}

(Plagiothecium ruthei) ( $\mathrm{r}$ )

- Lamina cells not in transverse rows, leaves not transversely undulate when moist; margins at apex often denticulate; leaves 1.5-2.5 (3) $\mathrm{mm}$ long, less strongly complanate, asymmetric, mostly with both sides curved; decurrent alar cells in 3-5 rows; plants of humid, but not particularly wet habitats......Plagiothecium denticulatum var. denticulatum

(Plagiothecium denticulatum) $(\mathrm{w})$

8 Leaves \pm symmetric, concave; plants julaceous, decumbent (examine older plants; young plants of other species can look similar); mid-leaf cells 65-120 (150) × (8) 10-12 (15) $\mu \mathrm{m}$.

Plagiothecium cavifolium (c)

- Leaves symmetric to \pm asymmetric, plane; mid-leaf cells wider or longer.

9 Majority of mid-leaf cells longer than $150 \mu \mathrm{m}$ and 10-20 $\mu \mathrm{m}$ wide (7-10 times as long as wide), not in transverse rows; apical end cell linear, elongate; leaf apex occasionally with rhizoid initials.

Plagiothecium succulentum (w)

- $\quad$ Mid-leaf cells (65) 75-140 (155) × 15-22 (25) $\mu \mathrm{m}(4-6$ times as long as wide) in \pm transverse rows; apical end cell 
rhomboidal; leaf apex usually with (few) rhizoid initials Plagiothecium nemorale (w)

Note: Wolski and Krawczyk (2020) recently described a new species closely related to $P$. nemorale, Plagiothecium angusticellum, which they also identified in a collection by L. Vajda from Börzsöny Mts. $P$. angusticellum is missing in the latest Hungarian and European checklists (Erzberger and Papp 2020, Hodgetts et al. 2020), and the differentiation from $P$. nemorale does not seem straightforward.

\section{Key to species of Orthothecium}

- $\quad$ Plants medium-sized to robust, often reddish, leaves 2-4 $\mathrm{mm}$ long, strongly plicate longitudinally.

\section{Orthothecium rufescens $(\mathrm{rr})$}

Note: missing in Erzberger and Papp (2020), recently discovered by Németh and Schmotzer in a single site in Bükk Mts.

- Plants delicate, mostly yellowish green, rarely reddish, leaves mostly $1.7 \mathrm{~mm}$ (to $2 \mathrm{~mm}$ ) long, without longitudinal plicae Orthothecium intricatum (r)

\section{Key to species of Fabronia}

- $\quad$ Leaf margins with unicellular teeth.......Fabronia ciliaris (rr)

- Leaf margins with pluricellular teeth, appearing ciliate. Fabronia pusilla $(\mathrm{r})$

\section{Key to species of Palustriella}

- Stems regularly complanately pinnately branched, tomentose, paraphyllia abundant; stem leaves cordatetriangular; alar cells numerous, forming a triangular group ascending the margin.

Palustriella commutata (r)

- Stems irregularly or subpinnately branched, not tomentose, paraphyllia few; stem leaves ovate to lanceolate; alar cells few, forming a group that does not ascend up the margin

Palustriella falcata (rr) 


\section{Key to species of Campyliadelphus}

- $\quad$ Stem leaves straight, sometimes curved, narrowly triangular lanceolate, about four times as long as wide, from ovate base gradually narrowed to long linear, \pm channelled acumen; costa strong, reaching higher than $2 / 3$ leaf length; leaf margin \pm distinctly denticulate; wetland species.

Campyliadelphus elodes (Campylium elodes) (r)

- $\quad$ Stem leaves straight to falcate, lanceolate, about twice as long as wide, from broad base suddenly narrowed to channeled acumen; costa thin, extending to mid-leaf; leaf margin entire; slender, soft, yellowish green plants of dry calcareous habitats. Campyliadelphus chrysophyllus (Campylium chrysophyllum) (w)

\section{Key to species of Campylium}

- Leaves gradually narrowed, 1.7-2.8 mm long, erect irregularly branched plants. Campylium stellatum (r)

- $\quad$ Leaves often abruptly narrowed into a long acumen, 1-2.3 $\mathrm{mm}$ long; creeping, often pinnately branched plants.

\section{Campylium protensum}

(Campylium stellatum var. protensum) (r)

\section{Key to species of Drepanocladus}

1 Costa reaching 2/3 of leaf length or more; leaves mostly falcate; acumen flat; alar cells various.

- $\quad$ Costa weak, mostly extending not far above mid leaf; leaves straight or falcate; acumen channeled; alar cells incrassate, porose, often reaching costa, distinctly decurrent; leaves 2-3 $\mathrm{mm}$ long, gradually and longly pointed from broadly lanceolate base; stem leaf insertion slightly curved.

Drepanocladus polygamus (Campylium polygamum) (r)

2 Alar cells in large groups extending across all or most of leaf base, cell walls thin; leaves nearly straight to moderately falcate, rarely strongly falcate; plants to $>10 \mathrm{~cm}$ long, green to brownish green

Drepanocladus aduncus $(\mathrm{w})$ 
- Alar cells in relatively small groups reaching 40-60\% distance from leaf margin to costa, the cell walls often incrassate; leaves often strongly falcate..

3 Leaves lanceolate to linear-lanceolate, longly and finely acuminate; costa reaching into apex........................................... 4

- Leaves broadly ovate-lanceolate, shortly acuminate, gradually narrowed from base to apex, concave; costa ending in leaf apex; plants robust, turgid, to $30 \mathrm{~cm}$ long, brownish yellow................. Drepanocladus lycopodioides ( $\mathrm{rr}$ )

4 Ratio of median leaf cell length (in $\mu \mathrm{m}$ ) to leaf length (in $\mathrm{mm}$ ) 18.0-24.5; alar cells often incrassate; leaves longly and finely pointed; often very robust plants, to $20 \mathrm{~cm}$ long; costa strong, (50) 70-100 $\mu \mathrm{m}$ wide at base, reaching to leaf apex

Drepanocladus sendtneri (rr)

Note: To compute the aforementioned ratio, examine 8-10 leaves from a homogeneous part of stem under the microscope, measure length of the longest and the shortest leaf and cell length of the longest and the shortest leaf cell, then compute mean values and use these for computing the ratios (Hedenäs and Bisang 2002).

- $\quad$ Ratio of median leaf cell length (in $\mu \mathrm{m}$ ) to leaf length (in $\mathrm{mm}$ ) 23-36.5; alar cells thin-walled; costa relatively weak, 30-75 $\mu \mathrm{m}$ wide at base, ending far below leaf apex.

Drepanocladus sordidus (n.s.)

Key to species of Amblystegium s.l. (incl. Amblystegium, Hygroamblystegium, Pseudoamblystegium subtile, Pseudocampylium radicale, Serpoleskea confervoides)

1 Leaves without costa or costa short and double, not reaching

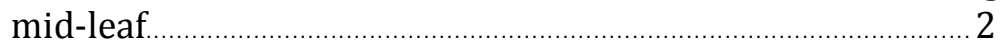

- $\quad$ Leaves with single costa extending to or above mid-leaf........ 3

2 Capsule curved; perichaetial leaves without costa; on shaded calcareous rocks.

Serpoleskea confervoides (Amblystegium confervoides) (w)

- $\quad$ Capsule straight or slightly curved; perichaetial leaves with costa reaching mid-leaf; on tree bark and rotting wood

. Pseudoamblystegium subtile (Amblystegium subtile) (w) Note: Mats of delicate pleurocarpous mosses on tree bark with erect capsules may be mixtures of other species, e.g. A. serpens without capsules and Leskea polycarpa with erect capsules! 
3 Costa reaching leaf apex, often bent in upper third ................ 4

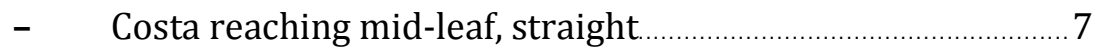

4 Costa very strong, mostly $>40 \mu \mathrm{m}$ wide at leaf base, hardly narrower towards the tip, mostly reaching to leaf apex, often slightly bent in upper third; plants growing in or near water.

- Costa less strong, distinctly narrowed towards the tip, bent above or not; plants not aquatic but growing in moist or wet habitats.

5 Leaves narrowly rounded at apex; branch leaves widest at (1/4) 1/3-1/2 leaf length; stem little and irregularly branched; plants growing in lime-poor flowing water.

Hygroamblystegium fluviatile (Amblystegium fluviatile) ( $\mathrm{r}$ )

- Leaves distinctly acuminate at apex; branch leaves widest at 1/8-1/4 leaf length; stem often densely and pinnately branched; plants growing in base-rich or lime-rich flowing water.

Hygroamblystegium tenax (Amblystegium tenax) (w)

6 Leaf cells at mid leaf rhombic or hexagonal, 2-4 times as long as wide; leaves distinctly widened in lower third and contracted at leaf base, often narrowed \pm abruptly towards leaf tip; costa always with a distinct bend.

Hygroamblystegium varium (Amblystegium varium) $(\mathrm{w})$

- Leaf cells at mid leaf often elongate; leaves not conspicuously contracted at their base, gradually narrowed towards the tip; costa not to at most slightly bent

Amblystegium serpens (cc)

7 Slender (to medium-sized) plants, leaves to $1 \mathrm{~mm}$ long; variable with regard to length of costa and length of lamina cells (from 2-3 to 4-6 times as long as wide)

Amblystegium serpens (including the more robust var. juratzkanum with leaves denticulate at base) (cc)

- $\quad$ Medium-sized to robust plants, leaves $>1 \mathrm{~mm}$ long ................ 8

8 Leaves decurrent along stem......Pseudocampylium radicale (Campylium radicale, Amblystegium radicale, A. saxatile) (r)

- Leaves not decurrent along stem, distantly arranged along stem; leaf margin entire; leaves distinctly contracted at leaf base.

Hygroamblystegium humile (Amblystegium humile) (w) 


\section{Key to species of Calliergon s.l. incl. Straminergon}

1 Plants almost unbranched; costa reaching 3/4 or slightly more of leaf length; stem leaves oblong, \pm imbricate; alar cells in decurrent group ascending up margin; often with rhizoids at leaf apex.

Straminergon stramineum (Calliergon stramineum) (rr)

- Plants irregularly to regularly pinnate; costa extending nearly to leaf apex; stem leaves often patent; alar cells in large triangular group not ascending up margins.

2 Alar cells often reaching costa, in a plane or slightly concave group, gradually differentiated from upper cells; leaves 2-3 times as long as wide; plants irregularly branched, erect, pale to dark green; autoicous........Calliergon cordifolium (r)

- $\quad$ Alar cells very sharply differentiated, rarely reaching costa, in a strongly concave group; leaves shorter and broader; $c a$ 1.5 times as long as wide; plants pinnately branched with turgid main stems and short, thinner branches, green, yellowish or brownish; dioicous...Calliergon giganteum (rr) Note: Depauperate plants may approach C. cordifolium.

\section{Key to species of Scorpidium}

- $\quad$ Plants turgid; stem leaves ovate to ovate-orbicular, strongly concave, apex acute or shortly acuminate; costa rarely reaching mid-leaf, often short and double or lacking.

Scorpidium scorpioides ( $\mathrm{rr}$ )

- Plants not turgid; stem leaves ovate-lanceolate, falcate, moderately concave, longly acuminate; costa reaching to $1 / 2-2 / 3$ leaf length.

Scorpidium cossonii (Drepanocladus cossonii) (rr) 


\section{Key to species of Pseudoleskeella}

- Usually clusters of deciduous branchlets in axils of upper leaves; stem leaves from \pm cordate base abruptly narrowed into acumen; costa reaching acumen; paracostal basal cells rectangular, more than twice as long as wide, other basal cells isodiametric.

Pseudoleskeella nervosa (w)

- Deciduous branchlets lacking; stem leaves ovate-lanceolate, evenly narrowed to acute apex; costa reaching to mid-leaf or $2 / 3$ of leaf length; all basal cells isodiametric (paracostal basal cells at most twice as long as wide); shoots terete when dry.

Pseudoleskeella catenulata $(\mathrm{w})$

\section{Key to varieties of Abietinella abietina}

References: Düll-Hermanns (1981) and Smith (2004)

- $\quad$ Stem leaves 1-1.4 mm long; branch leaves broadly ovate, shortly pointed, mostly $<1.2 \mathrm{~mm}$ long, length:width ratio $<$ 2.1:1, mostly ca 1.8:1; mid-leaf cells of branch leaves 1-1.5 (2) times as long as wide; leaves appressed in the dry state var. abietina $(\mathrm{w})$

- $\quad$ Stem leaves 1.5-2 mm long; branch leaves from ovate base lanceolate, longly acuminate, mostly $>1.2 \mathrm{~mm}$ long, length:width ratio $>2.1: 1$, mostly $c a 2.5: 1$; mid-leaf cells of branch leaves 1.5-3 times as long as wide; leaves patent when dry. var. hystricosa Note: The occurrence of var. hystricosa in Hungary is controversial (Erzberger and Papp 2020).

\section{Key to species of Thuidium}

1 Apical cells of branch leaves with 1 papilla Thuidium tamariscinum (w)

- Terminal cells of branch leaves with several apical papillae (often therefore appearing truncate or forked)

2 Costa of stem leaves reaching into leaf apex; apical leaf cells elongate; apex of stem leaves recurved; cells of paraphyllia with papillae apical (at the distal end of cells), appearing over cell wall; stem tip of well-developed plants curved, hook-like

Thuidium recognitum $(\mathrm{w})$ 
- $\quad$ Costa of stem leaves ending below leaf apex; apical leaf cells short; tips of stem leaves erect; cells of paraphyllia with a centrally placed papilla; stem tip \pm straight, not hooked.

3 Stem leaves with a long, fine acumen, the apex consisting of 3-4 uniseriate elongate cells (easily broken off!), perichaetial leaves without cilia.

Thuidium assimile (Thuidium philibertii) (w)

- $\quad$ Stem leaves more shortly pointed, apex not uniseriate; perichaetial leaves ciliate. Thuidium delicatulum $(\mathrm{w})$

\section{Key to species of Eurhynchium}

- $\quad$ Leaves 1.2-2 times as long as wide, patent; leaf apex narrow, margins forming an angle of $15-45^{\circ}$.

Eurhynchium striatum (w)

- $\quad$ Leaves 1.2-1.3 times as long as wide, appressed; leaf apex broadly pointed, margins forming an angle of $45-85^{\circ}$.

Eurhynchium angustirete $(\mathrm{w})$

\section{Key to species of Rhynchostegium}

1 Mid-leaf cells lax, 10-16 $\mu$ m wide, 3-5 times as long as wide; leaves subrotund ............ Rhynchostegium rotundifolium (w)

- $\quad$ Mid-leaf cells 4-10 $\mu$ m wide, 6-17 times as long as wide.......2

2 Leaves widely elliptical, concave, apex obtuse and apiculate; entire or denticulate only at apex; costa reaching mid-leaf; yellowish green to brownish, often silvery, glossy julaceous plants with dense leaves............ Rhynchostegium murale (w)

- $\quad$ Leaves ovate to elliptical, apex acute or acuminate; margin denticulate from base to apex.

3 Leaf apex acute; dark green plants with long straight branches and broadly ovate leaves denticulate all around; stem and branch leaves similar; basal cells weakly differentiated; aquatic or subaquatic plants in and by streams.

Rhynchostegium riparioides

- Leaf apex acuminate (Platyhypnidium riparioides) (w) 
$4 \quad$ Stem leaves from broadly ovate base \pm abruptly contracted to long acumen, acumen often twisted; alar cells ascending up margins; plants pale green, irregularly pinnate.

Rhynchostegium megapolitanum (w)

- $\quad$ Leaf apex not longly acuminate, flat; alar cells not or slightly ascending up margins.......... Rhynchostegium confertum (w) Note: $R$. confertum bears a superficial resemblance to Leptodictyum riparium; however, that species is slightly larger and has entire leaves.

\section{Key to species of Cirriphyllum}

- $\quad$ Stem leaves abruptly narrowed to filiform acumen; costa not ending in dorsal spine. Cirriphyllum piliferum $(\mathrm{w})$

- $\quad$ Stem leaves more gradually narrowed to lanceolate acumen; costa ending in dorsal spine....... Cirriphyllum crassinervium (Eurhynchium crassinervium) (w)

\section{Key to species of Oxyrrhynchium}

1 Primary stems rhizomatous, subterranean, with scale-like leaves; lamina cells 4-6 $\mu \mathrm{m}$ wide; leaf apex often twisted by $180^{\circ}$

Oxyrrhynchium schleicheri (Eurhynchium schleicheri) (w)

- $\quad$ Stems not rhizomatous, not subterranean; lamina cells 5-9 $\mu \mathrm{m}$ wide; leaf apex flat.

2 Stem leaves ovate to triangular lanceolate, gradually narrowed to apex, $1.5-2 \mathrm{~mm}$ long; branches with complanate, almost distichous leaves, very glossy; synoicous or autoicous, often with capsules; leaves longly decurrent, recurved at base; costa reaching into leaf acumen, occasionally ending in dorsal spine; stem leaf cells 60-90 $\mu \mathrm{m}$ long.

Oxyrrhynchium speciosum (Eurhynchium speciosum) (r) Note: Rhynchostegium riparioides is somewhat similar in habit, but distinguished by a smooth seta, if present. 
- $\quad$ Stem leaves rounded ovate heart-shaped, rather suddenly narrowed to apex, 1-1.2 $\mathrm{mm}$ long; plants decumbent, irregularly pinnate, to $10 \mathrm{~cm}$ long; leaves complanate or not; dioicous, rarely with capsules; costa reaching $1 / 2$ to $3 / 4$ leaf length, usually ending in conspicuous dorsal spine; stem leaf cells 40-60 $\mu \mathrm{m}$ long.

Oxyrrhynchium hians (Eurhynchium hians) (cc)

\section{Key to species of Rhynchostegiella}

1 Leaves narrow lanceolate or more often linear-lanceolate, 610 times as long as wide, longly acuminate; margins entire (or very finely denticulate near apex only); cells of leaf apex elongate; costa reaching into leaf apex; lamina cells 10-20 times as long as wide; frequently with sporophytes, seta smooth; plants forming glossy, silky yellowish green mats......

Rhynchostegiella tenella $(\mathrm{w})$

- Leaves more broadly lanceolate, 3-5 times as long as wide, bluntly pointed or acute, denticulate along margins; cells of leaf apex short, 4:1; costa of variable length; seta rough ......... 2

2 Mats dull dark green, costa reaching into leaf apex; leaf cells 5-7:1

Rhynchostegiella teneriffae (r)

- $\quad$ Mats glossy, light green; costa reaching shortly above midleaf; leaf apex narrowly lanceolate; leaf cells 8-10:1; on sunny or sheltered, warm sandstone and limestone rocks

Rhynchostegiella curviseta (rr) Note: the seta is smooth in $\boldsymbol{R}$. curviseta var. laeviseta (W.E. Nicholson and Dixon) Podp. (rr)

\section{Key to species of Homalothecium}

1 Costa reaching into leaf apex; seta smooth; stems prostrate or ascending, not attached to substrate with rhizoids; branches straight, not incurved when dry; leaf margin slightly denticulate all around; in appearance similar to $H$. lutescens. Homalothecium philippeanum (w)

- Costa ending below leaf apex, extending to 9/10 leaf length, sometimes terminating in dorsal spine; seta papillose; leaf margin denticulate at leaf base or at apex.

2 Plants irregularly branched, rarely \pm pinnate, to $15 \mathrm{~cm}$ long; 
stems usually loosely attached to substrate; branches straight; basal leaf cells porose, leaf margin irregularly finely denticulate or entire; capsules usually curved, endostome well developed; plants yellowish green.

Homalothecium lutescens (c)

Note: This species resembles somewhat Brachythecium glareosum, but is distinguished by porose basal lamina cells.

- Plants pinnately branched, stems creeping, attached to the substrate by rhizoids; branches incurved when dry; basal cells not porose, margins denticulate at base with some teeth recurved, entire above; capsules erect; endostome reduced, without cilia Homalothecium sericeum (c)

Key to species of Brachythecium s.l. (Brachytheciastrum, Brachythecium and Sciuro-hypnum)

1 Leaves with sharply set-off, long and narrow acumen (hair point); stem leaves ovate or narrowly ovate; transition between leaf lamina and acumen short, but not abrupt; lamina cells 6-12 $\mu \mathrm{m}$ wide..........Brachythecium tommasinii (incl. Brachythecium tenuicaule, syn. Cirriphyllum germanicum, Rhynchostegiella tenuicaulis) (Cirriphyllum tommasinii) (w)

- $\quad$ Leaves more gradually narrowed upwards, or with broad

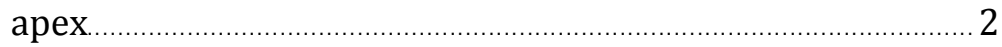

2 Costa long, ending at least $80 \%$ up the leaf.............................. 3

- $\quad$ Costa shorter, ending 50-70\% up the leaf ................................. 6

3 Alar groups reaching costa; costa mostly percurrent; autoicous, sporophytes frequent; operculum conical; seta \pm rough above, smooth below.

...Sciuro-hypnum populeum (Brachythecium populeum) (w)

- Alar groups not reaching costa, small, marginal, costa not percurrent; seta rough

$4 \quad$ Leaves strongly plicate, stem leaves triangular or narrowly triangular-ovate, \pm gradually narrowed towards apex; medium-sized plants; dioicous, sporophytes rare; operculum conical.......................Brachythecium geheebii (rr)

- Leaves plane, abruptly narrowed into apical portion; medium-sized or small plants; operculum conical or rostrate 
$5 \quad$ Medium-sized plants; stem leaves not decurrent, abruptly narrowed into short acumen on average 3 cells wide, often twisted $180^{\circ}$; costa very stout in the lower part of the leaf, distinctly narrowing above, ending shortly below leaf tip or reaching into it; stems prostrate, branches irregular, ascending; operculum rostrate.

Sciuro-hypnum flotowianum (Eurhynchium flotowianum, Cirriphyllum reichenbachianum) (w) Note: S. flotowianum resembles $S$. populeum in habit, but can be distinguished from that species by the costa not ending in leaf apex and leaf margins recurved only below.

- Small plants; stem leaves distinctly decurrent, abruptly narrowed towards narrow apical portion that is at least 250 $\mu \mathrm{m}$ long, not twisted; costa less stout; dry branches strongly curved; operculum conical.

Sciuro-hypnum reflexum

(Brachythecium reflexum) (rr)

6(2) Alar groups reaching costa; plants of moist or periodically wet environments.

Sciuro-hypnum plumosum (Brachythecium plumosum)(rr)

- $\quad$ Alar groups not reaching costa

7 Alar cells dilated, thin-walled and hyaline, forming a large, distinct, decurrent group; plants of moist or periodically wet environments

Brachythecium rivulare $(\mathrm{w})$

- $\quad$ Alar cells not inflated, alar group hardly decurrent; plants of usually dry habitats (except B. mildeanum)

8 Alar groups extending up along margin in a band or an ovate group.

- $\quad$ Alar groups different ........................................................................ 10

9 Dioicous, sporophytes rare; leaves erect and imbricate, therefore branches usually julaceous; margin of branch leaves entire or very finely denticulate; branch leaf costa smooth, rarely ending in an indistinct spine on abaxial side; seta smooth.

Brachythecium albicans (c)

- Autoicous, sporophytes frequent; leaves erect to patent; margin of branch leaves distinctly to coarsely denticulate; branch leaf costa frequently ending in a distinct spine on abaxial side; seta at least partly rough

Brachythecium campestre (r) 
10 Leaves \pm distinctly plicate; plants large to medium-sized; alar groups small, marginal, mainly consisting of quadrate or rectangular cells; plants dioicous or autoicous

- Combination of character states different; plants autoicous....

11 Median lamina cells 35-65 $\mu \mathrm{m}$ long; plants dioicous; margin of branch leaves denticulate to finely so; seta smooth or rough; costa ending in distinct or indistinct spine on abaxial side; leaves very strongly plicate, reminding of a Homalothecium.

- Median lamina cells 40-150 $\mu$ m long; plants autoicous or dioicous; margin of branch leaves almost entire to coarsely denticulate; seta smooth; costa rarely or often ending in spine on abaxial side

12 Costa reaching 75-85\% up the leaf, very stout at leaf insertion; margin of branch leaves denticulate; seta rough (but sporophytes rare); median lamina cells 35-60 $\mu \mathrm{m}$ long; plants growing on base-rich, but not calcareous rocks

Brachythecium geheebii (rr)

- $\quad$ Costa reaching 50-75 \% up the leaf; margin of branch leaves denticulate to finely so; seta smooth; median lamina cells 50-65 $\mu \mathrm{m}$ long; plants growing in dry calcareous habitats, on small stones at the ground, never on rock

Brachythecium laetum (rr)

13 Dioicous; costa smooth or rarely ending in a small spine on abaxial side; margin of branch leaves finely denticulate to almost entire; median lamina cells $40-130 \mu \mathrm{m}$ long; stem leaves elongate-triangular, near apex with a long and narrow, often twisted piliferous portion; plants growing in dry calcareous habitats.......... Brachythecium glareosum (w)

- Autoicous; costa often ending in a distinct spine on abaxial side; margin of branch leaves distinctly to coarsely denticulate; median lamina cells 54-150 $\mu \mathrm{m}$ long; stem leaves triangular-ovate, near apex narrow but not piliferous; plants growing in base-poor to base-rich habitats

Brachythecium salebrosum (c)

14(10) Stem leaves 0.35-0.6 (0.9) $\mathrm{mm}$ wide; plants small (to medium-sized); alar groups small, marginal, mainly consisting of quadrate to rectangular cells, distinctly delimited; branch leaf spine of costa and prorate cell ends of 
costa strong, rarely absent

- $\quad$ Stem leaves wider; plants large; alar groups indistinctly delimited

15 Seta smooth; some lamina cells distinctly prorate

Brachytheciastrum olympicum (rr)

- Seta rough; lamina cells of stem leaves hardly prorate, of branch leaves prorate. Brachytheciastrum velutinum (Brachythecium velutinum) (cc)

16 Seta smooth; costal spine absent or rarely present and very weak.

- $\quad$ Seta rough or partly rough 18

17 Leaf margin entire or finely denticulate; alar cells regularly rectangular; median lamina cells of stem leaves 8-13 $\mu \mathrm{m}$ wide; rarely with sporophytes; plants of moist habitats

Brachythecium mildeanum (w)

- Leaf margin denticulate; alar cells quadrate to short rectangular; median lamina cells 7-9 $\mu \mathrm{m}$ wide; capsules often inclined; often with sporophytes; plants in mostly dense, but usually small turfs, with erect shoots, in open deciduous forests in calcareous areas

Brachythecium capillaceum (r)

18 Branches often complanate; costal spine relatively strong; seta rough above, smooth below; leaf margin strongly denticulate; plants growing in different types of forest, on forest litter, humus-rich soil and soil-covered stones and rocks, sometimes even on rotting wood; also in spruce plantations.

Sciuro-hypnum curtum

(Brachythecium curtum, B. oedipodium auct.) (rr)

- Branches not complanate; costal spine absent or occasionally present and very weak; seta completely and conspicuously rough; leaf margin denticulate; common plants of nutrient-rich habitats with very wide ecological amplitude. Brachythecium rutabulum (cc) 


\section{Key to species and varieties of Hypnum including Buckia}

1 Alar cells increasing in size towards leaf base, $12-20 \mu \mathrm{m}$ wide; medium sized plants

- Alar cells homogeneous, of equal size, hardly $>10 \mu \mathrm{m}$ in diameter; small plants.

2 Plants complanately \pm regularly pinnately branched, pale to whitish green, leaves strongly curved, margins denticulate in upper half, in particular the branch leaves; alar cells yellowish, forming excavate auricles, somewhat decurrent; growing mostly on soil Hypnum jutlandicum $(\mathrm{r})$

- $\quad$ Plants irregularly pinnate, green to yellow-green; leaves denticulate only at apex, rarely down to mid-leaf; variable; growing mostly on bark and rock. Hypnum cupressiforme 3

3 Plants complanate, branches usually less wide than principal stem.

- Plants not complanate, in general julaceous, branches as wide as the principal stem, mostly robust plants with ovatelanceolate to linear-lanceolate, \pm concave leaves

Hypnum cupressiforme var. lacunosum (w)

4 Plants usually forming mats, leaves mostly strongly falcate, usually turned towards the substrate; alar group slightly to strongly excavate.

Hypnum cupressiforme var. cupressiforme (cc)

- $\quad$ Plants usually forming wefts, leaves \pm straight or slightly falcate, usually oriented away from the substrate, shoots often slightly julaceous; alar group conspicuous, strongly excavate, alar cells incrassate, often brownish

Hypnum cupressiforme var. subjulaceum (n.s.)

5 Leaves ovate, rather abruptly narrowed to the acumen, concave; dioicous; plants julaceous, often erect, in yellowish green to brownish green mats; on calcareous rocks

Buckia vaucheri (Hypnum vaucheri) (w)

- Leaves ovate-lanceolate, gradually and longly acuminate; autoicous, often with capsules; leaves weakly falcate, denticulate all around, in particular branch leaves; alar groups fairly distinct; capsule erect or curved, lid rostrate; plants pale green, 2-4 cm long; on tree bases and tree trunks Hypnum pallescens var. reptile $(\mathrm{w})$ 


\section{Key to species of Taxiphyllum}

- Costa short, double, ceasing before mid-leaf, rarely not developed; leaves \pm complanate; plants to $1 \mathrm{~cm}$ long, pinnately branched, appressed to the substrate; with a cucumber smell. Taxiphyllum wissgrillii $(\mathrm{w})$

- Leaves without costa; leaves not complanate; plants more robust, glossy, julaceous, to $2 \mathrm{~cm}$ long; not smelling like cucumber. Taxiphyllum densifolium (w)

\section{Key to species of Calliergonella}

- Leaves straight, ovate or elongate-ovate, above suddenly narrowed to a rounded, occasionally apiculate apex; stem and branch tips pointed due to closely imbricate leaves.

Calliergonella cuspidata $(\mathrm{w})$

- $\quad$ Leaves \pm falcate-secund, longly and gradually tapering from an ovate or elongate-ovate base to a narrow or occasionally obtuse apex; stem and branch tips not pointed.

Calliergonella lindbergii (Hypnum lindbergii) (w)

\section{Key to species of Rhytidiadelphus}

- $\quad$ Stem leaves falcato-secund, not squarrose; alar cells lacking; shoot tips hooked.

Rhytidiadelphus loreus (rr) Note: missing in the latest checklist (Erzberger and Papp 2020), recently discovered in Somogy County by Cs. Németh.

- $\quad$ Stem leaves squarrose; alar cells differentiated, hyaline or orange-brown coloured; shoot tips not hooked.

Rhytidiadelphus squarrosus (w)

Key to species of Neckera s.l. (incl. Alleniella, Exsertotheca, Neckera)

1 Leaves transversely undulate. 3

- Leaves plane, not transversely undulate. 2

2 Leaf apex rounded, rarely obtuse; leaves $0.3-0.6 \mathrm{~mm}$ long; mid leaf cells 8-25 $\mu \mathrm{m}$ long.

Alleniella besseri (Homalia besseri, Neckera besseri) (w) 
- $\quad$ Leaf apex obtuse to very shortly acuminate, apiculate; leaves 1.5-2 mm long; mid leaf cells 20-60 $\mu \mathrm{m}$ long.

Alleniella complanata (Neckera complanata) (w)

3 Leaf margin narrowly recurved from base to apex, at least on one side, broadly incurved in basal part on other side; plants small, mostly to $2-3 \mathrm{~cm}(5 \mathrm{~cm})$ long; often with filiform small-leaved flagelliform caducous branches; dioicous, sporophytes rare, exserted...Neckera pumila (n.s.)

- Leaf margin broadly incurved on one side at leaf base, otherwise flat, not narrowly recurved; plants medium-sized to robust, $3-20 \mathrm{~cm}$ long; flagelliform branches rare; autoicous or dioicous, sporophytes immersed or exserted....4

$4 \quad$ Leaves gradually tapering from mid-leaf to sharp tip; plants medium-sized, 3-5 (10) cm long, leaves to $2.5 \mathrm{~mm}$ long; nearly exclusively epiphytic; autoicous, often with immersed capsules Neckera pennata (r)

- $\quad$ Leaves \pm parallel-sided for most of their length, abruptly tapering to short, obtuse tip; plants robust, 5-20 (30) cm long, leaves 2.5-4 mm long; mostly saxicole, more rarely epiphytic; dioicous, sporophytes rare, capsule exserted

Exsertotheca crispa (Neckera crispa) (w)

\section{Key to species of Thamnobryum}

Reference: Mastracci (2003)

- Branch leaves distinctly concave and glossy, with a short and coarsely dentate apex; shoots unbranched or irregularly branched; submarginal cells not elongate.

Thamnobryum neckeroides (n.s.)

- $\quad$ Branch leaves plane, with an elongate and dentate apex; shoots dendroid; submarginal cells elongate, sharply delimited from the other lamina cells towards the costa.

Thamnobryum alopecurum (w)

\section{Key to species of Isothecium}

- $\quad$ Margins denticulate to below mid-leaf; branch leaves longly and finely pointed; branching \pm dendroid. 
- Margins entire or denticulate only towards apex; branch leaves shortly pointed, ovate-oblong to broadly lanceolate, apex obtuse, acute or shortly apiculate; leaves concave, appressed. Isothecium alopecuroides (c)

Key to species of Anomodon s.l. including Pseudanomodon, Claopodium

1 Leaves narrowed to an attenuate apex; leaf cells unipapillose or pluripapillose. 2

- Leaf apex broad or narrow, obtuse or bluntly pointed; leaf cells pluripapillose.

2 Leaf terminating in a long, hyaline, uniseriate point; lamina cells pluripapillose.

Claopodium rostratum (Anomodon rostratus) (w)

- $\quad$ Leaf not terminating in uniseriate hyaline point; lamina cells unipapillose. Anomodon longifolius (w)

3 Leaf apex triangular-acuminate, denticulate; plants often with attenuate (progressively smaller leaved) branches

Pseudanomodon attenuatus (Anomodon attenuatus) (c)

- Leaf apex rounded or apiculate, entire. 4

4 Leaf base decurrent, irregularly tearing when removed; papillae only on the outer side of the leaf base; leaves gradually narrowed to tapering apex, homomallous, robust plants, to $10 \mathrm{~cm}$ long. Anomodon viticulosus (c)

- Leaf base auriculate; auricles rounded, all of their margin with high, partly branched papillae; leaves abruptly contracted from broadly oval base to an almost linear, lingulate, paralell-sided apex, not homomallous; slender plants, to $5 \mathrm{~cm}$ long. Anomodon rugelii (rr) 


\section{GLOSSARY}

Most of the definitions of this glossary are compiled from the following treatments: Magill (1990), Malcolm and Malcolm (2000), Frey et al. (2006), Damsholt (2002), Paton (1999), Smith (2004), Watson (1981).

\author{
abaxial - see dorsal \\ acidophilous \\ acrocarpous
}

acumen (pl. acumina)
acuminate

acute

adaxial - see ventral

adventive thalli

air chamber

alar cells

\section{alveola (pl. alveolae) \\ amphigastrium \\ (pl. amphigastria) \\ androecium \\ angular cells \\ angulate \\ annulus (pl. annuli)}

\section{antheridium \\ (pl. antheridia)}

\section{antical}

side away from stem or axis; back, dorsal, or lower surface of leaf or costa (opposed to adaxial)

acid-loving, preferring an acid habitat, growing on substrata that are acid in reaction

refers to the production of archegonia and later sporophytes at the apices of the main stems; the main stems are usually erect, tufted and sparingly branched

a slender, tapering point

slenderly tapered with an angle of less than $45^{\circ}$; longer than acute

sharp pointed, with terminal angle less than $90^{\circ}$ but greater than $45^{\circ}$

side towards stem or axis; ventral or upper surface of a leaf or costa (opposed to abaxial)

lateral thalli, e.g. in Metzgeria, which break away and form a means of asexual reproduction

specialized internal air-containing cavity common in most complex thalloid liverworts, e.g. Marchantiales referring to cells at basal margins (angles) of a leaf; these cells are often differentiated in size, shape or color from other leaf cells, e.g. Dicranum; see auricles

a depression, e.g. on the surface of a spore

underleaf in leafy liverworts; see underleaf

antheridia and surrounding leaves (perigonium), the male inflorescence

see alar cells

angled, having angles or corners

in stegocarpous mosses a zone of variously differentiated cells between the capsule urn and operculum, facilitating opening of the capsule; cf. valve

male gametangium; a multicellular globose to broadly cylindric, stalked structure containing spermatozoids

the dorsal surface of a stem; the leaf margin oriented towards the shoot apex of a longitudinal or obliquely inserted leaf (opposed to postical); in leafy liverworts with conduplicate leaves the antical lobe may also be called dorsal lobe 


\author{
aperture \\ apical \\ apical lamina \\ (pl. laminae) \\ apiculus (pl. apiculi) \\ apophysis \\ (pl. apophyses) \\ appendiculate \\ archegonium \\ (pl. archegonia) \\ arcuate \\ areola (pl. areolae)
}

\section{areolation \\ ascending \\ attenuate \\ auricle}

\section{autoicous}

axil

axillary hair

axis (pl. axes)

basal

basal cell

basal membrane

biconvex

bifid an opening or hole

at apex, summit or point of a structure

in Fissidens the part of the leaf above or distal to the vaginant and dorsal laminae

a short, abrupt point

a strongly differentiated, sterile neck at the base of a capsule, between seta and urn; e.g. Polytrichum (see hypophysis, neck)

with short, thin, transverse projections (see nodulose)

female gametangium or sex organ; a multicellular, flask-shaped structure consisting of a stalk, venter, neck and containing an ovum

curved

small angular or polygonal surface area differing in colour or structure from the surrounding area, forming a pattern or network; e.g. air chambers on a thallus; see also alveolae

the cellular network of a leaf or thallus

pointing obliquely upward; away from the substrate slenderly tapering

a small, ear-like lobe; often present at the basal margins of leaf in mosses; e.g. Climacium (see alar cells); also on thalli and other organs in liverworts with archegonia and antheridia in separate clusters on the same plant (see synoicous, paroicous, dioicous, monoicous] [the suffix "-oecious" strictly applies only to sporophytic or diploid sexuality, and thus is inapplicable to bryophytes; however, it is nonetheless frequently employed (autoecious) as an alternative spelling and pronounciation to "-oicous"] the upper angle formed by the axis and any organ that arises from it; e.g. leaf and stem, stem and branch

hair in the leaf axils

the main stem; a conceptual line around which structures (leaves, branches, etc.) develop

at the base, bottom or proximal end (opposed to terminal or distal)

cell at the base; in leaves, frequently differentiated cells of the lower $1 / 4-1 / 3$ of a leaf (cf. lamina cells); cell at point of attachment of an axillary hair

a short tube or cylinder often supporting segments and cilia of the endostome; e.g. Bryum; or teeth of the haplolepidous peristome; e.g. Tortula convex on both sides, e.g. the costa of Grimmia teretinervis

divided into two parts, see bilobed, bifurcate 


\section{bifurcate \\ bilobed \\ bistratose \\ border \\ bract \\ brevipilose \\ brood bodies}

bulbil

bulbous

caducous

calcicole

calcicolous

calcifuge

calciphile

calyptra (pl. calyptrae)

campanulate

\section{canaliculate \\ capitulum (pl. capitula) \\ capsule}

Y-shaped or forked; leaves divided into two \pm equal parts

divided into two lobes or segments

composed of two cellular layers; e.g. leaf blades that are two cells thick

cells along a leaf margin that differ from other leaf cells in their shape, size, colour, or wall thickening

a modified leaf associated with a gametangium or gemma-cup (cf. perichaetial leaf, perigonial leaf) with a short hair

any structures that function as asexual propagules such as gemmae, bulbils, tubers or reduced branches or leaves

vegetative propagule; a small, deciduous, bulb-like axillary propagulum

swollen, bulb-like

easily or soon falling away

growing in calcareous habitats, as on dolomite and limestone

growing on a limy substratum

avoiding calcareous habitats

favouring calcareous habitats, as on dolomite and limestone

a membraneous covering of haploid tissue over the developing sporophyte, derived from the archegonial venter. In mosses the venter generally ruptures near the base, is carried upwards by elongation of the seta, and frequently expands to form a protective covering over the capsule. In liverworts the structure is strictly an epigonium that ruptures near the apex and remains at the base of the seta; see vaginula

bell-shaped; referring to a calyptra that is elongated and cylindrical; a campanulate-cucullate calyptra is cylindrical and split on one side only, e.g. Ceratodon purpureus; a campanulate-mitrate calyptra is cylindrical and undivided or equally lobed at the base, e.g. Grimmia pulvinata

channelled (lengthwise); as in leaves or thalli

head; e.g. Sphagnum

the sporangium; terminal spore-producing part of the sporophyte; in most mosses it is differentiated into an apical operculum, central urn (spore-bearing region) and a sterile basal neck or hypophysis; in most liverworts and hornworts it is a uniform structure containing spores and elaters or pseudoelaters and usually opens by splitting into 4 (or 2) valves 


\author{
carinate \\ catenulate \\ cauline \\ caulonema \\ (pl. caulonemata)
}

central strand

cernuous

channelled
chlorenchyma
chlorocyst
chloronema
(pl. chloronemata)

chlorophyllose

ciliate

cilium (pl. cilia)

circinate

clavate

cleistocarpous

collenchymatous

columella like a boat keel; winged

chain-like; e.g. arrangement of leaves on the stem of some species of Leskeaceae

of the stem

in mosses the second of the two growth stages of a typical protonema (the first stage is called chloronema). A caulonema typically has pigmented walls and oblique cross-walls, whereas a chloronema has hyaline walls and transverse crosswalls. Only the caulonema ordinarily produces the buds which develop into the familiar gametophytes of an adult moss

a small group of elongate cells forming a central axis of some stems and thalli, usually colored and thinwalled in transverse section

nodding or drooping, orientation of a capsule with its longitudinal axis intermediate between horizontal and pendulous

hollowed out like a gutter and semicircular in cross section (cf. keeled)

tissue composed of cells containing chloroplasts green (chlorophyllose) cell; generally used in contradistinction to hyalocysts; e.g. leaves of Sphagnum, Leucobryum

in mosses the first of the two growth stages of a typical protonema (the second stage is called caulonema). A chloronema typically has hyaline walls and transverse cross-walls, whereas a caulonema has pigmented walls and oblique crosswalls. Only the caulonema ordinarily produces the buds which develop into the familiar gametophytes of an adult moss

containing chlorophyll; generally green unless masked by some other pigments

fringed with hair-like appendages (see fimbriate) a delicate hair- or tooth-like structure fringing a leaf, thallus or other structure, or alternating with the processes of the inner peristome (endostome) curved in a circle; e.g. leaves of Sanionia uncinata thickened towards the apex; club-shaped indehiscent; capsule without a regular mechanism for opening; e.g. capsule lacking a operculum and annulus and hence opening irregularly (opposed to stegocarpous)

with cell walls more heavily thickened at the (leaf or exothecial cell) angles; e.g. Aulacomnium palustre; (see trigones)

the central, sterile tissues in the sporogenous region 


\author{
comal tuft \\ comissure \\ complanate \\ complicate-bilobed \\ concave \\ concolorous \\ conduplicate
}

conical
connate
connivent
convex
cordate
cortex (adj. cortical)
corticolous
costa (pl. costae)
crenulate
costate
cribrose
crispate, crisped
cryptopore

cucullate

cuneate (cuneiform)

cuspidate

cuticle

of a capsule in most mosses and hornworts a tuft of leaves at tip of stem or branch; e.g. Bryum junction; e.g. in leaves of Sphagnum, the seam between adjacent cell walls of hyalocysts and chlorocysts

flattened or compressed, such as leaves flattened into more or less one plane, e.g. Plagiothecium

a bifid leaf with the two segments folded together longitudinally

having an outline or surface curved like the interior of a circle or sphere

said of two or more parts of structures that have the same colour strongly folded longitudinally along the middle; e.g. the leaves of Fontinalis antipyretica or the sheathing part of the leaves of Fissidens; in liverworts like Scapania short for bilobed-conduplicate, one lobe folded over the other cone-shaped; operculum of Bryum

joined, used when similar parts of an organism are fused together

directed or pointing together, though not fused, as the tips of leaf lobes inclined and converging towards one another

having an outline or surface curved like the exterior of a circle or sphere

heart-shaped, said of leaves attached at the broad end

the outer layer of cells of the stem, surrounding the medulla

growing on bark

nerve or midrib of a leaf or thallus, always more than one cell thick

with minute rounded teeth

having a midrib (costa), opp. ecostate

finely perforated; e.g. peristome teeth of Grimmia wavy; often used more loosely to mean variously curled, twisted and contorted

having immersed stomata, with the guard cells sunken below level of the exothecial cells and often \pm covered by them (opposed to phaneropore)

hooded or hood-shaped; a calyptra split along one side only; also used to describe leaves strongly concave and erect or inflexed at the tips, like a monk's cowl

wedge-shaped

ending abruptly in a stout, rigid point (cf. apiculate) an extracellular cutinized layer on the epidermis of 
cygneous

cylindrical

deciduous

decumbent

decurrent

\section{dehiscent}

\section{dendroid \\ dentate \\ denticulate \\ deoperculate \\ dextrorse \\ dimorphic \\ dioicous \\ diplolepidous}

\section{discoid \\ discolorous}

distal

\section{distichous}

divergent

dorsal

\author{
dorsal lamina \\ (pl. laminae) \\ dorsiventrally \\ compressed \\ ecad \\ echinate
}

most complex thalloid liverworts, leaves or stems of mosses, setae and capsules of mosses and capsules of hornworts

curved like a swan's neck; e.g. seta in many species of Campylopus

elongate and circular in transverse section

falling off, compare caducous, fugacious

with stem prostrate, but with ascending tips

with basal leaf margins extending down the stem past the leaf insertion as ridges or narrow wings; e.g. Plagiomnium elatum

the capsule opening regularly by means of an annulus and operculum or valves (opposed to indehiscent)

having a growth habit like a tree

with sharp teeth directed outward (see denticulate)

finely toothed (see dentate; subjectively distinct)

referring to capsule after the operculum has fallen

forming a right-handed helix (like in a normal screw); e.g. twist of seta (opposed to sinistrorse) occurring in two forms; e.g. with leaves of two forms with archegonia and antherida on separate plants peristome type originating from 2 rows of cells on the outer surface of the tooth and one on the inner surface; usually consisting of a double ring of teeth, the exostome and the endostome; cf. haplolepidous also disciform, flattened into a plate or disk said of two or more parts or structures that differ in colour

away from the base or point of attachment; towards the apex of a leaf or stem: the outer, convex face of a spore (opposed to proximal)

leaves alternating in two opposite rows; e.g. Fissidens, Distichium

(1) spreading from a point of attachment, (2) spreading in opposite directions

(of leaves) the abaxial, back or lower surface; (of peristome teeth) the outer face; (of stems or thalli) the upper surface, away from the substrate (opposed to ventral); see also antical (liverworts with conduplicate leaves)

part of the leaf blade opposite the sheathing base, at the back of the costa and below the apical lamina; e.g. Fissidens

flattened on the dorsal and ventral sides

an organism that is modified by its environment with stiff bristles (spore surface) 


\author{
ecostate \\ edentate \\ elater \\ (pl. elateres, elaters)
}

\section{ellipsoidal \\ elliptical \\ elongate \\ emarginate}

emergent

endostome

entire

epapillose

ephemeral

epidermis

(adj. epidermal)

epilose

epiphragm

(pl. epiphragmata)

\author{
epiphyte \\ erect \\ erecto-patent \\ erose \\ esinuose \\ evolute
}

excavate without a costa, opp. costate

without teeth; i.e. entire leaf margins

a differentiated elongate cell, dead at maturity and normally with one to three helicoidal wall thickenings, found interspersed among the spore mass in most liverwort capsules; function: to break up and subsequently help disperse the spores

a solid that has an elliptical outline

oblong with convex sides or ends

stretched out; e.g. linear

broadly notched at the apex (compare with retuse, more narrowly notched)

partially exposed, referring to capsules or perianths only partly projecting beyond the tips of perichaetial leaves (cf. exserted, immersed)

the inner circle of a diplolepidous peristome, formed from contiguous periclinal wall-pairs of the primary and inner peristomial layers; typically a weak membraneous structure consisting of a basal membrane bearing segments and cilia. The endostome is homologous with the haplolepidous peristome

without teeth; \pm smooth on the margin; not divided into lobes, e.g. leaves, thalli

without papillae; opp. papillose

short-lived; refers to an organism which completes its life cycle in a single season

the outer cell layer of a stem or thallus; frequently fragile and ephemeral

lacking hairs or a hair point, opp. pilose (hairy)

in Polytrichaceae: a circular membrane formed by the expanded tip of the columella and attached to the ends of the peristome teeth; it partially closes the mouth of the capsule after the lid has dropped away. Similar structure in Weissia brachycarpa, $W$. condensa, $W$. rostellata

a plant growing on another plant

with leaves directed toward stem apex; with leaf margins curved upward (adaxially); with capsules straight, not curved

spreading at an angle of $45^{\circ}$ or less (cf. spreading, patent)

ragged or irregularly notched as if gnawed by an animal

not wavy, opp. sinuose

rolled out, of a leaf lobule which is unrolled or plane, not inflated

hollowed out 


\section{excurrent \\ exostome \\ exothecial \\ exothecium \\ explanate \\ exserted

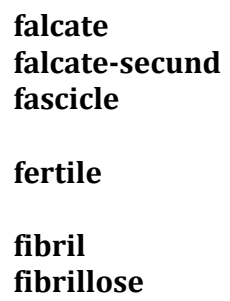

filiform

filament

fimbriate

flagellum (pl. flagella), adj. flagelliform

$\begin{aligned} & \text { flexuose } \\ & \text { foliose } \\ & \text { fugacious }\end{aligned}$
furcate
furrowed
fusiform
gametangiophore

gametangium

(pl. gametangia)

gametoecium

(pl. gametoecia)

gametophore extending beyond the apical margin; e.g. an awn formed by a protruding costa

the outer circle of a diplolepidous peristome, formed from contiguous periclinal wall-pairs of the outer and primary peristomial layers; missing or rudimentary in haplolepidous peristomes

with reference to the exothecium

the outermost layer of the capsule wall, consisting of exothecial cells, the capsule epidermis

flattened and spread out

projecting and exposed; e.g. capsules or perianths held clear of the tips of perichaetial leaves (cf. emergent)

curved like the blade of a sickle

strongly curved and turned to one side

a group, cluster or bundle of branches; e.g. branches in Sphagnum

producing sex organs (antheridia, archegonia), opp. sterile

fine, fiber-like wall thickenings

with fine, fiber-like wall thickenings (fibrils; applied to Sphagnum hyalocysts where fibrils may be spiral or annular)

slender and elongate, filamentous, thread-like

a single row of cells attached end-to-end, long and sometimes branched

fringed, generally with radiating cell walls of partly eroded marginal cells, e.g. stem leaf apices of Sphagnum fimbriatum

refers to a long thin shoot with small (reduced) leaves, functioning as a means of asexual propagation

slightly and irregularly bent, twisted, or wavy

leafy or leaf-like; closely covered with leaves

vanishing or readily falling away (see caducous, deciduous

forked (see bifurcate)

grooved

spindle-shaped, narrow and tapered at both ends

a specialized gametangia-bearing branch, producing either archegonia (archegoniophore) or antheridia (antheridiophore)

vessel bearing gametes; e.g. archegonium, antheridium

gametangium and surrounding leaves (see androecium, gynoecium)

the leafy stem of the gametophyte, in mosses produced from buds on the caulonema stage of the 


\author{
gametophyte \\ geminate \\ gemma (pl. gemmae)
}

gemma cup

gemmiferous,
gemmiparous
gibbous
glabrous
globose
guard cells

guide cell

gynoecium

(pl. gynoecia)

habitat

hair point

hamate (or hamulose)

haplolepidous

heterogeneous

heteromorphous

heterothallic

homogeneous protonema and usually bearing sex organs (gametangia) later

the haploid, sexual generation; in bryophytes, the dominant generation

arranged in pairs, e.g. the marginal teeth in Mnium

uni- or multicellular, filamentous, globose, ellipsoidal, cylindrical, stellate or discoid brood bodies, relatively undifferentiated, serving in vegetative reproduction (cf. brood body)

cup-shaped, gemmae-containing structure of thalline (Marchantia) or foliar (Tetraphis) origin, presumably structured to aid in distribution of gemmae by water splash (cf. splash-cup)

bearing gemmae

swollen or bulging on one side

smooth, not papillose, rough or hairy (see naked)

spherical

the specialized inflatable epithecial cells surrounding a moss or hornwort stoma, usually paired and kidney-shaped, but in some species of the moss family Funariaceae only a single cell with a central slit-like opening, sometimes also used for the cells surrounding air-pores in the epidermis of thallose liverworts

large, highly vacuolated, thin-walled and longitudinally arranged cells found in a median layer across the costa of many mosses, part of conducting parenchyma; e.g. taxa of Pottiaceae characteristically have guide cells sandwiched between two layers of stereid cells in the costal cross section

a structure containing female reproductive organs (archegonia)

local environment

usually formed by an excurrent costa; e.g. Tortula

hook shaped, more abruptly curved than falcate; syn. uncinate

peristome type originating from one row of cells of the outer surface of the tooth and two rows of cells on the inner surface (homologous to the endostome of diplolepidous mosses)

made up of contrasting or unrelated parts; opp. homogeneous

having different shapes

male plants much smaller than female plants, e.g. in Riccia frostii

uniform or composed of similar parts; opp. 


\section{homomallous \\ homomorphous \\ hyaline \\ hyalocyst}

hyalodermis

hydroid

\author{
hypophysis \\ (pl. hypophyses) \\ imbricate
}

immersed

\section{incised \\ inclined \\ incrassate \\ incubous}

incurved

indehiscent

inflated

inflexed

inflorescence heterogeneous

pointing the same way (opposed to heteromallous)

having the same shape

colorless or transparent

large, empty, water-storage cell as in leaves of Sphagnum and Leucobryum

differentiated external cells; e.g. thick-walled, enlarged or hyaline; stem epidermis of enlarged, hyaline cells; i.e. chloroplasts very few or lacking; such cells may be protoplasmic (e.g. Cephalozia) or not (e.g. Sphagnum) at maturity

tracheid-like conductive cell in the central strand of some bryophytes, especially mosses, sometimes also in the costa

a strongly differentiated, sterile neck at the base of the capsule, between seta and urn; e.g. Polytrichum closely appressed and overlapping; e.g. with the leaf margins overlapping like shingles on a roof submerged or below the surface; referring to a capsule or perianth exceeded by the blades or awns of the perichaetial leaves (cf. emergent, exserted); or to sunken stomata (see cryptopore)

cut or dissected into sharp divisions

bent down; capsules that are between the erect and horizontal positions, i.e. drooping

with thickened cell walls

lying upon; an oblique leaf insertion in which the antical (distal) leaf margins are oriented toward the dorsal stem surface; when viewed from above the antical leaf margins will overlap the postical (proximal) leaf margins of the leaves directly above; found in some leafy liverworts; e.g. Lejeunea (cf. succubous)

curved upward (adaxially) and inward, subjectively stronger than inflexed and weaker than involute; applied to leaf tips and margins (opposed to recurved)

describes a capsule that does not dehisce by means of a lid or valves; the spores are released by the rupture or decay of the capsule wall; syn. cleistocarpous

swollen or bladderlike; puffed up; e.g. the lobules of certain species of Frullania or Lejeunea, or alar cells of Cratoneuron (opposed to explanate) bent upward (adaxially) and weakly inward; applied to leaf margins or leaves on a stem (cf. incurved, involute, inrolled; opposed to reflexed) a structure containing sexual reproductive organs 
innovation

involucral flap

involucre

involute

irregular

isodiametric

julaceous

$\mathbf{K +}$

keel

keeled

laciniate

lacunose

lamella (pl. lamellae)

lamina (pl. laminae)

\section{lamina cell \\ laminate \\ lanceolate}

lateral a new branch, especially one that arises below an inflorescence

a flap of thallus tissue covering the gynoecium; e.g. Pellia epiphylla

a protective sheath of tissue of thalline origin, surrounding a single antheridium, archegonium or sporophyte in certain liverworts; often used loosely as a general term of any sheath-like structure surrounding sporophytes or gametangia

rolled upward (adaxilly) and tightly inward, applied to leaf margins (syn. inrolled; cf. incurved; opposed to revolute)

asymmetric; not fitting any detectable pattern about as broad as long; applied to cells about the same diameter in all directions; including square, rounded, or hexagonal

smoothly cylindric; like a catkin, referring to stems or branches with strongly imbricate leaves

colour reaction with a $2 \%$ solution of potassium hydroxide $\mathrm{KOH}$, giving either reddish or yellowish colours, e.g. in Pottiaceae or Schistidium

a ridge formed along a sharp fold of a leaf (Fontinalis), or perianth (Lejeuneaceae), in liverworts in particular the line of the fold between the smaller dorsal and the larger ventral lobe of a conduplicate bilobed leaf, or between the larger dorsal and the smaller ventral lobe of a leaf

sharply folded along the middle, like the keel of a boat; V-shaped in cross section; e.g. leaves of Grimmia pulvinata, Fontinalis antipyretica (cf. carinate)

fringed with appendages coarser than cilia and more than one cell wide; cf. ciliate, fimbriate with depressions or perforations on a surface parallel photosynthetic ridges or plates along a leaf blade, or costa; e.g. Polytrichum, Pterygoneurum

the flattened, generally unistratose and green part of the leaf blade excluding the costa and border; the expanded part of a thallus (see apical, dorsal and vaginant laminae)

cell of a lamina (see areolation)

like a lamina, said of leaf primordia with a flat blade lance-shaped, in bryology narrow and tapered from near the base; narrowly ovate-acuminate [used elsewhere for narrowly elliptical and tapering equally to both ends]

at the side; e.g. lateral branches or thallus wings (cf. basal and terminal) 
$\operatorname{lax}$

leaf

lenticular
lid
limb
limbidium (pl. limbidia)

linear

lingulate

lobe

lobule

lumen (pl. lumina)

lunate

mamilla (pl. mamillae)

mamillate

mamillose

marginal

marsupium

(pl. marsupia)

mat

median

medulla

midrib

mitrate (mitriform)

monoicous loose; referring to large thin-walled cells, as well as to nature and spacing of leaves on stem, or of stems in a tuft

a photosynthetic outgrowth from the stem; in bryophytes generally consisting of a unistratose lamina with or without a multistratose costa; (also called phylloid, indicating that only analogue to but not identical with the leaf of higher plants)

doubly convex, lens-shaped

see operculum

the upper part of a leaf (the opposite of base)

border, differentiated leaf margin, e.g. in Fissidens

bryoides

very narrow, elongate with nearly parallel sides

tongue-shaped; oblong with a slightly broadened apex

any segment of a divided (lobed) leaf or other organ; the larger segment of an unequally divided leaf in leafy liverworts (see lobule)

a small lobe; e.g. the smaller segment of an unequally divided leaf in leafy liverworts

the cell cavity

crescent shaped

strongly bulging surface of a cell; also used for various hollow papilla-like protuberances without associated local wall thickening; i.e., with the cell lumen extending into the protuberances

convex to hemispherical with a blunt central projection; e.g. operculum of Grimmia orbicularis

with mamillae

at the margin, especially as applied to a leaf

a modified shoot calyptra; associated with development of sporophyte in a pouch-like structure that penetrates downward into the substrate (geocauly)

a densely interwoven, horizontal growth form; e.g. Brachythecium, Hypnum

central, middle; e.g. median leaf cells are from the upper middle of a leaf, midway between costa and margin (see mid-leaf)

the interior, non-cortical part of the stem

chief median part of a thallus (cf. costa)

conic and undivided (similar to a bishop's mitre) or equally lobed at base, referring to calyptrae (opposed to cucullate; see campanulate) e.g. Grimmia

bisexual; with antheridia and archegonia on the same plant, including autoicous, synoicous, 


\author{
mucilage cell \\ mucro (pl. mucrones) \\ muticous \\ mycorrhiza \\ neck
}

nodulose

\begin{abstract}
oblate
oblique

obloid

oblong

obovate

obovoid

obtuse
\end{abstract}

ocellus (pl. ocelli)

oil-body

oil-cell

operculum

(pl. opercula)

orbicular
oval
ovate
ovoid
palmate
papilla (pl. papillae)

papillose paroicous, and polyoicous (opposed to dioicous; monoecious, see note after autoicous)

a specialized cell that is either filled with or secretes a gelatinous, water absorbent substance, presumably a mucopolysaccharide (syn. slime cell) a short, abrupt point (see apiculus)

without a point or awn

fungal hyphae in symbiosis with some liverworts

(1) in mosses: the sterile basal portion of a capsule between the base of the theca (urn) and the top of the seta (syn. apophysis, hypophysis (2) the cylindrical upper portion of an archegonium

with nodular thickenings; minutely knobbed; sometimes referred to intracellular wall thickening; e.g. Racomitrium

wider than long

slanted; e.g. an oblique leaf insertion is one that is between transverse and longitudinal

a solid with an oblong profile

rectangular with rounded corners or ends

egg-shaped with apex broader than base

an inversely ovoid solid

broadly pointed; more than $90^{\circ}$ - used by some authors to mean blunt or rounded

an idioblastic leaf cell having one large oil body and lacking chloroplasts, also found in underleaves, bracts and perianths of certain leafy liverworts (Frullania)

a membrane-bound, terpene-containing organell unique to the cells of liverworts

an idioblastic cell characterized by a very large oil body, common in thalloid liverworts; e.g. Marchantia

the lid covering the mouth of most moss capsules; usually separated from the mouth by an annulus to open the capsule (see stegocarpous)

nearly circular

widely elliptical

outline of an egg with base broader than apex

an egg-shaped solid

with finger-like lobes radiating from centre

cell ornamentation, a solid microscopic protuberance of cell wall (see papillose, and slime papilla)

bearing papillae; monopapillose - bearing one simple unbranched papilla on the cell surface. Loosely applied to any minutely rough surface, that may be strictly mamillose; e.g. pottioid leaves 


\section{paracostal paraphyllium (pl. paraphyllia)}

paraphysis

(pl. paraphyses)

parenchyma

paroicous

patent

pectinate

pedicellate

pellucid

peltate

pendent (pendant)

pendulous

\section{percurrent \\ perennial \\ perforate \\ perianth}

perichaetial leaf

perichaetium

(pl. perichaetia)

perigonial leaf

perigonium

(pl. perigonia) beside the costa

small green outgrowths of various shapes, i.e., filiform, lanceolate, scale- or leaf-like or sometimes branched; produced randomly on the stems or branches of many pleurocarpous mosses; e.g. Thuidium. In hepatics, occasionally on stems or associated with perigonial bracts; e.g. Scapania (cf. pesudoparaphyllia)

hyaline or yellowish, usually uniseriate, hair often associated with antheridia and archegonia of mosses

a tissue of relatively undifferentiated, usually thinwalled and isodiametric cells, with non-overlapping end walls

with antheridia and archegonia in a single gametoecium but not mixed, the antheridia in the axils of bracts just below the bracts surrounding the archegonia (paroecious; see note after autoicous)

of leaves spreading from the stem at an angle of $45^{\circ}$ or more

resembling a comb

borne on a stalk or pedicel, such as most bryophyte gametangia

translucent

shieldlike structure fixed on a central stalk

hanging downward (cf. inclined, pendulous); e.g. pendent branch (Sphagnum, opp. spreading branch) hanging, pendent; e.g. capsules drooping and inclined beyond horizontal; stems and branches that hang

extending to the apex

a plant in which the vegetative parts live year after year

pierced through

organ of foliar origin enclosing the archegonia in most leafy liverworts

modified leaf or underleaf (bract; bracteole) associated with the gynoecium; collectively forming the perichaetium

the gynoecium; strictly the ensheathing cluster of modified leaves or underleaves (bracts; bracteoles) and perianth, if present, enclosing the archegonia modified leaf or underleaf (bract; bracteole) associated with the androecium; collectively forming the perigonium

the androecium; strictly the cluster of modified leaves or underleaves (bracts; bracteoles) enclosing the antheridia 
perigynium

peristome

phaneropore

piliferous

pinnate

pitted

plane

pleurocarpous

plica (pl. plicae)

plicate

pluristratose

polyoicous

pore

porose

postical

primordium

(pl. primordia)

procumbent

propagule

(propagulum)

prorate

prosenchyma in some Jungermanniidean liverworts a tubular extension of the stem tissue surrounding the gynoecium, elevating the female bracts and perianth (if present)

a circular structure, generally divided into $2^{\text {n }}$ (i.e. 4 , $8,16,32$, or 64 ) teeth, arranged in a single or double (rarely multiple) row around the mouth of a capsule; (see endostome, exostome, prostome; also teeth, inner, outer, single and double peristome)

with superficial stomata; with guard cells at the same level as other exothecial cells and not sunken in chambers (opposed to cryptopore)

having a hair point

with numerous, spreading branches on opposite sides of the axis and thus resembling a feather

having small depressions or holes in the cell wall; sometimes called pores; in chlorocysts they are conspicuous as depressions in thickened walls between adjacent cells; e.g. Dicranum

flat, not curved or wavy, referring to leaf margins or blade

refers to the production of archegonia on short side branches in mosses; as a result the sporophytes appear lateral; most pleurocarpous mosses are prostrate, highly branched and often mat-forming longitudinal furrow or pleat

with longitudinal furrows or pleats (plicae)

in several layers

with several forms of gametoecia on the same plant a small aperture, the opening in the wall of some cells; e.g. in leaf hyalocysts and hyalodermis of Sphagnum; also the central opening in a stoma (see pseudopores, air pores, pit)

having pores

the ventral surface of a stem; that leaf margin oriented towards the base of a longitudinal or obliquely inserted leaf (see proximal; opposed to antical); in leafy liverworts with conduplicate leaves the postical lobe may also be called ventral lobe the embryonic stage of a leaf or other organ, made up of undifferentiated (unspecialized) cells spreading, prostrate

reduced bud, branch or leaf serving in vegetative reproduction (syn. diaspore, see brood-body)

having papillae or mamillae borne at the tips of cells, or formed by projecting cell ends; e.g. Philonotis

a tissue made up of narrow elongate cells with 


\author{
(pl. prosenchymata) \\ prosenchymatic \\ prostome \\ prostrate \\ protonema \\ (pl. protonemata)
}

\author{
proximal \\ pseudopapillose
pseudoparaphyllium
(pl. pseudo-
paraphyllia)

pseudoperianth

\author{
pseudopodium \\ (pl. pseudopodia)
}

pseudopore

pyriform
quadrate
receptacle tapered overlapping end walls (opposed to parenchyma)

cells characteristic of prosenchyma

a rudimentary structure outside, and usually adhering to, the main peristome teeth; e.g. some species of Orthotrichum; (also called preperistome) lying flat on the ground, creeping

a filamentous, globose or thalloid structure resulting from spore germination and including all stages of development up to the production of one or more gametophores. The protonema is extremely variable as to the amount of chlorophyll present, the degree of obliqueness of its end walls and the degree to which it branches (cf. chloronema, and caulonema). In liverworts a globose, short thalloid or filamentous structure generally gives rise to a single gametophore; in mosses the protonema is typically filamentous although Sphagnum, Andreaea and Tetraphis have \pm thallose protonemata

near the base or point of attachment; the internal face of a spore (opposed to distal)

having projecting cell walls seen in transverse section of leaf lamina, similar to papillae, but at the cell wall between adjacent cells, not at the cell lumen (German: Pfeilerpapillen); e.g. Dicranum brevifolium, sometimes Flexitrichum flexicaule

Small, unistratose, filiform or foliose structure resembling paraphyllium, but restricted to the areas of the stem around branch primordia; often found in pleurocarpous mosses

a hyaline unistratose sheath outside the calyptra for protection of a single archegonium and the sporophyte (not derived from leaves, thus not being a true perianth)

an elongation of the gametophyte axis below the sporophyte in Sphagnum and Andreaea, serving the function of a seta; also applied to a similar extension of a stem tip bearing clusters of gemmae

pore-like structure with a thin membrane that may be revealed by staining; e.g. in Sphagnum leaves, consisting of a fibril ring without an interior perforation

pear-shaped

square or nearly so

a disc or wart-like mass of tissue bearing antheridia or archegonia and found directly on the thallus (e.g. Conocephalum), inside the thallus (e.g. Pellia), or elevated and terminating a gametangiophore (e.g. 
recurved

reflexed

reniform

reticulate

retort cell

retuse

revolute

rhizoid

\section{rhizoid furrow \\ rhizoid initial \\ rhizomatous \\ rhomboidal \\ rostrate, rostellate \\ rostrum (pl. rostra) \\ rudimentary \\ rugose}

saccate

saxicolous

sclerodermis

secund

septate

serrate

serrulate

sessile

seta (pl. setae)
Marchantia)

curved downward (abaxially) and inward; in leaves, referring to margins, apices, or marginal teeth; in peristome teeth curved outward and \pm downward (opposed to incurved)

bent down (abaxially) and inward generally referring to leaf margins or leaves on a stem (opposed to inflexed)

kidney-shaped

forming a network

a type of cortical cell in some Sphagnum species shaped like a retort with a projecting neck ending in a pore

notched at the apex (especially when referring to leaf shape); less deep than emarginate

rolled downward (abaxially) and backward, referring to a leaf margin (opposed to involute)

hair-like structure that functions in absorption and anchorage; in liverworts and hornworts one-celled and usually hyaline; in mosses usually brown to reddish, simple or branched, multicellular filaments, generally with oblique end-walls (see tomentum)

a furrow in the stalk of Marchantiales, for conveying rhizoids to the male or female receptacle

rhizoid-generating cell; such cells are usually smaller than neighbouring cells

having a slender underground stem, horizontal and creeping, analogous with the rhizome of higher plants

oblong-hexagonal

beaked, narrowed into a slender tip or point

beak

incompletely developed, vestigial (cf. reduced)

with transverse wrinkles or undulations; e.g. leaves of Neckera crispa

sac-like; abruptly and deeply concave; e.g. forming a

sac

growing on rocks

an internal tissue of thick-walled cells forming a cylinder inside the hyalodermis; e.g. stem of Sphagnum

turned to one side; e.g. leaves on a stem

divided by cell walls; having partitions

saw-toothed; with marginal teeth pointing forward

(towards apex)

minutely serrate

without a stalk or seta

elongated portion of the sporophyte between the 


\section{sexual condition}

\author{
sheathing \\ sheathing lamina \\ shoot \\ shoulder
}

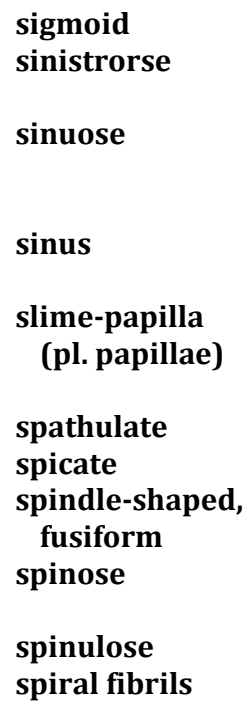

spore

spore sac

sporogonium sporophyte

spreading capsule and foot (cf. pseudopodium)

denotes the distribution of sexual organs within / among plants, see autoicous, dioicous, polyoicous, synoicous

surrounding and clasping the stem, base of seta or capsule; sheathing base of leaves is frequently composed of hyalocysts (cf. blade)

see vaginant lamina

a stem plus leaves and other appendages

an area of abrupt narrowing; e.g. the area on a leaf where the leaf base is abruptly narrowed to the upper lamina or blade or a similar constriction on an exostome tooth

S-shaped

forming a left-handed helix (opposed to a normal screw); e.g. twist of seta (opposed to dextrorse)

wavy, as in leaf margin, or as in intracellular wall thickening of Racomitrium (see nodulose); opp. esinuose

the notch or indentation between two segments, as in a bifid leaf

clavate mucilage-secreting cell, common on young leaves and often terminating very short, uniseriate filaments (slime hair)

tapering proximally from a broad, rounded apex

arranged in the form of a spike

narrow (more than 3 times as long as wide) and tapered at both ends

with sharp, pointed teeth; also very high, sharp leaf cell papillae or mamillae

minutely spiny

wall thickenings arranged spirally in the hyalocysts of Sphagnum species and giving the cells their mechanical strength

a reproductive unit produced in a capsule as a result of meiosis; usually minute, mostly spherical and generally unicellular bodies that give rise on germination to a protonema

layer(s) of cells lining the inside and outside of the archesporium

see sporophyte

the spore-bearing generation; initiated by the fertilization of an egg; remaining attached to the gametophyte and partially dependent on it; typically consisting of foot, seta and capsule forming an angle of $45^{\circ}$ or more (but less than $90^{\circ}$ ); e.g. the adaxial angle between a leaf and stem (see widespreading, erecto-patent, squarrose, patent) 


$\begin{aligned} & \text { spreading branch } \\ & \text { (Sphagnum) } \\ & \text { squarrose } \\ & \text { stegocarpous }\end{aligned}$
stellate
stem
stereid
sterile
stipitate
stolon

stoma (pl. stomata)

stratose
stria (pl. striae)
striate
striolate
strumose

stylus (pl. styli)

substereid

substrate

subula (pl. subulae)

subulate

succubous branch that at least at the point of insertion turns away from the stem (opp. pendent branch) spreading at right angles

referring to capsules with a dehiscent operculum (opposed to cleistocarpous)

star-shaped

the main gametophyte axis of mosses and leafy liverworts; grows by means of a single apical cell slender, elongate, thick-walled, fiber-like cell found in groups (stereid bands) in the costa or stems of some mosses

without reproductive structures or sporophytes; generally referring to absence of sexual structures but can also mean absence of asexual structures having a stipe or special stalk-like base a slender elongate spreading branch or stem, with small and often distinctly shaped leaves, which arches away from its parent plant like a runner of a strawberry plant, 'rooting' where it touches the substratum by producing rhizoids

minute opening in the capsule wall of hornworts, and usually in the capsule neck of mosses; surrounded or bordered by two guard cells

in layers; e.g. denoting thickness of leaves; i.e., uni-, bi-, multistratose (cf. seriate)

fine ridges or lines

marked with fine ridges or lines (striae)

finely ridged

with a goiter-like swelling (or struma) at one side of the base, applied to some capsules; e.g. Ceratodon, Cynodontium strumiferum

a column; a one-celled, uniseriate or multiseriate, subulate to triangular structure found between the lobule and the stem in certain leafy liverworts; e.g. Frullania

almost with the characteristics of a stereid, but with walls not as strongly thickened

the substance on which a bryophyte grows; e.g. soil, bark, rock

a long, slender point

slenderly long-acuminate

lying under; an oblique leaf insertion in which the antical (distal) leaf margins are oriented toward the ventral stem surface; when viewed from above the antical leaf margins will lie under or be overlapped by the postical (proximal) leaf margins of the leaves directly above; found in various leafy liverworts (cf. incubous) 
sulcate

supra-alar cells

synoicous

terete

terminal

terrestrial

terricolous

thallose

thallus (pl. thalli)

theca (pl. thecae)

tomentose

tomentum

(pl. tomenta)

trifarious

trigones

tristichous

truncate

tuber

\section{tuberculate \\ tuberous \\ tuberculate rhizoid (pegged rh.)}

\section{tubular \\ tubulose}

tuft

tumid

turbinate strongly plicate, with deep longitudinal furrows or grooves; e.g. capsules of Ulota

in Racomitrium the cells immediately above the alar cells

with antheridia and archegonia mixed in the same gametoecium (synoecious; see note after autoicous) rounded in cross section

at the apex, tip or distal end (opposed to basal)

growing on (dry) ground

growing on soil (terrestrial)

of or pertaining to a thallus

a \pm flattened gametophyte, not differentiated into a stem and leaves

the spore-bearing portion of a moss capsule (see urn; opposed to hypophysis)

woolly, densely radiculose; beset with tomentum

a felt-like covering of abundant rhizoids, on some stems or rarely leaves; e.g. stems of Dicranum arranged in three rows or ranks; syn. tristichous generally triangular or circular intracellular wall thickenings, found at the point where three (or more) cells meet; especially common in leaf cells of liverworts (see collenchymatous)

in 3 ranks

abruptly cut off or squared off at the apex

(in liverworts) a geotropic outgrowth from the shoot apex, composed of perennating tissue, allowing for aestivation and subsequent continued growth or vegetative reproduction; (in mosses) gemmae borne on rhizoids (rhizoidal gemmae), found in many acrocarpous mosses; e.g. Bryum

with small warts

like a tuber (rhizoidal gemma), e.g. swollen parts of underground persistent protonema of Ephemerum species

rhizoid with uniformly dispersed intracellular wall projections or tubercles that increase the surface area per unit volume; in some thalloid liverworts; e.g. Marchantiales (syn. pegged rhizoids)

cylindrical and apparently hollow

tubelike, usually referring to leaves with strongly incurved or broadly overlapping leaf margins; e.g. Campylopus

growth form with stems erect but radiating at the edges; small cushions; caespitose habit; e.g. Orthotrichum

inflated, swollen

shaped like an old-fashioned child's top, obconic, i.e. 


\section{turf}

$\begin{aligned} & \text { turgid } \\ & \text { uncinate } \\ & \text { underleaf }\end{aligned}$
$\begin{aligned} & \text { undulate } \\ & \text { unipapillose } \\ & \text { uniseriate }\end{aligned}$
unistratose
urceolate
urn
vaginant lamina
vaginate
vaginula
(pl. vaginulae)

valve

ventral

ventral scale

\section{ventricose \\ vermicular, vermiform}

verrucose

verruculose

verticillate

vesicular

vesiculose

vitta (pl. vittae) an inverted cone

growth form with stems erect, parallel and close together; often covering extensive areas; e.g. Bryum argenteum

plump or swollen

hooked; tip bent in the form of a hook

ventral, variously modified leaf in most leafy liverworts (syn. amphigastrium)

wavy

with a single papilla per cell

in one series; applied to a hair-like structure comprised of a single row of cells

one-layered; comprised of a single cell layer; e.g. most bryophyte leaves

urn-shaped, applied to capsules constricted below a wide mouth and abruptly narrowed to the seta

spore bearing portion of a capsule (opposed to neck; syn. theca)

in Fissidens, one of the two clasping laminae below the apical lamina

sheathing

a ring or sheath enveloping the base of the seta, derived from the base of the archegonium and surrounding stem tissue and remaining after the separation of the calyptra

one of the parts or partially detached flap of tissue into which the capsule of most liverworts and hornworts separates upon dehiscence; rare in mosses (e.g. Andreaea)

(of leaves) the adaxial, top, or upper surface; (of peristome teeth) the inner face; (of stems or thalli) the lower surface, next to the substrate; (opposed to dorsal); see also postical (liverworts with conduplicate leaves)

a unistratose, leaf-like structure of epidermal origin, often hyaline or reddish; ventral scales most commonly occur in two or four rows along the ventral surface in complex thalloid liverworts bulging on one side below (like a stomach) worm-shaped; long, narrow and somewhat wavy, commonly with rounded ends; usually applied to cells

covered with small wart-like elevations irregularly roughened

whorled

composed of blisters inflated, bladderlike

a band or ribbon; in liverworts the longitudinal 
wart

water sac

wedge-shaped

weft

wing

xeromorphic

zig-zag

zygote stripe of longer, often thicker-walled cells in a leaf lamina resembling a nerve but only one cell layer thick; e.g. Diplophyllum albicans

a small elevation or protuberance (cf. papillae)

an inflated or inrolled lobule or leaf part, usually filled with water; e.g. Frullania

see cuneate

a loosely interwoven, often ascending growth form: e.g. Thuidium

a thin, flat membranous expansion or appendage such as the margin of a spore; the keel of a perianth or folded leaf, or loosely applied to the lamina of a thallus or basal angles of leaves; i.e. alar cell region adapted for dryness

alternate from side to side; a line with numerous reversing angles e.g. median line on diplolepidous exostome tooth

the product of the fusion of two gametes; fertilized ovum before it has undergone mitosis or meiosis 


\section{INDEX OF GENERA}

(accepted names in normal print, synonyms in italics)

Abietinella 18, 28, 74, 219

Acaulon 17, 24, 51, 64, 145

Alleniella 6, 19, 29, 47, 228, 229

Aloina 17, 24, 48, 145, 146

Amblyodon 26, 59, 63

Amblystegium 6, 18, 27, 77, 78, 82, 216, 217

Amphidium 24, 53, 71

Anacamptodon 13, 27, 33, 74, 78, 203

Anastrophyllum 20, 31, 32, 43

Andreaea 13, 17, 23, 44, 126, 246, 251

Aneura 5, 22, 39, 109

Anomodon 6, 19, 29, 33, 49, 75, 230

Anthoceros 20, 37

Antitrichia 29, 75, 78

Aphanorrhegma 51, 64, 65, 131

Apometzgeria 110

Apopellia 22, 39, 111

Archidium 24, 51

Asterella 6, 17, 22, 31, 32, 38, 112, 114

Athalamia 38, 113

Atrichum 23, 48, 126, 127

Aulacomnium 18, 26, 56, 61, 66, 69, 71, 211, 234

Barbilophozia 6, 16, 20, 41, 42, 85, 89, 90, 92, 93

Barbula 10, 12, 25, 58, 69, 71, 169, 171

Bartramia 26, 52, 67, 72, 73, 189

Bazzania 21, 40

Blasia 22, 39

Blepharostoma 21, 40

Blindia 25, 56, 66, 174

Blindiadelphus 25, 33, 56, 59, 72, 174

Brachydontium 25, 54

Brachytheciastrum 6, 19, 28, 79, 223, 226

Brachythecium 6, 19, 28, 33, 76, 79, 223-226, 242

Bruchia 24, 33, 51, 72

Bryoerythrophyllum 25, 58, 67, 71 
Bryum 6, 8, 10, 26, 33, 49, 50, 60, 61, 64, 65, 73, 190-198, 232, 235, 250,251

Buckia 6, 19, 28, 84, 227

Bucklandiella 176, 177, 184, 185

Buxbaumia 9, 10, 17, 23, 45, 130

Callicladium 28, 33, 83

Calliergon 6, 18, 27, 77, 218

Calliergonella 19, 28, 80, 81, 83, 228

Calypogeia 17, 21, 31, 40, 98, 99

Campyliadelphus 18, 27, 76, 79, 215

Campylium 18, 27, 76, 81, 215, 217

Campylophyllopsis 27, 81, 83

Campylopus 8, 9, 17, 24, 49, 54, 62, 63, 133, 134, 141, 236, 250

Campylostelium 25, 58, 71

Cephalozia 20, 31, 32, 86, 87, 240

Cephaloziella 16, 20, 31, 32, 42, 43, 44, 87, 88, 89

Ceratodon 24, 53, 55, 67, 70, 143, 144, 233, 249

Chenia 6, 25, 49, 50, 64

Chiloscyphus 21, 40, 104, 105

Chionoloma 25, 56, 69, 72

Cinclidotus 17, 25, 33, 50, 146, 147

Cirriphyllum 18, 28, 79, 221, 223, 224

Claopodium 6, 19, 28, 49, 75, 230

Clevea 6, 17, 22, 31, 38, 112, 113

Climacium 27, 75, 232

Cnestrum 24, 33, 55, 67, 142

Codonoblepharon 26, 55, 62, 64, 71, 203

Codriophorus 176

Cololejeunea 21, 31, 41, 108

Conardia 27, 78

Conocephalum 6, 17, 22, 31, 38, 112, 113, 246

Coscinodon 9, 25, 175, 176, 181, 187

Cratoneuron 27, 76, 78, 240

Crossidium 17, 25, 33, 48, 147

Crossocalyx 20, 43

Ctenidium 29, 82

Cynodontium 24, 33, 53, 55, 58, 67, 70, 72, 141, 142, 173, 249

Desmatodon 54, 59, 67, 153, 161, 168

Dialytrichia 17, 50, 146

Dichodontium 24, 58, 59, 66 
Dicranella 17, 24, 33, 53, 55, 58, 59, 63, 72, 73, 135-137, 200

Dicranodontium 24, 59, 63

Dicranoweisia 24, 56, 70, 141, 142

Dicranum 9, 11, 24, 33, 55, 59, 63, 66, 134, 140, 141, 142, 231, 245, 246,250

Didymodon $11,12,17,25,33,56,57,61,66,68-72,147-151$

Diphyscium 23, 51, 69

Diplophyllum 17, 21, 36, 41, 94, 95, 252

Distichium 24, 36, 47, 236

Ditrichum 9, 24, 33, 58, 72, 73, 133, 143-145

Drepanocladus 11, 18, 27, 33, 76, 77, 79, 215, 216, 218

Encalypta 17, 23, 49, 53, 55, 56, 62, 69, 130, 131

Endogemma 6, 17, 21, 32, 41, 101-103

Entodon 29, 81

Entosthodon 23, 53, 56, 60, 65, 66, 132

Ephemerum 18, 25, 51, 73, 169, 170, 250

Eucladium 25, 57, 66

Eurhynchiastrum 28, 79

Eurhynchium 18, 28, 76, 78, 79, 220-222, 224

Exsertotheca 6, 19, 29, 47, 228, 229

Fabronia 18, 27, 78, 82, 214

Fissidens 9, 17, 24, 33, 36, 47, 137-139, 232, 235, 236, 242, 251

Flexitrichum 5, 17, 24, 58, 63, 133, 143, 144, 246

Fontinalis $18,27,82,211,235,241$

Fossombronia 17, 22, 39, 111

Frullania 17, 21, 31, 32, 42, 106, 107, 240, 243, 249, 252

Funaria 9, 24, 54, 65, 131, 132, 239

Fuscocephaloziopsis 20, 32, 86, 87

Grimmia 9, 12, 25, 33, 55, 57, 61, 175, 176, 180-188, 232, 233, 235, 241,242

Gymnocolea 20, 44, 91, 94

Gymnostomum 6, 18, 25, 54, 63, 70, 170, 171

Gyroweisia 6, 25, 54, 70, 170

Hamatocaulis 28, 76

Hedwigia 9, 11, 18, 26, 46, 49, 51, 70, 188, 189

Helodium 28, 33, 75

Hennediella 6, 18, 25, 54, 67, 153

Herzogiella 27, 84

Heterocladiella 29, 74, 80

Heterocladium 7, 29, 74, 80 
Hilpertia 6, 18, 25, 33, 49, 57, 58, 64, 158, 160, 163, 165

Homalia 29, 47, 228

Homalothecium 18, 28, 75, 222, 223, 225

Homomallium 29, 84

Hookeria 27, 47

Hydrogonium 7, 12, 18, 25, 33, 61, 71, 171

Hygroamblystegium 6, 18, 27, 77, 78, 216, 217

Hygrohypnum 27, 76, 81

Hylocomiadelphus 29, 82

Hylocomium 29, 82, 83

Hymenostylium 25, 54, 72

Hypnum 6, 19, 28, 33, 81, 82, 84, 227, 228, 242

Imbribryum 6, 26, 50, 60, 61, 65, 73, 190, 193-195

Isopaches 6, 16, 20, 89, 91, 92

Isopterygiopsis $27,48,83$

Isothecium 19, 29, 77, 79, 83, 229, 230

Jamesoniella 40, 41, 101

Jungermannia 6, 17, 21, 41, 101-103

Kindbergia 28, 79

Leiocolea 44, 103, 104

Lejeunea 22, 42, 108, 240, 241

Lepidozia 21,41

Leptobryum 26, 59, 63

Leptodictyum $27,47,79,221$

Leptodon 29,74

Leptophascum 64

Lescuraea 28, 33, 75, 76

Leskea 28, 75, 216

Leucobryum 14, 17, 24, 53, 54, 63, 135, 234, 240

Leucodon 29,80

Lewinskya $14,26,52,55,62,70,71,203,204,206-208$

Liochlaena 6, 17, 21, 31, 32, 41, 101, 102

Loeskeobryum 29, 83

Lophocolea 21, 31, 40, 44, 104, 105

Lophozia 6, 7, 16, 21, 31, 43, 85, 89, 91-94

Lophoziopsis $6,16,21,85,91-93$

Lunularia 6, 17, 22, 37, 112

Mannia 6, 17, 22, 31, 32, 38, 114, 115

Marchantia 6, 17, 22, 37, 38, 112, 114, 231, 239, 243, 247, 252

Marsupella 17, 21, 42, 43, 100 
Meesia 26, 59, 66

Mesoptychia 6, 16, 17, 21, 44, 89, 91, 94, 103, 104

Metzgeria 17, 22, 39, 110, 231

Microbryum 6, 17, 18, 25, 33, 49, 50, 54, 57, 69, 151-155

Microeurhynchium 28, 78

Mnium 6, 18, 26, 50, 59, 64, 201, 202, 239

Myurella 27, 80

Nardia 6, 17, 21, 41, 44, 100, 101

Neckera 6, 19, 29, 33, 47, 228, 229, 247

Neoorthocaulis 6, 16, 20, 41, 42, 85, 89, 90

Niphotrichum 176

Nogopterium 29, 80

Nowellia 20, 42, 86

Nyholmiella 26, 33, 52, 62, 70, 203, 204, 206

Obtusifolium 6, 16, 20, 89, 91

Orthodontium 26, 33, 56, 60, 73

Orthothecium 7, 18, 27, 83, 214

Orthotrichum $10,13,26,33,49,52,55,62,64,70,203-211,246$, 250

Oxymitra $6,17,22,31,115$

Oxyrrhynchium 18, 28, 79, 221, 222

Oxystegus $56,69,72$

Palustriella 18, 27, 75, 214

Paraleucobryum 24, 62, 139

Pedinophyllum 21, 31, 41, 106

Pellia 22, 39, 111, 241, 246

Phaeoceros 20, 37

Phascum 6, 9, 18, 64, 68, 151, 153, 166-168

Philonotis 8, 26, 52, 73, 189, 190, 245

Physcomitrella 51, 64, 65, 131

Physcomitrium 24, 33, 51-53, 64, 65, 131-133

Plagiobryum 49, 60, 65, 73, 191

Plagiochila 21, 40, 41, 102, 106

Plagiomnium 6, 18, 26, 50, 63, 201-203, 236

Plagiopus 26, 52, 67, 189

Plagiothecium 9, 10, 14, 18, 27, 33, 47, 81, 212-214, 235

Plasteurhynchium 28, 76

Platydictya 27, 82

Platygyrium 28, 84

Platyhypnidium 220 
Pleuridium 24, 51, 72, 143

Pleurochaete 66, 171

Pleurozium 29, 81

Pogonatum 17, 23, 48, 126-129

Pohlia 9, 18, 26, 34, 59, 60, 65, 73, 136, 198-201

Polytrichastrum 17, 23, 48, 126-129

Polytrichum 17, 23, 34, 48, 126, 128, 129, 232, 240, 241

Porella 17, 22, 31, 42, 108

Pottia 6, 18, 49, 51, 54, 57, 64, 68, 152-155, 166, 167

Preissia 112

Protobryum 51, 64, 68, 153, 166

Pseudanomodon 6, 19, 29, 75, 230

Pseudephemerum 24, 51, 73, 143

Pseudoamblystegium 6, 18, 27, 216

Pseudocampylium 6, 18, 27, 34, 216, 217

Pseudocrossidium 18, 25, 58, 68, 155

Pseudoleskea 75, 76

Pseudoleskeella 18, 28, 74, 75, 80, 82, 219

Pseudoscleropodium 28, 77

Pseudotaxiphyllum 27, 48

Pterigynandrum 27, 80, 82

Pterogonium 80

Pterygoneurum 18, 25, 48, 155, 156, 241

Ptilidium 22, 40

Ptilium 29, 82

Ptychostomum 6, 26, 49, 50, 60-62, 64, 65, 73, 190-198

Pulvigera 26, 62, 70, 203, 204, 206

Pylaisia 29, 84

Pyramidula 23, 52, 53, 64, 131

Racomitrium 25, 34, 45, 175-177, 180, 184, 185, 243, 248, 250

Radula 17, 22, 41, 109

Reboulia 6, 17, 22, 38, 112-114

Rhabdoweisia 24, 55, 66, 72, 142

Rhizomnium 6, 18, 26, 50, 201

Rhodobryum 26, 50, 64, 190, 191

Rhynchostegiella 18, 28, 79, 222, 223

Rhynchostegium 18, 28, 34, 79, 220, 221

Rhytidiadelphus 7, 19, 29, 81-83, 228

Rhytidium 29, 76

Riccardia 22, 39, 109, 110 
Riccia 4, 6, 7, 11, 14, 17, 23, 31, 32, 37, 115-121, 239

Ricciocarpos 6, 17, 23, 115

Saelania 5, 17, 25, 55, 66, 143

Sanionia 28, 76, 234

Sarmentypnum 27,77

Scapania 17, 21, 31, 32, 42, 94-97, 235, 244

Schistidium 8, 10, 25, 34, 52, 68, 69, 175, 177-180, 186, 188, 241

Schistochilopsis 5, 6, 16, 21, 89, 91

Sciuro-hypnum 6, 19, 28, 76, 79, 223, 224, 226

Scleropodium 77

Scorpidium 18, 28, 77, 81, 218

Seligeria 8, 25, 52, 53, 56, 72, 174, 175

Sematophyllum 29, 34, 83

Serpoleskea 6, 18, 27, 216

Solenostoma $6,17,21,41,101-103$

Sphaerocarpos 23, 32, 37

Sphagnum 10-12, 14, 17, 23, 34, 44, 122-126, 233, 234, 238, 240, 244-249

Sphenolobus 20, 43

Splachnobryum 25, 34, 65

Straminergon 6, 18, 27, 77, 218

Streblotrichum 12, 18, 25, 58, 71, 169

Syntrichia $6,10,11,18,25,49,57,61,68,156-165$

Syzygiella 6, 17, 20, 40, 41, 101

Taxiphyllum 19, 28, 34, 47, 83, 228

Tetraphis $23,45,61,239,246$

Thamnobryum $12,19,29,34,74,229$

Thuidium 9, 18, 28, 49, 74, 219, 220, 244, 252

Timmia 12, 17, 23, 56, 67, 130

Tomentypnum 27,75

Tortella $10,11,18,25,57,66,67,171,172$

Tortula $6,9,11,12,18,25,34,49-51,54,57-59,64,68-71,153-$ $168,232,239$

Trichocolea 21,40

Trichodon 24, 72, 73, 135, 143

Trichostomum 18, 25, 57, 58, 69, 172, 173

Trilophozia 6, 16, 21, 41, 89, 90

Tritomaria 6, 16, 21, 41, 89, 90, 91

Ulota 8, 26, 30, 55, 62, 70, 203-205, 207, 250

Warnstorfia 77 
Weissia 18, 25, 34, 51, 54, 57, 69, 167, 173, 237

Zygodon 26, 53, 55, 62, 64, 71, 203 


\section{PETER ERZBERGER \\ KEYS FOR THE IDENTIFICATION OF BRYOPHYTES OCCURRING IN HUNGARY}

Keys for the identification of all bryophytes presently known to occur in Hungary are presented. The three groups: Hornworts (2 taxa), Liverworts (149 taxa), and Mosses (541 taxa) are treated separately. Bryophyte identification using these keys proceeds in two steps: 1 . Artificial keys to the genera, 2. Keys from genera to species, arranged systematically according to recent taxonomy. Each species of the Hungarian bryophyte flora is assigned to one of six frequency classes (very common: cc, common: c, widespread: w, rare: r, very rare: rr, not seen: n.s.). A glossary explaining the technical terms used in the keys and an index of genera are included. 